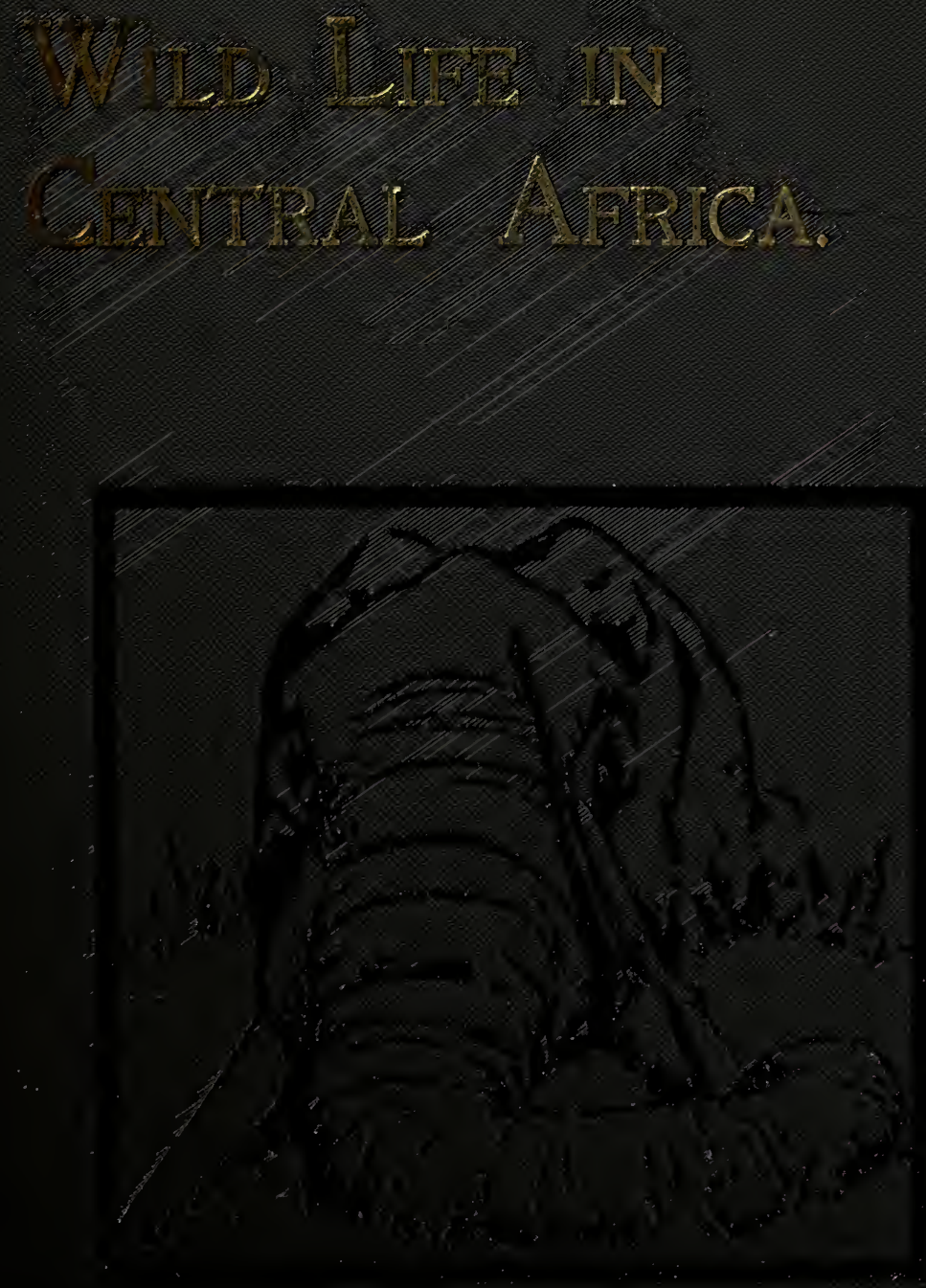

BY

D. D. LYELL。 
(2)

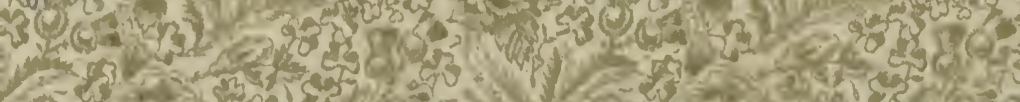
ouf 7xter 10 $x^{1}=$

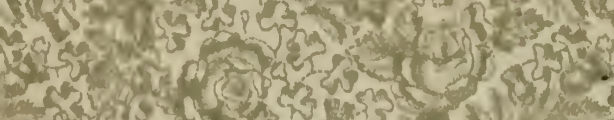

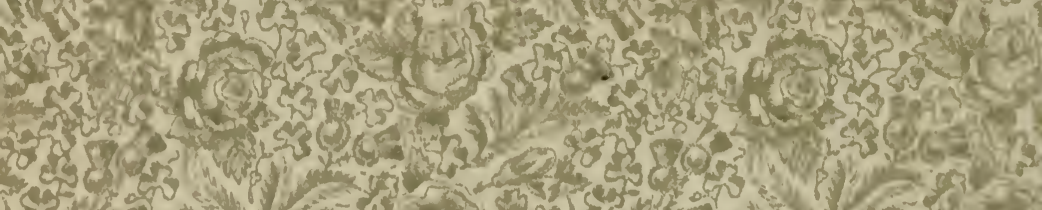

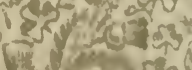

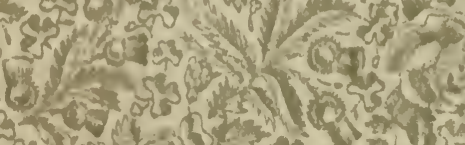
(a) 3 .

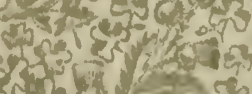

(3)

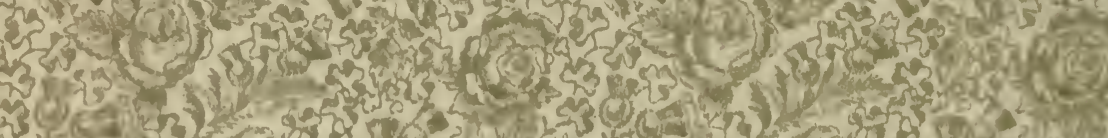

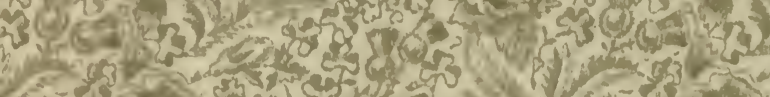
बif 7 a 2] Non. a

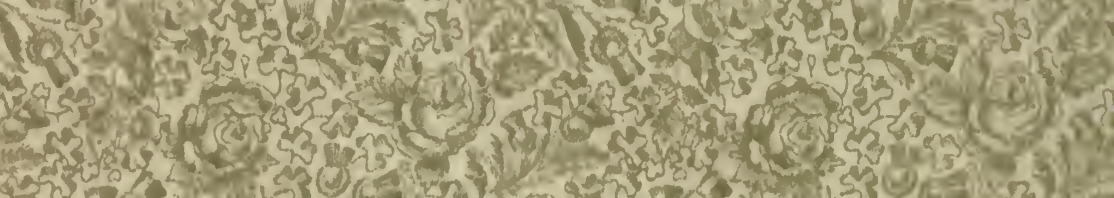

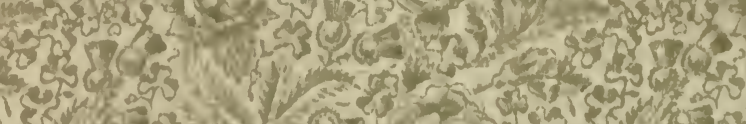
b.

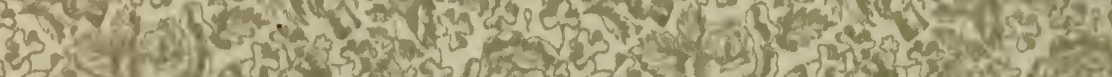

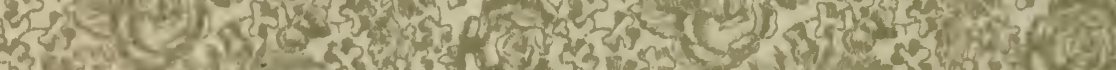

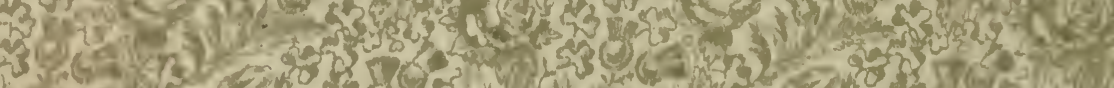

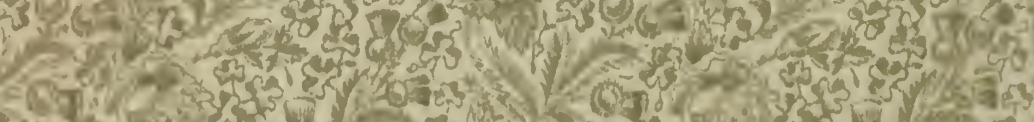
a (3)

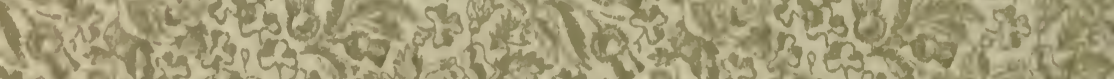

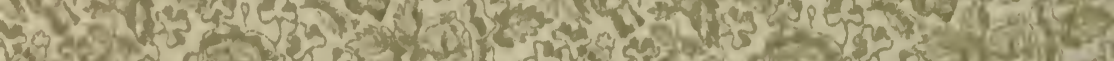

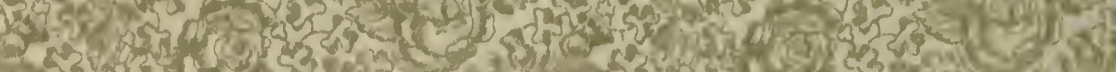
I)

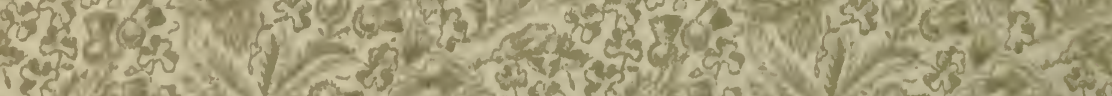

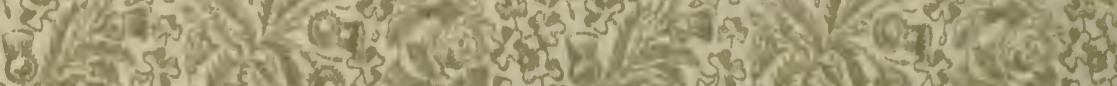

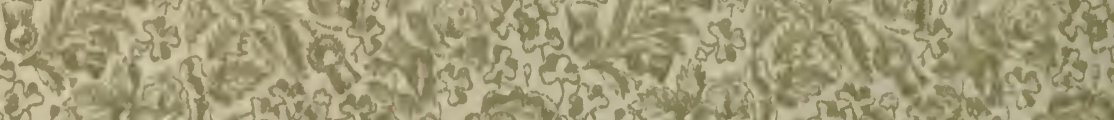
2. 30 (2)

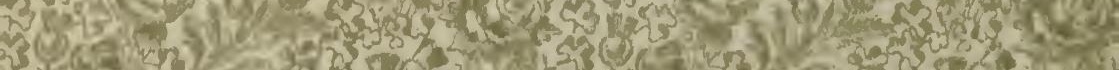


is $(3.50)$ and

\section{Nats.}

ing 185

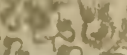

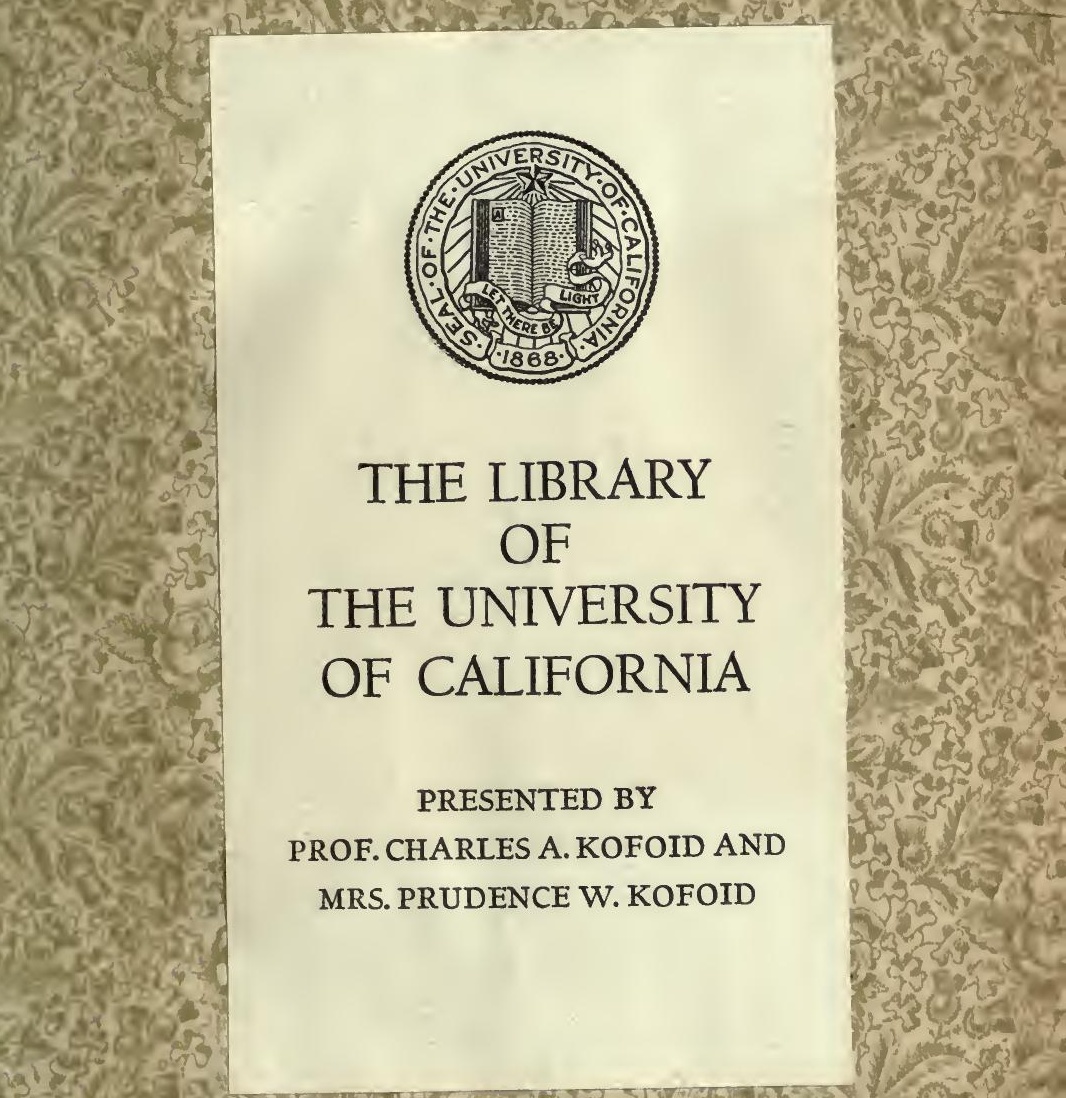

PROF. CHARLES A. KOFOID AND MRS. PRUDENCE W. KOFOID

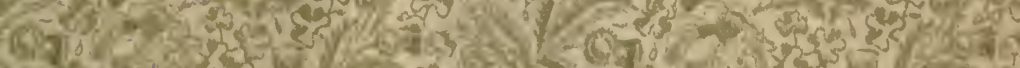

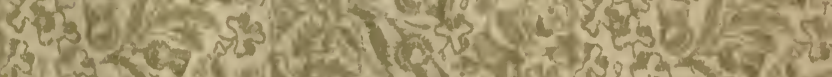

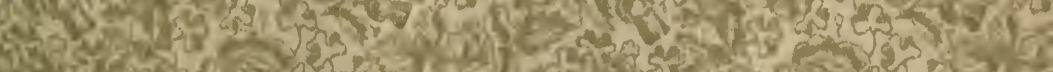


Digitized by the Internet Archive in 2007 with funding from Microsoft Corporation 


\section{WILD LIFE IN CENTRAL AFRICA.}


、 $-$

. 


\section{WILD LIFE IN CENTRAL AFRICA.}






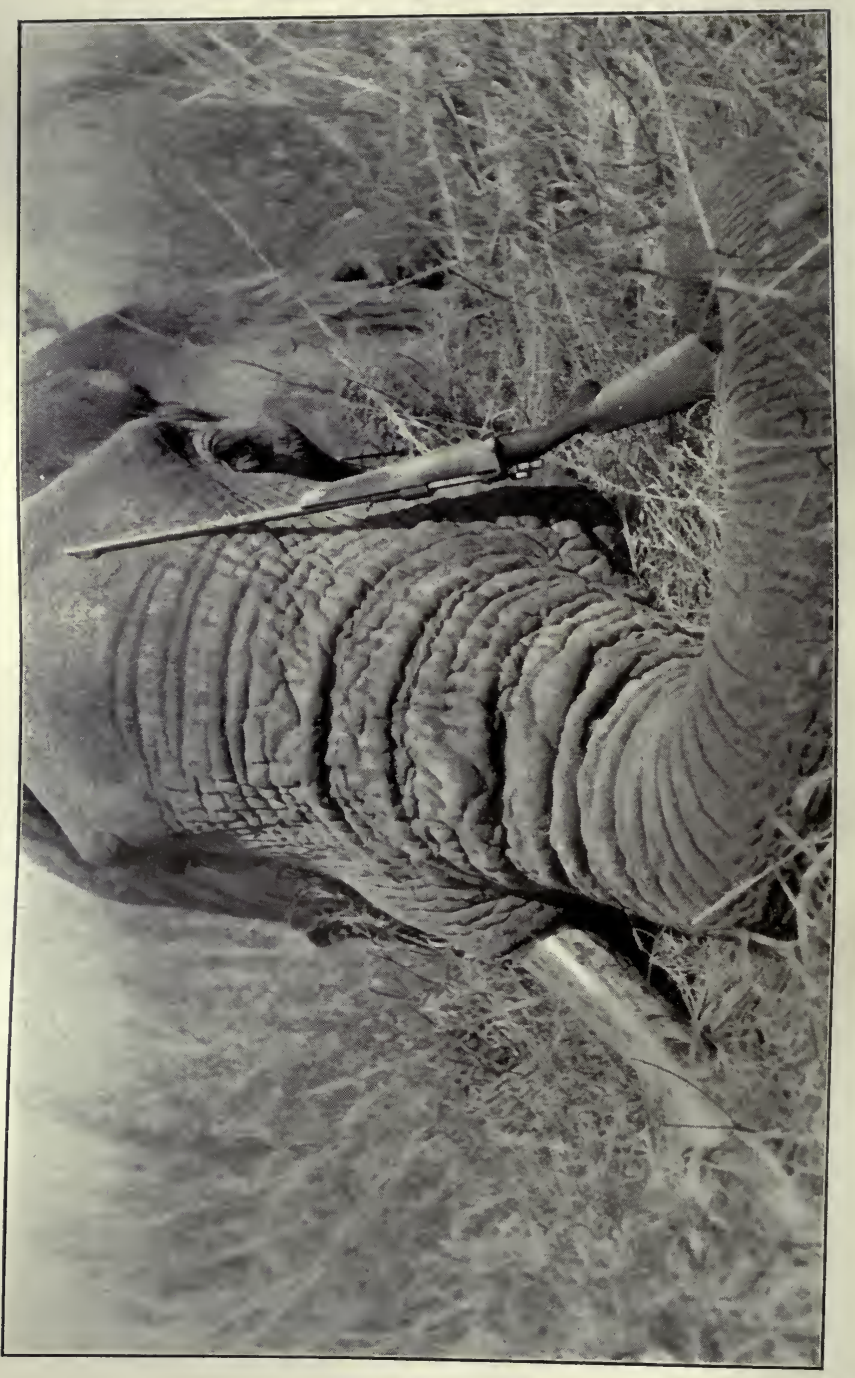

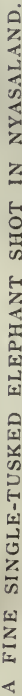




\section{WILD LIFE}

IN

\section{CENTRAL AFRICA.}

DENIS D. LYELL,

Author of "Hunting Trips in Northern Rhodesia," "Nyasaland for the Hunter and Settler," etc.

ILLUSTRATED BY PHOTOGRAPHS AND DRAWINGS BY THE AUTHOR.

THE FIELD \& QUEEN (HORACE COX) LTD. Windsor House, Bream's Buildings E.C. 
PRINTED BY THE FIELD \& QUEEN (HORACE COX) LTD. WINDSOR HOUSE, BREAM'S BUILDINGS, LONDON, E.C. 


\begin{abstract}
I DEDICATE THESE PAGES ON WILD LIFE AND SPORT TO MY BROTHERS AND SISTERS IN MEMORY OF PAST HAPPY DAYS.
\end{abstract}





\section{INTRODUCTORY.}

THIS book is a simple account of the ripe experience of ten years spent in Central Africa, which is the tract of country known as Nyasaland and North-Eastern Rhodesia. The former protectorate used to be known as British Central Africa, and the latter territory is now amalgamated with North-Western Rhodesia, known collectively as Northern Rhodesia, to distinguish it from Southern Rhodesia, which embraces the old-time territories of Matabeleland and Mashonaland.

For the last ten years I have spent a wandering sort of life in Nyasaland and North-Eastern Rhodesia, so, to get a short and descriptive title, I use the title "Wild Life in Central Africa."

I am afraid this is rather a disjointed kind of volume, digressions are frequent, and possibly there is a certain amount of repetition. For this I can only plead that I have suffered much from malarial fever, both in India and Central Africa, and my memory is such that I sometimes forget what I have written soon afterwards.

Some people may think that this is rather a matter-offact kind of volume; but, then, I am a matter-of-fact sort of person, and dislike embellishing my writing with fanciful or fictitious matter, or to read such literature written by other authors on sport and travel.

These pages are intended for the nomad big-game hunter, who loves to get away from the beaten track, where he can be free of the irksome conventionalities of civilised life, and where he can find a freedom that is impossible in more settled countries. 
There is no country in Africa more isolated and cut off than are the territories I write of, and, in the parts away from the townships and settled districts, the hunter and traveller will find the country and people in the primeval state they were before Europeans first settled in these regions.

In this volume I write rather pointedly and emphatically on some subjects connected with sport, and I lay great stress on the iniquity of firing long-range shots at game when it is usually not difficult to get fairly close and do good work. My reason for doing so is that such a lot of rash and careless shooting takes place that many harmless animals are sent off to die a slow and lingering death, unless they have the good fortune to be killed quickly by some prowling lion or leopard that may come on them.

I do not lay claim, especially in my earlier days of hunting, to bagging everything I fired at; but, with experience, I found that it pays to get to close quarters and make certain of my shot, with the consequence that I hardly ever lose anything I fire at nowadays.

The beginner is apt to get excited, and shoot carelessly, without taking pains to align his sights on a certain spot, and he usually thinks it sufficient if he manages to hit the beast anywhere in its body; but this is not good shooting, and neither will it lead to clean killing. What he should do is to pick the exact spot and aim at that; so close quarters are necessary if he is to see the exact angle at which the game is standing. It is all a matter of angle; for game is not always found waiting broadside on, and many positions are presented to the hunter.

A good range for antelopes is 100 to I 50 yards; and for large game like elephant, rhino, or buffalo, a range of sixty or seventy yards is best, as the first bullet is the all-important one; and the subsequent following up of a wounded dangerous beast is not so risky as when long shots are fired.

It is perhaps needless to remark that animals styled "dangerous game" are seldom dangerous until they are 
interfered with or wounded; and the only animals that may act offensively are man-eating lions at night, animals with young which are closely approached, or those that have been recently wounded and left by another hunter.

The following pages have been written in the bush, and I have had no opportunity of getting at books of reference, though these were not much required, as the book deals almost solely with my own experiences.

Having kept diaries for the ten years I have spent in Central Africa, I have found it difficult, out of so many notes, to find the most interesting; so I have given the most recent, as they will give the sportsman a better idea as to the conditions pertaining at the present day, though the country has changed little since I first knew it in 1903; and there are still hundreds of square miles that have hardly ever been trodden by the foot of civilised man, and there game will be found in abundance by anyone who takes the trouble to go and look for it.

This is a country where camping out causes little hardship in the dry season, which is from May to December ; and the three great essentials of camp life-shade, fuel, and water-are plentiful, while native labour is cheap and. abundant. The country has not yet been spoiled, as British East Africa has been, by the influx of wealthy sportsmen who have thrown their money about without a thought for those who may follow them.

Besides giving a certain number of shooting experiences, I give other information on licences, tracking, the natives and other matters which may be of interest to my readers, and if my ideas do not meet with approval, I can only say that they are the thoughts of a single individual, though I have tried not to let my pen run away with me when discussing any matter that may have several sides. Perhaps the lonely life I have led for so long in the silence of the bush is apt to make a man dogmatical and opinionative; but I like people who have decided opinions, so I hope my reader will make allowances if he does not agree with all I write. 
The trophy hunter who comes here should manage a six months trip for a sum of $£ 50$ monthly, including passages from, and return to, home; and if he goes about on his feet instead of engaging twelve to sixteen men to carry him in a machilla, he would have no difficulty in doing the trip for the sum stated.

He should bring his rifles, cartridges, tent, camp outfit, and clothes and boots, from home, as these things are difficult to procure here. Foodstuffs can be got in the townships, but they, too, would cost less to bring out and they would be fresh.

The Army and Navy Stores and other firms know how to pack provisions in useful cases not weighing more than 5olb: each, which is the usual weight of a porter's load, though I think 4olb. better if long marches are taken. Such cases when empty are very useful for sending home small horns, curios, or headskins of small size; and for the larger trophies nothing can beat large green canvas bags.

I give some pages on camp outfit and rifles, so need not discuss the subject now at any length.

The best time to arrive here would be the month of June, as the grass fires do not usually take place much before July, and the best route is from England to Chinde. If a sportsman could only afford three months in the country, he should get all the game he wants in the Chiromo district, which is only four or five days' journey from Chinde by river steamer; and the game includes elephant, buffalo, eland, waterbuck, hartebeest, zebra, sable antelope, bushbuck, reedbuck, duiker, oribi; and a possibility of lion, leopard, kudu, and other animals.

In conclusion, I have to thank the proprietor and the editor of the Field newspaper for permission to use some articles I wrote for that periodical at different times.

Also I am obliged to a good sportsman who writes to that journal in the name of "Mannlicher" for having given me permission to quote a short letter about "Photographing Big Game." 
My friend George Garden, of Mlanje, Nyasaland, has again allowed me to use some of his fine photographs, and I would like to acknowledge his kindness here.

I may say that most of the photographs of game are by myself, but some are not as good or clear as I would like, which is doubtless due to the effect of a damp climate on the films.

The photographs of the situtunga, sassaby, black and red lechwe have been kindly sent me by Mr. J. E. Hughes, who has had much experience of the country bordering Lake Bangweolo, and who is, I believe, prepared to act as guide to any sportsmen wishing to make a shooting trip in these regions.

D. D. LYELL.

Bua River, Nyasaland.

March 20, I9I3. 



\section{CONTENTS.}

$\begin{array}{lllllllllll}\text { INTRODUCTION } & \ldots & \ldots & \ldots & \ldots & \ldots & \ldots & \ldots & \text { vii }\end{array}$

Chapter I.

Remarks on Sport and Making a Home in the Bush _.. I

Chapter II.

Shooting in Central Angoniland

I5

Chapter III.

Further Shooting Experiences in Central Agoniland...

Chapter IV.

Hunting Elephant and other Game

\section{Chapter V.}

The Risks of Big-Game Shooting ...

Chapter VI.

Tracking Game, Licences, Camp Notes, etc....

Chapter VII.

Memories of Big-Game Hunting

\section{Chapter VIII.}

Field Notes on the Game 
Field Notes on the Game (continued)...

\section{Chapter X.}

Native Characteristics, Customs, and Beliefs ...

\section{Chapter XI.}

Various Subjects for the Sportsman and Naturalist ... 236

Appendix.

Ballistics of the best known High Velocity Rifles 


\section{INDEX TO ILLUSTRATIONS.}

A fine single-tusked elephant shot in Nyasaland . Frontispiece. My permanent hunting camp

Crossing Bua river, near Likasi, Central Angoni...Facing page I land

Showing how palm-pole door is made

The Mlanje mountains, Nyasaland

Zebra (Burchell's) shot in Nyasaland

‥ , , , 2

Horns of kudu bull shot in North-Eastern

Rhodesia

Very old eland bull shot in Nyasaland ...

-.. , , ,

My camp in Central Angoniland...

+.. , , ,

Roan bull shot in North-Eastern Rhodesia

Elephant bull shot in Nyasaland...

... , , ,

Fence round dead elephant

... , ,

Sable bull shot in North-Eastern Rhodesia

Hippo shot in the Bua river, Nyasaland ...

Trees broken by an elephant

Lioness (photo by G. Garden)

.. , , ,

1.-Spoors of antelopes in miniature

2.-Spoors of game in miniature...

... , , ,

3.-Spoors of pachyderms

... , , ,

4.--Spoors of the carnivora, etc., in miniature ..

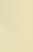


Buffalo bull shot in Nyasaland $\quad . . \quad \ldots \quad \ldots$...Facing page 145

Buffalo cow shot in Nyasaland $\quad \ldots \quad \ldots \quad \ldots \quad \ldots \quad,, \quad$, $\quad$ I 47

$\begin{array}{lllllllll}\text { Tree broken by an elephant } & \ldots & \ldots & \ldots & , . & \ldots & \text { I } 49\end{array}$

A hunting camp in the bush $\quad \ldots \quad \ldots \quad \ldots \quad \ldots \quad, \quad, \quad, \quad$ I 5 I

Eland bull being skinned for preservation _.. , , , 153

Kudu bull shot in Nyasaland $\quad \ldots \quad$,. $\quad \ldots \quad$, , , $\quad$ I 54

Sable bull (photo by G. Garden)... . . . . $\quad$, $\quad$, $\quad$ I74

Sassaby (photo by J. E. Hughes) $\quad \ldots \quad$... $\quad, \quad$, $\quad$ I 80

Situtunga (photo by J. E. Hughes) $\quad \ldots \quad \ldots \quad \ldots \quad, \quad, \quad, \quad$ I 82

Red lechwe (photo by J. E. Hughes) $\quad \ldots \quad$... , , , $\quad$ I 84

Reedbuck ram shot in Nyasaland $\quad \ldots \quad \ldots \quad, \quad, \quad, \quad 18_{5}$

Impala (photo by G. Garden) $\quad \ldots \quad \ldots \quad \ldots \quad \ldots \quad, \quad \quad \ldots \quad, \quad$ I 86

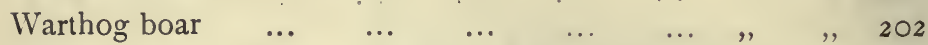

Mkumbi, an old Angoni chief $\quad \ldots \quad \ldots \quad \ldots \quad \ldots \quad, \quad, \quad 2$ I 8

A son of Africa-Central Angoniland ... .. , , , 228

Fig. I.-Eland bull, showing the way to take measurements for specimens intended for mounting in museums... $\quad \ldots \quad \ldots \quad \ldots$

Fig. II.-Impala head and neck, showing the way to take head skin ...

Fig. III.-Reedbuck, showing the way to take whole skin

Roan antelope head, showing the method of removing horns from core

...Facing , , $24 \mathrm{I}$

Black lechwe (photo by J. E. Hughes). .. .. , , , 253

Bullets cut from game $\quad \ldots \quad \ldots \quad \ldots \quad \ldots \quad \ldots \quad$, $\quad \ldots \quad, \quad, 263$

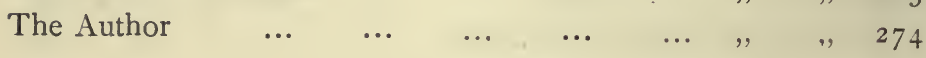




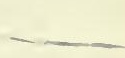




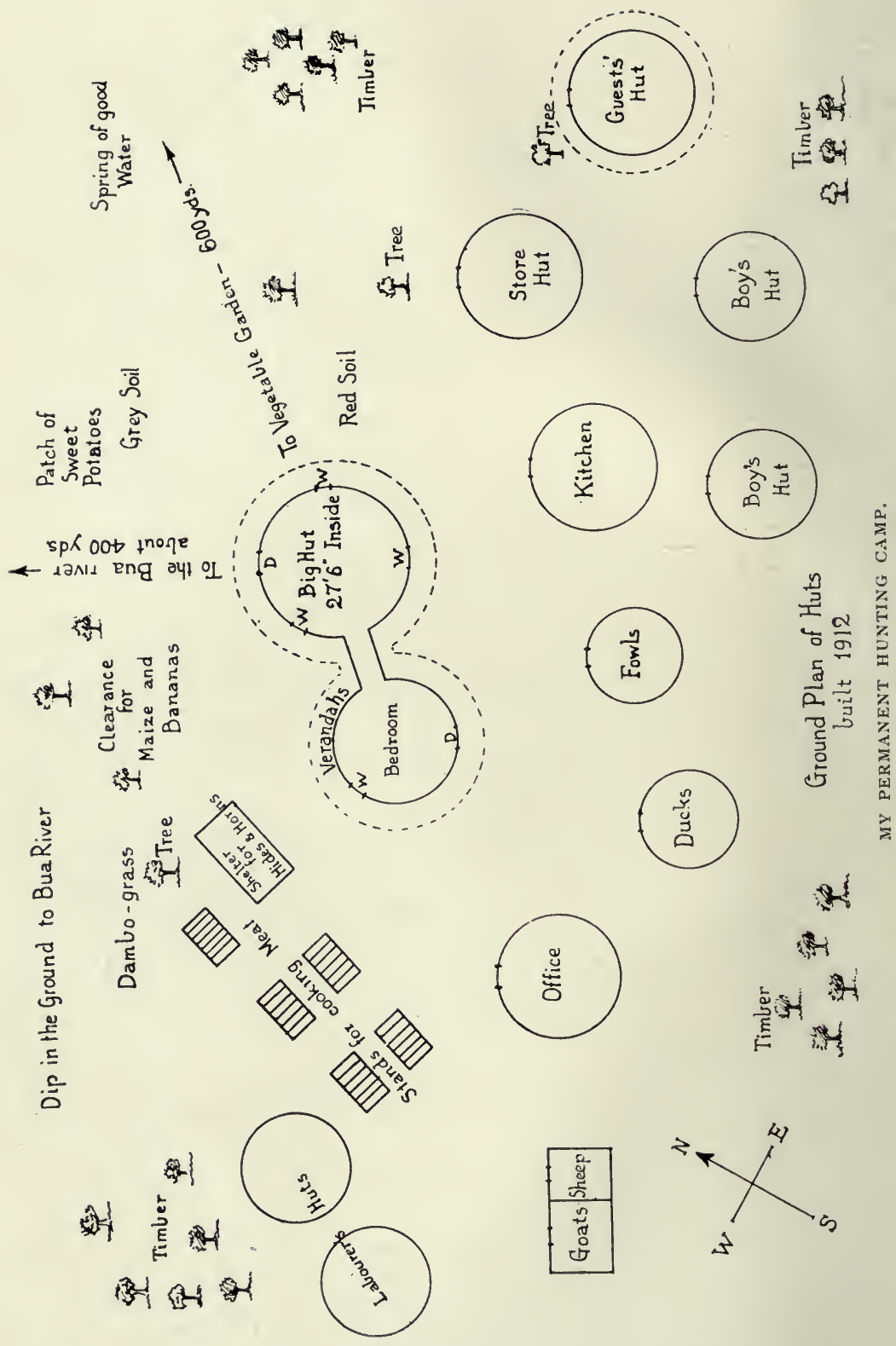




\title{
Wild Life in Central Africa.
}

\author{
CHAPTER I.
}

Remarks on SPORT AND Making a Home IN THE BUSH.

British East Africa and Central Africa compared-Long-range shooting at game-Somali hunters compared with other natives-Life in a tent unhealthy-Village life and tropical pests-Rats-White ants-Fleas killing ducks and fowls-Bees and hornets-Snakes-Hut buildingCutting poles-Native bark string-Grass cleaning-Grass seedsKnowledge of use to young colonists-The best type of man for a colonial life.

THERE are few countries among our British possessions that can offer a better field for the hunter or field-naturalist than do the territories in Africa known as Nyasaland and Northern Rhodesia, the latter formerly known as North-Eastern, and North-Western, but now under one administration. There the sportsman or traveller will, in the wilder parts of the country, see the land and people under primeval conditions, and the cost of such travel will not be so excessive as it has become in British East Africa, where wealthy men have foolishly squandered their superfluous wealth to the detriment of poorer, though often better, sportsmen than themselves. In I9I I I visited British East Africa, and I am bound to admit that it is a splendid game country, although the conditions of shooting on the plains are not nearly so sporting as they will be found in the country I am to write of in this volume. On the plains a man usually rides about on a pony or mule, and it is customary to fire very long shots at game; in fact, the animals there seem to have learned the range of modern rifles to a nicety, and it is difficult for the man who 
likes to take his shot at between 100 and 200 yards to get as close as that without much trouble.

With modern high velocity small bores, some of which shoot point-blank to about 300 yards, there is not a great difficulty in hitting a large animal like a zebra or wildebeest at that range, but it is more difficult to make good shooting on medium or small-sized animals, such as Grant's and Thomson's gazelles, and I, personally, think it a great shame that this long-range shooting should be practised, for many men who could not hit an $\mathrm{i} 8 \mathrm{in}$. bull at 400 or 500 yards think nothing of pumping several clips of cartridges into herds of animals at these absurd ranges. After killing a great quantity of African game, I have found that if an animal is much over I50 yards off it is a very difficult matter to discern the true angle at which it is standing, and if this cannot be ascertained it is nearly impossible to place the bullet in a vital spot, and sc kill it neatly and humanely.

The eyesight of mankind is not capable of seeing true angles much over I 50 yards, especially when using the ordinary open or peep sights usually fitted to sporting rifles, although a telescopic sight might be a help in doing so; but these sights are too bulky, and too easily damaged, and very few practical men with average eyesight use them.

In a later chapter I intend to write fully on sporting rifles, as I consider the subject one of great interest to all sportsmen. I also intend to treat of the natives further on, but I will mention here that I found the natives of British East Africa very poor hunters and trackers. The Somalis have proved themselves useful to sportsmen, and some of them are very plucky; but so are many races of African natives, and bravery in danger is not the prerogative of any single race of mankind. Personally, I found the Somalis a veritable nuisance, as they do not get on well with the natives, and they are perpetually grumbling and wanting something. In fact, they have been so spoilt by kind and generous treatment that they expect to be 


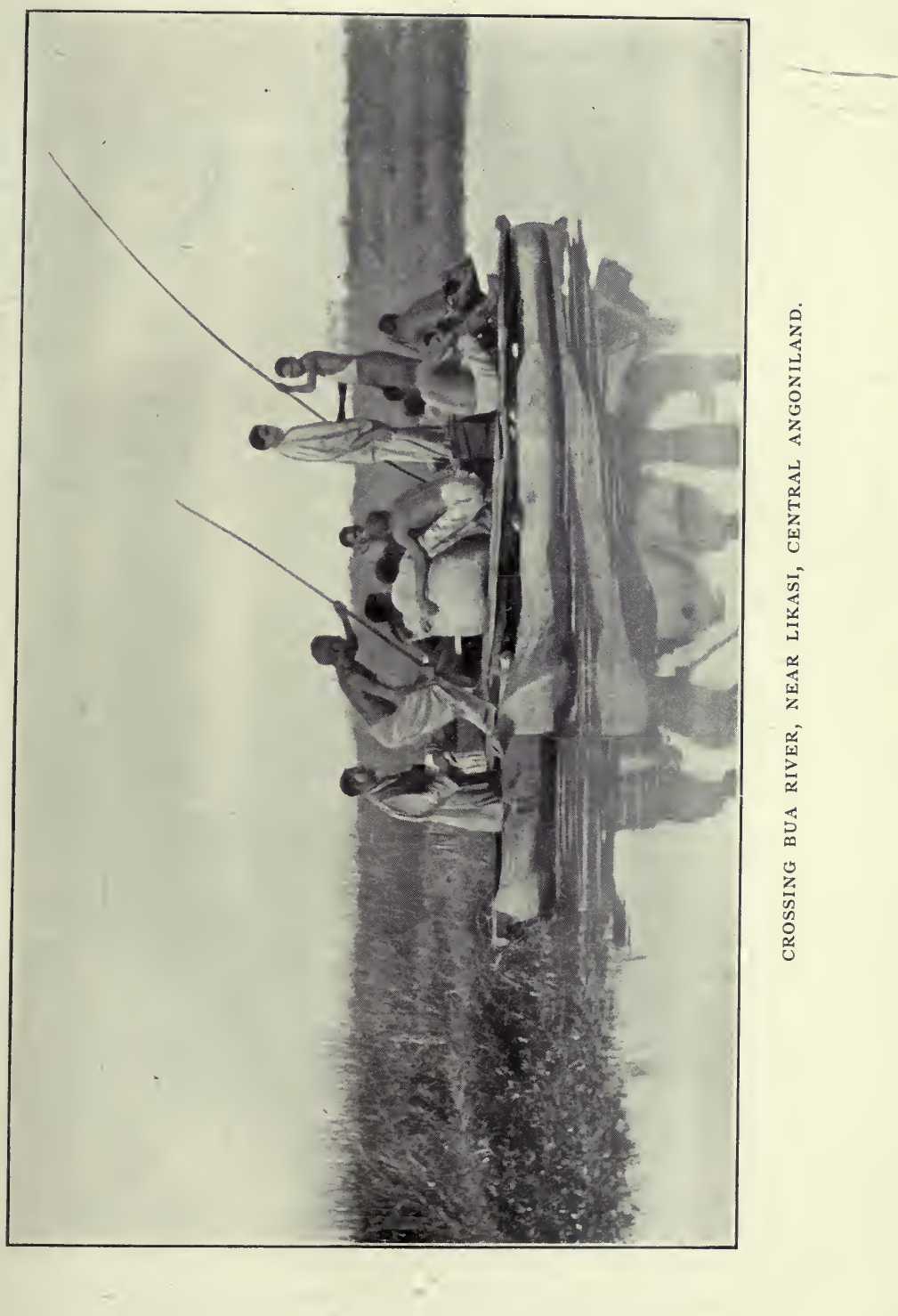



treated like Europeans, so they demand, and receive, all kinds of luxuries such as flour, tea, sugar, ghee, salt, seasonings, rice, etc., not to mention European clothing, such as boots, putties, hats, shooting coats, and other things.

What a difference such a swaggering specimen of humanity presents to the Nyasaland or Northern Rhodesian tracker, with his yard or two of cloth or a skin round his loins, who tramps about on bare feet, and can often track game as well as a Bushman of the Kalahari Desert, and who is charmed if he is presented with an old worn out blanket and an empty flour tin to cook his porridge in.

The Central African gunbearer or tracker does not ask a tent, water bottle, cooking pot, or any of the luxuries expected by the Somalis, and neither does he get from $5^{\circ}$ to 100 rupees a month, but is pleased with a humble fee of from four to six shillings and a yard of cloth, or some salt every week to buy food, though the old hand gives his men meat to barter with the villagers for their flour, sweet potatoes, ground nuts, etc.

It is known that the natives of British East Africa are the poorest trackers or hunters in any territory in Africa; so I cannot understand why people praise them; but then such Europeans cannot have hunted with really good native trackers in a bushed country or they would know better.

In Central Africa the game has often to be spoored, especially large antelopes such as eland, kudu, sable, and roan; and of course big game like elephants, rhino, and buffalo are nearly always tracked, as they are not often come on by chance.

This spooring work lends the chief interest to big game hunting, as anyone who is a fair shot can align a rifle barrel straight and kill game if he only keeps cool and gets close enough. In Central Africa most shots will be obtained at a distance of 150 yards or less, and I have not often found it necessary to fire at 300 yards or over, unless in the case of following up a wounded beast. This is, I think, the only excuse for-long-range shooting, as all men deplore losing a hit animal, which will go off and be shunned and turned out 
of the herd by its comrades, and will eventually die a slow, painful death, unless it is killed by a lion, leopard, hyena, or pack of wild dogs.

Having compared British East Africa with this country, I will now go on to give an account of making a camp in the wilderness. In North-Eastern Rhodesia and Nyasaland I have made several big camps, as it is most uncomfortable being in a tent always. A tent is either too hot or too cold, and it is always a cramped abode for anyone liking a fair amount of space. Besides, a man cannot keep healthy in a tent during the rainy season, as the ground is usually damp and sodden. So, without a preliminary description of how I got there, except to say that it was on my legs and not by machilla, I will bring my reader to a spot in the African bush situated near the source of the Bua River in Nyasaland.

On the journey from Blantyre I had shot a considerable amount of game for my "boys" (all native servants are called "boys" here), and once I had heard a lion grunting early in the morning near the Rivi-Rivi stream.

I left the path to look for this lion, but he did not "speak" again, and as the ground was hard and stony I could not find his tracks, so I failed to get a shot. On getting to Memeza's village (this chief is a son of Mpseni, the late paramount chief of the Angoni race living in this district), I rented a fair-sized native hut, as I knew it would take about two months to build my camp, and my single fly "Whymper" tent was rather old and weather-worn, and I wished to keep it for further shooting trips. Besides, as I have mentioned, life in a tent is uncomfortable over a long time.

A thatched hut, if clean and free from fleas and other human tormentors, is a much better habitation in every way, but I knew from much past experience that the rats and village dogs and pigs would prove a nuisance.

Of all tropical pests I would give the ubiquitous rat first place, as these dirty vermin are fearful destroyers of all property. I have had the following and other articles gnawed 
and destroyed by them, so it will be seen that a rat's "menu" is probably one of the most varied of any living creature.

To enumerate some of these articles, I can mention rifle stocks, the rubber heelplates often fitted to heavy weapons, leather and web slings of rifles and bags, putties, clothes, sponges, corks of waterbottles, lead articles, books (for the gum or glue in the binding), vulcanite pipe stems and other articles made of that substance, indiarubber articles, leather body belts, hats (it is most cheering to find a hole the size of a crown piece in a new double "Terai" which cost a guinea), skins, horns, all food stuffs, etc. I could easily give a page full of other articles if I cared to, and it is enough to state that rats, and next to them white ants, cause a great amount of loss to the settler here. Traps are of little use, as they get too wary after a time, and there is generally plenty of food kept in the native bins, and offal in quantity for them to feed on. Cats reduce their numbers and make them clear out, although they often get very cute and keep aloft in the thatch where the felines cannot reach them. Other pests, such as mosquitos, fleas, hornets, tarantula spiders, scorpions, centipedes, snakes, biting ants, and other tormentors, do not compare with rats and white ants.

With the latter one can take care not to build over a nest, although some parts of this country are so bad that it is difficult to keep clear of them. I have noticed that white ants and fleas are most troublesome in the dry season, whereas snakes, scorpions, centipedes, and some other insects are worse in the rains. Even after taking great care to build my huts in a place apparently clear of white ants, they eventually found their way in, and came up through the mud on the floor, eating skins and boxes, and on the walls they got up the poles and would come out and eat things hung on pegs or nails.

It is a good plan to put one's cherished possessions in watertight tin boxes which are impervious to rats or ants, and every night before I turn in I have a look round and lock things up. Unfortunately, one is inclined to leave this 
until an article has already suffered a certain amount of damage, and most of my belongings bear the marks of rats' teeth, or pieces eaten out of slings and bags by white ants. It is worth mentioning that neither rats nor white ants care to eat green Willesden canvas, such as tents and guncases are made of, and this is a much better material than leather or brown canvas for the tropics. When bees make up their mind to hive they can prove a great nuisance, and I once lost over ten fowls which were stung to death by a swarm. Eventually, they settled in a brick chimney (I was then living in a brick house in Zomba), and in the evening I smoked them out and they dropped into my bedroom by the hundred, which I discovered later when I went to bed, for many were only dazed and stupefied with the smoke, and they soon woke up and began to crawl about.

Black ants are bad biters, and I was seldom more amused than when an officer of the King's African Rifles in Zomba, who apparently had never had any previous knowledge of their ways, stood over a line of the "warriors" until many of them had climbed up the legs of his pants. Then he jumped and rushed into his house and undressed quicker than I ever saw a man do before. His "boys" and I then helped to unload him, which was a difficult business, as he was unable to stand still for long. These ants have very strong mandibles, and if a man were too sick to move, or tied up, a swarm would soon kill him. I have had several ducks and fowls killed by them, and once they nearly killed a calf which they had attacked.

Lately, a swarm of fleas appeared at my camp and settled on the ducks and fowls, and the birds' necks and heads got covered with them. They were so numerous that they resembled fine bead work. In three months I had lost nine ducks and about a dozen fowls, when I tried to kill the fleas by rubbing on various strong solutions of corrosive sublimate, permanganate of potash, or boracic acid; and on one duck I tried a rubbing of paraffin oil, which quickly killed the fleas; but it killed the duck also, for it gave a few shivers and expired. I fancy that when the fleas felt the oil, in 
their dying struggles they all began to bite hard, which proved too much for the duck.

Hornets, especially a variety, native name magu, sting most painfully, and if a bush is touched where they are hanging to their paper-like nests they dart out and sting. I have still a lively recollection of two fastening on to the lobes of my ears and the shooting pain that followed. Why each hornet chose an ear lobe I cannot say; but the fact was evident, and the pain did not cease for several hours. In India, a variety (possibly more than one variety) builds its nests in the tea bushes, and the Indian women get badly stung at times. In fact, I have seen several women nearly killed by them, and I have heard of a few cases where people died from the numerous stings inflicted, and in one instance a pony was stung to death. As these insects generally attack the necks of their victims, death is often caused by suffocation, as violent inflammation and swelling results.

I have not found that snakes are so dangerous as statistics would cause one to believe, for I spent nearly seven years of my life as a tea-planter in Cachar, Assam, Sylhet, and the Terai Dooars. During that time I only heard of two or three cases of death from snake-bite, so I cannot understand how the Government can issue statistics of thousands of deaths annually. Like others, I can only believe that the majority of deaths are murders pure and simple, which are reported to the authorities as snake bites. While working in a tea-garden snakes are often disturbed, and I suppose I have killed over 300 Indian snakes, and the worst varieties were cobras and banded kraites. In Africa, by far the worst snake is the puff-adder, as he is usually in a torpid condition, with heat or cold, so is much more liable to be touched. His skin, too, greatly resembles dried dead leaves, and it takes quick and clear eyesight to spot him as he lies quiescent. Some of the water snakes are very deadly and so are the mambas (of three varieties, I think). Personally, I have had narrower escapes from snakes than wild animals, for I can remember three narrow 
shaves from puff-adders, two from mambas, and one from a deadly type of water snake.

I will now leave the subject of pests and mention the building of my camp, which may be of interest to any wanderer who intends to live or settle here for a time.

It was in May, I9I2, when I started operations, having already been ten years in Central Africa, so I was quite well experienced in this kind of work.

The first thing I did was to get labourers, and there was no difficulty about this, as scores of natives came to me to apply for work. In 1903 I had lived in this district and they knew that there would be plenty of meat going, for nothing attracts a native here more than nyama (meat or game). Some of my carriers wished to stay on for a month, and, including them, I wrote on over fifty men and boys. The women here do not work much for Europeans, as they do in India, for they have their own duties to perform. However, when I wanted grass for thatching purposes later on, they brought me thousands of bundles, receiving for each load a lump of fresh meat, or in some cases partially cooked meat, which is the best way to preserve it here. I make stands with fires underneath and cut the meat in long strips, gashing it all over so that the heat and smoke can get well into it. In this condition it lasts for several months, and if it gets slightly "high," this is no matter, as the natives like their meat with a strong gamey flavour.

After noting the names of the labourers, I went off with a few men to look for a site not too far from the Bua River. The first spot I picked was unsuitable; as the natives informed me it had been used as a cemetery, so I selected another site near it. Even here there were three old graves within 50 yards, but as I am not superstitious, and as the natives said that they had no objections, I got the men to come along and clear the ground of all grass and bushes, and I had to fell some trees also.

In a dambo, or open grassy space, pretty clear of bush and usually wet in its lower parts in the rainy season, I found a 
nice spring of clear water, which was a lucky incident, as it is better not to have to drink water from a running stream where the natives wash constantly. As a matter of fact I seldom drink water unless in the shape of tea or coffee. Tea I consider the best drink for tropical countries, as the water to make it with must be boiled. It assuages thirst better than cold water, and also induces a perspiration, which is a good thing in the tropics. Coffee is rather a bilious compound to be drinking constantly, and cocoa induces thirst and is too fat and heavy a fluid for frequent use.

After I had cleared about two acres of ground I sent the men off to cut poles, and to get that indispensable material for binding known to the natives as maluzi. This string is the inner shreds of bark, which are pulled off in lengths of from $5 \mathrm{ft}$. to roft. or more, and is taken from the bovu tree. When wanted very strong it is twisted up in strands. The natives use it for all kinds of binding, for nails are never used by them for hut building.

The best trees for poles are the masuko and maula, both of which are impervious to the borer insect, which soon gets into soft wood and riddles it with hundreds of holes. Besides, soft woods such as the bovu, which supplies the bark string, do not stand the damp, and soon get rotten.

It is best to remove all the bark from the poles, and this is done by hammering it with a piece of wood, or with the back of the axe. If the poles are not cleaned the bark opens and proves a receptacle for all kinds of pests, and the mud of the walls is apt to crack when the bark opens with changes of climate.

When the men cut the poles in the bush they should be cut rather long, then cleaned, and afterwards cut to the proper length, after being inspected. I have found it useless to expect the natives to cut them off to the exact length wanted, unless they are marked for them. The best height for the walls of the dining and sitting hut is about $\mathrm{gft}$., and as the poles will be sunk in a trench about I $8 \mathrm{in}$. deep, they should be trimmed to $10 \frac{1}{2} \mathrm{ft}$. A round hut is measured out by getting two sharp pegs and a long piece 
of string. A small loop is made and put over the centre peg, and when the exact diameter wanted is fixed, another loop is made and the other peg inserted, and a circular line made. The space for the door should be marked, but in cutting the trench for the poles the earth should be left intact in the doorway.

For the verandah another line is made, and this can be marked by deepening the line with a hoe, so that while at work the men's feet will not obliterate the mark. I made my hut $27 \mathrm{ft}$. wide inside, with a verandah of $9 \mathrm{ft}$., which made a total diameter of $45 \mathrm{ft}$., as of course the verandah goes right round. Then I made a smaller hut near, $6 \mathrm{ft}$. less inside, with a verandah all round, and the two huts I joined with a passage. I had some difficulty in knowing what kind of doors to make, as the ordinary native door is made from the stalks of maize when dry (called impaissi), and these are loose affairs and soon get broken. At last I thought of getting the poles of the Chiwali palms, which I knew grew near the Bua, a few miles off, so I sent men to cut them, and when they had arrived I got two men to tackle the doors, which are made by putting five or six stakes into the ground and then making holes in the palm sticks and pushing them on. A strong wooden pole is put on as a backstay, and then a strip of palm stick is nailed on. I managed to get some nails from the Government officer at Fort Manning (six miles off), and also some rough boards out of which I fashioned a table, a few racks, and some small windows. He also kindly lent me a saw, plane, two augers, and a few tools. Having no hammer, I did the best I could with a small American axe I possessed, and I may say such a tool is most useful in the bush for all kinds of work. The natives are very expert axemen in a way; although they doubtless could not compete with the European bushmen of Australia, New Zealand, and Tasmania. The natives' axes are made of soft wroughtiron, and are seldom wider than $\mathrm{I}_{2} \mathrm{in}$. in the blade. Some of the African trees are very hard and they will splinter a hard-tempered European axe. In building huts or a house, 


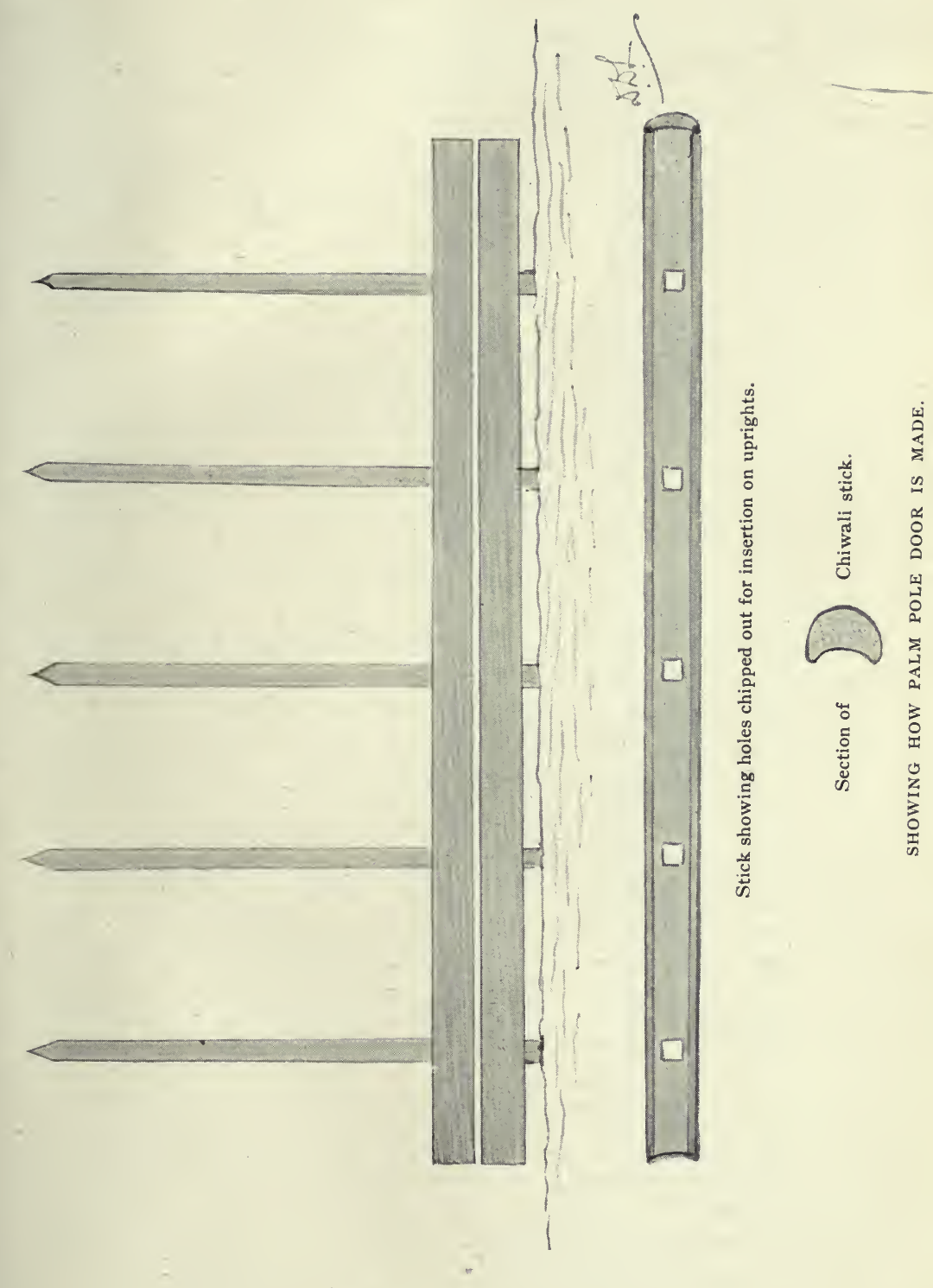



one has to study the prevailing winds, and the natives will be able to say from what direction they usually come. The door should be placed on the lee side so that the wind will not rush in and bring dirt with it, and blow out the lamps or candles.

When the poles for the walls had been cut and trimmed to the right length they were put in the ground, and strips of bovu wood were brought and the poles firmly bound in four circles.

Then long poles for the roof were procured, and care should be taken not to get wood that the borer will eat into. Masuko and maula are best, as these are common trees over most parts of the country. To get the pitch of the roof, four men hold up a pole each while another stands about 25 yards off to see that the angle is right. Then these four sticks are firmly tied and others are put in between and tied. Some of these poles, especially the first four, have forked ends which are pushed into one another and the spaces form gaps to insert other poles into. Then, when the poles are about a foot apart on the tops of the wall poles, the roof is fastened with strips of wood firmly tied with maluzi string. The floors of the huts should be raised about 9 inches or a foot, and then children can be got to hammer it with slabs of wood flattened at the ends. The verandah is made by placing poles from one of the circular strips of binding on the roof to poles laid across the upright verandah poles, and these should be at nearly the angle of the upper part of the roof. I was fortunate enough to find some white clay in a dambo not far away, which was of a nice French grey colour when it had dried on the walls of the huts.

I got native women to smooth up the floor with flat stones, and to do this they got some dark coloured earth, which was made into a paste, and when half dry the flat stones were rubbed over it, making a fine polished surface, which, however, did not last long, even when covered with mats and skins. I am afraid this account of hut building will prove rather tedious and dry reading, and though I would like to get on 
to the shooting I must still give a few lines about the thatching of the roof. If the grass is wanted very clean it is possible to comb it out on a kind of large hackle, but more than half of it will disappear in doing this, as it is full of short fibre.

So as to have the interior nice, I got about twenty-five bundles of sicaira grass, which is naturally clean, of a pale yellow colour, and very strong and long. This I put on under the ordinary grass and it prevented short stalks and grass seeds from falling into the hut. The grass here usually seeds about May or June, so it is best, if it is full of seeds, to leave it lying for a few days in the sun and then shake it well, to get rid of the thousands of sharp seeds, which are very disagreeable if they fall on one's blankets, clothes, or into the food.

It is most interesting superintending such work, and if the natives are stupid or aggravating it is best to be patient and try to teach them. The climate often makes Europeans most irritable, and the intensely aggravating qualities of some natives make it very hard for a man to keep his temper, especially if he be of a quick, sensitive, and energetic nature. If a native gets more than one order at a time he will only remember the last. A white man, if he is asked to do three things, usually does them in the order named; not so a native, for he would likely forget the two former orders, and possibly the last, too, as he would get hopelessly muddled.

I think all young men who intend to live in a wild country should have some knowledge of the following subjects :

1.-Gunnery-shooting with rifle and gun.

2.-Zoology and taxidermy.

3.-Mechanics, including motor and ordinary cycle repairing.

4.-Carpentry and wood work.

5.-House building, brick making, and some knowledge of surveying.

6.-Horses, riding, and some knowledge of veterinary work.

7.-Stock-such as cattle, sheep, goats, and pigs.

8.--Medicine and rough surgery. 
9.-Gardening, especially vegetable growing and planting.

10.-Boating and fishing.

II.-Rough camp life and cookery.

12.-Skinning and butcher work.

Any youth who has some practical knowledge of these subjects will make a most capable colonist. In wild countries I have often met men who could not use a saw, hammer, or file; and as for using an axe or adze, they would probably have amputated a toe at the first attempt. Some could not even clean a rifle or gun properly, and their knowledge of all useful subjects was practically nil. In most of our best schools boys are now taught many useful subjects, and in most cases such knowledge will be vastly more useful to them in after life than a knowledge of extinct languages, such as Latin or Greek.

Certain very sensitive and refined persons might turn up their noses at taxidermy, or skinning and butcher work; but it is quite possible to retain refinement, and yet have a knowledge of how to use one's hands and brains; and it will certainly lead to comfort in the long run.

There are doubtless thousands of Britons living at home who would be glad to leave their occupations and go abroad; but circumstances prevent them doing so, and they get rid of superfluous energy by playing games such as football and cricket. But such games, strenuous exercise though they may be, are a very inferior training for a wild natural life in a primeval country.

It has often been proved that the best men for a rough life abroad are the moderate sized, wiry individuals, and not the large, lusty men, who usually are the first to break down under prolonged hardship and discomfort.

The same applies to the natives of Central Africa, and when starting out on a hard trip I usually pick out the smaller men, some of whom show little fat or muscle on their bodies.

[Since the completion of this volume a new regulation has come into force in Nyasaland regarding the occupation 
of Crown lands, and a man can no longer build a permanent hunting camp in the bush, or he will be liable to a penalty of $£$ ioo fine and a further penalty of $£$ io a day after notice to quit has been given.

I think this is rather a harsh and unjust law when applied to parts far removed from civilisation, and it is evident that there is one law for the blacks and another for the whites, for the former can go where they like, build villages, and cut timber on Crown lands.

Land is no longer sold here by the Administration as it used to be, and it can now only be leased for a term of seven, fourteen, or twenty-one years; so if a man wishes to buy land, he can only do so from people who acquired it before the new regulations came out.

Of course a man can still travel about and pitch a tent; and, I suppose, make a rough shelter, and use timber for firewood; but, as I have said, he cannot erect a permanent shooting camp here, and spend his time hunting and making notes on natural history, as I did, without special permission, and this, I fancy, it would be difficult to get at the present time.] 


\section{CHAPTER II.}

\section{Shooting in Central Angoniland (Nyasaland).}

A slight description of Central Angoniland-Nyasaland well watered and thickly bushed-The rainy and dry seasons-Grass fires-Cold at night -Plateaux in Nyasaland-Distance walked in Central Africa-Some rules for hunting-Two elands shot-One wounded and found deadPain suffered by wounded beasts-Vital shots at game-Tenacity of life in game-Elephants and rhinos easy to kill-Mr. Selous's opinion of tenacity of life in lions-The first bullet the all-important oneClose quarters best with dangerous game-Fine sable antelope shotHorns and ivory shrinking with age and heat-Natives' fondness for meat-The best country for large sable heads-Eland cow and bull shot-Good cow eland horns-Remarks on hunting game-Three zebras killed-Zebra meat causing rash-Cutting the throats of game -Good hunting tribes-Search for an elephant-Hartebeest shotVegetable nuisances-Some good kudu heads got in Central AfricaAbundance of kudu.

Central Angoniland is perhaps one of the best game countries left in Africa, as it is still in the same primeval condition as it was before the whites came to the country some twenty years ago. As I will enumerate the game in later chapters, I will only say that nearly all the species known to exist in Nyasaland are found here, and the only species that are absent are the Nyasaland gnu and the inyala. The puku is found on the Bua River, the only locality where it is known to exist here; although it is extremely abundant in the adjoining territory of NorthEastern Rhodesia.

The topographical aspects of the country are on the whole a vast undulating extent of bush, with a dambo here and there, and many hills. I have mentioned before that the word "dambo" means a grassy space, sometimes clear of trees, but often with bushes or trees here and there, and 
usually there are plenty of ant hills, which form fine stalking cover for approaching game. The drainage of the surrounding bush finds its way to these places, and many of the rivers in this country have their source in some such marshy hollow.

Compared to many of our other possessions in Africa, Nyasaland is well favoured with trees and a good water supply, and the rains being regular, the natives are able to depend on the soil producing a plentiful supply of food. In the course of time the amount of timber they cut to make their gardens will doubtless affect the rainfall, although they naturally never go very far from water. They are very wasteful with the timber, as they collect it in heaps and burn it, for they believe that the wood ashes make the soil more productive, and, certainly, vegetables such as pumpkins seem to grow best where there are plenty of ashes. The rains usually break about the beginning of December, and they last until April or May.

About August all the grass has got yellow and dry, and the natives then burn it; and this is ruinous to the growth of the trees in the dryer parts of the country. They start these fires so as to get the field mice, which are burnt to death; and millions of reptiles, insects, and birds must be killed also; and in some cases I have heard of young elephants and antelopes being burnt to death. The hottest months are those of September, October, and November, and at this time the heat can be terrific in some parts of the country, such as the Chiromo marsh. In North-Eastern Rhodesia, the valley of the Luangwa River is very hot, and the same can be said of the valley of the Zambesi River.

In May, June, and July the nights are often cold, and fires are a comfort, but about August the weather gets hotter by day and night, although the nights are never uncomfortably hot on the higher levels. There are many ranges of hills and detached kopjes scattered all over Nyasaland and North-Eastern Rhodesia.

In Nyasaland the best known mountains are the plateaux on Mlanje and the Zomba range, and people often go to 


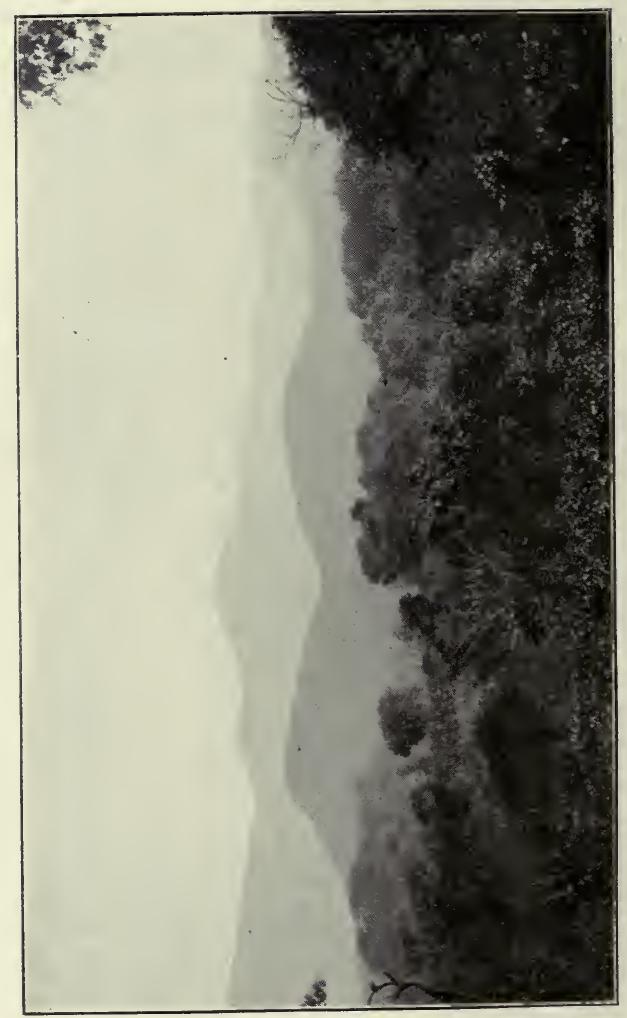

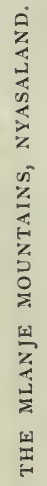


these places for a change. The cold during June and July can be bitter on either of these plateaux, and natives taken there should certainly be provided with a blanket, for cold generally crumples up a native, although he can usually stand any amount of heat.

The scenery on the Mlanje Plateau is very beautiful and many cedar wood forests will be seen, and there are also many clear streams of pure, cold water. Any visitor to Nyasaland, or even people who settle there, should make a journey to this plateau, for the climate and vegetation are quite different from any other that will be experienced or seen in the country. The plateau has, besides the cedar forests, many beautiful heaths, and the air is cool and crisp and quite exhilarating after the atmosphere of the plains.

In this chapter I intend to give some account of my experience of game in Central Angoniland, so I will now begin to do so.

While my huts were building I often went for a walk into the surrounding bush, and my favourite time was about 3 o'clock in the afternoon, when the sun began to lose its power and sink in the west. The only disadvantage about the afternoon shoot is that game killed has to be left out for the night, especially if it is a large bodied beast, and from the European point of view this does not improve the meat for the table, but natives do not mind it in the least.

I have often wondered how many miles I have walked through rough bush and along native paths in Central Africa. Having lived in the country for ten years, I must surely have covered quite 20,000 miles on foot. I have never kept a record of the distance covered, although in my old diaries, most of which are at home, I have kept notes of most of the game I have shot, and of all my many journeys after game.

When living in some lonely hut or house, very few days pass that I do not go out into the bush with my rifle. Life in such a place, far from civilisation and libraries, would be intolerably slow if one did not spend the time in this way. It is interesting to take notes of the game, and for a couple 
of years or so I was constantly taking rough sketches of their footprints, or spoor, as well as sketching their droppings and making notes on their habits.

There are three important rules that should be observed by all who hunt big game, and these are :

I.-Observance of the direction of the wind.

2.-To make as little noise as possible.

3.-Get close for the shot so as to hit a vital spot.

There are plenty of other rules, but these are certainly the most important; at least, they are according to my ideas.

On May 25, I912, I went out with several men carrying the cartridge bag, camera, and an axe; and we went along slowly-for it is useless walking quickly, as one makes too much noise and cannot scan the country for gameand especially on the look out for elands, as a great number of these animals had lately been visiting the native maize gardens in the vicinity of Memeza's village. Every morning their fresh tracks could be seen, and a herd of these large antelopes will do as much damage as an equivalent number of cattle, and in a further chapter I will mention the amount of damage done to the natives' crops by elephants and other game. It is enough to mention here that the natives are not allowed to kill large animals, and they usually only hunt pig and small buck with their pariahlike dogs, and run the animals down by speed of foot and terminate the business with their soft iron spears or knobkerries.

As it was late when I left the village I did not intend to go far, but this was not necessary, for after leaving the maize fields and getting into the bush for less than a mile I saw some large animals about 300 yards off, and knew at the first glance that they were elands. I may mention that seeing game is more a matter of habit and knowing what game looks like than exceptional power of eyesight. A white man can become just as quick as a native in this respect after plentiful experience; and having shot a great deal of game, and seen much more, I find I usually see it now before the natives who accompany me. Spooring 
game is a more difficult matter, but the European can learn to do this also if he only makes a proper study of the subject.

On seeing the elands I told the natives to lie down, and I proceeded to stalk them, and after some difficulty I got to within I 50 yards, which is near enough to make good shooting at animals of their size.

The game was. suspicious, so seeing a good bull that presented a fair shot, I aimed at his shoulder and pressed the trigger. He immediately gave a shiver and raised his forelegs from the ground, as elands often do when hit well forward, and dashed off with most of the herd, but another bull was a bit slow in moving, and I immediately fired at him also. The herd consisted of over thirty animals, and the wounded beasts. were soon lost to sight, so I took the spoor and soon found blood, and after tracking for a short time I found the animal lying dead. This was the second bull fired at, and as I could not find any more blood on the tracks, and it was rapidly getting dark, I covered up the dead eland and went back to the village, deciding to return the next morning to look for the first animal I had hit. After a wash and a good dinner, succeeded by several pipes, I went to bed and was up at cock crow next morning. As I can never eat much early in the morning, two cups of tea and some toast was all I waited to dispose of, and then I started for the dead game, accompanied by over fifty natives. We soon reached the eland and found it had not been interfered with by carnivorous animals during the night, although I noticed fresh hyena spoor in the sand near it. I always hang my pocket handkerchief over game, and this usually serves to keep off lions, leopards, or hyenas.

While I was measuring the horns of the eland and taking a snapshot with my Kodak, a man who had wandered about 200 yards off called out that he had found the other eland lying dead, and so it proved, and on following his tracks backwards I found he had only run about roo yards from where he was hit and then fallen dead. He did not go off 
with the herd, but took a line of his own, which was the reason we had failed to notice his spoor in the grey light of the previous evening. This was satisfactory, as I knew that I had not lost a wounded beast, although if he had gone off I would have spent the whole of the day in trying to find him. The worst feature about shooting is wounding and losing a fine animal, as its sufferings must be great. The other herd animals shun it, because, I think, the smell of fresh blood is disliked by them; so it has to lead a solitary existence until it dies from its wound, or death in some other shape or form puts a termination to its sufferings. This eland had been hit through the large arteries leading into the heart, and this is quite as good a shot as the heart one. In some ways it is better, for if the bullet strikes a little back the lungs will probably be punctured. Game shot in the heart, or in the big arteries above that organ, usually give a shiver and draw themselves together, and dash off at a quick pace and fall dead within a short distance.

If struck in the lungs they may go farther and leave a more plentiful blood spoor, and this blood will be lightcoloured and frothy. A shot in the kidneys usually kills. game pretty quickly, as such a wound has a sickening effect and it causes severe internal hæmorrhage. Shots in the brain, centre of neck, and in the spine usually drop game where they stand, and, of course, animals often drop with shots in other parts; but they will probable get up again and run off. If an animal is found lying stretched out on its side it is usually done for, and on the point of death; but if sitting up, it will likely have the strength to get on its legs and bolt. Sometimes a wound seems to paralyse a beast's nervous system, and it is then able to stand several subsequent wounds in deadly parts of its body without showing much distress for some time. It is wonderful how tenacious of life wild animals are, and the small duiker, considering its diminutive size, is an example of this. It is difficult to say what is the toughest species, but the kob family is probably the most tenacious of life; 
and waterbuck and puku are two of the toughest I have met with, although if properly hit with the first bullet they are as easily killed as anything else.

Although lions are said to be pretty tough if not hit well forward, a deep wound will probably cause their death; for being carnivorous feeders their wounds are more liable to suppurate and cause inflammation in a very short space of time.

Elephants and rhinos are easy to kill, and so are buffaloes if well hit; although an old buffalo bull can carry off a lot of lead if he is not struck well forward.

Mr. F. C. Selous has mentioned that he has found lions easy to kill, and most people who have shot elephants have found it very easy to kill them with small or medium bore rifles. Of course it is imperative to get close if one is to expect to place the bullet well, and certainly the most important shot with all game is the first one. People who fire long range shots at dangerous game, and then have to follow up the animals, really take much more risk in doing so than they would do in approaching close for the first shot, when they could make tolerably certain of placing their bullet in a vital spot. Also it must be remembered that a small bullet in the right place is always better than a large one in the wrong place.

After seeing the natives started on cutting up the elands. one of which I had given complete to Memeza to divide with his brother and one or two other headmen of adjoining villages, I started off to try to find some more game, and soon reached a dambo, where, however, nothing was visible. I walked along the edge of the timber, and every now and then I turned round and looked back, when suddenly I saw a bull sable leave the bush on the opposite side and begin to cross the dambo towards my side. It was a good 600 yards off when I first caught sight of it, so I turned back and ran inside the thick bush, for I wanted to get a shot at it before it reached thick cover. When I thought I was about 200 yards from the place I made for the open again, and saw the sable walking slowly towards the bush. I sat down 
and fired at it with the 200 yards leaf up as it was walking, and I missed. The sable stopped, so I quickly pumped another cartridge into the magazine of my $7^{\circ} 9 \mathrm{~mm}$. Mauser rifle and fired again, this time with better results, as I heard the bullet make the welcome "phut." The sable started forward and was soon into the bush, so I followed, and suddenly saw him standing looking back. I fired quickly, he dropped, and I thought I had broken his backbone. On approaching close he suddenly jumped up and ran off at a great pace, and I missed him. I felt disgusted at my bad shooting, but I determined that I would follow him all day if necessary. From the glances I had had of his long curved horns I knew he had a good head, so I was soon on his tracks, which were easy to follow as long as he was running, for a sable cuts deep into the soil, and his hoofs spread much when he is moving quickly. At last he began to walk slowly, but he got into country where the ground was covered with a thick carpet of dry fallen leaves, perhaps the most difficult type of country to spoor in that it is possible to find. Then we lost the spoor completely, and I thought I was to lose the sable, but I spread out the men and told them to look for the tracks, and to keep their eyes open for the game. I was walking in the centre of the line when I caught sight of the sable standing nearly 200 yards away. There was no time to sit down and take a steady shot, so I fired standing, and very quickly, and I was delighted to see him drop, and on going up to him I found that the last bullet had entered close to the point of his shoulder and got him in the heart-a particularly good shot, but at the same time a very lucky one, for I could not depend on shooting so straight every time.

The horns were a fine pair, measuring close on $42 \mathrm{in}$. on the curve, and they eventually dried to $4 \mathrm{I} \frac{1}{2} \mathrm{in}$., as all horns do after being kept for a time. Ivory also dries up, and a 5 olb. tusk may sometimes go down to $46 \mathrm{lb}$. or so if kept in a hot, dry climate. Horn and ivory substance is full of moisture, and as this evaporates there is a slight decrease in weight and measurements. 
As we had not brought out any water with us we were all rather thirsty and tired, so after photographing the dead sable we started back for the village, which was only about four miles off.

How different are one's feelings when returning successful from what they are after a fatiguing day when some fine animal has been missed or, worse still, wounded and lost!

In the latter case every step is tiring, and one's own feelings are reflected on the men, who keep silent and glum. Sometimes when a large animal, such as an elephant, has been killed, the natives will sing and carry the tail, and wave it as they get near the village. Possibly another man has got a load of meat and the villagers will run out and beg a bit.

All natives are extremely fond of meat and the amount they are capable of eating at a sitting is prodigious, and I am sure some of them could dispose of ten pounds without feeling in any way uncomfortable. After a succession of great gorges natives will become dazed with too much flesh; in fact they get drunk with meat. Elephant meat they are very fond of, as they believe that eating it gives them strength.

The sable antelopes in the Eastern and Southern parts of Central Africa, such as in Nyasaland, for instance, seldon grow very long horns, and a head of $42 \mathrm{in}$. or $43 \mathrm{in}$. may be considered an exceptional one. I saw a head in Fort Jameson which measured 47in., and this trophy was picked up near the Mangazi valley.

On the plateau above Lake Tanganyika some sable with very large horns have been shot, but the best place for large sable trophies is North-Western Rhodesia, where heads of $45 \mathrm{in}$. are common, and where they have been shot up to 5 oin. and slightly over.

As I always give natives most of the meat of any game I shoot, only keeping part of it and the head and skin for myself, this large quantity of meat was soon finished, and I still wanted many bundles of grass for my huts, so on the 29th I went out again to try to fill the larder. 
I had walked some way before I saw any game, when suddenly I saw an eland feeding not far off. On getting near enough for the shot, I saw it was a cow with a particularly good head, so I fired at her neck and made a good shot, for she dropped in her tracks.

Then a bull appeared and ran off, but stood and looked back from a distance of slightly over 200 yards, and I also fired for his neck, but made a bad shot, for the bullet took him under the ear. He dropped dead, which was satisfactory; but I like to hit where I aim. The cow was still alive when I came back to examine her, so I ended her pain with a bullet behind the shoulder. She had horns measuring $3 \mathrm{I} \frac{1}{2}$ in. on the straight, but the right horn had an ugly inward twist which spoilt the symmetry of the trophy.

The question of giving pain to animals is the worst feature about game shooting, and yet after all it is necessary to get meat, and a well-placed bullet kills humanely.

Many people who have never experienced the fascinating and exhilarating sport of big-game hunting allege it is cruel; but I fancy that these people are not averse to eating a nice bit of roast beef or tender mutton, and if they do not kill the cattle and sheep themselves, others do it for them. The killing is usually the most distasteful part of the business to the hunter, and it is quite a mistake for people to say that sportsmen are devoid of kind or humane feelings, for every good sportsman likes to give a beast a chance for its life.

Our remote ancestors had to hunt to get meat to eat, and this spirit has been handed down to many of us, and it will be a long time before it disappears. Big game hunting is good training for young men, and a man learns a lot when busy at it, so it is to be hoped that the splendid game countries we possess in Africa, Asia, and Canada will be preserved for generations yet to come. A man who is expert at circumventing animals in their natural haunts will likely prove as efficient when the game is two instead of fourfooted; and there is no better training field for officers than the haunts of wild game. Game inhabits all types of country, 
from the mountainous ridges of the Himalayas to the long flat stretches of desert found in parts of Africa. In hilly country the game will be searched for with a glass and then stalked, and this is probably the highest form of big game shooting. In Central Africa, unless an animal is tracked up step by step, it will probably be shot by tramping about the bush, and compared to hill stalking or the steady spooring work necessary in tracking, this bush tramping is really poor sport, as the animal is seen all of a sudden, and the shot fired almost immediately, without any preliminary work except some rough walking.

Consequently, I put deer stalking in Scotland or any other country, and markhor and ibex shooting in the Himalayas, on a much higher plane than the generality of African shooting; although to be successful in the latter, one has to exercise much care to go quietly, as at certain times of the year the ground is covered with hard, brittle leaves, some of which go off like a pistol if they are trodden on.

Most people who shoot in Central Africa wear heavy boots, and. often riding breeches and gaiters, and it is impossible to "still hunt" in such a dress. The best footgear is either thick rubber-soled boots or shoes, or others with chrome soles; and the nether garments should be pants, known as "shorts," and I have found it best to shoot in bare legs. Sometimes it is pretty hard on the skin, although, with practice, the legs get hard, and one's eyes become used like a native's to choose an easy path. A European who has not been accustomed to walk about in rough country usually keeps his eyes in the air, but a good bushman's eyes are all over the place, for he will glance down and seek a path free from holes or obstructions, and the next second his eyes will be ranging the country ahead and to the sides in search of game.

If I had not accustomed myself, after ten years of rough bush walking, to keeping a good look out where I put my feet, I would probably have been bitten several times by poisonous snakes, such as puff-adders, or I would have 
broken my legs by putting them into old ant-bear holes, which are often quite hidden by thick grass growing round them.

This is a great country for honey, and the natives range the bush looking for it in holes in trees, and sometimes they put out bark tubes for the bees to hive in. They usually collect it in a dirty manner and bring it full of bark and grass chips, and also full of maggots, but it can be strained, and a piece of old mosquito netting is useful for this. As most of the game meat got here lacks much fat, except the eland's, which often has a lot, the system needs two. substances, and these are fat and sugar.

I am certain sugar is a great strengthener for those taking hard bodily exercise; in fact, one often gets a craving for sweet things; so nothing could be better or more wholesome than honey, which it is usually easy to procure during the dry season.

After a spell of looking after the work at my camp I sallied out again on June 2, and came on a herd of zebras, and shot three of them. I cannot say I like shooting these harmless, beautiful animals, and many is the herd I have passed by without harming them, although in some districts they prove a nuisance, as they make a great noise when running, especially on hard, stony ground, and they thus disturb more valuable game. Many is the elephant that has been lost owing to a rushing herd of zebras, for the noise they make frightens other game and makes them bolt too. Many of the natives refuse to eat zebra meat as they say it gives them a rash or itch, and the young children are said to suffer from this rash more than the adults; but perhaps this skin rash is caused more by overeating than by the kind of meat partaken of.

Again, different families of natives eschew the flesh of some species of game. Some will not eat bush-buck, others bush-pig, and so on. This is not a caste prejudice, but purely a personal one.

Mohammedans will not eat pig and sometimes refuse to touch the animal, and hippo is often barred. In Nyasaland 


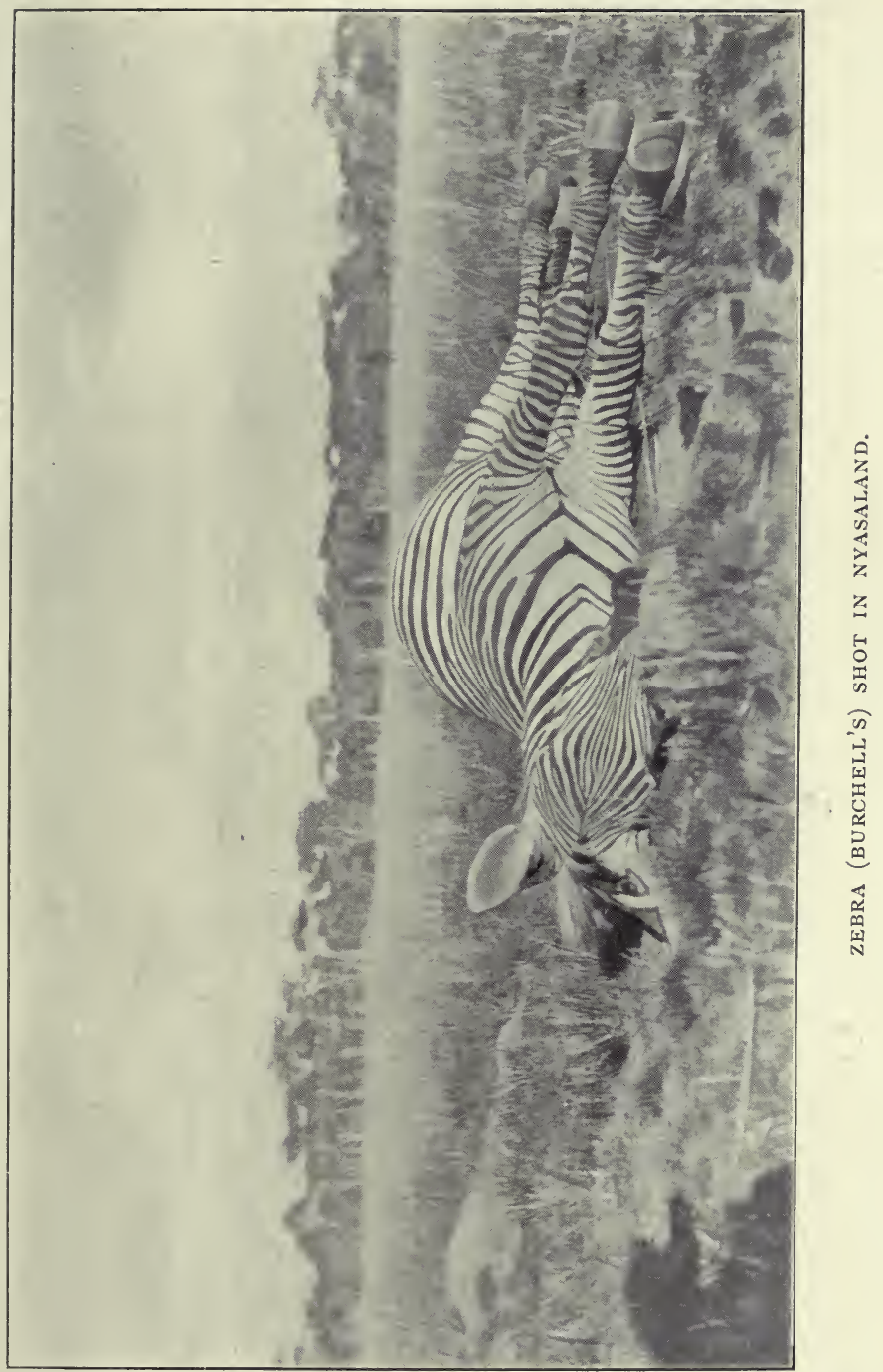



the Yao tribe-called Ajawa by the natives-are Mohammedans, and unless the throat of an animal is cut they will not eat the meat. The throat has to be cut when there is life in the animal; but the Yaos are not so particular in this respect as the Indian Mohammedans, for I have seen them cut the throats of dead animals, although they always pretend that they are not quite dead.

This throat cutting is often a nuisance to the sportsman who wants to keep the masks of game for setting up, and in such a case the African Mohammedan will usually be satisfied if he is allowed to stab the beast's throat near its junction with the chest. In India this rite is called "hallalkaro."

When a beast falls it is a mistake to allow the men to rush forward, as the animal may get up again, so I always restrain my men and approach first, and it is needless to remark that one should never approach an animal, especially a dangerous animal, with an empty rifle. Many fine trophies have been lost by omitting to follow this simple rule, and quite a number of elephants have got up and been lost by not making sure they were dead by putting in a final shot.

The best races of natives I have met for bush and spooring work are the Awemba, who live in northern parts of North-Eastern Rhodesia, but I have also seen excellent hunters and trackers belonging to such tribes as the Akunda, Awisa, Achewa, Angoni, Asenga, and Yaos. It usually depends on whether a native lives in a good game district, and whether he is fond of hunting. As to pluck, this is not singular to any particular race of savages, although the paramount races, such as the Awemba, Angoni, and Yaos, are more likely to act bravely in an emergency than members of slave tribes.

On June 7 I went out to try to find some elephants that had been coming to the fallen maize stalks near Kamwendo's village. I had Kamwendo with me and he is one of the best elephant trackers I have ever seen, and once he gets on the spoor of a good bull he is almost 
certain to take one up to him. He has been with me on several trips and most of the Europeans who have hunted elephants here have had him with them, and he must have seen over fifty big bulls shot, if not more. He is an Achewa headman, and his village is about eight miles south of Fort Manning. He is always ready to go out with sportsmen, so if anyone comes here who wants a shot at an elephant Kamwendo will take him to the best places and do the tracking work.

Besides being a good spoorer, he is an agreeable native to get on with as he is always civil, and he knows all the villages and elephants' haunts for many miles around, and he is very popular with the natives as he is fond of beer, and often goes off on visiting rounds to look for it. A native will often travel twenty or thirty miles to a village where there is beer, and I know several headmen who are constantly on the move to try to find it.

Kamwendo took me to his gardens and we found the spoor of a single bull elephant, but the tracks were two days old, so we went off to a drinking hole about six miles away and on getting there we found the night's tracks of three small elephants, two bulls and a cow, but Kamwendo agreed with me that they were not worth following, as the tusks would not be more than 2 olb. to $25 \mathrm{lb}$. each.

It does not follow that the best tuskers have the largest feet, but there is a limit, and any elephant with tracks less than 5oin. in circumference is not likely to be a very large one. An average measurement for a big bull's front feet will be about 54in. in circumference, and some of the largest will measure $56 \mathrm{in}$. or $58 \mathrm{in}$. As we were looking round, I spotted a herd of hartebeests feeding near the top of the dambo, and as my men asked me to shoot one I went off to stalk them. I may say here that there is only one variety of hartebeest in Central Africa, Lichtenstein's, and in referring to hartebeests this is the variety that is meant.

With some trouble I got to within I 50 yards, as I think the game had seen us at the water hole and were slightly 
suspicious. I fired at one which dropped in its tracks and then fired at another which also fell to the shot, but it jumped up at once and ran off. The first one very soon expired, so I started off to try to find the other. I put it up once, and, judging by the way it ran, it did not seem to be badly damaged. As we were all thirsty and rather tired, we returned to the water hole, where I made some tea in a small kettle I had brought out, and demolished some bread, a tin of sardines, and three hard-boiled eggs. Then, after a smoke, I left some of the men to cut up the dead hartebeest, and went off with Kamwendo and another man to try to find the wounded animal. Once again, about 4 p.m., we disturbed it, and as it was going strong, and the sun was sinking, we had to leave it and get back. I had spent a good six hours on its tracks, so had done my best to find it, for I loathe wounding and losing a beast. It was past sundown when I got home, and by this time the nightjars were hovering round in the open spaces after moths, and the frogs in the Bua were croaking hard. Darkness soon comes on there, and, if there is not a good moon, it is uncomfortable being benighted in rough bush country; and many is the fall and hard bump I have received when stumbling back to camp in the dark. Bare legs are certainly best for daytime when one can see where he is going, but at night a pair of putties or light gaiters would be a comfort and save some painful stabs and scratches.

There is a vile vegetable growth in this country which is called chitaisi, and its pod is covered with numberless fine hairs, which cause a most painful itching and rash. On a wintry day, and when these pods are ripe and ready to fall, the minute hairs get blown all over the place, and if they get into clothes or blankets they prove a great nuisance. When following elephants into thick cover the hairs will drop on one's arms and neck, and I can assure the reader that they are just like hundreds of sharp needles, with some irritating acid put on them, being pressed into one's flesh. The itch ceases in a few hours and leaves a rash like nettle stings, but it does no further damage; although if a 
man's blood was in bad order, and he scratched the skin off to get relief, it might end in an attack of blood poisoning.

There is another variety of this buffalo bean-Angoni name, kasi-which the natives eat by breaking the pods and cooking the beans, from which they remove the hard skins after boiling well. The Achewa race call the bean chitaidza. One of the worst districts here for the buffalo bean is Mlanje, where the vegetation is rank and tropical.

Scrubb's ammonia eases the itching, but then a sportsman cannot carry a bottle of it with him when tramping in the bush, so he will need to put up with it, and he is sure to meet it sooner or later if he shoots here when the grass is long.

There is another plant which flowers annually which is very irritating and makes one cough hard as the dust gets down one's throat, but this bush is only present in some districts.

Of course there are plenty of thorns and stinging plants, which, not being a botanist, I cannot give the scientific names of; but after a few years, insects that sting and plants that irritate are not much noticed, as the skin gets hardened and inured to them. The newcomer always suffers more than the old hand, as his skin is soft and his blood rich, a fact that insects seem to find out soon.

June I 3 saw me on the tramp again, and on this day I went through some lovely undulating country, just like a wild, untended park at home, although, of course, the vegetation was very different. I saw several oribis and let them go, for it is a mistake firing at such small fry, as the shots put other game on the qui vive.

I have often thought a "Maxim Silencer" fitted to the rifle would be handy, and yet it does not seem quite sport to use such a contrivance, as the game has quite a heavy enough handicap against it already, with rifles of great velocity and killing power.

While going along we suddenly disturbed a kudu bull in some thick bush, and as kudu bulls do not usually give one 


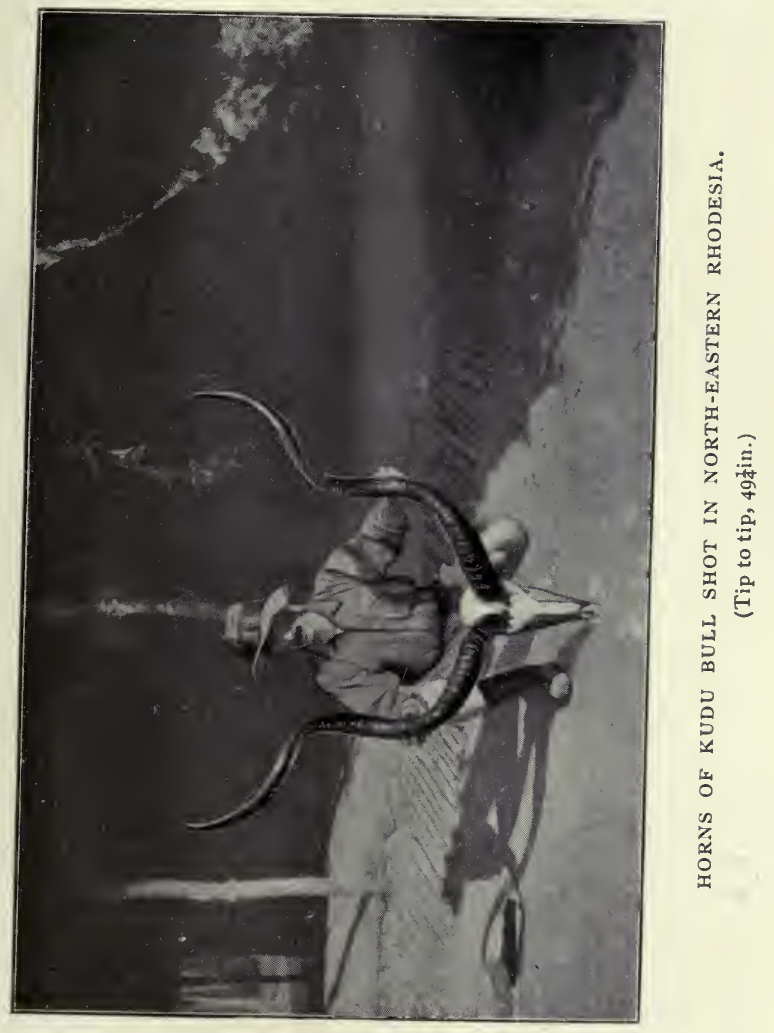



much time for contemplation, I fired at him quickly and saw a sapling between us shake and then drop over. $\mathrm{He}$ started forward and then turned and ran, but stopped after going about fifty yards and looked back, when I got him in the lungs, and he fell and died in less than a minute.

His head was not a very good one, but it is very difficult seeing the horns of an antelope which is startled, as he holds his head high with the horns laid over his back. The first bullet, which had cut the sapling, had splintered and left several scores along his back, one of which had cut the skin for a length of a foot.

Once when marching to Tete I shot a very fine bull kudu with 57 in. horns, and in this case, also, the bullet penetrated a small sapling and then hit the kudu in the lungs, making a hole as large as'a i 2 -bore spherical bullet. This kudu fell in his tracks and died almost immediately.

The best kudu head I have seen in Central Africa was one belonging to a kudu shot by Captain C. H. Stigand, near the Shire River, in Nyasaland, and as far as I can remember its horns measured as follows :

$\begin{array}{lllllll}\text { Curve } \ldots & \ldots & \ldots & \ldots & \ldots & \ldots & 63^{\frac{5}{8}} \text { in. } \\ \text { Straight } & \ldots & \ldots & \ldots & \ldots & \ldots & 45, " \\ \text { Tip to tip } & \ldots & \ldots & \ldots & \ldots & \ldots & 45^{\frac{1}{4}}, "\end{array}$

I have never had the good fortune to shoot such a fine kudu as this, although I shot two kudus in North-Eastern Rhodesia, on October 10, I908, one of which exceeded Captain Stigand's head in two of its measurements.

The dimensions were as under:

$\begin{array}{lcccccc}\text { Curve } \ldots & \ldots & \ldots & \ldots & \ldots & \ldots & 54^{\frac{1}{2}} \text { in. } \\ \text { Straight } & \ldots & \ldots & \ldots & \ldots & \ldots & 46^{\frac{1}{2}}, " \\ \text { Tip to tip } & \ldots & \ldots & \ldots & \ldots & \ldots & 49^{\frac{1}{4}}, \\ \text { Circumference } & \ldots & \ldots & \ldots & \ldots & \text { 10 } \frac{3}{4},,\end{array}$

This head was an abnormal one, as it will be seen that there is only a difference of $8 \mathrm{in}$. between the curve and straight measurements, whereas the usual difference is quite a foot. 
The other kudu I shot at the same time as the above head had also a fair pair of horns, as they measured :

$\begin{array}{lcccccc}\text { Curve } \ldots & \ldots & \ldots & \ldots & \ldots & \ldots & 53^{\frac{1}{4}} \text { in. } \\ \text { Straight } & \ldots & \ldots & \ldots & \ldots & \ldots & 41^{\frac{1}{2}}, \\ \text { Tip to tip } & \ldots & \ldots & \ldots & \ldots & \ldots & 32 \frac{1}{8}, " \\ \text { Circumference } & \ldots & \ldots & \ldots & \ldots & 1 I^{\frac{1}{4}}, "\end{array}$

These measurements show a more normal head in every way, and the circumference measurement also shows that the animal was older than the one bearing the abnormally wide horns.

A kudu head is certainly one of the finest trophies a sportsman can hope to get in Africa, and these animals being very wary, as a rule, and not so often shot as many of the antelopes inhabiting more open country, they are still numerous in parts of Nyasaland, Portuguese territory, and North-Eastern Rhodesia, and will likely remain so for many years to come.

I think, as do the majority of men who have shot in Africa, that the kudu is quite the finest antelope there, although a few hunters might give first place to the sable antelope or the gemsbuck. A kudu's horns look well on a wall, and so do a gemsbuck's, but a sable head, owing to the great backward curve, does not show up as well as the other two heads mentioned. Owing to their wary and retiring habits, kudu are more difficult to find and bring to bag than most antelopes, but this only enhances the value of the trophy to the lucky sportsman who manages to bag a good head.

I have heard men say that kudu are scarce in Central Africa, but they are really one of the most numerous species, and there are plenty of them, only they inhabit rough, broken country where the walking is often hard, at least to people who like to find their sport easy. 


\section{CHAPTER III.}

\section{Further Shooting Experiences in Central ANGONILAND.}

Two bull elands shot-One a very large one-Measurements givenWeight of a large eland-Rich fat obtained from elands-Change to my new camp-List of huts made and cost-An insolent native-False evidence-The best way to treat an insolent native-Oribi and reedbuck shot - Hartebeests companionable animals - Roan antelope wounded and found later-Two roan antelopes killed-Collecting blood smears of game-A fine roan lost in North-Eastern RhodesiaGood trophies shot by chance-A splendid pair of elephant tusks obtained by Mr. Melland in North-Eastern Rhodesia-A friend shoots two lions on his first trip-Loneliness of life in the wilds-A fine lion missed-A tropical storm-Game in heavy rain-A fine impala lost-Articles quoted from the Field: "Long Shots at Big Game," "Photographing Big Game," "Measurements of African Crocodiles."

I WAS on the trail again on the $5^{\text {th }}$, as the elands had been coming every night to the gardens to eat the fallen and dried maize stalks, and it did not take me long to get on the spoor of a large herd, which, judging from the large footprints of some of them, contained some big bulls. On fairly soft ground elands are very easy beasts to spoor, as, being very heavy, they leave deep footprints.

We had gone perhaps four or five miles when I caught sight of the herd, just as Kadango, the best man I had with me, saw them. As the game had not seen us, I told the men to lie down and keep low ; for they often put their heads up-to watch proceedings, and this has sometimes scared the game and frightened them away as I was 
crawling up close. By the time I had got to within I 50 yards the elands were beginning to think all was not right, for some of them faced in my direction with their horns laid back. I fancy they heard an occasional leaf crack, as all the vegetation was very dry and brittle. Suddenly they ran, and I saw a very large blue bull trotting clear of the others and fired twice at him, hearing both bullets tell. Then I lost sight of him for a time, but, seeing another bull with the herd which had a fine pair of horns, I waited for them to slow down, which they soon did.

I fired at him, and he went off looking very groggy. I ran after him, telling Kadango to go after the big bull and keep it in sight if possible. I soon got closer to my animal, which had stopped after running about 300 yards and looked back, and I fired a steady shot at its shoulder at a range of seventy yards or so. It did not move, but I saw it shiver slightly, so I immediately fired again for the same place, and it fell on its side, and was soon dead. On going up to it I found that it had three bullets all within 6in. of each other, just about right for the heart, except that the first one was about 4 in. too far back. As I was looking at this fine animal, I heard Kadango calling me, so I went towards the sound and soon saw him running. He said the big eland was lying down, but was still alive, so I went back and soon saw it sitting with its forelegs under it; but one hind leg stretched out in an unnatural position, and I knew this limb was broken. It had probably been splintered by my first shot and then broken under the great weight of the animal. I soon put the poor beast out of its misery, and then sat down to rest and have a smoke.

This was by far the heaviest eland I had ever shot, or seen, but I foolishly allowed him to lie as he was, and so I could not get an exact measurement of his height, as the muscles and sinews had stiffened up by the time the men had returned with the villagers I had sent them back for. 



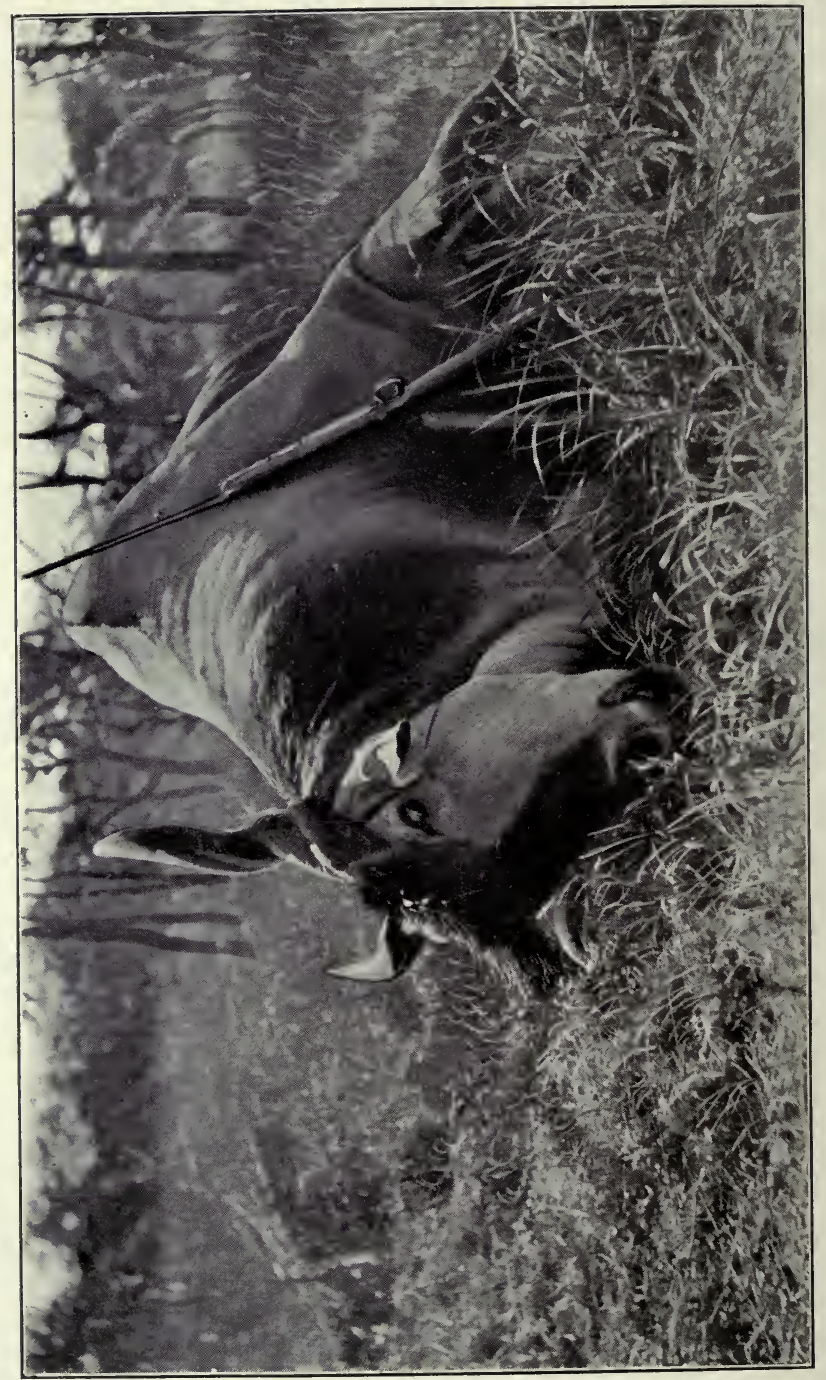

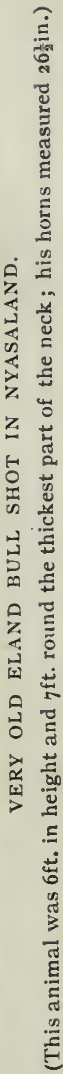


Here are the measurements, which were most carefully taken with a steel tape :

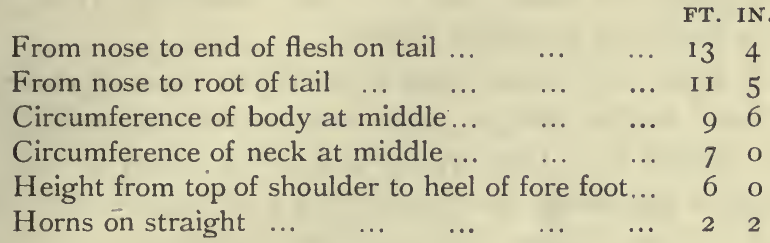

About two years ago I shot another large bull eland, which gave a height of $6 \mathrm{ft}$. $\mathrm{o} \frac{1}{2}$ in. at the shoulder, and he measured $8 \mathrm{ft}$. $8 \mathrm{in}$. round the middle of the body and $5 \mathrm{ft}$. gin. round the centre of his neck, and his.horns were $29 \frac{1}{2}$ in. on the straight.

He was certainly a younger bull than the very large one I have given detailed measurements of, but, like all fullgrown beasts, he had the thick tuft of matted hair on the frontlet of his skull.

Whether the measurement of a dead animal's height is a true index as to the height he stands when alive I cannot say, although I do not suppose the difference can be possibly more than one or two inches.

The eland which I hit with three bullets grouped close together was also a fine beast, full-grown, but not aged, and his height was an inch less than the old bull's, but his

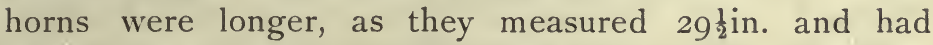
amber-coloured tips. Elands that are very old sometimes wear their horns down to less than $2 \mathrm{ft}$. in length, as they are constantly rubbing them on trees, and they are also often splintered and broken as well.

Elands are such grand, inoffensive animals that one regrets killing them, and yet they give good sport in tracking, and the meat and fat they yield is often needed by the hunter. I got over $15 \mathrm{lb}$. of fine, rich fat from the old bull, and this has to be boiled down in pots and the refuse skimmed off. The fat should first be chopped up into small pieces and boiled for several hours, and it should not be washed in water, as this tends to make it go bad. 
Moreover, it should not be stored in tins, and the best receptacles are large native earthenware pots. Pieces of strong paper or cloth can be tied round the rims of the pots to keep the contents clean.

This large bull eland took twenty-five men all their time to remove to the village, some four miles off, and none of them carried less than $7 \mathrm{olb}$., and in the case of two men carrying a leg slung on a pole they had considerably more, so this bull must have weighed between r $800 \mathrm{lb}$. and $200 \mathrm{olb}$. as he stood, for in such a large beast there is a great loss of weight in blood and the contents of the paunch when cutting up. A large bull's skin is very heavy, and it took two strong men to carry this one slung on a pole with the fat, heart, kidneys, and liver enclosed. The skin of the neck is almost as thick as the hide on a hippo's back, which is slightly over $\mathrm{I} \frac{1}{2}$ in.

Bull elands are much taller and heavier than the cows, and the three animals where the male exceeds the female to the most noticeable extent are the elephant, eland, and kudu. The sexes in other game do not appear to vary so much; at least, this is my opinion, which is founded on considerable experience of African game.

The tracks of male elephants and elands are also much longer and broader than those of the cows, but in kudu there is not a great difference, although the bull is slightly larger.

On the 28th I was out again, and saw two warthogs, both of which I hit hard. One ran about I 20 yards and fell dead, but the other I could not find, although I spent several hours tracking it. Next day I sent a native headman, named Shauri, with some other men and a lot of dogs, to try to find it, but they returned unsuccessful, so I can only suppose that it was slightly hit, as the $7.9 \mathrm{~mm}$. RigbyMauser rifle I generally use makes a very severe wound in all game if the bullet strikes full in the body.

In a further chapter I intend to write a few pages on my experiences with high velocity rifles, as I think it a very interesting subject to all big-game men. 



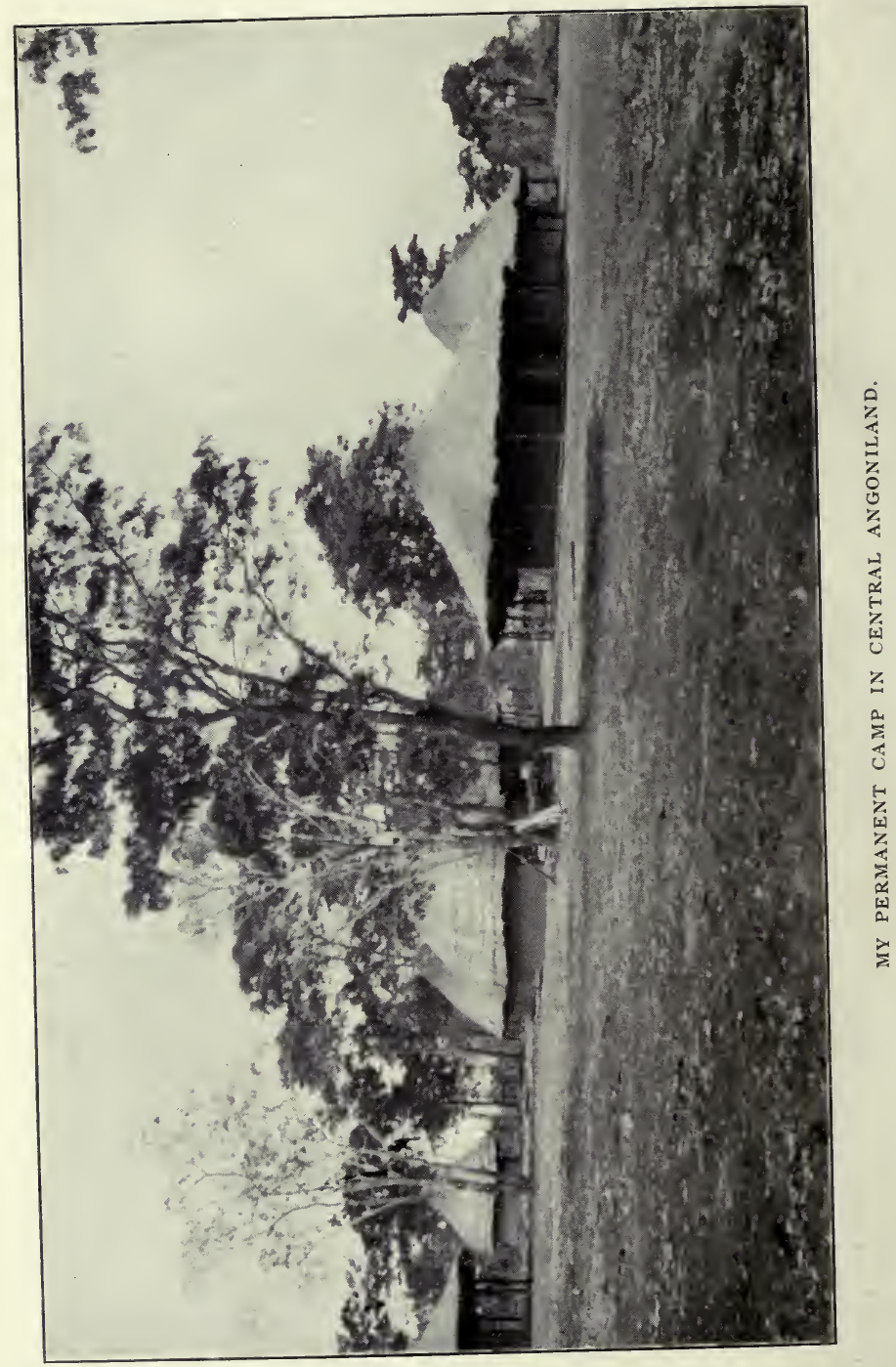


On the 2gth I transported all my goods from the village to my new camp, as the huts were fairly dry, although they were rather damp and chilly during cold nights. However, large $\log$ fires soon dried them, and I was much more comfortable here away from the rats, pigs, and dogs which haunted the village.

The air smelt sweeter, too, for a native village is a dirty odoriferous place, not to mention the filth and dust that is always blowing about.

My camp had taken about a month to build, and the labour necessary cost me $£ 7$ Ios., and for this moderate amount I had the following huts:

I.-One large round hut $45 \mathrm{ft}$. across the verandahs.

2.-One smaller hut (joined to the former by a passage).

3.-One guests' hut.

4.-Three boys' huts.

5.-One kitchen.

6.-One store.

7.- Two labourers' huts.

8.-One goat and sheep hut (oblong and divided in the centre).

9.-One fowl and pigeon cote.

I0.-One large shed for storing horns and skins.

This certainly seems a lot of work, but the smaller huts did not have much time or trouble spent on them, except that I saw that they were strongly made and well thatched, and I mudded them all, and put a coat of grey mud on them so that they would all be the same colour.

When I came from Blantyre I brought a Yao man with me who had come to ask for work. He was a huge fellow, quite $6 \mathrm{ft}$. in height and strong in proportion, and he was a "gay Lothario" with the women and particularly fond of native beer.

This he used to buy with money and barter for meat, but one day when I was out shooting he left his work and, in sight of other men working for me, paid several visits to a stand where I had stored a lot of half-cooked meat. 
Then he left his work and went off to barter the meat for beer, and he thus got very tipsy. Ubibu, the name he went by, was when sober a kind of mountebank, as he used to make a fool of himself and try to make the natives laugh.

On getting back to the village from the bush where I had been shooting, the natives told me that Ubibu had stolen the meat, so I sent to the place where he ought to have been working to call him, but he was absent.

At last he was found, and came swaggering up in a very cheeky manner and asked what I wanted with him.

I then asked him why he had left his work and why he had had the impertinence to steal my meat, when he usually got a very plentiful share, as he was strong and accustomed to carry heavy loads.

He was very insolent, so I lost my temper, very naturally, and told some men to get hold of him, for he had moved off, shouting as he went. The men came back with him; at least, he was walking in the centre singing and shouting.

Now, I did not wish to take the law into my own hands, but I knew from past experience that if he was allowed to go without being hurt l would lose respect and control; so I told the men to lay him down and instructed my head capitao, Nterimanja, to give him eight strokes with the thin end of a knobkerry.

Nterimanja, having served as an askari (soldier), was a pretty lusty fellow, and he knew his duty, so he laid on pretty hard, but Ubibu got up smiling, and went off cursing Nterimanja, who was a Yao like himself, and saying he would bewitch him. As Ubibu had been paid for his previous month's work the day before, there was nothing due to him, so I told him he was dismissed.

At that time there were several natives returning from the South African mines with a good deal of money and a box of clothes, and Ubibu met one of these fellows in an adjoining village, and this man-after several days had elapsed-persuaded him to go to the Boma (Government office) and report me. 
This would have been all right if Ubibu had seen fit to tell the truth, but he lied horribly and informed the Assistant Resident that I had given him forty strokes with the chikoti (hide whip, called sjambok in South Africa). Now, I did not even possess a chikoti at that time, but the Assistant Resident did not know this, and he believed Ubibu's story, although he was a clever official and a very sensible man.

I wonder why he did not examine the man's body, for a native who got even twenty strokes would likely be unable to walk well for some time. Thinking the case was too serious for him to adjudicate on, he gave Ubibu two shillings and a letter, and sent him to Lilongwe, the head station of Central Angoniland, and some seventy miles off. The Resident (or Magistrate) passed Ubibu on the road without getting the letter, but I had gone to Fort Manning, where I had seen both the Resident and Assistant Resident, and told them the true facts of the matter, so, on the Resident getting back to Lilongwe, he sent back Ubibu to Fort Manning. On the day the case was heard I gave the knobkerry to the owner to carry off to the Boma, as he was a witness. All my witnesses admitted that Ubibu had been beaten with the knobstick, and when this was produced it was found to be badly splintered. This, it was easy to notice, had been done on a rock, as the marks showed; but it also shows how natives will often not only lie, but will combine to blacken a case. The court capitao and interpreter belonged to the same tribe as Ubibu, and I heard afterwards that when I was sitting with the Assistant Resident in his house, before we went up to his office, the interpreter, at the instigation of Ubibu, hammered the knobkerry on a rock they were sitting on. As I had taken the law into my own hands, very foolishly, but I think very naturally, I had the pleasure of paying Ubibu three shillings in cash and refunding the two shillings given him by the Assistant Resident to pay for his food on the road to Lilongwe.

On July 2 I shot an oribi and also a reedbuck ram that was running with four does. Reedbuck and oribi are 
usually seen in couples, although one sometimes sees from three to five of each species together. The medium and smaller sized antelopes do not seem to care to intermingle with other species as do sable, hartebeest, gnu, and zebras.

Perhaps the most companionable antelope is the hartebeest, and solitary bull gnus are also fond of seeking the company of a herd of hartebeests, as I have noticed on several occasions.

On the 9 th I wounded a bull roan, and although I tried my best to find it I was unsuccessful, as I lost the spoor on some hard ground, for the animal began to walk slowly and leave very shallow impressions behind.

Being unwell on the following day, I sent out a man named Zovi with some other men to look for the roan, as he had been with me when I hit it and knew where to go. They found it and finished it with a few spear thrusts, so I only kept the hind legs, skin, and head, and gave the natives the rest of the meat.

At this time I was collecting blood smears of game for the Sleeping Sickness Commission, which had a big camp at Kasu Hill, away to the south; and for this purpose I had got permission to shoot game above the number allowed on my licence. However, I did not need to shoot much extra game, and I only did so when I got into other parts of the country where there was a better chance of finding parasites in the blood of the game. As there were few tsetse flies in this locality, it was most improbable that any parasites of sleeping sickness would be found in the blood of game here; and so it proved, for all the slides I sent to Sir David Bruce were found to be free of trypanosomes.

In taking blood smears it is usual to take two from each animal. One is called a thin smear and the other a thick smear. To take the former a drop of blood about the size of a S.S.G. shot is dropped on one end of the slide, and with the smooth edge of another slide this is flattened and spread on the glass. A larger drop of blood is used for the thick smear, and it is allowed to partially dry before rubbing, so that it will be thicker in form. 


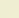

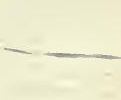




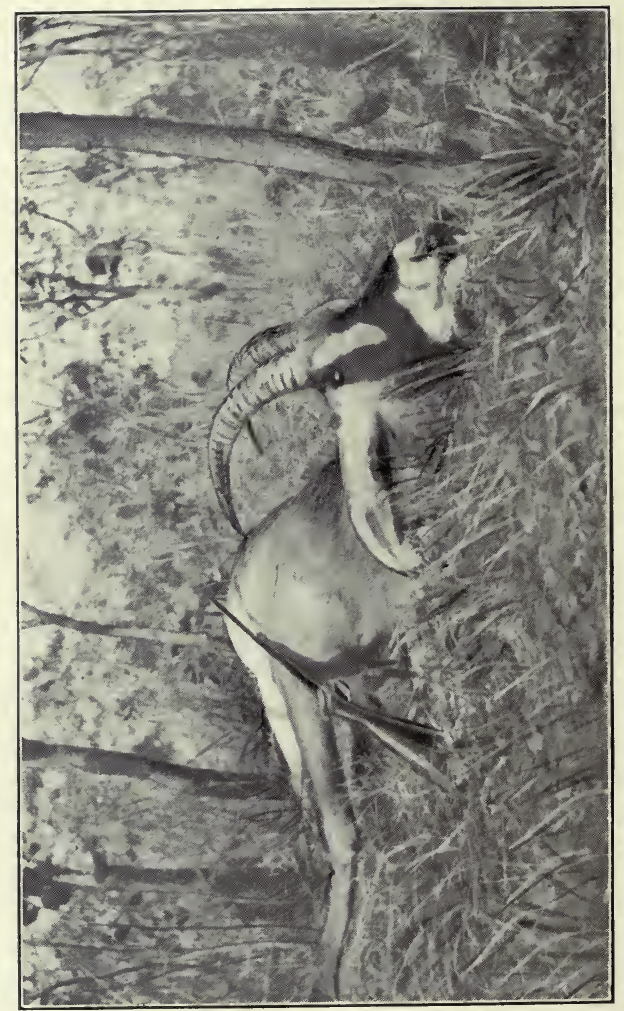

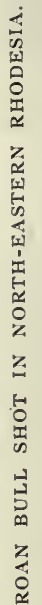


As there were more roan antelopes about and I wanted their blood for smears, I went out on the IIth, and when tramping along with Zovi I saw a herd of the wanted animals, so I shot two, a bull and a cow. The bull had a pretty, though not long, pair of horns, as they only measured 26in. on the curve.

The best roan head I ever saw is, unhappily, not in my collection, as he went off, taking with him a really fine pair of horns. It was on a wet day, as I was tramping from the Luangwa River to Fort Jameson, in North-Eastern Rhodesia, and I was within eight miles of Sasare Mine at the time. As I led the party, with a man behind carrying my rifle in its cover to protect it from the wet, I suddenly saw the roan standing in a small dambo within seventy yards of the road. He saw us at the same moment, but did not run at once. I sprang for the rifle and dragged it from its cover and pumped a cartridge into the barrel from the magazine. Just at this moment the roan turned and went off very fast, and I am sorry to say that I missed him clean.

If I had not been very tired at the time, for I had come a long way that day, I would have followed him up and tried my best to kill him, as I saw that he had a lovely head. I had just got this rifle out from home, and did not know its shooting well, or I might have made a slightly better shot. It is often the way that the best heads are presented to one like this, and all the best trophies I have heard of as being shot in Central Africa have been due to lucky chances, and not to persistent efforts in tracking up, or looking for, an exceptional animal.

Captain Stigand's kudu was come on by chance, and the best buffalo head procured in North-Eastern Rhodesia was shot by a Mr. Grimes-the poor fellow soon after contracted sleeping sickness, of which he died-who was told by the natives that a big buffalo had been coming to their gardens, near where his camp was pitched. He went out and killed it with a 405 Winchester nitro rifle, and its horns measured over $48 \mathrm{in}$. outside measurement, and, moreover, they were beautifully shaped and more closely resembled 
the heads shot in Uganda than the usual type of this country, which are seldom wide.

Again, Mr. Melland, of the Northern Rhodesian Administration, shot a grand bull elephant with a single 400 bullet before he noticed the size of the ivory. It ran off hard hit and was found later, and its tusks weighed close on I $20 \mathrm{lb}$., but they dried to about i r $6 \mathrm{lb}$.

Many men who have never killed an animal of a certain species sometimes have the luck to get a very fine trophy at the first go off, and not long ago a friend of mine (Mr. W. P. Ronaldson) went to the Chiromo Marsh to shoot, and on his first day bagged two large lions. Now, I have been there several times, and I have heard lions roaring and grunting at night, but I have not had the luck to meet any in that locality, although it is a famed haunt of these large felines. I could give many other instances of men getting fine trophies or shooting some rare species (such as the inyala) purely by chance. I would give something to shoot an inyala, but as yet I have not seen one alive, and yet several men, some of whom have had slight experience, have been fortunate enough to shoot one in Nyasaland.

So it is in many circumstances of life, for those who want a thing do not get it, and those who care not are more fortunate.

At a certain moment one man may be soaked with rain, and at the same moment another man somewhere else on the face of the globe may be dying of thirst. It is a world of contrasts, but to meet them one has usually to go to the wild, unfenced wilderness. Those whose untamed spirits urge them to travel such country usually see the best and the worst, for their lives are spent amongst vivid contrasts. This spirit-the Germans aptly call it "wanderlust," I think-divells in the hearts of many at home who must long, at times, to get to the vast spaces of the earth. Those are the lucky ones who can go and return as they wish. Sometimes it is possible to get too much of the wilds, for comforts are rare and discomforts common. I think, 
judging from my own experience of tropical Africa, that one longs for the cold, exhilarating air of home more than for good food; although this, too, is often desired when one is low with fever and satiated with unpalatable stuff.

The intense loneliness and monotony of a solitary life, away from others of their own kind, have a bad effect on the minds of many men, as they get morbid and inclined to suffer from melancholia, when they often act foolishly.

About the year r905 I spent twelve months at a place called Mzazas, on the Luangwa River, and during that time only four men visited me, and once I went away to see a man I knew some sixty miles off. As Mzazas was not a health resort and I underwent an attack of blackwater fever there, I was naturally pretty bad at times; but I cannot say I regret the loneliness, as I was out in the bush every day looking for game and making a collection of drawings of game spoor.

Sometimes, when a man is beginning his shooting experiences, over-keenness may lose him an animal he is very anxious to bag. Besides the large-horned roan antelope I have mentioned, I can remember several other trophies that I should have bagged if I had shot more steadily. Once when on a shooting trip, in December, I903, to the country bordering Lake Chiuta, with Captain Mostyn, of the King's African Rifles, I lost a lion in the following way. Every day my friend and I used to go off in a different direction and meet in the afternoon or evening when we returned to camp. One day I had got on the fresh spoor of a herd of buffalo, which took me across the mud and swamp of the lake, and I had followed them many miles when my men and I noticed the tracks of some Portuguese native hunters, who had cut the spoor of the buffaloes just ahead of us. We then stopped and began to return to the tents, and we had just reached the swamp when we disturbed a fine, light-maned lion which was lying in a low hollow, with some tall grass in its centre. I had 
handed over my rifle to my gun-bearer a few minutes before and was walking a short distance in front, and, instead of passing through the tall grass in the hollow, I passed to one side. The men following went right through it, and I suddenly heard a series of hoarse grunts, so, naturally, stopped and turned round to look. The lion must have seen or heard me pass, but he was so excited with the shouts of the men that he forgot my existence and ran towards me, looking back at the natives. I gave a shout, and the lion then noticed me and stopped and crouched, putting his head on his paws. I regretted not having my rifle in my hand, for he was only about two paces from me, and I could easily have brained him. I held out my hand for the rifle, and the man who was carrying it very pluckily came round with it.

Just as I got it in my hand the lion bolted to the right, and I foolishly fired a running shot at him, instead of waiting for him to stand, which I think he would have done within roo yards or less. My bullet must have passed just in front of his face, for he swerved sharply and was soon into some thick bush, where I lost sight of him, and, although the men and myself beat up the bush, we never saw him again. When the lion bolted I was amused at the action of a boy who had a soft iron knife in his hand, for he gave a yell and ran after the lion. What he thought he could do if the lion had stopped and waited for him I cannot say.

When we were crossing the swamp one of the worst tropical storms of thunder, lightning, and rain that I have ever seen came on, and the lightning was so close that I feared some of us would be struck. While tramping along in the mud and lashing rain I noticed several herds of game, and they stood like horses or cattle with their tails to the driving storm, and would hardly move out of our way. I saw several reedbucks, also, and I remember one male had a very fine head, but he was more lively than most of the other game, for he ran off before I could get the rifle from its cover. We got home at dusk soaked and 
tired, and this was one of the black days in my diary and one of the hardest.

Just after this experience I was shooting near the Shire River, and one day I saw the largest horned impala I have ever seen in Central Africa. His head more resembled the size of the British East African type, though I cannot say what it measured, as I missed a fairly easy chance at him at about seventy yards range.

Again, in North-Eastern Rhodesia I wounded and lost a very fine bull sable antelope, whose horns were much better than a 43in. head I had bagged about a month before. I knocked this sable down and had walked up to within twenty yards of him, and then turned my back to pull my Kodak from its case to get a snapshot. While I was doing this I heard the thud of his feet and turned round to see him disappearing into the thick bush near. I followed this sable for two days and never saw him again, and I believe my bullet grazed his spine, which dropped him and caused paralysis for a few moments. The loss of this beast was, of course, due to my own carelessness, although if the boy who was carrying the camera had been a sharp-witted lad he would have told me the sable was getting up and running off, as he was looking at it. Then I would likely have had time to get in another shot with the chance of killing or crippling it. Anyhow, I lost the best pair of horns I have seen on a living sable antelope, and I am sure they were not much less than 46 in.

Every incident such as this is a fine lesson, and it is generally remembered when a similar incident arises; and of course there would not be much interest in game shooting unless there was a certain amount of uncertainty.

The lucky days are not perhaps so common as the unlucky ones, but the luck is sure to change if one keeps hard at it. The best hunter, if not always the best shot, is the man who is hard-working and persevering.

Before closing this chapter I will give a few of my articles which have appeared in the Field newspaper at different 
times, as I have the kind permission of the proprietor and editor of that journal to do so. Here is one about long range shooting at game which may be of interest :

\section{LONG SHOTS AT BIG GAME.}

SIR,--In your issue of July 9 I notice a letter by "Canities Adest" entitled "Long Shots at Stags." I have also seen other letters on the same subject, one by Mr. Dunbar-Brunton referring to some long shots he made at game in North-East Rhodesia. I have had considerable experience of big-game shooting in Nyasaland and Northern Rhodesia, and I have seldom found it necessary to shoot at a greater range than about 200 yards, and most shots will be taken at 100 or 150 yards.

I do not consider it sportsmanlike for a man to make a practice of shooting at game over 150 yards, and if he cannot get to within that distance he cannot be a good hunter. Even on the big plains (called dambos here) there is usually enough covert to enable one to get a reasonably close shot, and only on a very few occasions have I found it necessary to shoot at game over 200 yards off. Of course, some men might be able to kill a buck better at 300 yards than another man would at IOO yards, and with modern rifles, such as the $\cdot 280$ Ross, $\cdot 256$ Mannlicher, or '275 Mauser, a matter of fifty yards or so may not make so much difference when a man is blessed with good eyesight, and when the game is standing in the open. In the old days in Southern Africa the Boers used to fire at springboks at distances over 500 yards, and often kill them, but I believe that for one buck they killed they missed or wounded many. A springbok is about the size of an impala, and the heart of the latter measures 5 in. long by $3 \frac{3}{8} \mathrm{in}$. broad, so it would need a remarkably good shot to hit it at a distance of over 150 yards. The lungs are larger, but under the ordinary conditions of shooting in this country it is unsportsmanlike, I consider, to shoot at a buck over 150 yards, unless meat is urgently required or the beast has been wounded by a previous shot. Many men who know they could not hit a Ift. "bull" at 300 or 400 yards think nothing of pumping a magazine full of cartridges at a buck at that distance, whether it is standing or running.

When a man has been walking for some distance in a hot tropical sun, and is perhaps shaky with fever or exertion, he cannot expect to shoot as well as he would at a gunmaker's range on a cool day at home. It is all very well to say that rifles are so accurate and have such a flat tr.jjectory nowadays that it is easy to kill game at 300 and 400 yards; but the question of eyesight comes in. Any good modern rifle with a velocity of 20ooft. per second is capable of killing an animal a mile off; but that is no reason why animals should be shot at when it is impossible to locate their vital organs or to discern the true angle at which they are standing.

The ignorance displayed by some men who ought to know better is amazing. For instance, men will fire at hippos from a river steamer in motion and expect to put a bullet into a circle of about 5 in., which is, roughly, the size of a hippo's brain. For one hippo that they kill by a fluke they will wound over twenty. The wounded animals retire into the weeds 
and attack the first native canoe that passes near, probably drowning the poor native, or, at least, causing him the loss of his canoe and its contents. Some people who go after buck, when asked if they got anything, will say, "No, but I hit several," apparently very proud of the performance. If he had said, "No, but I wounded one, and followed it until I lost the spoor, or darkness came on," he might be called a sportsman, for even the best of hunters will have the bad luck to wound and lose an animal at times.

In the hands of a man who knows what he is doing a magazine rifle is a great advantage, but in the hands of a tyro who loses his head and gets excited it becomes a curse. I really think that the administration of the different protectorates in Africa should make it unlawful for a man who knows nothing of big-game shooting to use a magazine rifle until he is accomplished enough to use it properly. A single loader or double is not only better for him, but for the game. If he had a single loader he would naturally take more trouble to get closer, and fire with greater care. A man once said to me: "I never try to get close, for I have five shots in my magazine, and surely I can hit a beast with five shots!"

He may have hit some of them, but he did not bag many, unless he counted the wounded as "bagged." Men who go in for big-game shooting and are well up in their subject are generally humane and kind-hearted men, and all of them deplore the loss of a wounded animal, for they know the sufferings that it has to undergo, and in hourly terror from carnivorous beasts, which can take it at a disadvantage.

A modern expanding bullet makes a fearful wound, for the diameter increases as the bullet penetrates. In some cases the exit hole in a small antelope will be as large as a saucer. Such a wound in the body of a large antelope like a roan, kudu, sable, or waterbuck will almost invariably cause its death. I have shot a great number of antelopes, and I have seldom found other bullets than my own in the animals, so I presume that nearly all wounded beasts die sooner or later.

I quite agree with "Canities Adest," and his letter applies to Central Africa just as much as it does to deerstalking at home, for the amount of rash hooting that goes on out here is appalling.
Field, October 8, 1910.
D. D. L.

I now give two letters from the same newspaper about photographing big game and the dangers incurred while doing so, and I have the permission of "Mannlicher" to give his ideas on the same subject.

\section{PHOTOGRAPHING BIG GAME.}

Sir,-In your issue of January 20 I notice a paragraph entitled " Mr. Kearton's Cinematograph." I quote the last sentence: "Mr. Kearton and his brother, who has helped him, have done wonders, and when we remembe that a photographer has to approach very much nearer to his subject than a sportsman does to his game, we cannot but admire the 
personal courage that has led them to incur a real risk in the pursuit of science." Now, I quite agree with this, but I would like to point out that animal photographers really take less risk than do men whose desire it is to kill the game they hunt. Most hunters know that few wild animals are really dangerous until they are wounded, and it is usual for them to make a bolt as long as they have the strength to do so.

Mr. Radclyffe Dugmore, in his interesting book "Camera Adventures in the African Wilds," makes some rather derogatory remarks about the man with the rifle, and there can be no doubt that he and his comrade, as well as Mr. Kearton and his brother, all took great risks in photographing lions and rhinos; more especially the latter, as in certain parts of British East Africa these animals are known to charge without provocation. Perhaps getting to within twenty yards of a crusty rhino might, however, be sufficient excuse for it to charge, and so we can hardly blame the animal for acting on the defensive.

Men who take telephotographs do not need to get much closer than a man who is trying to kill with a rifle. When a lion, buffalo, elephant, rhino, or leopard is wounded and followed into dense grass or bush, I am certain the risk is infinitely greater than it is to try to photograph any of those animals which are unwounded, and I am sure that all practical hunters will ayree with me. I do not for a moment wish to detract from the dangers undergone by big-game photographers, for it needs much courage to go close to dangerous game with a camera; but I contend that the danger is really less than it would be if the game had been wounded and was being fol'owed with a rifle.

A famous surgeon who visited British East Africa wrote some derogatory remarks about lion shooting. Following lions on horseback with a pack of dogs may not be very dangerous, or following them with a crowd of natives and four or five guns may also lack much danger; but to follow a wounded lion, buffalo, elephant, or rhino into dense covert by oneself accompanied by only a second gunbearer is very dangerous. The graves of many good sportsmen all over Africa prove it, and so does the record of those who have had the bad luck to get mauled.

Field, April 20, 1912.

D. D. L.

Sir,-As one who, like Mr. Lyell, has had long experience of hunting great game in most parts of the African continent, I heartily endorse his remarks as to the nonsense that is talked about the danger incurred in ge:ting these photographs. I also agree with him that getting close-range photos of rhino, particularly in East Africa, involves more risk than any other animal. With a telephoto camera it is not necessary to get anything like so close to the really dangerous animals as a really good man does when hunting alone. A telephoto lens will give excellent results of elephants at 100 yards; but the old hand after elephants gets vastly closer than this before taking his shot, ditto with rhino. I have shot rhino in various parts of Africa, and never found them particularly dangerous till I went to East Africa, for the first and only time, twelve years ago. As regards lions, in broad daylight the danger is practically nil until the animal has been 
wounded, or at least shot at. It is true that with a vast crowd of beaters and the backing of several reliable guns the danger is but small; while the dog method, about which we have heard so much lately in connection with a holocaust by an American hunter, which included a few good lions, but many of a tender age, is almost devoid of danger, and, far from being a new thing, was on one occasion utilised by that good sportsman Mr. Butter with great success. The large number of fatal accidents, though in many cases due to the inexperience and want of steadiness of the sufferers, shows how true it is that the genuine sportsman, who hunts single handed and on foot, runs the very greatest risk when following up wounded animals into more or less dense covert.

MANNLICHER.

Field, April 27, 1912.

Then to conclude this chapter I will give other articles from the same newspaper about the length of African crocodiles.

I sent a query to the Field of March I2, I910, asking if anyone could say whether an African crocodile had been killed measuring over $22 \mathrm{ft}$., and here are the replies by the best authorities on the subject, and a further letter I wrote on the same subject:

\section{MEASUREMENTS OF AFRICAN CROCODILE.}

In reply to his question on this subject I may refer Mr. D. Lyell to the late Dr. John Anderson's "Reptiles of Egypt," in which (pp. II-12) the statements made by travellers or other observers regarding the length of Crocodilus niloticus, the common crocodile of Africa, are quoted and discussed. Although there have been reports of crocodiles 5oft. long, Dr. Anderson concludes that there is no record of the actual measurements of any Nile crocodile over I $7 \mathrm{ft}$., and that the greater size attributed to other ' specimens has been all guesswork. The limit of growth, however, is quite unknown.-G. A. Boulenger.

- In reference to Mr. Lyell's query in last week's Field it may be mentioned that it is very difficult to obtain trustworthy information with regard to the maximum dimension of crocodiles of any kind, and that this is especially so in the case of the African Crocodilus niloticus. Those who shoot them seldom take the trouble to measure such as are brought to land. That Indian crocodiles commonly attain a length of from $15 \mathrm{ft}$. to $20 \mathrm{ft}$. is well known, and there is little, if any, doubt that they sometimes grow to a much greater size. It is stated, for instance, in Gunther's "Reptiles of British India," that both $C$. porosus and $C$. palustris sometimes grow to 3 oft., and there is in the British Museum a skull of the first-named species killed in Bengal in 1840 , which was stated by the donor to have belonged to a 
reptile measuring $33 \mathrm{ft}$. in length. On the other hand, there does not appear to be any record of the African crocodile attaining anything approaching such dimensions. The largest specimen of this species in the British Museum, at the date when the Catalogue of Chelonians and Crocodiles was published, measured just under $\mathrm{I}_{5} \mathrm{ft}$. ( $4 \frac{1}{2}$ metres) in length; and Dr. Voeltzkow, who made a special study of these reptiles in Madagascar a few years ago, states that the largest specimen he measured was $13 \mathrm{ft}$. long. Again, writing of Egyptian crocodiles, Dr. J. Anderson, in his "Reptiles of Egypt," states that there is no authentic record of any specimen exceeding $17 \mathrm{ft}$. in length. Mr. Selous, on page 291 of his "Hunter's Wanderings," refers to a $\mathrm{I} 3 \mathrm{ft}$. crocodile as a large one. So far as I can discover there appears to be no record of an African crocodile 22ft. in length.-R. L.

Field, March 19, 1910.

SiR,-I must thank Mr. G. A. Boulenger and Mr. R. Lydekker for their answers in the Field of March 19 with reference to the length of the African crocodile.

I have shot a number of crocodiles in the Zambesi and Luangwa rivers, and the largest one I taped measured $14 \mathrm{ft}$. Once on the Zambesi, while travelling in the river steamer Hamburg, I saw and wounded a much bigger one. It was lying asleep on a sand bank about midday, and I used a 303 rifle with a soft-nosed bullet. When the bullet struck, the crocodile raised its tail in the air and brought it down with a thump, as these reptiles often do when well hit. Thinking it was dead, I picked up a pair of binoculars, and through them I saw the blood pouring out of the wound between the neck and shoulder. While I was looking I heard the crack of two Snider rifles, and on turning rcund I found that two Portuguese soldiers had both fired. Their bullets did not strike the crocodile, but passed over it and raised the sand some distance beyond. However, the crocodile seemed to revive, and was quickly in the water before I could reload and fire again.

This was by far the largest crocodile I have ever seen, either in India or Africa, and it seemed half as long again as the $14 \mathrm{ft}$. one that I measured. Its bulk and girth were enormous and far exceeded an $18 \mathrm{ft}$. garial I once measured in the Brahmaputra River in Assam. The skipper of the Hamburg, who had been some time on the Zambesi, told me that he had never seen one approaching it in size. It was well hit with a raking shot, and I fancy it died, but shall always regret that I did not fire again and make sure of this, for I could have persuaded the skipper to stop the steamer and put me ashore so that I might have taped the animal. In fact, he said he would have done so had the crocodile not escaped. The I $8 \mathrm{ft}$. garial I measured in the Brahmaputra was a large one, but I believe I have seen a few bigger. In 1894 these animals were very plentiful, although in five or six years they got scarcer, as many people used to fire at them from the passing steamers.

I have an idea that the late Sir Samuel Baker mentions a large crocodile in his book on the sources of the Nile, but it is so many years since I read the work in question that I have forgotten the facts. 
A crocodile is an awkward animal to skin, for the skin is very firmly attached to the body. A good many natives are killed by these animals every year, and in places where they are dangerous the natives make a circular fence in the water to protect themselves when bathing and drawing water.

Shire River, Nyasaland.

D. D. L.

[The passage referred to by our correspondent is, no doubt, that in "Wild Beasts and their Ways" (ch. xiii.), where Baker wrote of having seen on a bare patch of grey granite on an island in the Victoria Nile "two vast forms each as thick as the body of a hippopotamus, and of enormous length. These two antediluvian monsters glided slowly and fearlessly along the gently sloping granite, and when half beneath the water they exposed a breadth of back which was the most extraordinary sight I have ever seen in my long experience of crocodiles." The canoe in which he was travelling at the time was about 3 oft. long, and he judged the surface of the granite at about 6oft., but "would not presume to estimate the length of these extraordinary creatures." $-E_{D}$.]

Field, July 16, 1910. 


\section{CHAPTER IV.}

\section{Hunting Elephant and Other Game.}

A good locality for elephants-A large race of elephants-Stretching skins of game-The spoor of three elephants found-One a very large oneGood tracking-Damage done by elephants-Easily killed with small bores-The largest bags of elephants in a day-The use of anthills to. spy from-An elephant lost through the carelessness of a native-Lose a shot at moving elephants-Mistake of firing uncertain shots-Excitement of elephant shooting-Hot weather-Try a different directionThe spoor of a good tusker found-Follow him and find him in a bad bit of country-Hit him, and he runs and falls dead-A good tuskOld wounds in elephant-Actions of an elephant shot in the lungsElephants die hard-Measurement of the cavity of an elephant's brain -Size of elephant's feet-Position of elephant's heart-Good quality ivory found in Nyasaland and adjacent countries-Bad smell of dead elephants after lying in the sun-Noise made by opening elephant's. stomach-Natives cut themselves-A lively night with hyænas-Weird noises made by hyænas-I sight a small herd of buffalo and see a herd of sable antelopes-Central Africa a network of paths- "Closing" paths-Usual time of year for grass burning-Destruction caused by grass fires-Hot ground-Shoot a kudu bull-Carry off elephant meat -Another trip-Two sable antelopes shot-Wound a bull and lose itElephant scared-Meet a white man and his wife-Two eland bulls. shot-Fat got from elands-Natives dirty butchers-Noting position of vital organs in game-Change camp and see spoor of lion and buffalo-Young eland killed by lion-Extreme heat at end of dry season-Go after hippo-Shoot one-Time taken by hippo to rise when shot-Four hippos shot in Zambesi River-Crocodiles in the Bua River-Go after game and find it wild-A tropical storm-Damage done to native crops by elephants, hippos, and other game-The appetite of elephants - Elands and pigs destructive - "Garden " elephants dangerous animals - Poachers of game-Boers great destroyers of animal life-Reserves for game-Connection of game and sleeping sickness-Impossibility of exterminating game in Central Africa.

ON September 16, 19 12, after having engaged a few carriers, I started off for Maponda's village, and Kamwendo, the good elephant spoorer, arranged to meet me there on the evening: 
of the same day. Some years before, in 1904, I had shot a fine 5o-pounder near the same village, and Maponda (a woman chief) and her people remembered the fine feeds of meat, so were very glad to see me come along again. The vicinity of her village is in one of the best elephant localities in Nyasaland, and I suppose over twenty large bulls have been shot there by Europeans at different times. I know that many skulls can be seen ; that is to say, if one happens to pass where they are. The elephants in this district are a lanky, tall type of animal, and the one I shot in 1904 must have reached I Ift. or slightly more, and the natives told me he was the tallest elephant they had ever seen. He fell dead in a kneeling position against a small tree, so I could not get his shoulder measurement. $\mathrm{Mr}$ T. A. Barns (who shot the large elephant now in the South Kensington Museum) has killed several in that locality measuring close on IIft., and the height of the elephant mentioned, in the Natural History Museum, is stated to have taped I Ift. 4 in. when shot. An elephant or giraffe skin, or, indeed, the skin of any large beast, can be stretched a considerable amount when being set up in a wet condition, and it would be an easy matter for a taxidermist to mount a I $2 \mathrm{ft}$. elephant out of an I Ift. skin.

If a lion's skin is immersed in water for a day or two it could be made to stretch quite a foot, although the width measurement would likely decrease somewhat if the length were increased. Thus, unless the hunter is a principled man, he could add on several inches to the height of a trophy without the most expert naturalist or taxidermist being able to detect it, as skins intended for natural history specimens are not pegged out, and they shrink considerably in drying. I have no doubt that there are several specimens in different museums which represent taller animals than they were when alive. I believe it is possible to stretch a game head by soaking it for a long time and then hanging heavy weights to the tips of the horns. Of course, no self-respecting sportsman or taxidermist would do this, but a few trophy dealers in South Africa would likely be 
quite willing to take the trouble if it enhanced the value of a head and brought them a pound or so extra.

I was up before dawn on the morning of the 17 th, and Kamwendo took me to some maize-fields where the elephants often came at night to eat the dried-up stalks. All game are fond of maize and millet stalks, and they come a long distance to feed on them, as well as invading the growing crops, unless the natives sit up on stands with a drum or old tin, which they beat at times all through the night.

We were very lucky, as we found the spoor of three elephants, one a fine, big fellow, judging from the size of his footprints.

Again, I was much interested in noticing Kamwendo's fine tracking, , for he instinctively seemed to know where the elephants would leave the garden, and he took me to the bush, where we cut the spoor at once.

Following a large bull elephant is the most exciting sport there is in the world, for one has so many opportunities of seeing what such a beast is capable of. Trees that seem unbreakable are sometimes broken and splintered, and one marvels at such power, and perhaps a new hand might feel a shiver go down his backbone when imagining the grip of such a trunk being placed on his neck, or thinking what would happen to his body if the mighty foot was suddenly placed upon it.

Yet, with all his immense strength, the elephant is a wonderfully easy animal to kill, if one can only hit him properly. Even a $\cdot 256$ Mannlicher will kill an elephant most efficiently when in the hands of a good, cool shot.

That six to seven tons of bone, flesh, and muscle should drop to a projectile weighing 158 grs. seems something like a miracle, but it has been made possible by the ingenuity of civilised man. More elephants have been shot in Central Africa with $7.9 \mathrm{~mm}$. Mausers than with any other weapon, and the bullet only weighs $225 \mathrm{grs}$.

The largest bags of elephants which I have read of as being made in one day were eighteen shot by Mr. Viljoen 
in Southern Rhodesia, and that famed elephant-hunter, the late Mr. A. H. Neumann, once bagged sixteen in a day, using a 303 and a ro-bore rifle. But after this wandering from the tracks, I must get back again to the elephant I was after.

The fresh spoor led us into some bad country, bad for puny man, but, of course, nothing to the elephant; and some of the long, half-dry grass towered over our heads, and I hoped when I got into this kind of country that the elephants would stand in more comfortable surroundings for the last round.

In such grass it is often difficult to move, once one leaves the broad tracks of the elephants, and I have found that elephants are much more inclined to be disagreeable in such country than they are in more open timber land. Therefore it is a very sound plan to climb anthills to look round or send men up trees for the same purpose, so as not to get right under the animals before being aware that they are so close.

Not far from this place, and when approaching an elephant which had been blowing red anthill dust all over himself, I once mistook the animal for an anthill, and got so close that I could have touched his stern with the muzzle of my rifle. Luckily the elephant was asleep, and I and the man with me were able to retreat and get to the anthill which I knew was near the elephant.

On crawling to the top of it, he was still asleep and swaying gently backwards and forwards, and my sight was just on the orifice of his ear when my gunbearer, in his eagerness to see results, cracked a stick or bit of dry reed. At the sound the elephant twisted right round (just like a top being spun), and the bullet that I fervently hoped would have punctured his brain went into his side somewhere, and he went off; and, although I did my best to find him, I failed.

Kamwendo took me along splendidly until, at about I I a.m., we suddenly saw the three elephants wandering about, feeding. I told the men who were carrying some 
lunch and water to sit down and wait, and gave Kamwendo the 400 single cordite and took the $7.9 \mathrm{~mm}$. Rigby, and we approached the monsters.

Suddenly the elephants began walking fast in our direction, and, as the grass was long, Kamwendo and I made for a more open part where there was some timber, and when we reached a fairly large-sized tree I stopped.

The game did not seem to be much alarmed, and I thought they would stand every moment. The three beasts, the largest being a splendid bull with long white tusks quite 6olb. each, passed me at a fast walk; and I have regretted many times since that I did not fire at him then, as I might have got to his heart or lungs. However, as I object to fire risky moving shots at such fine animals, I waited for him to stand. Instead of doing so, the elephants suddenly got the wind of the men I had left behind, and they suddenly put up their tails and started off at full pace, and then got into the thick grass. I had spoilt a fine chance in not taking a snapshot, and lost two splendid tusks, so I was not in a good temper when I sat down to have some food after a most tiring and exciting morning's work. A smoke soon put me into a better frame of mind, and I thought I might see the same elephant again some day; which was really not much satisfaction, as elephants travel long distances and do not come to be shot. After lunch I took the spoor and followed for about four miles, but the elephants never slowed down, and I knew they would not likely stop for many miles, so I trudged back to camp without the tail which is usually cut off to show that there is an elephant less in Africa.

Every sportsman has to put up with misfortune, and I was no stranger to it; but I knew the luck would change with some more hard leg work. Elephant spooring is hard work, for the country to be traversed is often very stiff going, and it is this that makes the disappointments in elephant shooting so hard to bear. It is not usual to get up to an elephant without going through dense country, and the prolonged excitement tires one almost as much as the 
strenuous exercise. If one actually sights the animals, and for some reason cannot get a shot, the remembrance is inclined to be tantalising. However, I had the consolation of knowing that I had not wounded a splendid beast and lost it, which is always the worst remembrance of all.

It was late in the afternoon when I reached my tent, and during the day's walk I had seen eland, kudu, and other game, although I did not fire at any of them, not wishing to frighten any elephants that might be within hearing.

The sun is dreadfully hot in the months of September, October, and November ; and the atmosphere is particularly sultry and oppressive in the latter month, just before the rains break. People at home occasionally experience this oppressiveness just before a thunderstorm ; but it is very much more intensified in Central Africa.

It is usually hotter to sit in camp than tramp about in the sun, as the exercise induces perspiration, and this makes the body feel cooler. This may seem a paradoxical remark, though it is true nevertheless.

On the following day I was out of my camp bed as early as usual, which was at first cockcrow, about half an hour before sunrise. I was feeling slightly feverish with the previous day's work, but it never does much good to lie up, unless one is so bad that movement is impossible; and, besides, I have often noticed that there is nothing so good as a stiff walk to get rid of fever. Kamwendo suggested that we should go in a different direction, to which I was quite agreeable, as I hoped that direction might be easier country than I had been tramping through the day before.

I think Kamwendo was feeling a bit tired also, for he certainly led me through much more open country, but we found no fresh elephant spoor until about II a.m.; by which time we had made a long semicircle of quite fifteen miles. Then Kamwendo, who was leading the way, gave a grunt and pointed down, and there I saw the absolutely fresh tracks of a fine bull elephant. He had not passed more than twenty minutes before, and his droppings were 
steamy and hot. This was a piece of good luck, as I had given up hopes of seeing any spoor on this day, and I had no idea I should have the good fortune to find absolutely fresh tracks. Both Kamwendo and myself knew that we would soon see this elephant, for he had been moving slowly along, feeding occasionally, and he was bound to rest soon, as the sun was intensely hot, and elephants, like human beings, prefer to slow off a bit about midday in tropical Africa.

The men were told to wait, and Kamwendo carried the 400 with strict injunctions that he was not to fire unless I told him to, a thing I have never yet asked a native to do.

Then we walked along steadily, and in about ten minutes saw the elephant standing on the opposite side of a large dambo in some long grass. On our side the grass had all been burned by the natives, but the fire had not touched the opposite side, which was annoying. The elephant looked huge as he stood flapping his ears against his sides, and every now and again blowing dust over his body with his trunk. As we were crossing the open to reach an anthill not far from the elephant, he began to move slowly into the tree bush near, stopping here and there to pick a few leaves from the trees.

As the grass was very long among the trees and I knew it would be difficult to see him from the ground when enveloped in the grass, I moved to another anthill farther on and just ahead of the elephant. He then began to ram a tree with his forehead, and he seemed to have something wrong with him, as he was never still a moment.

I changed ground again to yet another anthill, and it was fortunate I did so, as the elephant began to move to an open space about ioo yards from me. As he was busy picking some leaves, I took a steady aim for his brain and fired.

Instead of dropping in his tracks, as I had hoped, he gave one or two painful grunts and dashed past me, getting the four remaining shots in the magazine as he 


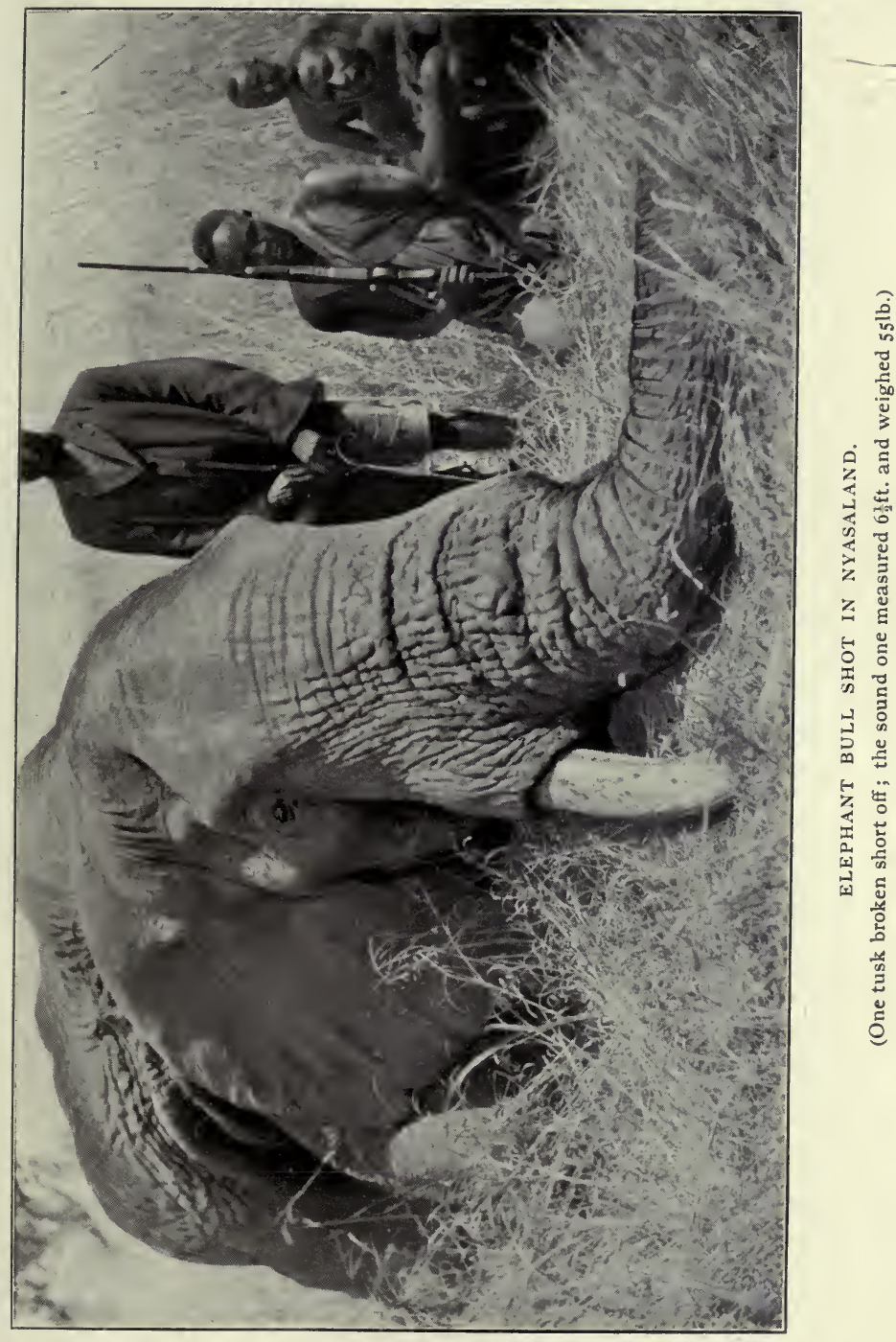



went by like a whirlwind. I saw the dust fly when some of these bullets cracked on his hide, but I could not tell exactly where they went. The stricken beast now ran towards the place I had first seen him standing, and, as I could see nothing when I came down from the anthill, Kamwendo and I ran towards the place where he had disappeared. We then heard a man shouting something, and, as we could not hear what he said, I told Kamwendo to go over to him and find out. I moved forward, and then saw the elephant standing some seventy yards off, and as I had got into the burned dambo and the elephant looked very annoyed, I thought I had better get under the cover of the grass again.

As Kamwendo approached, I heard Tereka, the other man, shout something to him, and Kamwendo passed on the message that the elephant had collapsed.

We then went close to an anthill within fifteen paces of the elephant, from where I saw the poor animal on his knees, and I could see his side moving as he breathed, so I fired another two shots, one at his head and one behind his shoulder, and he died.

Leaving our perch on the anthill, we went to look at him, and I was very disappointed to see that he had only one sound tusk; but it was a beauty, and when I got it out I found that it weighed 55lb.-afterwards it dried to $53 \mathrm{lb}$.- and measured $6 \frac{1}{2} \mathrm{ft}$. long, and it was beautifully curved and without a crack or flaw.

The stump of the other tusk, broken short off at the lip, proved to weigh I 4 lb., and it was all cracked and diseased.

This elephant had a bullet, about 450 bore, nickel covered, in his head, and also a 303 bullet in his shoulder.

The pain of the bullet wounds, and especially the nerve of his broken tusk, must have caused the animal tortures, and this accounted for his strange behavour in butting the tree and showing so much restlessness. I found the bullet that killed him was one of my running shots which had gone through his lungs, and Tereka told me that before the elephant fell he put his trunk in the air three times. This 
is a common act when an elephant is shot in the lungs, and I have seen them do it several times. It is evidently caused by the suffusion of blood in the lungs which gets coagulated and causes suffocation.

When an elephant is killed, more particularly a large old bull, it is usual to find native bullets in his carcass; sometimes these are round and at other times oblong, and they are simply pieces of iron made in the roughest way by being hammered with stones.

It is not so common to find European bullets, although it is not unusual to do so. The large nickel-covered projectile was either a $450, \cdot 475$, or 500 , but it had got so misshapen that it was difficult to recognise its bore. The sportsman who fired it had evidently hit a tree, which reduced the velocity of the projectile and flattened it, so that it had no penetration in the hard bone of the skull.

It is a memorable sight to see such a large animal as an elephant die, and they sometimes die hard and make stupendous efforts to rise when they get on their knees. They also groan and sometimes scream with pain, and it is impossible to witness such a sight without feeling great pity for the suffering giant. Puny man is no longer a weakling compared to such large creatures when he is armed with a good modern rifle and knows how to use it efficiently.

Not very far from my dead elephant was the dried-up skull of a large bull shot by an officer who once lived at Fort Manning, and Kamwendo told me the tusks were as heavy as the one I had just got. I measured the depth of the brain cavity and found it to be exactly a foot. In my "Nyasaland for the Hunter and Settler" I gave two sketches of the cavity in an elephant's head, one sketch being by my friend Mr. Martin Ryan, and the other by myself. It shows how small a mark it is, and also how difficult a one, as it is buried in the centre of a mass of bone and flesh.

The feet of my elephant measured 56 in., and he was a tall, large-bodied animal, but, owing to the kneeling position 
in which he fell, it was impossible to get his height measurement. The three.largest elephants I have shot have all fallen in this kneeling position, and it is not uncommon for elephants to do so; although I think they usually fall flat on one side or the other. Perhaps animals generally fall on the wounded side, although small antelopes are often carried over by the force of the bullet. I think, when they run some way before falling, that they usually fall on the side that the bullet enters. I have heard it remarked that it is easier to kill an elephant from the right as it is stated that his heart lies more to that side than on the left. This, however, I consider a fallacy, as the heart is placed almost centrally in the cavity of the body. If an elephant should be cut up to examine the position of the heart and lungs, they naturally, by the force of gravitation, sink with their weight towards the side nearest the ground.

There can be little doubt that the elephants in Nyasaland and Northern Rhodesia are probably as large as any breed of elephants in Africa, with regard to their height and weight, for the late Mr. A. H. Neumann has written in his "Elephant Hunting in East Equatorial Africa" that the largest bull out of many he measured gave a height of I oft. gin. at the shoulder.

The ivory in Equatorial Africa is not usually of such fine quality, as it is found farther south, although the best bulls have much heavier and longer tusks.

After the elephant fell I took several photographs, and then we cut off the tail and went back to the village. As we got near, the villagers noticed the tail, and they began to shout to one another that an elephant was dead, and I have no doubt the following day's work of cutting-up was looked on as a sort of local outing.

My only regret was that the elephant had not two sound tusks, but when I got glimpses of him before shooting I could only see the side with the long tusk, so I naturally thought that he would have another on the opposite side. Elephant shooting is certainly full of luck, and I was sorry that the fine elephant I had seen the previous day had not 
given me a better chance to shoot him, as his tusks were much finer than this elephant's, and, moreover, he had two perfect ones.

The elephant was left untended that night, and early next morning I changed my camp to the carcass, as there was water in the big dambo near.

In the night the hyænas had arrived on the scene and eaten about half the trunk, and they must have been very pleased to find such a quantity of fine meat waiting to be devoured. Before pitching the tent I took care to get to the windward side of the elephant, as I knew from past experience that there would soon be a strong aroma about; but at this time of year the wind is very changeable, as the great heat causes eddies in the air, so I could not get away from the stench, which kept coming round at every slight change of the wind.

The first thing I did was to make a large grass fence round the carcass, which gained me another native name, as the natives immediately christened me "Kampanda," the fence-maker. I also made a rough covering over the tent, and it was about 3 p.m. when all this work was completed, at which we had all worked hard. Then I got men on to the work of chopping out the tusks, while others began to hack up the body.

Before I had any experience of strong animal smells, the worst effluvia I can remember was that of the whalers which used to return to Dundee from the Arctic regions, and they certainly had a strong smell, but nothing compared to a putrefying elephant under a tropical sun. However, one can become accustomed almost to anything in this world. I once shot three hippo in the Lupata Gorge of the Zambesi River and carried most of the skin to Chinde under some boxes, and elephant tusks wrapped in canvas.

This skin got wet in the bilge water, and what with the dampness and heat it putrefied rapidly, and when I got to Chinde the people there informed me I was polluting the atmosphere, so I sent the skin to a sandbank some distance away, and it was given to the fishes. When my elephant 


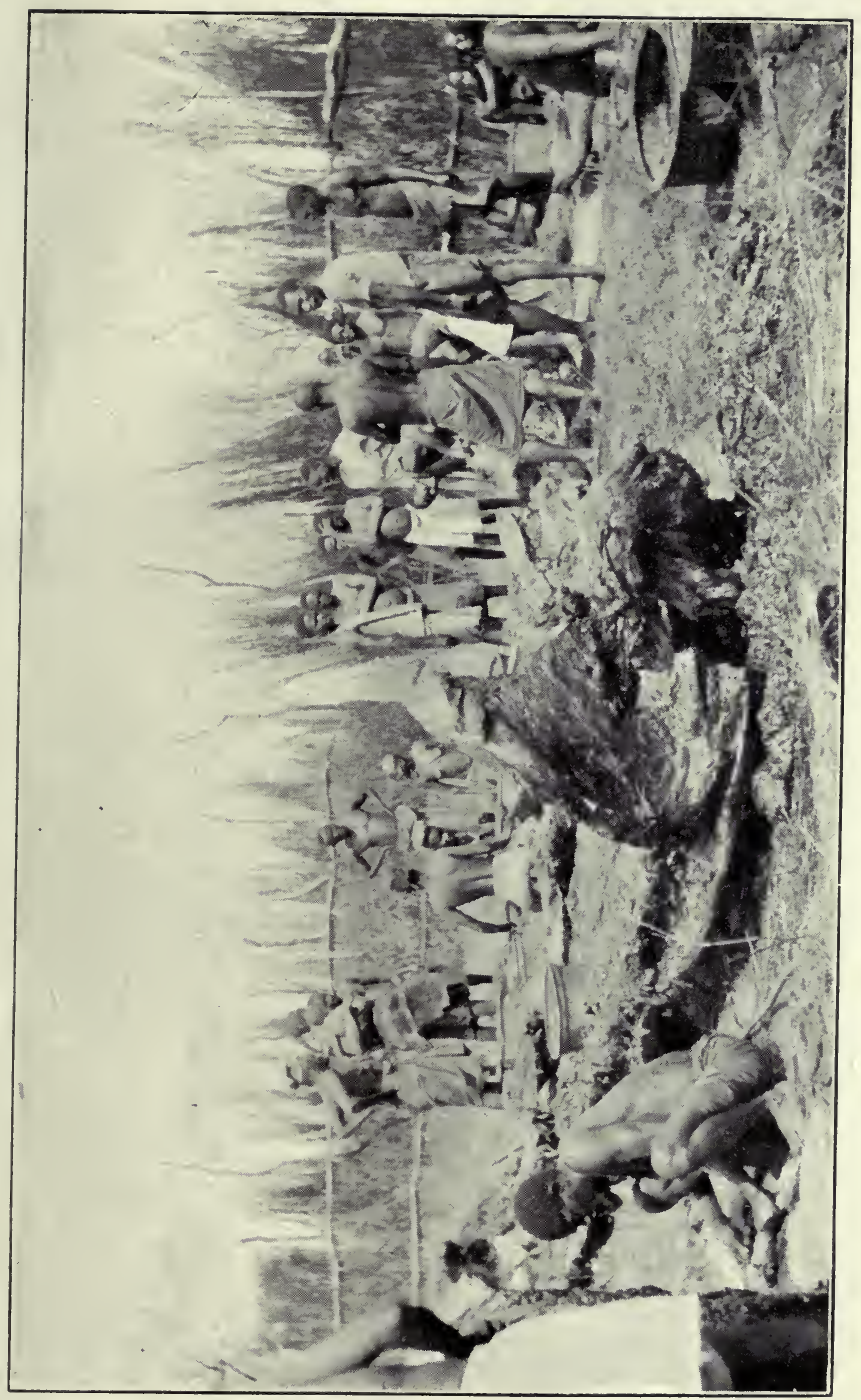

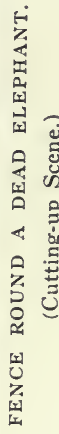



tusks, in their canvas wrapping, were deposited in the African Lakes Corporation store, there was an instant use of handkerchiefs by the employees, and I was asked if I did not think it horrible. All I could reply was that I had been sleeping every night for over a week in very close proximity to a much worse smell, and surely the slight aroma of the canvas sacking was a very meagre odour and not worth worrying about.

When the sun began to sink low I took my rifle and went for a lonely stroll down the dambo, but the only game I saw were two reedbuck which cleared off quickly.

On getting back to the elephant the stomach had just been opened, and the bad air and a lot of filth came out with a series of shrieks, for all the world just like a boiler letting off steam in jerks.

Some of the natives had cut themselves, and I had the pleasure of bandaging some bad gashes. If a native cuts himself when cutting up game he will often rub the injury with fresh dung, and they often put cowdung on bad sores and ulcers. The consequence is that, instead of doing them any good, they make their sores much worse, and I have seen some ugly ulcers simply caused by carelessness in not keeping the first injuries clean and covered.

Night soon falls in the tropics, and the camp presented a lively sight with the many camp fires and the constant chattering of the natives, who were revelling in abundance of meat, and lumps of fat cut from the inside of the elephant.

About 8 p.m. the hyænas began to howl, and by midnight the noise was deafening. The small fire I had made in front of my tent soon went out, but the elephant enclosure was bright with many fires; so the hyænas paraded within a few paces of the tent, and I could not sleep, as their shrieks and howls, intermingled with melancholy, disappointed groans, were continued all night.

People who have not heard a number of hyænas collected round meat have no idea what weird noises they can make, and these are always intensified when the animals cannot get at what they are longing for. 
Next day I sent most of the meat off to Dua's village, not very far away, and in the afternoon I packed up my kit and went off to camp in that village, as I wished to try for a second elephant in the vicinity.

I also sent off some men with meat to my camp on the Bua River, and told my cook, Yakobo, to bring a lot of women back to help carry more of the meat.

Then I went off to try to find a small herd of buffalo I had seen on the morning of the I8th, and which I had left alone, as I was looking for elephant spoor at the time.

The buffaloes had evidently been frightened by the shots fired at the elephant, and it is possible that the smell of the dead animal had reached them, as such a perceptible smell may doubtless be carried by a strong wind for many miles.

While looking for the buffaloes, or their fresh spoor, I saw a large herd of sable antelopes, headed by a fine horned bull, and I spent some time watching him feeding. As I had still hopes of finding the buffaloes, I did not attempt to shoot him, so I left them undisturbed to go on with their grazing. However, I might as well have had a shot, for, after tramping about all the morning, I failed to find the buffaloes or their fresh tracks.

While coming back to the tent I saw a warthog boar and fired at him, and he ran hard for about fifty yards and fell on his side. He was an old fellow with very thick tushes, which, however, had been worn very short.

Warthogs are very prolific animals, and they would need to be so to hold their own, as they are not only much hunted by the natives, but lions and leopards must kill great numbers of them. I must admit I like shooting at them, as they present a fine target for a white front sight, and I am always on the look-out for a good pair of teeth, as I think they are nice trophies.

Central Africa is a network of native footpaths, and it is impossible, in most parts of the country, to go for many miles without striking a path. Many other paths branch off, and, if the traveller is being followed by carriers, it is usual to mark the path that should not be taken by 
making a line or more across it, or by putting over it some freshly broken small branches, leaves, or grass. In this way it is possible for the natives to follow people in front, and it is seldom that they take the wrong path. In very wild country sometimes the track is invisible, and it is then followed by watching the trees and bushes for "blaze" marks ; and, should these be old and partly obliterated, it is sometimes no easy matter to get along quickly, as frequent stops will require to be made for careful examination. Occasionally, the grass is tied in knots, but these marks soon go in the annual grass fires which sweep through the country every year.

The time for burning the grass varies in different localities, and it depends on the duration of the rains. The usual time for it is July, August, and September, and it is a grand sight, especially at night, to see a great fire sweeping along with a strong wind.

Many small mammals, reptiles, and insects are killed in these conflagrations, and the natives' main reason for burning the grass is to get the small field rats and mice that are killed, as I have mentioned before.

In parts of the country that are dry the trees and bushes get scorched and burnt, and this keeps them small and stunted. A dead tree, or a dead branch on a sound tree, will sometimes get alight and smoulder for months, and elephants often burn themselves by rubbing on them.

Great numbers of young antelopes and other animals must also be killed, especially those which have just been born and are helpless. I have heard of young elephants being killed, also, and animals like land tortoises and snakes must be killed in thousands.

Returning to the subject of native paths, it will be noticed how these twist and curve, and yet, on the whole, keep a good direction from point to point.

A native will never worry about removing an obstruction such as a small boulder or fallen tree, and he will invariably go round it. In the dry season, when many of the smaller rivers and streams are dry, short cuts are made by walking 
down the sandy beds, and this is hard work, as the sand is often more than ankle deep and very hot. However, it is softer and cooler than the hard, stony ground, and the natives like to get to such places, which afford easy going for a time.

Near the Luangwa River, in North-Eastern Rhodesia, I have often seen the ground so hard and hot that it caused pain to touch it with the hand, and the sand was often so heated that a handful could not be retained for long. Riflebarrels, tin boxes, and, indeed, all metal objects were untouchable at times, and I have seen the oil oozing out of my rifle-stocks with the intense heat.

A native path is always preferable to a broad road, as it is more shady, and, being curved, it is not so monotonous to walk along.

For the man who rides a bicycle, the broad, hoed road will be best, but, personally, I would much rather walk along a twisting native path than on the European road.

Many is the shot at game one will get while tramping along these native footpaths, especially if there early in the morning or late in the evening, when the game has not retired to lie up, or when it again gets on the move as the heat of midday decreases.

On the evening of September 2 I I went out and saw a lot of game, including a large herd of kudu. They were some way off when I first noticed them, but the ground was covered with many anthills, so, with a good deal of crawling, I got to within shooting range and loosed off at the only bull I saw. As the bush was very thick where the kudus were standing, I could not see the horns of the male well. Anyhow, my bullet told, and the stricken animal ran a short way and stopped to look back, when a second bullet dropped him.

As it was too late to skin and cut up the game, I covered him with grass, and before I left I tied my handkerchief to a bush close to the carcass. Early next morning the men I sent for the meat found that no carnivorous animal had interfered with it during the night. 
I was trying to sleep about 9 p.m., although the smell of the pile of dead elephant was fearfully strong when the wind veered round, when I heard people shouting in the distance. This was Yakobo and my carriers returned with about fifty women to earry the meat. Most of them had babies, and the row was deafening, but I told my cook to give them a lot of the meat, and I felt rather sorry they could not eat it all up, for the stench was absolutely sickening.

I managed to get asleep about midnight, but was awakened several times during the night by the loud chattering and the cries of infants, who, being too young to fill up on "high" elephant, were doubtless kept from their usual nourishment by the mothers, who were busy chewing elephant meat. When natives feed the working of their teeth can be heard at some distance, and in the intervals they chatter like monkeys, so it was not what might be called a peaceful night for me.

I got a lot of the meat away early, and sent men out at earliest dawn to bring in the kudu meat, and by 9 a.m. they had got back to the village.

After presenting the headman with a lot of meat I started off and reached my home on the Bua River at I o'clock; and this was pretty quick work for the eighteen miles of rough country that lay between.

When I got the elephant meat on the stands with big fires underneath, the maggots had a lively time.

I remarked to Yakobo, my cook, that surely the natives would refuse to eat such meat, but he said that many of them rather liked it with plenty of maggots in it. Personally, though I can stand a good deal in the way of strong meat aromas, it nearly made me sick to get a whiff of it or even to look at it.

I felt very sorry for the young infants, whom the mothers carry in a cloth or skin on their backs, for the drip, drip from these baskets right on the heads of the children must have been almost too much for such tender specimens of humanity; at least, I thought so, but on my remarking this to the women they only smiled and said it was chabe (nothing). 
I had promised each porter half the contents of her basket, so they were quite pleased and happy. They would willingly have walked twice as far for the same amount of their beloved nyama. In Africa meat does not keep fresh for a week or more, as it does in Britain, and a day or so is enough to make it too high for the European's use. When well cooked it lasts a bit longer, but four or five days is as much as it will stand, even in June and July when the nights are quite chilly.

On October 3 I went off for another shoot to Maponda's village, as I had heard that the elephants were back again to that locality. However, I might have saved myself the trouble, for I could find no recent elephant spoor, as the animals were evidently still suffering from fright.

On the $4^{\text {th }}$ I walked a long distance and came on a large herd of sable antelopes. Most of them were feeding in some fairly long grass, though a few were lying down. With some difficulty I got to within shooting distance, and from the back of an anthill I was able to watch these splendid animals for some time. This herd consisted of quite twentyfive head, and the only bull I could see was in the worst position for a shot, as is often the case. He was not a very large animal, and I thought there might be another bull somewhere about. I needed the meat for myself and the men, so I fired at a cow which was lying down and which presented a good shot. I may say that, unless a lying animal shows up fairly well, it is usually a mistake to fire at one in this position, although there is the advantage of knowing the game will not likely move when one is aiming, as a standing beast will often do. The sable got the bullet and half rolled over with the shock, but recovered herself and jumped up and bolted. I knew she was as good as dead, as I was steady, so I looked round for the bull I supposed to be about.

Sure enough, he appeared from behind a large anthill covered with long grass, and I fired a shot at him and heard the bullet strike, but he went off strongly. 



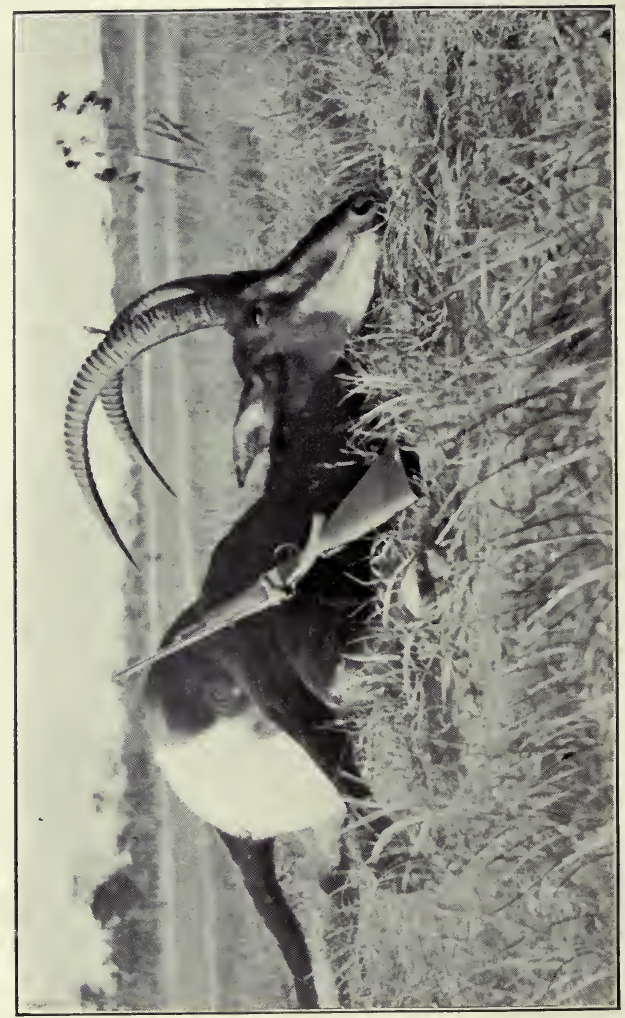

章 
I then took the spoor and soon found the body of the cow, and I was looking round to see if the bull was visible, when I heard two coughing grunts and then saw a sable running. Thinking it was the bull, I threw up my rifle and fired, and the sable fell as the bullet took it just under the tail. On walking up to it I found that I had shot another cow. The grunts I had heard were certainly made by the bull, as I never heard a cow sable make these hoarse sounds, and I think the cow had joined him, and that he was probably lying down, and had gone off in a different direction, which I did not notice, as my attention was taken up with the bolting cow.

As it was pretty late, I covered up the two sable and decided to return early next morning and try to find the bull.

Next morning I came back with all my men to cut up the meat and to resume the search for the wounded sable. The cows were both very fat and in the highest condition, and the natives relished this, as they got most of the meat.

I spent many hours trying to trace the wounded animal, and I could not find him, but I shot a reedbuck ram after I had left the sable spoor.

Finding this locality no good for elephants, as they had evidently been scared away by the smell of the dead one, I changed camp to Mitala's village, about eight miles from Maponda's, where I found the old camp of a white man who had been shooting there a month or two before.

Telling my cook to superintend the pitching of my tent and to make some lunch, I took three men and went for a stroll, and found a lot of old elephant and buffalo spoor. I came on a large herd of roan antelopes, and could have shot one had I cared to do so, for they would hardly move away; at least, they would let me approach to within 150 yards, and then run for two or three hundred yards, and stop and look back. Besides the spoor I have mentioned, the whole ground was covered with the tracks of elands and roan, and this was evidently a big-game haunt of the best description. 
On getting back I found my tent pitched, and was just going to call for food when I heard the shouting of machilla men in the distance, and soon saw them coming round a bend in a path. A machilla is a hammock on one or two poles.

Then I saw a tall white man walking behind, and soon they arrived at my camp, and turned out to be Mr. and Mrs. Barns, who had camped here before, and since then had been shooting in another locality.

My cook soon added to the lunch, and while we were eating it we talked about shooting experiences.

In the evening I went out and shot two bull elands, each falling to a single $7.9 \mathrm{~mm}$. bullet, although I gave each of them a finishing shot to put them out of pain. These elands were with a herd consisting of quite I50 animals, one of the largest herds of elands I have ever seen. I could have shot several more had I wished to do so, as they were quite tame and would hardly clear out. Those I had shot were both full-sized bulls, one slightly larger than the other, and I gave one to Mr. Barns and kept the other for my men. Neither was very fat, and it is quite impossible to tell whether an animal will have plenty of inside fat until it is cut up. Many beasts that look fat will not have any inside fat, and others that look thin may be full of it. This fat is found round the heart and kidneys, and the intestines are often covered with it. It should be kept as clean as possible, and I get the natives to put it in the hide and transport it to camp in that way.

In cutting up a carcass the natives are usually very careless, and they do not seem to mind dirt getting on the meat, although, of course, when this happens it can be washed off.

Meat does not keep well when it gets wet, and no water should be put on the fat, as this is apt to make it go rancid when boiled and rendered down.

It is useful, when cutting up an animal, to take note of the exact position of the vital organs, such as the heart, lungs, liver, and kidneys, as a knowledge of their positions 
is a great help in directing a bullet for a killing shot. Naturally, when a beast is lying on its side all the organs mentioned will incline downwards with their weight, but a very good idea can be got of their natural positions, and this is a great help to good killing, and I advise young sportsmen to study the matter.

On the 8th I had a long walk round Matisi dambo, where there was water, and near there I found the tracks of a small bull and a cow elephant. These tracks I followed for some distance until I found that the animals had joined a small herd of cows, and as the bull, judging by his spoor, was not worth shooting, I left them and did a long round to look for the tracks of a bigger animal.

After travelling many miles through some very rough, thorny country, I again found the spoor of the same two elephants, which I followed again for a short distance, thinking that they might be joined by a bigger animal. About midday, having seen nothing, and finding I was not far from camp, I made for it, and found lunch awaiting me.

On this day the sun was scorching hot, and the ground was covered with small, thorny bushes, which were very hard on bare legs, and I arrived back with many scratches.

As two men should not camp together, I left next morning for Maponda's village, although, by the unwritten rules of sport, it was Mr. Barns's duty to move on when he found me in camp. However, Mrs. Barns was feeling unwell, so I did the moving to save her the trouble and exertion.

On the eight miles' tramp to Maponda's I found the night spoor of a lion on the path in some sand, but, when he got on hard ground, no traces of his passage were visible. I also saw the tolerably fresh spoor of a herd of buffaloes, but I was not feeling quite fit enough to start after them. Besides these tracks there was plenty of eland and roan spoor about, and I saw some reedbuck and a warthog, which all bolted before I could get a shot.

On the Ioth I had a good try to find another elephant, and did a round of a good twenty miles, and 
went through some very likely country, but was not lucky enough to find any spoor fresh enough to follow.

In a dambo I found the carcass of a young eland which had been killed by a lion two nights before, and, strange to say, the lion had only eaten a small part of it, and had not returned the next night. If the moon had been good I would have made a machan near; but, as it was a long way from camp and the kill was old, I did not think it worth while.

When I got back to camp I had some food and a smoke, and then decided to return to my home on the Bua River, so I packed up and got home by sundown, having covered fifteen miles, which made a total of a good thirty-five miles for the day's walk.

From the path I saw a fine black bull sable a long way off, and he evidently saw me or the porters almost at the same instant, as he started off for safer quarters at once.

For the next few weeks I did not do much hunting, as I wished to give the game a rest, and the weather was terrifically hot and sultry, and I was not feeling too fit.

The heat was not so bad as the Luangwa or Zambesi valleys are in September, October, and November; but it was bad enough, and I have gone through so much heat that I find I cannot stand it as well as I used to do.

However, as my boys kept asking me for some fresh meat, and I also wanted some for myself, I went out on November I and came on a large herd of hartebeest, out of which I shot three animals.

At this time of year many dust devils (whirlwinds) are seen, and sometimes these are so strong that leaves and grass are taken high up into the air. Once, when coming from Tete to Fort Jameson, I was lying on my camp-bed at midday, with a pocket handkerchief lying on my body. A dust devil came along and picked up the handkerchief and took it out of sight. I fancy that many small birds are killed in these whirlwinds; especially cheepers that have not become strong and well feathered. 
Early in December I heard from a native that there were some hippo in the Bua, near Pinda's village, about twelve miles off, so on the $4^{\text {th }}$ of that month I got a few men and went off to try to find them.

As I made a very early start, I reached Pinda's about I0.30 a.m., and the native who had told me of the hippo, a man named Mankanga, went off with a few of the villagers to try to locate the animals, and I sat smoking and watching the natives at their daily tasks of pounding flour, making baskets, attending to their children, and other duties.

Soon Mankanga came back and told me there was a big hippo in a pool only a few hundred yards away, so I took my rifle and cartridge bag and followed him.

There was an anthill about fifteen yards from the bank, surrounded by papyrus and grass, and a few bushes grew out of this anthill forming good cover, so I got Mankanga to carry me through the water and mud to the place.

On getting on the top of the anthill, I soon saw the reddish brown head of the hippo in the middle of the deep pool, so I tried to get my $7.9 \mathrm{~mm}$. solid bullet under his ear, as he was nearly full side on.

The bullet hit with that distinct crack that is often heard when a heavy-boned animal is struck fairly in the head, and this sound is unlike the soft "phut" of a bullet hitting a thin-skinned beast behind the shoulder.

- I made a bad shot, however, for I saw by the way the hippo sank that he was not killed, as he splashed a good deal. When a hippo is killed in the water he usually sinks quietly without making any splash or commotion.

My bullet must have caused the poor beast great pain, for it immediately began to make the most extraordinary contortions, coming up and going down, and swimming in circles. Every time it came round 1 waited for the shot at the back of its head, and hit it four times out of five shots, one bullet going just over, as I was not quite quick enough. The sixth shot found the exact spot, and, as I have shot a good number of hippo in the past, I knew I had killed him, as he quietly disappeared beneath the surface. 
The sun and water were warm, and I thought he would come to the surface in less than two hours, so I went back to the village and attacked the lunch my cook Yakobo had prepared. After I had fared I attended to some bad blisters on my feet, and when I was busy at this Mankanga, whom I had left to watch, came and told me that the hippo had risen. I looked at my watch and found that the time this animal had remained below water was less than an hour. Once in the Zambesi I shot four hippo which came up in about the same time, and, again, I have known others to remain below the surface for over five hours. It depends on several conditions. Great heat and the fatness of a hippo make it rise quickly. A cold atmosphere, cold water, and a thin poor condition may keep a hippo under for several hours. Heat causes gas to generate more quickly in the stomach and entrails, and this causes buoyancy.

Some men then offered to swim out and attach a long bark rope to one of the hippo's legs, but, before allowing them to do so, I asked several of the villagers whether there were any crocodiles in this part of the Bua, for I knew that some parts were infested with these loathsome creatures, and some nine years before I had foolishly stood in the Bua almost up to my armpits shooting at hippo.

On that occasion some creature scraped against my bare legs and made me get out of the water very quickly. It may only have been a fish or a water turtle, but the following day, on getting a hippo out, I found that its skin was scored with the teeth of crocodiles, so I cannot help thinking that a small crocodile intended to seize one of my legs and may have been frightened by a movement or their white colour.

Anyhow, I have never again risked standing long in a river where I knew there were crocodiles, nor have I allowed my natives to take such risks.

If several men go in together and splash hard they frighten the crocodiles away, and on this occasion I told two 


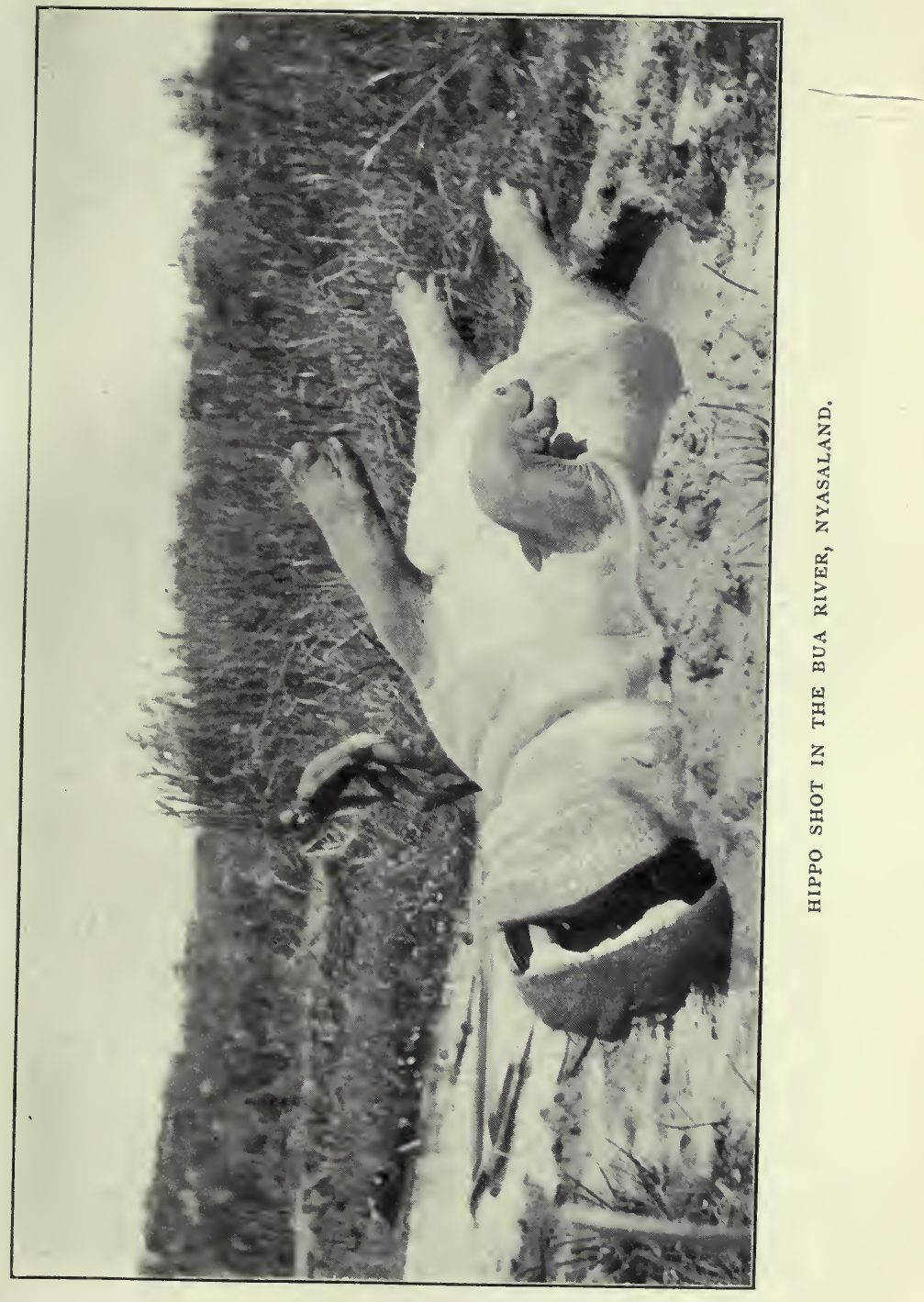


of the three men to keep on splashing hard, while the third was busy tying on the bark rope to one of the hippo's legs.

At first they were doubtful as to whether the hippo was dead, but I assured them it was, and said I would stand by with my rifle, which I did because I was not so sure about the crocodiles.

It took some time to make the rope fast, and as long to manœuvre the dead hippo to my side, as the papyrus grass kept catching the rope, and it broke several times. The bank was rather steep where I wished to get the hippo ashore, and, although over fifty men got hold, they could not get it up a muddy ledge, so I cut slits in the hide and passed a long pole through the gaps under the skin. This gave the men a good grip, and they then dragged the animal to where I wanted it.

As it was now 4 p.m., I knew, if I once began cutting it up, that natives would come in the dark and help themselves; so I told them they would have to wait until next morning, when I would reward all who had helped with plenty of meat.

Then I got some men and started off for a walk in the surrounding bush. Game was evidently plentiful, but I found it very wary, as several white men had been shooting there, and the natives are constantly ranging the country with their dogs in search of pig and small buck.

I saw a waterbuck, which I tried to stalk, but he went off, and so did a herd of hartebeest and a few reedbuck that I saw later. It was noticeable that the game had been much scared lately.

The sky was black, and the air had that sultry and oppressive feeling that portends an approaching storm, so when I got back to the path I made a. run for the village and got there just as the storm broke.

It rained hard for over two hours, and the earth could not take in the great quantity of water, so it soon looked like a lake, and all hollows became rushing torrents. 
The next day I returned lome; there were no more hippo about and elephants seemed scarce, as I had only seen some very old tracks.

Before closing this chapter I would like to give my reader some idea as to the damage elephants are capable of doing to native crops.

The late Mr. G. P. Sanderson, author of "Thirteen Years Among the Wild Beasts of India," in that volume gives details about the appetite of Indian elephants, and, as the African species is larger, their daily rations will be as great, if not greater. Sanderson had great experience of Indian elephants, as for years he was in charge of the Government keddahs in different districts in India, and he made a special study of their habits.

He remarks that an ordinary elephant will consume 6 oolb. to $700 \mathrm{lb}$. of green fodder in eighteen hours, and that a big tusker can dispose of quite 8 oolb.

Let us take the figure 7oolb. as the average amount for a single elephant in twenty-four hours; then a herd consisting of thirty animals, not an exceptionally large herd in parts of Africa, would eat 2 r,onolb. weight of green stuff every day.

This is a large amount to be consumed daily, or rather nightly, for elephants, although they often ravage native crops in daylight, prefer the night as a rule. It can, therefore, be easily imagined that in districts where elephants are numerous the damage they do may cause famine among the natives.

Hippos also do great damage to the native gardens, and near large rivers they leave the water at night and feed on the green crops, and, as they weigh about half as much as an elephant, we may calculate that a single hippo can eat 35 olb. of fodder during a night's feeding.

Then, other game, such as eland, kudu, sable, roan, and hartebeest, all invade native gardens and do great damage. A herd of eland can eat and destroy just as much grain as would a herd of large cattle.

In this district (Central Angoniland) elands are very plentiful, and the natives have to make strong fences to 
keep them out of the fields, but they push these down and find an entrance, and commit great havoc among the green crops.

Pigs are extremely destructive, and they are particularly fond of rooting up ground nuts and sweet potatoes; and all the smaller game animals, such as bushbuck and duiker, have a tendency to invade the native fields.

The natives, therefore, have to stand all this without the chance of reprisals, except against the smaller game, which can be hunted and killed with the help of their dogs and spears.

In parts of Nyasaland and North-Eastern Rhodesia these garden-feeding elephants get very dangerous, and, as the natives run from them whenever they are seen, they lose their natural fear of man and are inclined to become most troublesome.

I have been charged twice by garden-feeding elephants, and on both occasions I stood my ground and shot as carefully as possible. One of these bull elephants fell within fifteen yards of where I was standing, and I stopped the other and killed him with a lung shot as he swerved and gave me the sight of his shoulder.

Neither Nyasaland nor North-Eastern Rhodesia has a game warden, and it is time they did, not only to help the natives, but to supervise the game country and the more valuable game, and also to see that white poachers do not exceed the number of game allowed on their licences.

In British East Africa the game is now treated as a valuable asset, and there is a game warden and a number of game rangers; but I believe there are not enough to keep their eyes on such a vast extent of country, and much poaching and game slaughter occurs, principally by Boers from South Africa. The Boer is usually a fine, manly fellow; but no one can deny that he is a fearful slaughterer of animal life. I have met many Boers in Cape Colony, Natal, and Southern Rhodesia, and seen a few in British East Africa; but I never met one that was a true sports- 
man at heart-that is, a man who was interested in wild life from a natural history point of view. Their one idea is to kill, and they only keep a few skins and heads good enough to sell. They seldom take an interest in game trophies, except when they expect to get a few shillings for a good pair of horns, and very few take the slightest interest in field natural history.

Some of them are good shots, and many of them are good hunters as far as the killing goes; but few are good sportsmen, and the authorities should make an example of some of the worst of them and send them back to South Africa, where they have left little game to slaughter. Doubtless there are many Britishers whose methods are quite as bad as the Boers', and similar treatment should be meted out to them, for they are a nuisance of the worst description.

However, British East Africa has at least one very large reserve where the game is protected, but the settlers now think that land so near the railway should be opened for settlement; and doubtless in time they will manage, through legislation, to get rid of the large southern game reserve, which would be a mistake, I think.

Reserves which are far from communications are difficult to supervise, and it will be a pity if this splendid haunt of wild life is done away with.

Nyasaland and North-Eastern Rhodesia being well bushed countries, the game has a better chance of survival, and luckily there are no Boers there yet; but I think the Governments of these territories should try and protect the game by appointing game wardens in each territory. All licences issued should pass through their hands, and the power of refusing a "big-game" licence should be given to them. Also they should be given full authority to arrest poachers, either white or black, and any such case should be tried by the magistrates.

In these countries a great outcry has been made against the game, as it is supposed to tend to the increase and spread of sleeping sickness. 
The only thing to do in this case is to deport the native inhabitants and leave these areas vacant for some years, when the disease would die out. It is useless expecting that the game can be exterminated in such vast stretches of country, for an army of good shots would make little difference to it. Doubtless many animals would be killed, but the majority of the game would only leave for pastures new, and this, instead of getting rid of the disease, would only tend to spread it through the country.

If some contagious disease could be discovered to sweep away the tsetse flies, this would be the best way, but that seems almost impossible; so the natives should be moved, and, before being sent to another district, they could be carefully examined and segregated for a certain time in camps under medical supervision.

The extermination of game in a short space of time is absolutely impossible in such countries as Nyasaland and Northern Rhodesia, for these are heavily bushed and grassed regions, and game, when much molested, simply moves on until it discovers a locality where it is safe from molestation.

Those who agitate for the slaughter of game should bear this point in mind, and remember that tropical Africa is not a country of open plains like many parts of Southern Africa, where it was a comparatively easy matter to exterminate the game.

In any country where game can be hunted on horseback it would not take long to exterminate it or drive it into other districts; but in Nyasaland and Northern Rhodesia this could not be done, as the vegetation is too dense. Moreover, horses cannot be used for hunting there, as they cannot stand the climate and the bites of the tsetse flies, without dying very quickly of horse sickness. 


\section{CHAPTER V.}

\section{The Risks of Big-Game Shooting.}

The risks of big-game shooting-Causes of accidents-Men handicapped formerly with inferior weapons-Pluck of old hunters-Killing powers of modern weapons-Selous's adventures-Neumann injured by cow elephant-Captain C. H. Stigand's experiences with wild beastsSportsmen killed by elephants and buffaloes-Mr. George Grey's death -A large bag of lions made by Mr. L. Tarlton-Mr. George Garden attacked and injured by an elephant-Other deaths mentioned and possible causes of accidents-Buffaloes hard to stop-Native woman killed by lion near Zomba-Lion tragedies-Courage of some nativesNative ideas as to good killing rifles.

MANY men have been killed or injured by wild animals, and many more are likely to suffer in the same way so long as they continue taking the risks inseparable from hunting great game.

There is a saying that if only a man keeps it up long enough he is bound, sooner or later, to meet with misfortune; but if there were no risks, there would be no excitement in it.

Because a man is killed by a wild animal it does not follow that he was inexperienced, as he probably did all that a man could do, and yet suffered. His might be looked on as an exceptional case which helps to prove the rule, if any rule, in such an instance, can be laid down.

An accident is usually due to one or other of the following four causes, which I would put as follows :

(I) Recklessness and contempt of danger.

(2) Uncertain or long shots.

(3) Inferior weapons with insufficient stopping power.

(4) Ignorance of the game and its habits.

Formerly men were very heavily handicapped by having to use inferior weapons, for who can compare a single 
or double muzzle-loading rifle or smooth bore with the splendid weapons that can be procured at the present day. Imagine standing up to a growling lion or a shrieking elephant with one of these old weapons and having to keep one's wits about one while the powder was first put in, then the bullet rammed home, and, lastly, fumbling in a pouch or pocket for a minute cap to place on the nipple, before the shot could be fired. This all required a nerve that the modern sportsman does not require to display with his double hammerless ejector or quick-loading magazine rifle.

Take the old single 4-bore smooth bore, for instance, which I have handled in Mr. Selous's museum at Worplesdon, and imagine killing a crusty elephant or buffalo with it. The weight was little considering the charge it fired, so it must have kicked like a stubborn mule; more especially when it was dirty.

After showing me this prehistoric weapon and some of the trophies it and other old weapons had shot, Mr. Selous took me to his library and showed me his 375 cordite rifle. What a difference there was in the two weapons; and it made me think that not nearly so many men would hunt game at the present day, if they had to use these old muzzleloaders.

The old hunters, such as Oswell, Gordon Cumming, Baldwin, Selous, and many others certainly were men of courage and endurance, or they would not have done what they did.

A modern rifle of 450 or 470 bore has a much more paralysing effect on an elephant, rhino, or buffalo than had a 4 -bore or 8-bore rifle, be it a muzzle-loader or a breechloader, and, of course, the former high velocity rifles have the additional advantage of being quickly reloaded after being fired.

Although I have possessed $a^{\circ}+50$ cordite rifle, I have killed the few elephants I have shot with either a 303 or a $7.9 \mathrm{~mm}$. rifle, but there is no doubt that, if a man intends to shoot many elephants, these small bores are dangerous 
weapons to use continually, as their stopping power is not great enough.

Personally, as a man cannot shoot unlimited elephants nowadays in any British protectorate or colony, I find that I can kill elephants best with the rifle I use continually on smaller game, and that a small bullet in the right place is much better than a large bullet in the wrong place.

A friend who uses a $45^{\circ}$ No. 2 bore tells me that when hit well forward an elephant is practically anchored, as the shock to his system seems to take away all power of movement.

The $7: 9 \mathrm{~mm}$. Mauser rifles with a long, blunt bullet have tremendous penetration, for I once fired a solid at an mbawa (mahogany) tree, quite $2 \mathrm{ft}$. in diameter. The bullet went clean through it, and doubtless had sufficient velocity to kill a man after that. For head shots at elephant and hippo nothing can beat such a rifle, and they are infinitely superior to a weapon firing a light, pointed bullet, which will likely get bent and zigzag all over the place.

For killing soft-skinned game there are many good types of bullets, such as hollow-pointed, soft-nose, "Dum-Dum," and slit. The soft-nose and slit expand more readily than the hollow point and Dum-Dum, and the two latter types are much the best for buffalo and eland.

I will now mention a few incidents and accidents that have occurred to big-game hunters, and I will begin with Mr. F. C. Selous, certainly the most noted of living biggame sportsmen. As I have mentioned, he began his shooting career in Africa by using large 4-bore smooth bores (called by the Dutch "Roers"), and then he mentions using a ro-bore breechloader. One day, being unwell, he followed a herd of elephants with a $46 \mathrm{r}$ Gibbs falling block single rifle, using, I think, a solid bullet of 570grs. weight.

He killed five elephants and wounded a sixth, which he found a few weeks afterwards. He also mentions in his book "A Hunter's Wanderings in Africa" having 
killed rhinos, hippos, and lions quite easily with the same rifle, using, for them, a 36 ogrs. expanding bullet with a small hollow in the point. Mr F. Vaughan-Kirby-has also used these "46 I Metford rifles and speaks very highly of them in his "In Haunts of Wild Game," and in other volumes. There is no doubt that they were most excellent killing weapons, and much ahead of the ordinary black powder Express rifles of 450 and $\cdot 500$ bore that were used about the same period. The $45^{\circ}$ Express fired a very light bullet of 27 ogrs. with an abnormally large hollow in the point which extended to within a quarter of an inch of the base. Driven by 4 drs. to 5 drs. of powder, this bullet used often to fly into small splinters on striking the skin of a big antelope, or it would penetrate for an inch or two and then hit a bone and fly to bits.

A good many Indian sportsmen were killed by tigers when using these inferior weapons, and if they had been armed with a $46 \mathrm{r}$ of the type mentioned they would likely not have suffered. Mr. Selous quickly found out that a small bore (all rifles under 577 were then called small bores), used with a bullet either completely solid or with a good solid base behind the hollow in the point, was a thoroughly reliable weapon; so, when the $\cdot 303$ sporting rifle came into vogue, he soon got one and used it in Mashonaland and Matabeleland, and also on American game, with good results. He then tried a $\cdot 256$ Mannlicher, but doubtless found, as others and I have done, that it is rather too small in the bore for a good sporting rifle.

Then he got a 375 cordite rifle and has done good work with it, and I read in the Field that when recently in British East Africa he used a $\cdot 275$ and a 425 magazine rifle. During his many hunting experiences he has had several very narrow escapes from lions, elephants, and buffaloes. He was once knocked off his horse by a cow elephant and stunned by the shock.

When he came to his senses he mentions that he became aware of a strong smell of elephant. After a hard struggle he managed to release himself, and got away. 
He afterwards found that his horse had received a severe wound in the buttock from the elephant's tusk, but I think it eventually recovered. Again, a buffalo knocked his horse down, and Selous fell right under its horns. The buffalo then attacked him, and he managed to throw himself to one side and escape the main force of the blow, although he got a painful glancing blow which nearly dislocated his shoulder.

Then the buffalo left him, which it would not likely have done had it been badly wounded. The poor horse had received a terrible wound in the body, and Selous had to put it out of its pain by shooting it.

Again, in British East Africa, a buffalo charged and missed him, but got one of his gunbearers and gave him a severe blow which nearly killed him; as it was, the buffalo's horn broke to pieces a pair of prism glasses which the native had slung round his shoulders.

On another occasion a lion charged right up to him, and would doubtless have mauled him had he not stood his ground. In such a long career of hunting he has had many other narrow escapes, and he likely owes his escapes to very good nerves, agility, and great experience.

A great hunter of elephants and other game was the late Mr. Arthur H. Neumann, and he probably shot at least twice as many elephants as any man has done. I am aware there are several men who have shot from 300 to 500 of these animals, but I believe that Mr. Neumann shot about 1000 of them. Lately a book has appeared by Mr. Sutherland, and in a review of this book I read that he has shot 447 elephants, which is a great score.

Mr. Neumann had one very narrow escape from a cow elephant in British East Africa. He had wounded her with a 303 Lee-Metford, and she then attacked him. The magazine refused to act, and the animal knocked him down and drove one of its tusks through the biceps of one arm, at the same time injuring his ribs. He was not far from Lake Rudolf at the time, and he lay ill for a long time afterwards, but recovered to bag several 
more fine bulls with the same rifle. This accident was entirely due to the faulty construction of the early 303 rifles, for had he been able to load he would have doubtless killed, or at least have turned, this elephant. $\mathrm{He}$ mentions using a ro-bore and a 577 Express with solid bullets, with good effect, and I believe during the latter part of his life that he used a $45^{\circ}$ cordite rifle, and found that it killed elephants better than any rifle he had ever previously used. Neumann has left a great reputation in British East Africa, both among the whites and natives. I met a man who knew him intimately, and he told me that Neumann was a strange, silent man who had a great love of loneliness and the wilderness. He left one volume of his adventures entitled "Elephant Hunting in East Equatorial Africa," and those who have not read it should do so, as it is a book well worth perusal. Like most good hunters, Neumann did not embellish his writing with fanciful matter, and all he wrote is solid fact; so it is a lasting pity that he did not leave big-game shooters further accounts of his adventures, as they would have been most interesting reading.

Neumann was, I believe, an excellent game shot, and it was his custom to get pretty close to the animal he wished to shoot; and it is really safer to do this than to fire long uncertain shots, which are likely to wound, with the result that the elephant has to be followed up in thick cover, for all wounded animals take to the thickest cover they can find, which is infinitely more dangerous than going to within, say, twenty yards of an unwounded beast. For the brain shot it is absolutely essential to get close, or one will not be able to see exactly where to shoot, or the true angle at which the beast is standing. For the heart shot, much the best, really, sixty yards is a good distance. When elephants are in herds it is a mistake to go closer than this, as in their fright they run all over the place, and, unless there were some large trees about, it would be difficult to escape being trampled on. As I think I have mentioned, an elephant's brain is very small, considering 
the size of the skull and the mass of surrounding bone, ana it means shooting at an object not larger than $\mathrm{r} 2 \mathrm{in}$. by $6 \mathrm{in}$.; and, moreover, when one considers that this mark is completely hidden in the centre of the head, it shows how experienced a man must be to make good work with the brain shot.

An elephant's heart is about the length of an ordinarysized cushion, so it is not hard to hit. It lies half-way up, or down, the body, whichever way one looks at it-that is, it is fairly central in the cavity of the chest, and it lies right between the two shoulders.

If a man is standing slightly to the rear, then the shot should be placed behind the shoulder; if broadside on, then the bullet should be aimed right through the shoulder. Of course, solid bullets should always be used, as penetration is the great object to be desired.

I have heard of no man who has suffered such narrow escapes from wild beasts as has Captain C. H. Stigand, for while in Nyasaland he was nearly killed by a black rhinoceros, which gored him in the chest. If the wound had penetrated a little deeper it would have reached his heart. This rhino charged him unawares, which is an unusual thing for a rhino to do, as they do not always charge even when wounded, except in parts of British East Africa, where the rhinos, I have read, often charge when they see a human being, without waiting to be shot at.

Then, soon after the goring from the rhino, the same gentleman went to British East Africa and was badly mauled by a lion. He sat up for lions close to Simba railway station, on the Uganda railway, and he shot three of them. One was only wounded, and he got down from the platform and approached it. A charge immediately followed, and Captain Stigand, although he hit the lion in the chest with his ${ }^{2} 256$ Mannlicher, failed to stop or turn it. It seized him by the left wrist, and he fell with the lion on the top of him. His rifle was now useless, and with his right hand he could not reach a sheath knife he had on his belt, so he did the next best thing and began to punch its 
head. He found afterwards that his first bullet had broken its lower jaw, and the pain made it shift its grip further up his arm. Captain Stigand, being a powerful man, kept striking the beast with his fist, and at last it left him and went off. He managed to get to the small railway station, and, having some permanganate of potash handy, he put some of the crystals into the bites. Next day a train came along and took him to Nairobi, where he was ill for some time. If he had not used the permanganate I believe he would have lost his arm. I may mention that the lion was finished off from the train the same day, as it was seen lying quite close. Its skin, which I saw in London afterwards, was riddled with bullet-holes, and the skull showed the broken lower jaw, the result of the first shot. I cannot say I admire the men who peppered this lion from the railway carriage by daylight, considering that a single man followed it at night. This, although a courageous proceeding, cannot be recommended, for the simple reason that the odds are too much against the man, as it is quite impossible to make good shooting with a rifle when the sights are invisible.

A year or two before these events took place Captain Stigand was knocked down by a wounded elephant in North-Eastern Rhodesia, and his clothes were covered with blood from the animal's mouth and trunk. On this occasion he managed to escape the notice of the animal by lying quiet, almost right underneath it, and I believe he eventually followed up and killed it. Again, he was upset in the Nile by a hippo, which, I think he mentions in one of his books, badly bit one of the boatmen.

I read in the Field of January 25, I9r3, that Captain Stigand has been very badly injured by a bull elephant in the Sudan. It seems he was not hunting it, but trying to drive it from the natives' gardens, when it attacked him and put one of its tusks through his thigh, and then threw him some distance. All who know him, or of him, will be glad to hear he has recovered from the serious injuries he received. 
I hope he will not feel annoyed with me for describing his adventures with wild beasts; but as he refrains from mentioning these facts in his own writings, I see no reason why they should not be put on record, especially as some people who have mentioned them make mistakes in the details.

Since I have lived in Central Africa a good number of sportsmen have been killed by elephants, and a sad case was that of a Mr. Johnstone, who was killed about the year 1904, near the Luangwa river, in North-Eastern Rhodesia, by a big bull elephant he had wounded and followed up. I heard the evidence taken down which was given by some of his boys.

He wounded this elephant, and, on following, came up to it and gave it several more bullets. It then attacked him and knocked him down, and, in killing him, it broke one of its tusks into several pieces. I expect the ground was hard or rocky, and, when it struck, the tusk went right through him and hit the hard ground. Some of the natives said it also tore him in pieces, but I cannot say whether this is correct, though cases have been known of elephants treating a body in this way. Anyhow, he was in a frightful state, and his remains were brought to the native commissioner at Nawalia, and are buried there. This station has now been abandoned, and I expect the grave is untended and overgrown with vegetation. Such has been the fate of several other men I knew or have heard of.

Mr. Shaw, of the King's African Rifles, was badly hurt by a wounded elephant in Nyasaland, and he was taken to Fort Jameson hospital, twenty-two miles off, where he died shortly afterwards. This was his first elephant, and it is possible he may have acted recklessly in following it. However, men of great experience have been killed, for a Mr. Goddard, who had shot I io elephants, was killed by the next one he fired at. I have been told that he felt his nerve going and had a presentiment that he would come to grief soon, and so it happened. 
Then a Mr. Tilden, an American cotton planter near the Luangwa river, was killed by an elephant which he had hit and was following up. Perhaps these last three accidents occured through carelessness with the first shot. It is without doubt the all-important one, for it is usually taken when the animal is standing. If a man cannot shoot straight then, the chances are very much against him doing so with subsequent shots, especially if they are taken at an elephant running.

A few years ago a Mr. Crosby was killed on the western border of North-Eastern Rhodesia by a bull buffalo which he had wounded and followed. I was told that he knew his 303 rifle was in bad order and sometimes missed fire, and yet he had the temerity to follow one of the most dangerous beasts in Africa with such a weapon. He came on the buffalo suddenly on rounding an anthill, and it charged at once, knocked him down, and practically disembowelled him, as well as smashing his head to pieces. He had never shot a buffalo before, and doubtless did not exercise due care in following such a dangerous animal. Most experienced hunters, instead of approaching the anthill, would have given it a wide berth to one side, so as to see behind it, though, of course, it is an easy matter to talk $\mathrm{k}^{\circ}$ or write of an incident that one does not know the exact details of. However, the mere fact that he knew his rifle was out of order ought to have made him exceptionally cautious in following such an animal.

In such circumstances a man should spare a thought for his relatives when he is engaged on such a business, for the pain of his own death may not be so great as the indirect suffering it may cause to others, and, besides, as I have remarked before, no man goes after game with the object of being killed.

The intense and thrilling excitement of following a dangerous wounded animal, when undergone on many occasions, has usually one of two effects on the human nerves. It either makes a man all the keener to experience this excitement whenever the opportunity offers, or it has 
the opposite effect of shattering his nerve and making him shoot badly.

Some men feel more excitement before they see the animal they are following than they do when they get to close quarters, as they then quieten down and act coolly, and forget all about the excitement in the effort to put a good shot in and end the matter. This is the way with myself; and although I have hardly had any experience with lions or leopards, I have shot a few elephant, rhino, and buffalo, and I find I am much more excited when tracking one of these creatures than I am when I get close enough for my shot. Personally, I have had much more narrow escapes from snakes than I have had from any wild animal, and not long ago I was nearly struck by lightning, which raised a small cloud of steam from the wet earth not very far from where I was standing. Although I felt a slight tingling sensation in my feet and hands, I did not feel excited in any way, probably because I knew the danger was over when the flash had reached the ground.

Doubtless some men retain an even temperament from start to finish, and it is beyond them to feel excitement in any way, as they probably were born with little sensitiveness in body or mind.

Most of us have heard of the famous general who was a proud possessor of the Victoria Cross, which he won in the Indian Mutiny. He passed through dreadful scenes of human slaughter, and yet he admitted that he sometimes fainted at the sight of a cut finger or a spot or two of blood. Yet his mental strength subordinated his actions, so that he could face the thing his instinct loathed. So it is with all risks, and if a man possesses a strong enough mind he can subdue all sense of fear. Of course, when a thing is done many times, the mind and body become accustomed to the matter.

Some boys may be afraid to sleep in the dark, and yet may accustom themselves to do so; and many girls may be in a terror when they see a mouse or a rat, and get over it if they have to live where such vermin are plentiful. 
Centuries back, when the ancestors of Britons lived in caves and huts, what terror must have been theirs at times-at least, so some people believe; although I do not. For I imagine their nerves were dull and blunt like the nerves of the blacks of Africa, and they did not feel terror unti. danger was actually present.

African natives seldom dread peril until it is on them, as their minds are not sensitive, neither are their nerves so highly strung as those of the more civilised whites. Certainly the superstition that enwrapped the minds of early Britons must have always been a menace to them, just as the natives of Africa and other countries suffer to day. Unseen and imaginary fears often envelop them, and take away all power of reason or logical thought.

One of the saddest accidents to a white sportsman that has occurred for many years was that which befell the late Mr. George Grey, who was killed in British East Africa by a lion he had wounded. It charged, and he failed to stop it with a $\cdot 256$ Magnum rifle, although I believe it was hit several times.

I certainly believe that had he been using a stronger rifle, such as 350 or 450 , with heavy, blunt, expanding bullets, that he would not have been killed. Even a $7.9 \mathrm{~mm}$. Mauser would have been an infinitely better rifle than the $\cdot 256$, with its tremendous velocity and sharp, light bullet, which is most likely to fly to bits on striking hard substances. Further, at such a short distance the bullet is all the more liable to break up, and these modern ultra high-velocity rifles, with their light bullets, are simply a repetition of the old Express '450's, with their useless projectiles.

Mr. George Grey was known and liked all over Africa and in the Matabele Rebellion he did some splendid work. I think his action of going round by himself and warning the Colonists of danger from the natives was one of the finest deeds in African history.

Then he raised a corps which was named after him as "Grey's Scouts," and this band took a prominent place in 
quelling the rebellion, under the leadership of Mr. Grey, and other fine officers, among whom was Mr. Crewe, a most gallant fellow.

After that Mr. Grey took over the managership of the Tanganyika Concessions, a company which owns large copper properties in the Congo, and I have heard from many men who knew him of his fine work there. He thought nothing of starting off by himself with a blanket and a rifle, and riding a bicycle along bush paths for hundreds of miles, when he was engaged on urgent business. He was full of energy, and it seems a lasting pity that such a fine specimen of a Britisher should meet 'with a premature end in the way he did, and simply because he was using an inferior type of weapon. Because these $\cdot 256$ 's and ' 280 's are splendid military or target rifles is no reason that they are the best for sporting purposes.

Any medium-bore high-velocity rifle, such as a $35^{\circ}, \cdot 360$, or 375 , would be infinitely better, as they shoot heavy, blunt bullets.

One of the largest bags of lions made in British East Africa is that of Mr. Leslie Tarlton, and I believe he has shot fifty-four. He liked the 350 old pattern, with 3 io grains bullet, but found that the new 350 Magnum had the same fault as the $\cdot 280$, as the bullet is too light and it breaks up too readily. However, in a letter to me, Messrs. John Rigby and Co. said that they had now improved the bullets for this rifle. Very wisely they make the solids for the 350 Magnum with the ordinary blunt points; but 225 grains is rather light for the bore.

A good rifle has lately been brought out by Messis. Holland and Holland of 375 bore, with a very high velocity, but at the same time plenty of striking energy, and blunt nosed bullets can be used from it as well as sharp pointed projectiles.

In a few years the best gunmakers will stop supplying sharp pointed bullets for sporting purposes, and really "the sooner the better," for the most practical men object to using them, as they are unreliable. 
Even when using a good type of rifle and bullet an accident may happen, and Mr. George Garden, of Mlanje, in Nyasaland, was badly damaged by an elephant a few years ago in the Barue country, in Portuguese territory, south of the Zambesi. An elephant charged him, and, as he did not wish to kill it, the tusks being poor, he fired at its mouth with a $45^{\circ}$ No. 2 nitro rifle. The shock neither stopped nor turned it, and he was knocked down and his rifle sent flying. The elephant pommelled him badly with the base of its trunk and forehead, but, fortunately, did not trample on him or seize him with its trunk. It then left him, and was found dead some time afterwards. My friend had a bad time, as he was far from civilisation when the accident occurred, although he eventually recovered, and has killed several good elephants since with the same rifle. It is only necessary to read old sporting books to see that the heaviest rifles that can be procured will not necessarily stop an animal like an elephant.

In Central Africa all hunting is done on foot, as horses cannot be taken into tsetse-fly country, and, moreover, the country is not suitable for these animals, as they soon die of sickness.

It also costs a great deal to import them and get them transported from the deadly climate of the coast to the higher and more healthy country of the interior, so, except for a few animals found here and there, such as in Zomba, Blantyre, or Fort Jameson, none of these quadrupeds are used. There are a good many donkeys in the country. These animals being much tougher than horses in resisting bad climates and disease, they are more commonly used.

A very serious accident happened to a Mr. de Fries, on whom a wounded buffalo inflicted most severe injuries. He was ill for a long time, and he imust have had a good constitution to recover from the bad wounds he received on that occasion.

A short time ago I read of the death of Mr. Hubert Latham, who won a great name as a daring aviator. $\mathrm{He}$ seems to have been one of those plucky men who live for 
nothing but excitement. He was killed in the French Congo, and, owing to his daring and reckless nature, he doubtless took risks that may not have been necessary. Still, he was a very experienced big-game hunter, and in such cases it is very difficult to get the full details. In thick country it is often impossible to move at all, and the surrounding reeds or thick jungle may prevent a man using his rifle quickly in an emergency. Again, a misfire may occur or a cartridge may jam in the chamber at a critical moment, and leave a man practically unarmed and unable to defend himself.

In a fairly recent copy of the Field was the news of the death of Mr R. P. Fuller-Maitland, who was killed by a bull elephant in British East Africa, not far from Lake Baringo. He was a very young man, and it is most unfortunate for the sufferer and his relatives that such a life should be cut off in such an untimely fashion; but this is the price we pay for our love of wild sport, and those may be termed the lucky ones who live through many dangerous adventures with wild beasts.

A German officer, Lieutenant O. Graetz, who travelled by a motor-boat through some of the rivers and lakes of Central Africa, was tossed by a wounded buffalo while passing through the Chambesi River. He sustained a severe and painful wound in his cheek, which was torn open by the buffalo's horn. Worse luck, however, befell his companion, a young Frenchman named Mr. Octave Fiere, for the buffalo killed him at the same time, after mutilating his body in a dreadful manner.

Naturally, Lieutenant Graetz now considers the buffalo the most dangerous animal in Africa, although authorities such as Selous put it third; giving first place to the lion, and second to the elephant.

To decide such a matter a man would need to have shot equal numbers of all these animals, and also keep detailed notes of their behaviour under varied conditions. I cannot say I have had a sufficient experience to decide, although I agree with Selous that the lion should come first, as he is 
naturally possessed of a more ferocious temperament than elephants or buffaloes, and, moreover, he is a flesh eater. Further, his capability of taking cover is much greater than either of the former animals. As to the elephant and buffalo, the former is more likely to charge, I think, but he is easy to stop or turn, even with a very small bore rifle; but once a buffalo means mischief he has to be killed or knocked down, if his charge is at close quarters; and very few buffaloes charge at a greater distance than fifty yards.

I think on this account that the buffalo might come second, leaving third place for the king of beasts-the elephant. As the term "king of beasts" is usually given to the lion, I think that it should be transferred to the elephant, if by "king" we mean an animal that surpasses all others in strength, and which is invincible in the haunts of wild beasts.

However, no rule can be laid down, as animals differ greatly as to temperament in different localities, and it is quite impossible to say how any animal will act under given circumstances.

As this is a book about Africa, I do not wish to write of India or America. In the former country many sportsmen have been killed by tigers, and I think they are every bit as dangerous animals as lions. Many are shot from the backs of elephants or from platforms, except in some districts where it is usual to hunt them on foot. A fullgrown Indian tiger would be a match for a big lion, and, although the forequarters of the lion are probably more powerful than those of the tiger, the latter would gain in agility.

It would be a grand sight to see two of these fine beasts having a fight to the death.

The rhino, both black and white varieties, does not seem to have caused many deaths, although I have read of a few within the last twenty years. A good many men have been damaged by them, and that grand old sportsman, the late Mr. William Cotton Oswell, had adventures with both varieties when he was hunting in South Africa long ago. 
Some notes I have about deaths to white men include that of Prince Ruspoli, who was killed in Somaliland by an elephant. Then Colonel Armstrong and Mr. York met their deaths in Uganda in the same way.

Mr. F. L. James, also, was trampled to death by an elephant in West Africa, and Mr. Ingram was another victim to the same species.

Mr. Selous mentions the death of an Englishman named Firmin in 1870 , and a Swede named Dr. Wahlberg also was killed by an elephant in Matabeleland.

When Matabeleland and Mashonaland were taken over, a good many white men were killed by lions, and the deathroll in British East Africa must be very large indeed.

Yet a famous surgeon who visited that country on a non-sporting tour wrote some derogatory remarks about lion hunting.

Certainly, shooting lions after running them down with a pack of dogs is not a particularly sporting method, and neither is a beat composed of several hundred natives, and perhaps five or six guns; but if a white man tackles a single lion or a troop of lions all by himself, accompanied only by a gunbearer carrying a second rifle, he will get as much healthy excitement as he requires. Certainly, if the famous surgeon had gone in for this sport in the way mentioned, his statements would be vastly different. $\mathrm{He}$ had only to ask any resident doctor in Nairobi for a few details as to the people who have been treated there after being mauled by lions, to have got at the truth, which would have resulted in his expressing different ideas on the subject.

It is fairly well known nowadays that lions kill by biting, and only use their claws for gripping or to pull an object to their mouths. The paralysing effect of their bites seems to cause a numbness at the time, although soon afterwards the wounds become excessively painful. A lion does not use his paws to give a blow, like a tiger does, as was the popular idea long ago. $\mathrm{He}$ is said to come along the ground like a large dog, and on reaching his victim to 



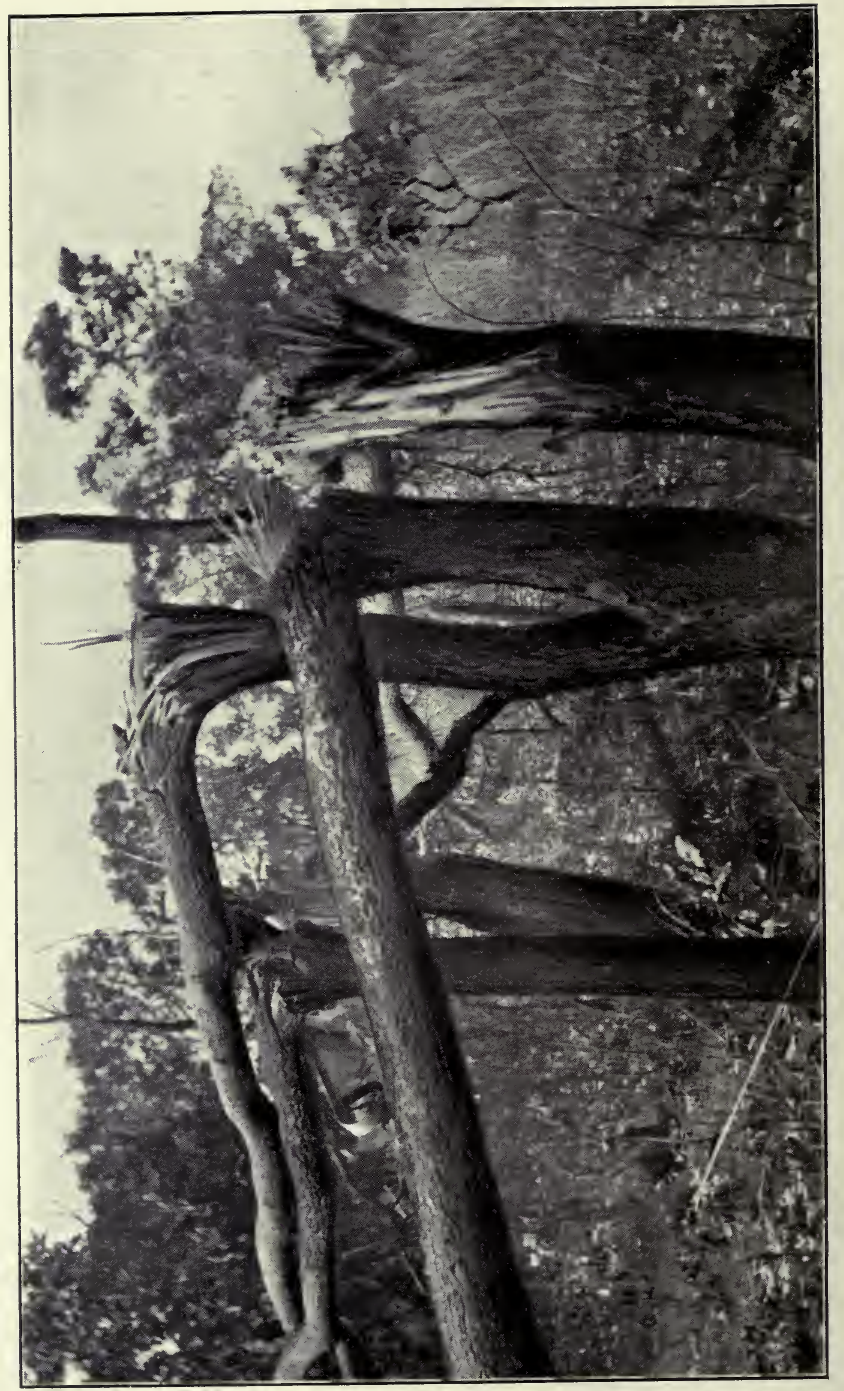

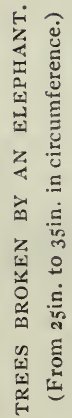


stand up on his hind legs and grip him with his jaws. Naturally, if a man was kneeling, or flat on the ground, the lion would not stand up, and in this case he would hold with his claws and bite with his teeth.

Another popular fallacy connected with wild animals is that the buffalo charges with his horns lowered. This he does not do, for he holds his nose straight out, quite protecting his head from the brain-shot. When within striking distance he lowers his horns, and either lifts his enemy in the air and catches him again or he knocks the hunter down and gores him, and also has been known to trample the body with his front feet. An elephant and a lion often leave their victim after mauling him slightly, but a buffalo will likely spend some time mutilating the corpse, and, although this may be termed vindictiveness, I do not blame the buffalo for resenting his injuries on the person who caused them, if he can get hold of him. He acts according to his nature.

Elephants usually pierce with their tusks or use their forefeet to trample a man, but sometimes they seize the body and tear it into fragments.

Anyone who has watched an elephant playing with a big tree, and has seen the way he can bend and break it, will no longer wonder how puny an object a man is when in the power of such a monster.

A rhino gores with his front horn, and, as he is a very powerful animal and his horns are sometimes very sharp, the man who escapes after getting beneath a rhino's nose may consider himself a lucky individual.

The natives seem to be more afraid of rhinos than they are of elephants, lions, or buffaloes; why, I do not know, except that they say he is always in a bad temper. He has the habit of turning over his dung with his front feet and horns, and the natives think this shows him to be a hot-tempered customer.

Rhinos are certainly very easy to kill with modern small bores, and a great number have been shot with 303 and 7'9mm. rifles. 
By climbing a tree for a distance of six or eight feet one could get away from a buffalo or rhino, but such a height would be no safeguard against an elephant, lion, or leopard.

When wounded, the leopard can be a very dangerous animal, although he is easy to kill as a rule. In charging he comes along with a spring or bound, and is thus very hard to hit. A friend, who has had the opportunity of shooting a good number of leopards, told me that, when wounded and followed, they will generally move on twice when disturbed; but that they almost invariably charge on being closely approached for the third time. They take cover behind the slightest vegetation, and, when lying quiet, they are most difficult to see. For following such an animal one could not possibly have a better weapon than an ordinary I 2 -bore shotgun loaded with A.A.A. or S.S.G.

In big-game shooting there are many indirect risks appertaining to the sport which might be considered, and possibly the worst of these is being bitten by a poisonous snake when tramping through rough bush and grass in bare legs. Personally, I cannot bear any covering on my legs while shooting in Central Africa, as putties are much too warm and they seem to prevent free action of the muscles. Gaiters are better, especially if made of cloth, but they soon get torn to hits by rough, sharp grass and thorns. Stockings, like putties, are too hot, and they do not last for any time in this country under the rough usage they are exposed to. Snakes do not seem to strike higher than the lower part of the calf; but, luckily, most of them seem to be possessed of acute hearing, and quickly glide off.

The puff adder is by far the most dangerous African snake, owing to its lethargic habits, and on several occasions I have had narrow escapes of being bitten, although I will not inflict the details on the reader, as snake śtories, like fish stories, are common, and unfortunately not all true. I think I have read more bunkum about snakes than of any other living creature, and most of the really " tall" stories come from America or Australia. 
It is a good plan to carry a small lancet and a small bottle or tube of permanganate of potash in the cartridge bag when shooting. There seems to be only one thing to do when bitten by a poisonous snake, and that is to immediately tie a ligature tightly above the wound, and then gash it with the lancet or a sharp bladed penknife, so as to induce it to bleed freely. Then the permanganate crystals are rubbed in after squeezing the blood out. Sucking the wound is good, but personally I would not care to allow a native to suck my blood, as their mouths are generally foul. Alcohol is often given, and particular care has to be taken to keep the sufferer moving, and on no account should he be allowed to lie down or go to sleep until some considerable time has elapsed.

I remember reading two cases of Europeans being bitten by puff adders and recovering. One was that of Mr. Frank Streatfield, who was bitten by a female puff adder on a voyage to England from South Africa. Luckily, medical aid was quickly available and he recovered, though I think he mentioned in the Field, in describing the incident, that he has never felt quite so fit since. It is certainly a reckless proceeding to handle dangerous snakes, and because a reptile does not object to being handled at one time is no assurance that it will always be in an equally docile state.

Of course the cobras and other poisonous snakes that Indian snake charmers use for public performances have been rendered innocuous by having their poison glands removed.

A small tube of permanganate is also useful for bites from wild animals, and every sportsman should make a point of carrying a little when out shooting.

I lately treated a native who was scratched by a leopard, near where I am at present living on the Bua River in Nyasaland. He was out with some natives hunting small buck and pig, and was alone on one of the flanks. The leopard suddenly jumped on his back and gave him a few scratches, and he got one rather painful gash where a claw 
had entered the orifice of his ear. I did not hear of the occurrence until two days afterwards, although the man was living within half a mile of my camp, and he knew he could have got medicine by asking for it. However, the natives seem to dislike appealing to white men when they are hurt or ill. On hearing of the affair, I took a basin and some medicine and went off to his hut, and he then seemed quite pleased to be treated. In less than two months he was quite sound, and if he had only come at once he would have got better in two weeks. Strange to relate, this man had had both his ears cut off for some crime, before the whites came to this country, about twenty years ago.

Natives are very touchy about any blemish of this kind, and it is considered to be bad form to make any remarks on such injuries. An old man who lives near my house was mauled several years ago by a leopard, and his wounds took over a year to heal up. Another accident occurred to an old woman, who had most of the calf of one of her legs torn off by an hyaena on a dark night. A wound of this kind must be dreadfully painful, as it is a tear and not a clean bite.

At another village, about three miles away, a lion took a woman last year (1912) and ate most of her. It then left the skull right on the top of a grave, which had a small mound over it. The superstitious minds of the natives were greatly disturbed over this weird action on the lion's part, and they firmly believe the lion was a human being who had died, and had come to life again in the guise of a lion. This idea was strengthened by the fact that a European who hunted up the lion fired several shots at it and failed to kill it. My informant, in telling me of the affair, remarked: "How could he kill a man who is bewitched?"

In this chapter I have not mentioned anything about the natives being killed or injured by dangerous animals, and yet the list would be much longer than that of the whites who have suffered. 



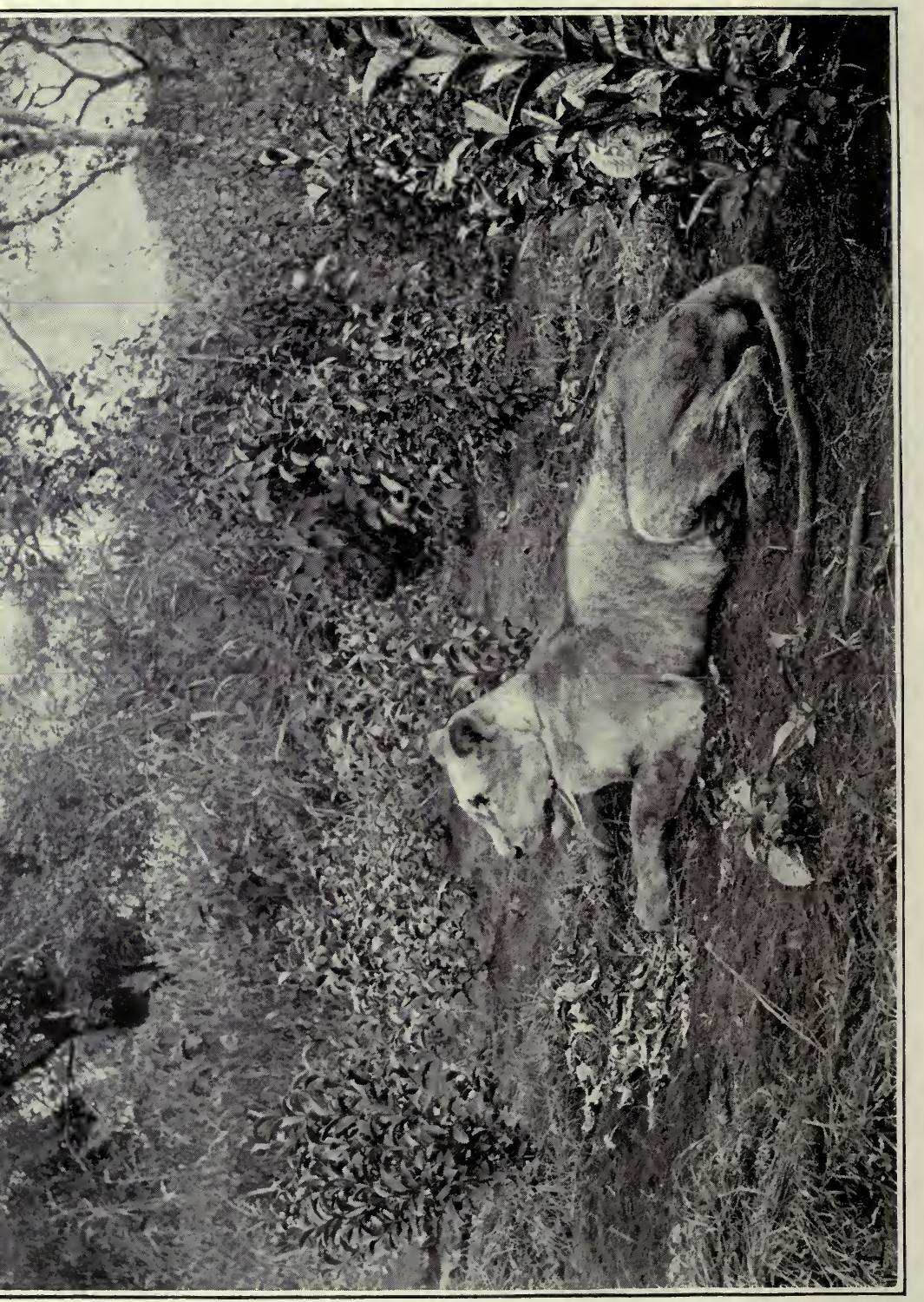


I have heard of a great number of natives being killed by lions, and several by elephants and leopards.

Buffaloes also have killed a few, and crocodiles very many.

Just after I arrived in Zomba in I903, a native woman was killed in a village by a man-eater. I went off, very keen to get a shot at the beast, and after a walk of ten miles, or slightly more, I reached the scene of the catastrophe.

Not knowing a word of the language, I had to depend on a boy who had come with me to explain the reason of my visit. He could not speak a word of English, but he had been primed by a white man in Zomba before I left. 'The small headman first produced a large native mat, on which I sat down, and some native beer and a pot of fried locusts were brought to me.

I tried the beer and rather liked it, as I was very thirsty, but the locusts were too much for me. Then the headman and some of the villagers took me to the hut, which was a flimsy grass affair, the walls as well as the roof being made of grass. I saw two holes in the walls, and I was able to picture the details of the affair. It seemed that the maneater forced its way through one side, and the husband of the woman, instead of standing by with an axe or spear, dived through the opposite side and left his wife behind.

She was a big, fat woman, and the lion had killed her by biting the back of her head. Then it had eaten some of the fleshier parts of her body, having also disembowelled her, and I particularly noticed that the lion had made some deep scratches on the hard mud floor of the hut, and no doubt it tried to scrape a hole wherein to bury the entrails.

It was a disgusting sight, and the smell was overpowering, both of the lion and human being. If natives are frightened they emit a horrible smell, and this carnal odour was more than I could stand for long, and so I departed.

The natives having collected, we first went into a big mealie field where there was a great amount of lion spoor. 
Then the tracks led into some thick bush, and here we found some bits of flesh, evidently some that the lion had carried off. I also saw some long mane hair hanging to a thorn bush.

We tried our best to get up to the lion, which we disturbed several times, but never got a glimpse of; although an old man who had mounted an anthill called out something, and began shaking his spear and pointing. I ran to the anthill, but by the time I got to the top the lion had moved on and at last took fright and went off for good, so I never got a shot.

I was inexperienced then, and if I had now the same opportunity, I expect I might have a different tale to tell of that day's proceedings. As I had to get back to Zomba on duty, I had to leave the same afternoon or I would have liked to have sat up for this lion.

Next day the natives burnt down the hut with its gruesome contents, as the lion kept hanging around that night, but was kept off by the flare of large fires and the beating of drums.

Many is the tragedy of this kind that has taken place in all countries where lions still exist, and it still goes on. The natives, of course, are very foolish, as they have abundant materials for making strong huts and inclosures; but they are too lazy and careless to do so, and they trust to luck, and hope that if anyone suffers it will be someone else and not themselves.

A man-eater does not proclaim his presence by roaring or grunting, and when he is on the look out for a meal he works silently. If he cannot break in through the walls, he has been known to jump on the roof and get through the thatch. I remember hearing in North-Eastern Rhodesia of a lion getting into a hut where there were three boys. $\mathrm{He}$ killed them all. Parts of Central Angoniland are bad for man-eaters, and the villages in the vicinity of, and including, Gwirisis, were surrounded by tall palisades to keep the beasts out. The villagers there belong to the Chipeta tribe, a poor, weak lot; and it is noteworthy that lions do not 
attack the villages of the Angoni tribe to such an extent. In the old days the Angoni hunted them with shield and spear, and I expect the lions have inherited a respect for that tribe.

I remember having a native pointed out to me who, with a large knife, had killed a leopard, which jumped on him.

One day I was passing along a path through the bush and walking quickly when I saw this man ahead of me, with a bundle of sweet potato leaves on his head and an axe in his hand. I thought I would test his nerve, so, having indiarubber shoes on, I walked close up, then sat down behind a big rock close to the path and uttered three or four sharp grunts something like a leopard's. The resemblance must have been pretty close, for at the first grunt he threw down his load and faced round, and approached swinging his axe and giving vent to an occasional yell. It was so amusing that I burst out laughing, and so did this native when he saw that the supposed "leopard" was a white man. He then looked rather disgusted that his leg should have been pulled in this way. However, he smiled again when I told him he had a "strong" heart, and he went off quite pleased with himself.

Natives, I am afraid, think the white men mad, and I have no doubt his story would amuse his friends when he told it round the fires that evening. Many natives are very plucky, and numerous incidents are on record of a native gunbearer or tracker going to his master's aid when in danger from some wild animal.

Again, others reason that it is foolish to run risks, as man has only been given one life, and hold to the old couplet that

He who fights and runs away

May live to fight another day.

Natives have great faith in certain white men whom they have often seen killing game, but their faith is more in the weapon than the man. Rifles that do not kill much game because they are not held straight are said to be 
bewitched, whilst others are supposed to have been influenced by a good medicine.

However, they believe that the white man is seldom afraid, although the most experienced of them know the difference between a reckless and reasoning courage.

It is a good thing that Britishers are usually willing to take risks, even when the odds are against them, and it is well that the natives should know this. 


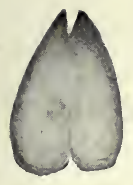

DUIKer.

(One-half size.)

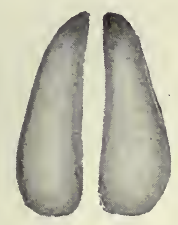

Puku.

(One-third size.)

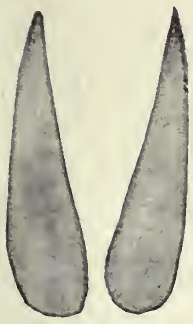

Situtunga. (One-third size.)

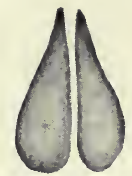

ORIBI.

(One-half size.)

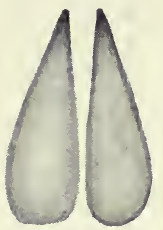

IMPALA.

(One-third size.)

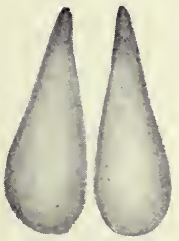

Sassa в.

(One-quarter size.)

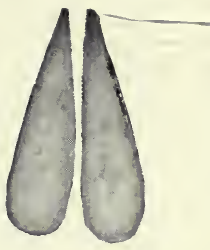

ReEDBUCK.

(One-third size.)

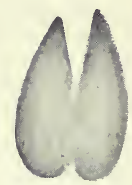

Bushbuck.

(One-third size.)

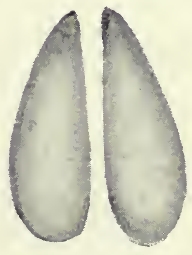

Waterbuck. (One-quarter size.)

(I) SPOORS OF ANTELOPES IN MINIATURE.

(Note.-Lichtenstein's Hartebeest like Sassaby, but larger.) 




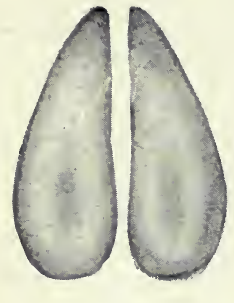

Sablz.

(One-quarter size

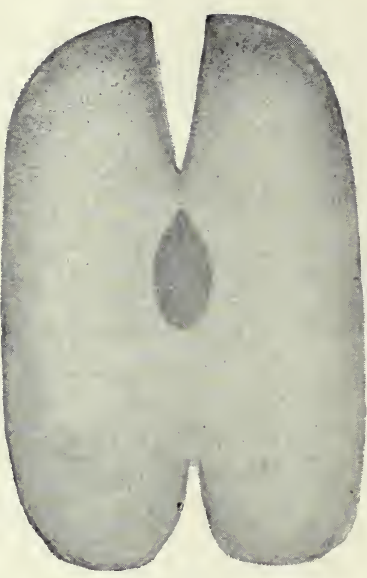

Giraffe.

One-quarter size.)

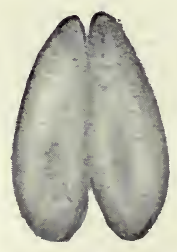

KUDU.

(One-quarter size.)
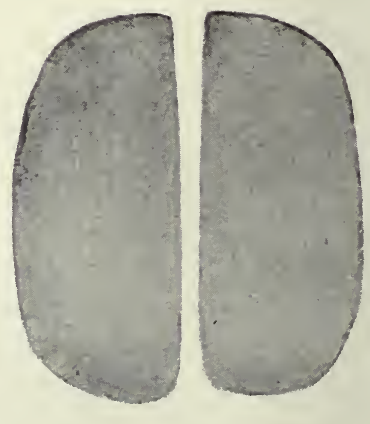

Buffalo.

(One-quarter size.)
(One-quarter size.)

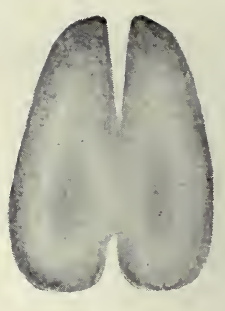

\section{GNU.}

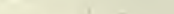
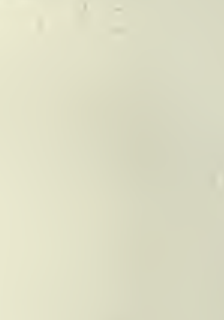

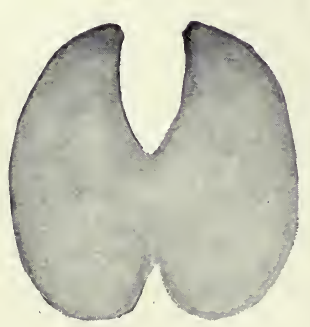

Eland.

(One-quarter size.) 


\section{CHAPTER VI.}

\section{Tracking Game, Licences, and Camp Notes.}

Knowledge of tracking useful to the hunter-Scarcity of blood spoor caused by use of modern rifles-The easiest time to track-Difficult country to spoor in-The droppings a good guide to age of tracks-Elephants swallowing stones-The usual method of hunting in Central AfricaDistinctive smell of different game-Anthills useful for stalking-Game fond of ashes-Fondness of game for high hills-Sharp grass and other vegetable nuisances-Ticks-Leeches in Africa and India-A deadly tea estate in India-The best spots to hit game and the effects of such wounds-Animals helpless with back leg broken-Tenacity of life in game-The best position for shooting-Game plentiful near perennial rivers in the dry season-The extinction of garie a difficult matter in Central Africa-Sleeping sickness and the best preventive for its spread-Licences and game allowance in Nyasaland, North-Eastern Rhodesia, and British East Africa-Poaching by white men-A letter quoted from the Field about German East Africa-Remarks on game protection-Game reserves and their uses-The cruelty of confining wild creatures in cages-The hardest sport in the world-A few notes or camp life-Advice for a man who gets lost in the bush.

IN previous volumes, particularly in "Central African Game and its Spoor," by Captain C. H. Stigand and myself, I have written a good deal about tracking, and there is no doubt that a good knowledge of this interesting part of big game hunting is necessary for any man who wishes to become an expert hunter.

Anyone who can walk well and hold a rifle fairly steady will be able to shoot a lot of game; but there are many cases when a knowledge of spooring will help a man to obtain a trophy that would be lost unless the hunter himself, or one of his native followers, be proficient in the art.

A good tracker can read on the ground the recent wanderings of game. Much lore on their habits can be 
ascertained in this way, and such study increases the pleasure of shooting a hundredfold.

Naturally the easiest animals to track are the heaviest in body, though if the ground should be stony or baked very hard with the heat of the sun, even they may leave very slight impressions behind them. But besides the footprints, there are the droppings to go by, and they are generally a greater index to the age of the spoor than the tracks themselves.

Again, all animals feed as they move about unmolested, and the nibbled grass or the branches and leaves torn from trees and bushes by elephant, rhino, and eland are also a silent guide to the observing sportsman.

Before going further, I may mention that the word "spoor" is a South African term for the tracks of game, and it may also mean the droppings or other traces of game as well as the footprints.

The time when a knowledge of spooring becomes most useful is when some animal is wounded and escapes for the time being.

In such an event there is the blood trail, as well as the tracks and droppings, as a guide to the path the animal has taken. Sometimes, if a beast is very hard hit, it will leave the herd and go off by itself, and in this case it is, of course, much easier to follow.

The high-velocity rifles used at the present time do not cause an animal to drop so much blood as was formerly the case with Express rifles shooting soft lead bullets, or big bore rifles or smooth bores.

It is not usual for a modern expanding bullet to pass through a large animal, and the small entrance hole soon gets blocked up with coagulated blood, and there may be very little blood spilt. If a bullet goes right through there is a better chance of the beast bleeding considerably, so a bullet like the "Dum-Dum" (with lead just exposed at the point) is a good type of projectile to use on animals like buffalo, eland, roan, kudu, hartebeest, and sable antelope. 


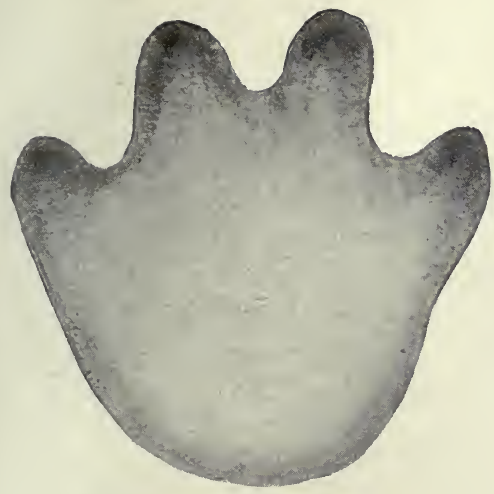

Hippo.

(One-sixth size.)

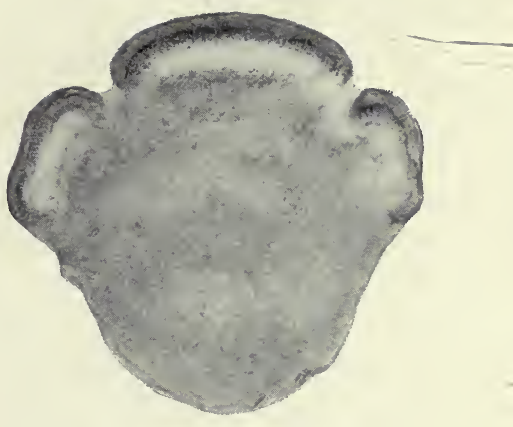

RHino.

(One-sixth size.)

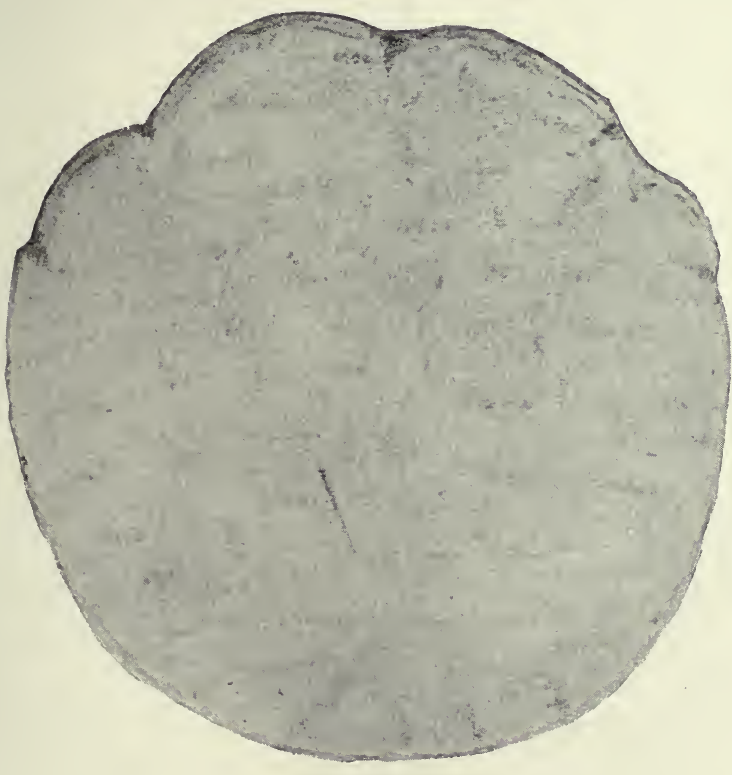

Elephant.

(One-sixth size.)

(3) SPOORS OF THE PACHYDERMS. 




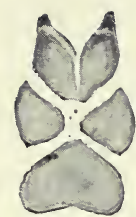

JaCKAL.

(One-third size.)

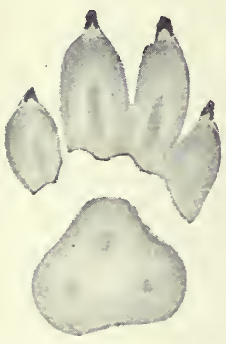

HY⿸厂⿷土丶

(One-fourth size.)

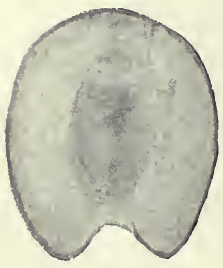

ZEBRA.

(One-fourth size.)

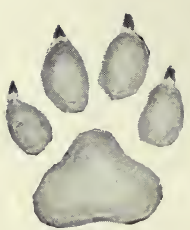

Civet Cat.

(One-third size.)

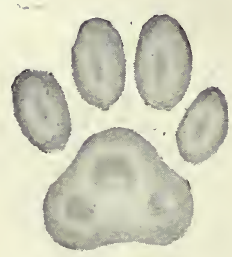

LEOPARD.

(One-fourth size.)

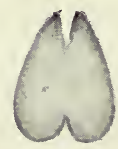

KasenYe. (One-half size.)

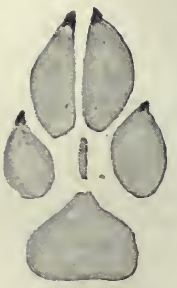

Hunting Dog.

(One-third size.)

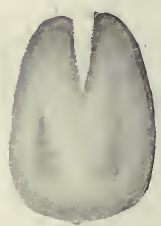

WARTHOG. (One-third size.)

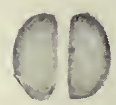

KILPSPRINGER. (One-half size.)

(4) SPOORS OF THE CARNIVORA, ETC., in MiNiATURE.

(Note-Lion Spcor similar to Leopard, but larger.) 
In a medium-sized buck, such as a bushbuck, impala, or reedbuck, a slit or a soft-nosed bullet will usually go right through, and then there will be plenty of blood to follow.

With elephant, rhino, and hippo, solid sheathed bullets should invariably be used, and a rifle like the $7.9 \mathrm{~mm}$. Mauser will sometimes drive a solid right through these animals when a body shot is taken. I have known such a bullet go right through an elephant's head, but this is unusual.

There seems to be such shock with modern bullets driven at great velocity that the arteries and blood vessels are seared, and bleeding does not take place.

Rifles like the $\cdot 280$, used with a sharp expanding bullet, seem to work great destruction in the flesh and tissues, and this prevents external bleeding. Such a weapon is doubtless most reliable for red deer and the smaller antelopes and other game of the world, such as bighorn, markhor, ibex, and bear; but most men who have had a good experience of African game like a heavier blunt bullet of the old shape.

In a later chapter I will have more to say about rifles, and I only mention them here in connection with the blood spoor they cause.

The easiest time to track is, of course, just after rain, as all old spoor will be washed over with sand or mud and recent tracks will show up distinctly.

Perhaps the hardest type of ground to spoor on is either rocky land or ground covered with a thick carpet of dried leaves, as the vegetation will often have to be turned aside to detect the marks on the earth.

If an animal is running hard there is little difficulty, as the soil will be thrown back and to the sides; and a running sable antclope leaves a very distinct trail, as his hoofs spread out more than do the majority of game. However, no hard-hit animal will keep up a fast run for more than a mile or two, and it will soon settle down to an easy walk, and will usually take to pretty thick cover. 
An easy spoor to follow is one through long, rank grass, as the beast's hoofs and body will press the grass over in the direction it is going.

Elephants in such a patch of country are very easily followed, and if there is a herd of any game nothing could be simpler than tracking in such a place.

Droppings are often eaten by beetles, sometimes almost immediately after they are deposited, and large dung like elephant's will remain warm for an hour or two, and if it is broken open it will often be steamy. It is certainly easier to tell if droppings are recently deposited than the exact age of footprints.

In windy weather the fine sand gets blown into the footprints, and small spiders sometimes make their webs over such marks, which would point to them being a few hours or more old.

By opening dung one can get a fair idea as to the food of various game, and it is astonishing what a varied "menu" all animals have. Both carnivorous and herbivorous game eat certain fruits, and the former are not above eating such creatures as mice, lizards, land turtles, locusts, caterpillars, and snails. In fact, anything that is eatable that comes in their way will be swallowed at times.

Elephants eat leaves, bark, fruits of many kinds, and, I believe, occasionally grass, and rhinos are said to feed solely on bark and thorns, but I once found grass in a black rhino's stomach, so it had evidently been grazing.

Elephants often swallow stones, and on several occasions I have found them in their stomachs. Quite recently I picked out thirty-eight stones from an elephant's stomach, and there may have been more that I did not find. These may be taken when the animals drink and it is possible that they swallow some when eating anthill mud, which they probably eat for its saline qualities, or for the acid contained in it.

The usual way to shoot in Central Africa is to go out and range the bush on the look-out for game, but if any special animal is wanted it is better to try to find the 
fresh tracks and spoor it up, and certainly this is the highest art of hunting.

I have mentioned that the pleasantest time to go out shooting is in the afternoon, when the grass and vegetation are dry and the sun is losing its power. There are two objections to this time and these are that if an animal is shot it has to be left out all night, and this spoils the meat for the white man's use. If the game is disembowelled, or "gralloched" as they say in Scotland, the smell will carry a long way, and it is bound to attract hyænas and perhaps lions if there are any about. The other objection is that should a beast be wounded there is no time to sponr it up and put it out of pain, and this is a very serious objection indeed, in my opinion, for it is cruel to leave a wounded animal for over twelve hours.

The disadvantage about the morning shoot is that the grass and vegetation, before the time of the annual fires, will be soaking wet with dew; in fact, so wet that one might as well walk through a pond. However, the sun soon gets strong and dries one if it is not a dull and cloudy day. Such a morning is sometimes beautiful with the sun's rays flashing on the dewdrops like millions of diamonds, and the sprays of long grass like a highly polished series of sword blades.

Often the "couch" of some game animal will be seen, and there is usually such a strong smell that it is possible to tell what species has been lying there. Buffalo have a strong odour, so have eland and waterbuck, and pig also leave a strong taint behind.

Sometimes I have smelt game before seeing it, and animals can have little difficulty in tracing their own kind by the sense of smell. I imagine, too, that the feet of animals leave a strong scent behind, which enables others to follow them.

Most game move about at night, when they eat and drink, and they lie up when the sun begins to get hot, which is about 9 or 10 a.m. 
Antelopes like to go into the open about 4 p.m., when the sun is beginning to wane, and the open spaces are a good type of country to search between that time and sunset. Early in the morning, game will often be found in the dambos, the small plains in Central Africa, which are generally covered with anthills in a more or less degree. These mounds form good cover for a stalk to a fair sporting range, and there are often clumps of bush or patches of grass left by the annual fires which serve the same purpose.

Warthogs, reedbuck, and oribi will occasionally be seen in the open during the hot hours, though the heat of October and November is generally too great for all of them, and they will keep to the bush.

I think I have mentioned that the grass fires usually take place in July, August, or September, but it all depends on the duration of the rains, and whether the grass has got dry and yellow enough to burn well.

Game is very fond of going to the dambos and licking up the salt contained in the ashes; and two or three weeks after the fires the fresh green grass will spring up and be eagerly eaten by the game; but this grass will likely get withered again until the rains in the early part of December bring it back to life. Then it will continue growing right up to March and April, when the rainy season usually ends.

All game is very fond of ascending hills, and even such large animals as elephants and buffaloes will often climb as high as 8oooft. Many of the ranges in Central Africa have plateaux on the tops, and Mount Chiperoni, in Portuguese East Africa, which is considerably higher than 8 oooft. above sea level, used to be, and doubtless still is, a favourite haunt of all the larger game.

Probably animals go to these places to get away from biting flies, and for coolness in very hot weather; and possibly the food has a different taste to that found at lower levels, and may act as a medicine or tonic.

It is certainly hard work following game in some of their wanderings, especially in the rainy season and before the 
grass is burned. About April and May the grass begins to seed, and some kinds of grass have seeds as long and sharp as needles; these cling to flannel shirts, socks, and other rough clothing, proving a very great nuisance.

At times grass seeds will be driven into the flesh, and as some of them seem to have barbed points, they are difficult to extract. Then there is the buffalo bean (chitaizi or chitedza), which I have mentioned before as being a pod covered with hairy spikes, containing some irritant poison and causing a severe itching, followed by a red rash, which, however, disappears in a day or less, if the blood is in good order.

There are also many different kinds of thorns and stinging nettles, and a painful object to rub against in thick grass is a fine creeper about the size of a leather bootlace, which is covered with sharp spikes. This creeper is difficult to detect, as it is green in the rains and turns yellow with the grass in the dry season, and when shooting in bare legs, as I usually do, I have had the skin badly torn by this vegetable string. It is very strong, so there is no use trying to break it, and one has to retreat a pace and then step over it.

Ticks are often numerous, and in some parts of Africa leeches are bad, but I never saw them so numerous in Africa as I did in parts of Eastern India.

While working at Ekaruni Tea Estate, in Sylhet, both the coolies and myself used to get covered with wire leeches, and it was useless trying to pull them all off, as they generally carry away a piece of skin, and the place is sure to fester, and often form a bad ulcer. I can remember occasions when I got home and applied some salt to them and collected from fifty to one hundred on the mud floor. Then a sprinkle of salt would make them vomit up the blood, and a pool of gore would collect over a foot in circumference. This would not have been so bad if it had been a very occasional event, but when it was repeated day after day, it made one feel like a sucked 
orange. The reason the leeches were so bad on the garden named was that I went there when the place was virgin jungle, and the land was very wet and swampy. With good drainage the land was dried, and the wet jungle, was cut down, so the leeches disappeared in the clearings. I have seldom seen such a deadly place for natives, as many died of cholera, dysentery, ulcers, blood poisoning, and other diseases. It reminded me of a description of Yambuya Camp, where Captain Nelson and his natives were starved and died of disease in the Stanley Emin Pasha Expedition.

Mosquitoes teemed on that place, and they were so bad that I used to sit and dine under a large mosquito net, having a smaller one stretched over my bed. The "boys" used to push the dishes under the large net, and a "boy" inside would put them on the table and remove them in the same way. The only recommendation this fever spot possessed was an abundance of snipe and jungle fowl, and there were a few deer about; but the jungles were so thick that it was almost impossible to see them, and one made such a noise creeping about that the game usually had plenty of notice before it was possible to get a glimpse of them.

I remember the monkeys proved a great bother, as they used to invade the young tea nurseries and eat the freshly planted seed and pull out the small bushes, so I shot a number with a small rook rifle. Baboons in Africa often damage tobacco and other plants, but they can be frightened away by shooting a few and hanging up a carcase or two as scarecrows.

The beginner at big game shooting may like to know the best spot where to hit game. When shooting, he should try to get the sight on a certain spot and not aim at hazard.

The two deadliest shots for game are the heart and the lungs, and, of course, a bullet in the brain or the centre of the neck will drop game at once; but these are unsatisfactory targets, as a bullet in the head will break the skull 
and if too high may remove a horn. Unless the animal is large, such as eland or buffalo, the neck is a difficult mark.

To hit the heart is a question dependant on the angle at which the game is standing, but if broadside on, the best spot is fairly low through the shoulder bone. The hearts of all game are lower than a line drawn horizontally across the body, and a buffalo's heart lies right down in the cavity of the chest. If the heart, or large arteries just above it is struck, the animal will usually give a shiver and dash off at a fast pace and then collapse after going forty to sixty yards; but often game will fall at once and die quickly. Personally, I prefer to see a beast run for a little way before falling, as animals which fall quickly often get up again and bolt. Of course a small buck is often knocked down by the concussion, and I have seen bushbuck and duiker lifted off their legs by the energy of the bullet, and this was particularly noticeable when I used a 318 "Axite" rifle, which has a velocity of $2500 \mathrm{ft}$. sec. and shoots a heavy, blunt point bullet of $25 \mathrm{ogrs}$.

For the lung shot aim at about six inches behind the shoulder, and pretty high. Shots aimed at the lungs may go high and break the spine, and then the stricken beast will collapse at once. If the lungs be punctured, game may run for a distance of from fifty to 200 yards before falling, or it may fall at once. When running off it will drop a lot of frothy blood from its mouth, and this blood will be a light crimson colour and covered with frothy bubbles.

If one sees this frothy blood, game will almost certainly be recovered if tracked up, and the beast will likely be found dead not very far away.

Animals with a broken front leg may travel for hours; but a broken hind leg will prevent game moving far, as the back legs are the driving machinery, so to speak, and the heaviest part of the animal is the hindquarters.

It is impossible to shoot much game without noticing instances of animals exhibiting great tenacity of life, and I have seen duikers run off with half their entrails dropped 
behind, and I once hit a warthog in the stomach with a soft-nosed bullet, and the stomach fell out of the exit hole and I picked it up on the spoor. I naturally thought the warthog would be lying dead; but it jumped up when approached, and I killed it with another bullet. This is not nice reading, and I will not mention other cases; I only state these to show how tenacious game is at times. Of course such incidents are exceptions, and not the rule; and they are the result of bad shooting in the hind quarters. With experience one learns to aim coolly and not to fire uncertain long shots at animals standing at unknown angles. After seeing the pain caused by indifferent shooting, the humane-minded sportsman will take greater care in aligning the sights of his weapon, and he will take greater pains to get within a good sporting distance.

Personally, I find the best position for a standing shot is a rest against a tree, taking care that the barrel does not touch the wood, as the jar will cause the bullet to fly wide. When the grass is long it is impossible to sit down and expect to see the game, unless one is perched on an anthill or rock; but in the dry season, when the grass is burnt and the leaves withered, I find that the steadiest position is to sit down and put an elbow on each knee, which is a favourite position among the deerstalkers in the forests of Scotland. I seldom lie down unless I get on an anthill, as even in the dry season there is usually too much vegetation in the way. A strong reed or twig is enough to turn aside a bullet, and it is sometimes very difficult to find a path for the bullet in thick bush, where the stems of the trees are closely grouped together.

The object of the sportsman is to bag males, as a rule; but many of the antelope cows carry good horns, and, to mention the principal, there are eland, sable, roan, and hartebeest; though none of them carry such fine heads as the bulls, for they are thinner and shorter, except in the case of the eland cow, which often grows horns as long as those of the bull. 


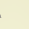




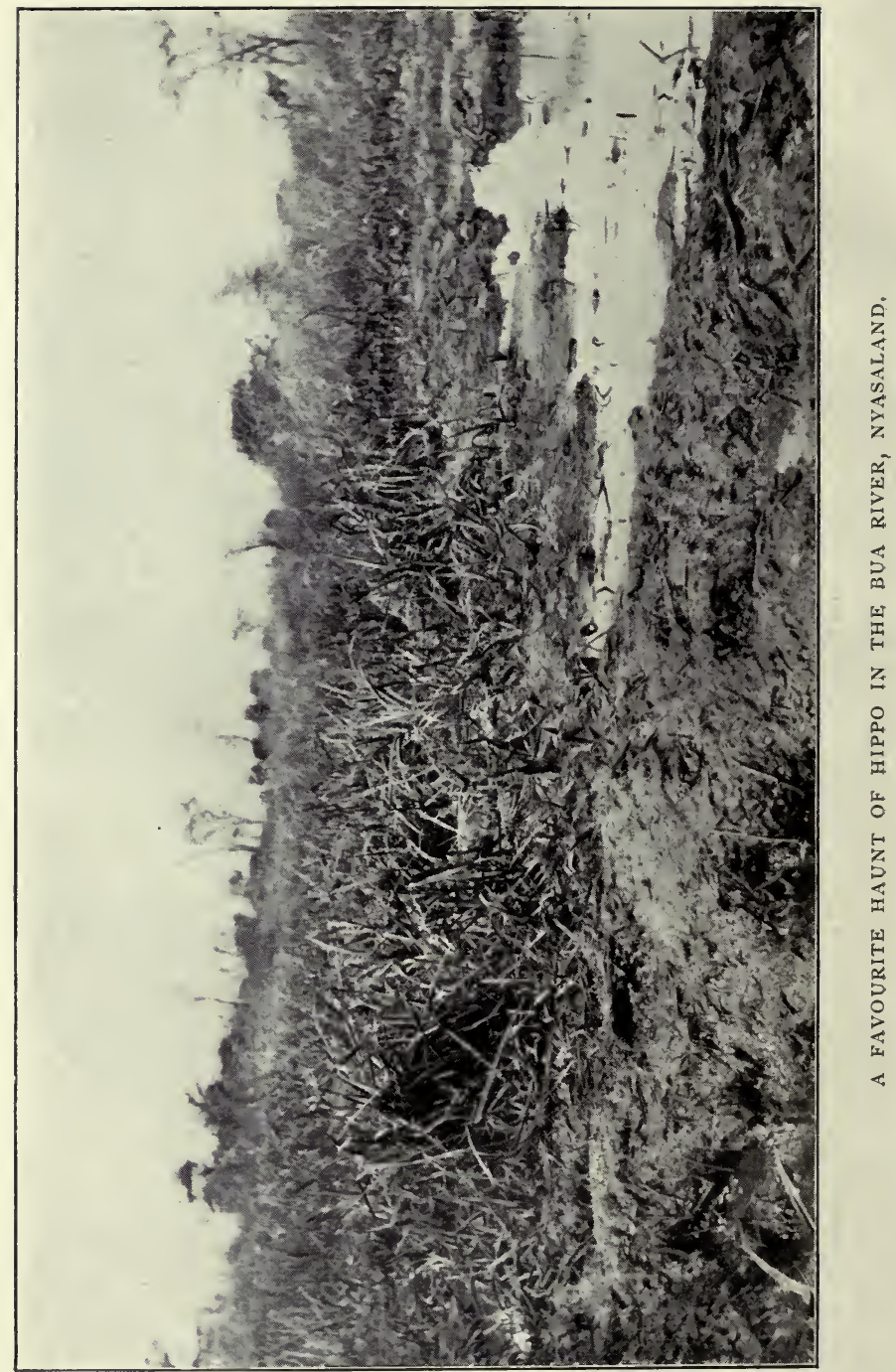


In good game haunts in Central Africa, game will often swarm in certain regions during the dry weather, when all the small rivers and streams have dried up. On the Luangwa River in North-Eastern Rhodesia, and on the Bua River in Nyasaland, game is very abundant from July to the end of November, as both these rivers are perennial.

During the months of the hard rains-January to March - there is water in every stream and hollow, and the game wanders about all over the country, although I think certain game remain in one patch of country throughout the year if they have not been much disturbed. It is this wandering habit amongst the fauna that makes it so difficult to get rid of the sleeping sickness; and to attempt to exterminate the game by shooting it would do harm instead of good, as most of it would only be driven into other country and take the disease with them. It would, therefore, be an infinitely easier matter to remove the native inhabitants into districts free of much game and tsetse flies, and those suffering from the disease could be segregated and attended to. As present it is quite impossible for the medical authorities to hear of a tenth of the number of cases that occur in sleeping sickness areas, and dozens of natives die without anything being known of them. If a disease area were depopulated for several years, the plague would fade away and become unknown in the course of time.

Native huts are flimsy affairs; they do not take long to build, and natives seldom occupy a village for more than ten years, as they change their locality to get fresh ground for their gardens.

In all British colonies and protectorates there are now stringent game regulations, and it is a good thing that the fauna of a country should be preserved for future generations of sportsmen and naturalists. As it may prove useful, I will now give some information referring to the cost of licences, and the number of game animals allowed to be killed annually in Nyasaland, North-Eastern Rhodesia, and British East Africa. 


\section{NyASALAND.}

There are now only two licences here and the visiting sportsman pays $£ \mathrm{ro}$, and a deposit of $£ .50$ is sometimes required which is returned when he leaves the country. A gun licence is also required, which costs ros.

The resident in Nyasaland, or a resident in the adjoining territory of North-Eastern Rhodesia, pays $£ 2$, and has to also take out the ros. gun licence.

The game allowed on any of these licences is :

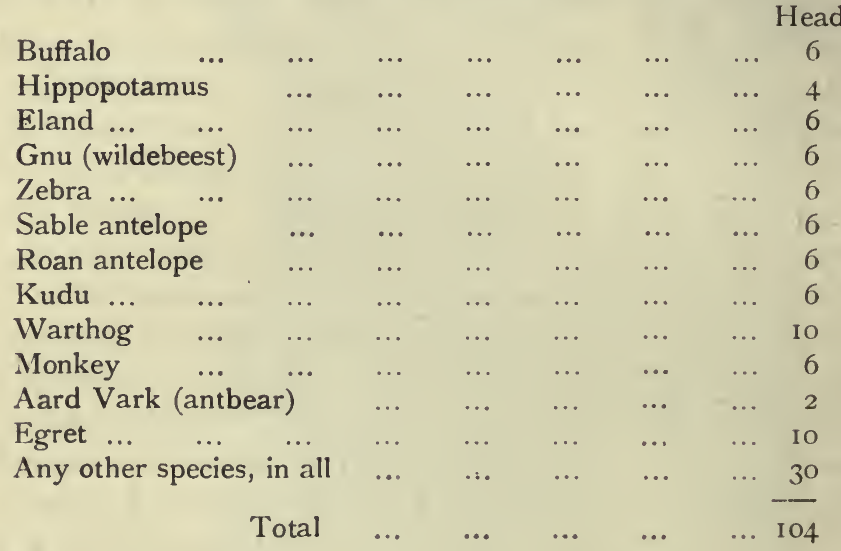

For shooting elephant the following licences are necessary :

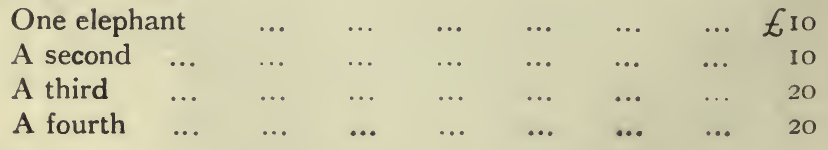

That is four elephants can be shot for $£ 60$. I cannot find any mention of the rhinoceros in the present game regulations of Nyasaland.

The above list is a very generous one, and it is sufficient for any man, in fact it will seldom be found necessary to. shoot the full numbers allowed, unless a man is doing little else than travelling about the country. 
The item giving thirty head includes the game which is not specified, such as waterbuck, hartebeest, bushbuck, reedbuck, impala, inyala, oribi, steinbuck, and duiker.

Carnivorous animals, such as lion, leopard, hyænas, wild dogs, cats of various varieties, otter, and all birds excepting egrets can be shot in any quantity, and all that is required for shooting them is the ordinary gun licence necessary for permission to carry a weapon of any kind.

\section{NORTH-EASTERN RHODESIA.}

It is probable that the game laws of the above territory may be changed to make them similar to the country known as North-Western Rhodesia, but this, I think, would be a mistake, for North-Eastern is not so often visited by sportsmen as no railway touches the country.

At present I believe that the game laws are as follows :

\section{Allowance on $£ 25$ Game Licence.}

Four elephant (ivory not less than I Ilb. weight for each tusk).

Five rhinoceros.

Four gnu (wildebeest).

Three zebra (males only).

Eland and all other game, except giraffe and other animals and birds which are protected.

The taking out of a $£ 25$ licence includes the ordinary charge of Ios. for a gun licence.

Allowance on $£ 2$ Licence.

Buffalo.

Roan antelope.

Sable antelope.

Kudu.

Hippopotamus (six only).

Lechwe.

Situtunga.

Puku.

Impala.
Reedbuck.

Waterbuck.

Hartebeest.

Oribi.

Duiker.

Klipspringer.

Warthog.

Bushpig.

Bushbuck, etc.

There seems to be no limit of the animals mentioned, except the hippo, of which six are allowed. 
As in Nyasaland, all carnivorous animals and other small mammals can be shot, and the same applies to birds, except those specially protected.

It will be noticed that eland, zebra, and gnu can only be shot under the $£ 25$ licence.

North-Eastern Rhodesia is a vast territory, teeming with game in places; and, both there and in Nyasaland, there are hundreds of square miles that have hardly been traversed by white men, and the game is as numerous at the present time as it was before Europeans settled in the country.

It always pays to break into new country and get away from the ordinary beaten tracks that have been much shot in, although even in country that has been well hunted, game will often be found in abundance.

The animals are difficult to drive out of country they like, and if they should be frightened and driven away, their homing instincts soon bring them back again.

\section{British EAST Africa.}

The "sportsman's" licence here costs rupees $75^{\circ}$ $\left(£ 5^{\circ}\right)$, and it allows of a large variety of game to be shot, though many of them belong to insignificant species producing poor trophies.

A resident pays rupees 150 , a traveller's licence costs rupees I 5 , and a landholder's licence is rupees 45 .

Here is a list of the Game Ordinance of 1909 and the game allowed :

$\begin{array}{lllllllll}\text { Buffalo (bull) } & \ldots & \ldots & \ldots & \ldots & \ldots & \ldots & 2\end{array}$

$\begin{array}{lllllllll}\text { Rhinoceros } & \ldots & \ldots & \ldots & \ldots & \ldots & \ldots & \ldots & 2\end{array}$

Hippopotamus (with restrictions as to district) $\ldots{ }^{2} \quad \ldots \quad 2$

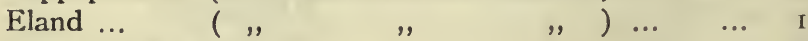

$\begin{array}{llllllll}\text { Zebra (Grevy's) } & \ldots & \ldots & \ldots & \ldots & \ldots & \ldots & 2\end{array}$

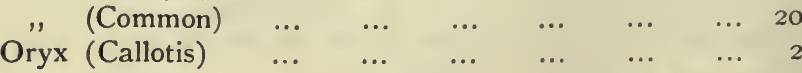

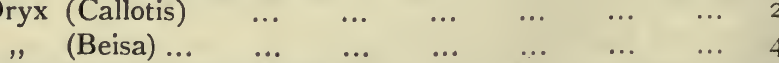

$\begin{array}{lllllll}\text { Sable antelope }(\text { male }) & \ldots & \ldots & \ldots & \ldots & \ldots & \text { I }\end{array}$ 
Head.

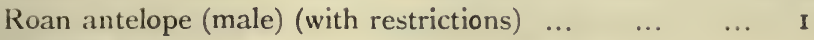

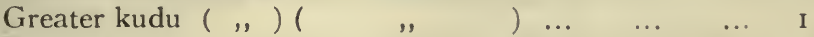

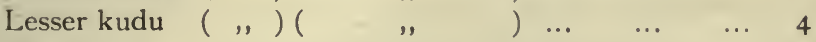

$\begin{array}{llllllllll}\text { Topi } & \ldots & \ldots & \ldots & \ldots & \ldots & \ldots & \ldots & \ldots & 2\end{array}$

(in Jubaland, Tanaland, and Loita Plains) $\quad \ldots \quad 8$

$\begin{array}{llllllll}\text { Coke's hartebeest } & \ldots & \ldots & \ldots & \ldots & \ldots & \ldots & 20\end{array}$

Neumann's hartebeest (with restrictions) ... $\quad \ldots \quad \ldots \quad \ldots$

$\begin{array}{lllllll}\text { Jackson's hartebeest } & \ldots & \ldots & \ldots & \ldots & \ldots & 4\end{array}$

$\begin{array}{llllllll}\text { Hunter's antelope } & \ldots & \ldots & \ldots & \ldots & \ldots & \ldots & 6\end{array}$

$\begin{array}{llllllll}\text { Thomas's } k \text { kob... } & \ldots & \ldots & \ldots & \ldots & \ldots & \ldots & 4\end{array}$

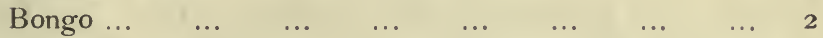

$\begin{array}{lllllllll}\text { Impala } \ldots & \ldots & \ldots & \ldots & \ldots & \ldots & \ldots & \ldots & 4\end{array}$

$\begin{array}{llllllllll}\text { Situtunga } & \ldots & \ldots & \ldots & \ldots & \ldots & \ldots & \ldots & 2\end{array}$

$\begin{array}{lllllllll}\text { Wildebeest } & \ldots & \ldots & \ldots & \ldots & \ldots & \ldots & \ldots & 3\end{array}$

$\begin{array}{llllll}\text { Grant's gazelle (four varieties of each) } & \ldots & \ldots & \ldots & 3\end{array}$

$\begin{array}{lllllll}\text { Waller's gazelle (Gerunuk) } & \ldots & \ldots & \ldots & \ldots & 4\end{array}$

$\begin{array}{llllllll}\text { Harvey's duiker } & \ldots & \ldots & \ldots & \ldots & \ldots & \ldots & \text { I0 }\end{array}$

$\begin{array}{llllllll}\text { Isaacs's duiker } & \ldots & \ldots & \ldots & \ldots & \ldots & \ldots & \text { I0 }\end{array}$

$\begin{array}{lllllllll}\text { Blue duiker } & \ldots & \ldots & \ldots & \ldots & \ldots & \ldots & \ldots & \text { I0 }\end{array}$

$\begin{array}{llllllll}\text { Kirk's dik-dik } & \ldots & \ldots & \ldots & \ldots & \ldots & \ldots & \text { I0 }\end{array}$

$\begin{array}{llllllll}\text { Guenther's dik-dik } & \ldots & \ldots & \ldots & \ldots & \ldots & \therefore & \text { I0 }\end{array}$

$\begin{array}{lllllllll}\text { Hinde's dik-dik } & \ldots & \ldots & \ldots & \ldots & \ldots & \ldots & \text { 10 }\end{array}$

$\begin{array}{lllllllll}\text { Cavendish's dik-dik } \ldots & \ldots & \ldots & \ldots & \ldots & \ldots & \text { IO }\end{array}$

$\begin{array}{llllllll}\text { Abyssinian oribi } & \ldots & \ldots & \ldots & \ldots & \ldots & \ldots & \text { 10 }\end{array}$

$\begin{array}{llllllll}\text { Haggard's oribi } & \ldots & \ldots & \ldots & \ldots & \ldots & \ldots & \text { I0 }\end{array}$

$\begin{array}{lllllllll}\text { Kenya oribi } & \ldots & \ldots & \ldots & \ldots & \ldots & \ldots & \ldots & \text { 10 }\end{array}$

$\begin{array}{llllll}\text { Suni (Nesotragus moschatus) } & \ldots & \ldots & \ldots & \ldots & \text { Io }\end{array}$

$\begin{array}{lllllllll}\text { Klipspringer } & \ldots & \ldots & \ldots & \ldots & \ldots & \ldots & \ldots & \text { I0 }\end{array}$

$\begin{array}{llllllll}\text { Ward's reedbuck } & \ldots & \ldots & \ldots & \ldots & \ldots & \ldots & \text { 10 }\end{array}$

$\begin{array}{llllllll}\text { Chanler's reedbuck } & \ldots & \ldots & \ldots & \ldots & \ldots & \ldots & \text { I0 }\end{array}$

$\begin{array}{llllllll}\text { Thomson's gazelle } & \ldots & \ldots & \ldots & \ldots & \ldots & \ldots & \text { 10 }\end{array}$

$\begin{array}{llllllll}\text { Peter's gazelle } & \ldots & \ldots & \ldots & \ldots & \ldots & \ldots & \text { to }\end{array}$

$\begin{array}{lllllll}\text { Soemmerring's gazelle } & \ldots & \ldots & \ldots & \ldots & \ldots & \text { I0 }\end{array}$

$\begin{array}{lllllllll}\text { Bushbuck } & \ldots & \ldots & \ldots & \ldots & \ldots & \ldots & \ldots & \text { 10 }\end{array}$

$\begin{array}{lllllll}\text { Bushbuck (Haywood's) } & \ldots & \ldots & \ldots & \ldots & \ldots & \text { 10 }\end{array}$

$\begin{array}{lllllll}\text { Colobi monkeys of each species } & \ldots & \ldots & \ldots & \ldots & 6\end{array}$

$\begin{array}{lllllllll}\text { Marabout stork } & \ldots & \ldots & \ldots & \ldots & \ldots & \ldots & 4\end{array}$

$\begin{array}{lllllllll}\text { Egret } \text { of each species } & \ldots & \ldots & \ldots & \ldots & \ldots & 4\end{array}$

$\begin{array}{lllllll}\text { Total } & \ldots & \ldots & \ldots & \ldots & \ldots & 3^{12}\end{array}$

If the-different varieties of Grant's gazelle and waterbuck are included this would bring the total up a little. 
Of course much of the game given is very localised, and without a long residence in the country it would be impossible to get specimens of all the species given in this list.

With regard to elephant a special licence of rupees $5^{0}$ is required to shoot one elephant, and the tusks must not weigh under 3 olb. each. To kill two elephants the charge is rupees $45^{\circ}$.

For permission to kill one bull giraffe the licence costs rupees I $^{\circ}$, and certain districts are prescribed.

Certainly no sportsman can complain about the limits enforced; but it is not the true sportsmen who do the damage to the game of British East Africa, but the unprincipled whites who get far from civilisation and slaughter the game. In a former chapter I have mentioned the damage the Boers do, and as that country now teems with men of that race it can easily be imagined how the game suffers.

There is only one way to prevent poaching, and that is to have sufficient game rangers to patrol the country in parties of from two to four men with full powers to apprehend and bring before the game warden the poachers who are caught redhanded.

One man is useless, as a witness is necessary, and such game rangers should be given the power to resist force by the use of firearms.

I admire the Boers as a fine, manly race, and I suppose most people do; but they are not sportsmen in a true sense, and they only slaughter game for the sake of the hides and an occasional fine head which they keep to sell.

The first thing to do is stop the exportation of hides and game trophies unless they have been shot under licences.

In German East Africa the decimation of the game has already reached a serious state, and I take the liberty of quoting an article which appeared in the Field of January 6, igi 2 . It reads as follows :

Our Berlin contemporary Naturwissenscha fliche Wochenschrift of December I7 (I9II) devotes two articles-one by Professor Fritz Bein and the other by Professor C. G. Schillings, to the appalling slaughter of big 
game which is now taking place in German East Africa, and the urgent need of prohibitive legislation in order that a remnant of the fauna may be saved.

Game reserves like those which have been established with such marked success in British East Africa, as well as restrictions on the number of head of game shot by individual sportsmen, and likewise regulations prohibiting the export of undersized ivory and trophies and skins for commercial purposes are apparently wanting in the adjacent German Protectorate, and it is to the lack of these that Professor Bein, who has lately returned from a tour in German East Africa, attributes in a great measure the rapid destruction of the fauna, which he designates a scandal to civilisation and a heartrending disgrace to the German Empire.

The slaughter on a big scale is not attributed to sportsmen who visit the country on hunting trips, and are for the most part men of culture and lovers of nature.

Nor is it due to collectors of specimens for legitimate scientific purposes, neither of these classes causing any appreciable diminution in the number of the game.

The touring sportsmen who spend from two to six or more months in the country are, indeed, an advantage to the country, for they bring and spend a large amount of money, which is much needed.

The real culprits are those who shoot for the purpose of obtaining record heads, and the professional hunters, who sell their trophies, and shoot every living thing they come across, from elephants to the smallest birds.

Many of these professional elephant hunters belong, it is said, to an extremely undesirable class, who in many instances have left their own country for urgent reasons. Worse even than these are colonies of South African Boers, who get their living by shooting rhinoceroses, elephants, and other animals yielding spoils of commercial value. Many of these Boers, it appears, were settled in the country at great expense by the Government in order to act as "pioneers of civilisation." Whereas the European sportsman, whether scientific or otherwise, travels with a big train and a large amount of impedimenta, the Boer goes about accompanied only by a single negro, with little more than his rifle and blanket, and lives on the flesh of the game he shoots and a handful of maize. Thus lightly equipped, he gets far away from the haunts of Europeans; and for some ten months in the year shoots to his heart's content without fear of interruption.

The remaining two months are spent on his small farm or field, which he pretends to cultivate to a certain extent, in order that he may figure as an industrious settler.

As the result of the destruction inflicted by hunters of the above types, Professor Bein states that whereas in a district in the heart of the Masai plateau, which he visited in $1907-8$, elephants were then abundant, when he revisited it in 1909-10, scarcely a single elephant was to be seen. The Boers, it appears, had been hunting in the district during the interval, and from a single herd had obtained no fewer than sixty pairs of tusks. During a five months' march through the same country, only five rhinoceroses were observed. Again, he states that in Lake Mweru district, 
a noted locality for rhinoceroses, where Schillings only a few years ago saw as many as twenty in a day, he could find only a couple of old tracks, but not a single living individual.

During the whole of his five months' journey in German East Africa, Professor Bein had only one opportunity of shooting elephants, and this was not due to any incompetence on his part, as he was accompanied by two experienced sportsmen who knew the country well, and were adepts in detecting game.

In Umbegwi it is stated that a Boer within a period of three weeks, shot nine elephants and sixteen rhinoceroses in an area of only a few square kilomètres. In a single week a professional English hunter killed one elephant and nineteen rhinoceroses, to say nothing of other game, in the Morogoro district; while, when Professor Bein was in the neighbourhood of Lake Mweru, a German hunter shot six elephants, which had been specially protected by a planter from the pure love of nature, despite the damage they inflicted on his crops.

All this, and more, goes on in spite of protests by the author, by the Duke of Ratibor, Prince Solms-Baruth, Paul Niedick, Professors Sarasin and Matschie, and Geheimrat Waldeyer.

Unless something effectual is done, and that speedily, Gernan East Africa will be denuded of its big game.

The above interesting article shows that in certain districts in German East Africa a great deal of game slaughter has taken, and is likely still taking, place.

One point I can hardly follow. It says that a Boer, accompanied by one negro, will go off for ten months with only his rifle and blanket.

One negro could not carry sufficient food and cartridges to last for ten months, and how could the Boer transport the horns, skins, or tusks with one negro?

A good lot of exaggerated matter is written about the extermination of game in parts of Africa; but at the same time there is much truth in the statements given. Unless a Government is prepared to spend money on game protection, and provide sufficient game rangers to patrol the country, the game will be slaughtered. However, the exportation of skins can be prevented by legislation, and the Boers and other game butchers would stop killing the game to any great extent if they found that their trouble was useless, and, moreover, they can be caught with efficient supervision. 
Of course, settlers object strongly, as a rule, to game destroying their crops and plantations, and no game reserve should be made near settlements, as it is not fair to men who spend money in planting concerns to have their fields devastated by wild animals.

More especially is this the case when stringent regulations disallow a beast to be shot, and no compensation is given for the damage it causes.

It behoves sportsmen to be open-minded in the matter, and also Governments ; and, after all, there is an abundance of room in the wilder parts of the country where game reserves can be made. It is better that such reserves should not be of too large an area, or it will be impossible to supervise them efficiently without going to great expense.

Game reserves act as feeders for surrounding country that is getting shot out, and this has already been proved in the United States of America; and they also form nurseries for the supply of specimens to zoological gardens and parks, although personally I think it is a shame to keep wild creatures in such confined quarters, where they only pine and die under the unnatural conditions of their lives, spent generally in a climate that does not suit them.

It is pitiful to see a beast like a lion confined in a small cage, and gone in the loins with the want of proper exercise and freedom; and such an act on man's part is infinitely more cruel than shooting game in the country it frequents. Some people may dissent from this view, and yet there are plenty of men who would prefer a quick death to solitary confinement for the term of their natural lives.

A weak-backed lion or a scraggy rhino, as seen in a zoo, is surely not a better guide as to the shape of the animals than well-stuffed specimens in a museum.

If people at home wish to know what a certain animal looks like, they have museums in all the large cities, which are open to inspection; but for a gaping crowd to go to gaze at some decrepit animal behind iron bars is nothing 
more nor less than a civilised kind of refined cruelty, and I hope the day is not far distant when all zoological gardens and parks will have to be abandoned by an Act of Parliament. Doubtless there are many who will not agree with the last sentence, but I let it stand, for I know that many sportsmen consider the imprisonment of wild creatures a species of slow torture, and a pandering to the noxious taste of crowds of the lower population of European countries. I have seldom met an intelligent and humane-minded man who did not deplore the shutting up of wild animal life in cages, and, when we consider the roving instincts of man alone, we can have some slight idea of the misery of such animals' lives, accustomed, as they are, to an unlimited freedom in their own countries.

The young which happen to be born in confinement doubtless also feel the constraint to some extent, for one cannot expect that the longing for liberty will leave such creatures in one or two generations.

Only a few species breed freely when in confinement, and the young are generally weak and feeble compared to pure wild stock of the same species which are born in their natural haunts. But enough of this subject for the present, for the writings of a single individual will never have an effect in the discontinuance of such refined cruelty by people who ought to know better. In its wild state game known as dangerous very seldom harms man unless it is interfered with or wounded, and certainly no man can object to any wounded beast trying to avenge its injuries on the person who inflicted them, and there would be little interest in big-game shooting if there were no chance of a "scrap" with an animal occasionally. There is really nothing very difficult in shooting harmless game; although the discomforts and hard work this may entail may be as great as the work necessary to find a lion or buffalo.

With regard to hard work, elephant hunting comes under a separate category, as no sport in the world will take more out of a man: especially if it be undertaken in October or November, just before the rains, when the 
heat of the sun is sometimes terrific; or right in the middle of the rainy season, when the coarse grass is from Ioft. to 2 oft. in height, and usually soaking wet and full of creepers and stinging plants.

There are many opportunities of exercising one's ingenuity when living in the wilds, as stores full of different necessaries are not found round the first corner as they are in large cities and towns at home.

The tent should be pitched under a big leafy tree; though care should be taken to inspect the branches to see if any are rotten and likely to fall if a gale springs up I remember once I was camped under a large tree and omitted this inspection, and a gale came on in the middle of the night, bringing down a large branch. Luckily for me it only touched a tent rope, giving the tent a bad shake, but if it had been a few feet nearer, I would not be writing this at the present moment, as it weighed a ton or more.

Some trees grow large gourd-like oblong pods, about I 8in. or more long, and I once saw one land on a native's head and knock him insensible. When he recovered he said that an enemy had tried to kill him by making the vegetable growth strike his skull, which, to say the least, was amusing.

The three essentials for a camp are the presence of shade, water, and fuel; and these are all abundant in Central Africa. If water cannot be found above ground it can often be got by digging in the bed of a sandy rivercourse. The presence of puku, impala, waterbuck, and reedbuck usually denote that water is somewhere near.

If a man gets lost in the bush by himself, and cannot find a path, the best thing he can do is to first try to find water, and then he should make a smoky fire on the highest spot near, and wait until his friends appear. Here I presume that he is careful not to leave camp without a box of matches, a rifle and cartridges, and a knife; which are real necessities in a wild country. With water and some meat he could live for a long time, taking care to keep a large fire going by day and night. Green leaves 
put on the bright fire would produce lots of smoke, and so would some green grass. He could break down branches to make a rough skerm round at the back, and with plenty of dry fuel and his rifle he would be safe from lions. If he had not many cartridges it would be a mistake to fire many shots, as a call for help; these should be kept and economised as much as possible. A compass is of little use unless one knows the direction travelled before his bearings were lost. The prevailing wind is a help, and if this is unknown, the angle of the trees and the bark will denote it. Rivers, too, if their direction is known, are an aid, but they usually twist more than appears on the maps of this country. Perhaps the best advice is to keep cool, which, of course, is easier said than done, and not to indulge in aimless wandering after one knows that the direction is lost. 


\section{CHAPTER VII.}

\section{Memories of Big Game Hunting.}

Old shooting experiences a pleasant memory-Game plentiful near the Luangwa River-Giraffes-Leopard seen-Lion followed into thick grass-Bird life on the Luangwa River-Vultures spotting gameNatives eating rotten meat-Crocodiles-A native taken by a crocodile -Fish and their poor eating qualities-Mushrooms and other edible fungi-Shoot a fine impala ram-Waterbuck plentiful-Bad climate near the Luangwa River-Great heat and thunderstorms-Wound a bull elephant-He charges and is killed-Garden-feeding elephants-Hit a tuskless bull elephant-A cow proves nasty-Thorn thickets inhabited by game-Follow elephants which run off and swim the Luangwa River-Kill six hippo-Track and shoot a bull rhino-Close quarters with a rhino-A good rhino horn-Go a trip to the Chiromo Marsh-Follow a wounded buffalo bull for six hours and kill himThe haunt of the inyala antelope in Nyasaland-Kill a very fine reedbuck ram-Chiromo district a good game country-Thorn country and the Tuchila Plain-Shoot a large eland bull-Bag some sable antelope-Difficulty of preserving specimens in damp weather-A good kudu specimen spoiled by a native - Thorns and sharp grass-Shooting in bare legs-Wound, track, and kill a hartebeest bull.

My memory often carries me back to some lovely game country and the exciting sport I experienced there, and one of the most lovely of them all was the vicinity of the Luangwa River in North-Eastern Rhodesia. The Luangwa is a very large river, especially in the rains, as it drains a vast extent of country. In the dry season many of the smaller rivers and streams dry up and when seeing them at this time it is difficult to believe that they can develop into rushing torrents of great force. I am now living on the head waters of the Bua River which is usually a quietly running stream about 3 oft. across. As I write this (March 23, I913) after about twelve hours' 
steady rain it has risen tremendously and is now in spate, in places about $300 \mathrm{ft}$. across, and a small bridge I made was carried away. When the rain stops this small river goes down almost as quickly as it rises.

In 1905 I spent a year at a place marked on the map as Mzazas, which was right in the centre of some of the best game country left in Africa. It was right opposite one of the two game reserves existing in North-Eastern Rhodesia. This reserve was made to preserve one or two herds of giraffe which inhabited that country. The Administrator of North-Eastern Rhodesia at that time was the late Mr. Robert Codrington, and he most kindly gave me permission to shoot in the reserve on condition that I did not interfere with the giraffes, a promise I kept. I saw their fresh spoor on many occasions, and once got a glimpse of them running off. As they were the first giraffes I had ever seen, I was interested in watching them for the short time they were visible.

I have since seen several herds of giraffe in British East Africa, where a bull can be shot on a special licence of fio, although somehow I do not have the ambition to shoot such a harmless and beautiful animal, and there is very little interest in the trophy of the mounted head and neck, or the tail.

Near Mzazas elephants were rather scarce, but rhinos were fairly plentiful, as the bush is full of thorn trees, the staple food of these animals. Most of the commoner game was abundant, and water-buck and impala swarmed. The waterbuck is one of the most beautifully formed antelopes of Africa, as he has a very fine carriage, especially when he is startled, and holds up his head and neck. The meat is poor eating, particularly that of an old bull.

I was never tired of watching the herds of graceful impala, and often have I lain and watched them feeding and resting. They made a lovely picture of animal life amongst the green tropical vegetation growing on both sides of the river. The most noticeable tree was the mopani, always found near large rivers in Central Africa. 


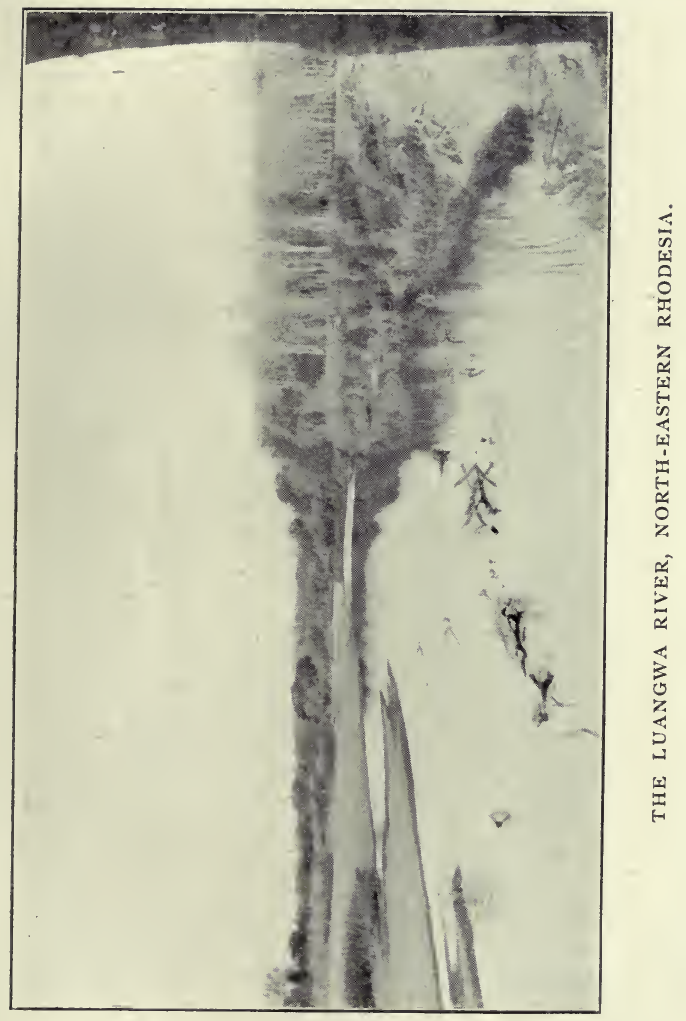



Roan antelopes were plentiful, but I never saw any sable near Mzazas. Zebra and hartebeest were in numbers, and puku, reedbuck, oribi, and duikers could be seen here and there.

Hippo were to be seen in the river occasionally, and buffalo, although they did not exist quite close to where I was living, were to be found in other parts of the Luangwa Valley, not more than a day's journey off.

Mzazas has a name as a good place for lions, but my usual bad luck with these animals seems to have followed me, for though hardly a day passed without my tramping through the bush, I never actually saw one of them near Mzazas.

On one occasion I heard two break away out of a patch of thick grass, and I ran round hoping for a shot, but by this time they had gone, and I spent hours on the spoor without any result.

There were a good many bushbuck, and occasionally I saw and shot warthogs. Once I got the glimpse of a bolting leopard which had been feeding on an impala fawn he had killed, but he was soon out of sight, just like a flash of yellow light.

One day I heard pig in some long grass, almost up to my neck, and seeing an anthill near, I went to it so as to try to see into the grass. There was a large tree which had a big branch overhanging the anthill. Just as I reached the top I saw a leopard jump from this branch and disappear, and, as it frightened the pig, I got a shot at neither.

Leopards are most wary animals, and I consider it is the purest fluke if a man gets a good chance at one. They nearly always lie up in thick grass or bush, and their hearing must be most acute, for they go off silently if disturbed at any distance; if come on close, all one sees is a yellow flash, and they are off for good. If lions and leopards would only stand and growl at the intruder it would be much better, as one would have a good chance of putting in a deadly shot, but they refrain from doing this unless they are wounded, and then instead of standing 
in the open they probably growl from behind a bush or patch of grass, where one cannot see anything definite to shoot at.

While living at Mlanje in I9I I some natives came and told me that a lion had killed a bushpig in some thick grass on the slope of a hill. I went off, and, after a walk of five miles or so, came to the place. The grass was not only thick, but it was over Ioft. high. I asked the natives to spread out and come in with me, but they refused, saying this was a very fierce lion. I knew it was foolish going into such a place without the backing of another gun or two, but I was keen to get a shot, so in I went. I had not gone twenty yards when there was a series of very loud grunts and growls, and the thick grass began to break. I was so enveloped that I did not know at first whether the lion was coming on or bolting, so I held my rifle ready and waited. He went past me, and I could not see a hair, although I saw the tops of the grass bending before him.

I then went out of the grass into a small patch of open ground, which was part of a native garden. The natives then pelted the grass with stones and lumps of mud, and the lion shifted several times, but refused to face the open. After this had gone on for about an hour, an old man, who was sitting on a rise some distance off, shouted to me that he could see the lion's head, so I ran over, and, after following the direction he pointed, I saw it too. I sat down, and missed the first shot; but, at the second, the head seemed to topple over, and I thought I had got him; but I was mistaken, for soon after we saw him get into some thick cover. In passing into this cover he did not show, and we only saw the grass and bushes swaying as he passed. It was now late in the afternoon, so I decided to get home and return with a friend next day. However, nothing more came of it, and I cannot say whether I hit him or not. Certainly, if I did so, it was not a good hit. A lion's head at a distance, enveloped in thick, dry grass of the same colour, is not a satisfactory target. 
One night at Mzazas I sat up for some lions that had been coming round, but, instead of coming to a fat pig I had tied up for them, they spent the night in chewing up some roan reim (thongs made of roan hide) I had stretched along some trees. This was fixed at about eight feet from the ground, and they tore it down with their paws, and then ate a lot of it.

The bird life in the Luangwa River was most interesting, and the shrill cries of the ospreys were often heard as they perched on some dead tree overhanging the river. The monkeys, too, used to chatter and cry in the early mornings, and late in the afternoons as they came to drink. Many beautiful kingfishers of several varieties could be seen, and the glint of their wings in the strong sunlight was like the flash of jewels. Geese, ducks, and waders were numerous, and I noticed many terns of a small species. Green pigeons, parrots, guineafowls, partridges, quail, and doves helped to fill the pot at times, and marabout storks, as well as storks and herons of other varieties, were abundant. One very pretty black and white coloured stork is known, I believe, as the saddle bill stork, from the formation of a saddle shaped plate on the posterior part of his peak.

When game was killed and left in the open the vultures would be the first to see it, and then the marabouts would follow. It is marvellous how the vultures can see meat at such a distance, for when one shoots a beast none may be visible. Then in half an hour one will notice some dark specks away in the blue, and these will get lower and lower in diminishing circles until they develop into these carrion feeders. But if it is properly covered, the vultures fail to see it, as I have proved on many occasions.

It is useless covering the game and leaving big patches of crimson blood lying near. Sand or earth should be thrown over such marks. My belief is that the vultures do not notice the game as quickly as they do a fair-sized patch of red blood, and it is this that first catches their vision, as they wheel far off in the heavens. When the sun went 
down, as it often did in the dry hot season in a mass of gorgeous colours, the hyaenas would wake up and begin to wander about. They must find their staple diet of dry bones a rather unsatisfying meal, so when a lot of meat falls in their way they make up for lost time. They will eat anything, but, indeed, many of the natives are quite as bad, and I have seen them relish meat that was positively moving with maggots. But it does not seem to do them much harm.

A robust negro will put away a good rolb. of meat in an evening, and probably fill up the vacant spaces with ufa porridge and sweet potatoes as well, and yet he will appear quite fit next morning, and ready to repeat the dose. Their digestive organs must be wonderful in their working mechanism, and Nature has been kind to them in this respect.

Crocodiles were very plentiful in the Luangwa, and on two occasions they left the water at night and took game I had left on a sandbank. I shot a good many, and then they got very cunning, and it took good stalking to get within range at times. More than half of those hit got into the water, and doubtless died soon afterwards of their wounds, or were probably eaten by their fellows before they had time to die, for I believe crocodiles are quite capable of cannibalism. One day a cow went into the river to drink and was seized by a crocodile, which was frightened off by the herd boy. However, as its udder had been dreadfully torn, I shot it to put it out of its misery.

When the river was low I used, instead of using an old dugout canoe, to cross the river where the water was about up to one's waist. I was returning one day with two men who were carrying an impala ram I had shot, and we had got to the river when the boy who was carrying the cartridge bag stayed behind. The men with the impala and myself had crossed the river at the ford, and were going along a path parallel with the river, when we heard a yell, which seemed to come from the direction of the ford. I got the men to lay down the buck, and we all 



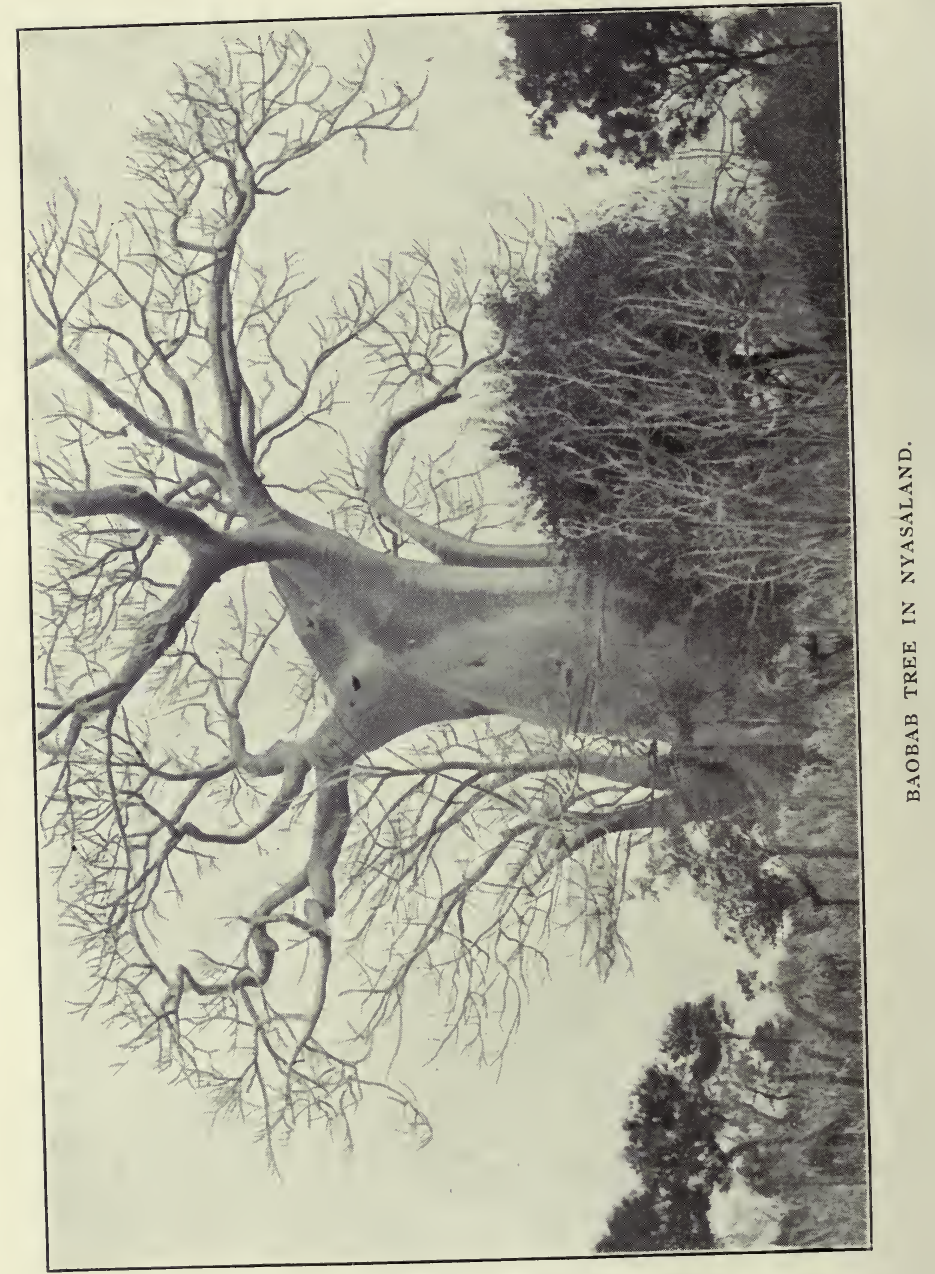


returned to see what had happened. On getting near we shouted for the boy, but no answer was returned, so I had a very good idea what had occurred. I did not fancy sending the two men to the other bank, or to cross again myself, and so, as my house was only about a mile away, I went there and got the dugout, and returned up the river until we came to the spot. Behind a stone we found the cloth of the-missing boy and my cartridge-bag, so the history of the tragedy was plain. He had, on reaching the river, thrown off his cloth and the bag and gone in to bathe, and one of the loathsome crocodiles had got him.

After that, I used to go there and lie in wait for any crocodile that left the water. I shot several, and I hope the maneater was among them.

When we got back with the cloth and told our sad story to the boy's wife, there was much wailing and cries of "Mai-o," but the woman was married again in a few months, and seemed to have forgotten the incident completely.

In my chapter on the characteristics of natives I will have more to say about this trait in their character; but it is enough to mention here that they have poor memories, however much they may feel such a loss at the time.

Crocodiles, sharks, and snakes are three of the most obnoxious creatures in the world, and one often wonders the reason why they were created. They may be no worse than man-eating lions or tigers, except that their quiet and invisible attack imbues them with horror and loathing.

The Luangwa valley being very hot and tropical, the grass got very long and thick in the rainy season, and shooting was a wet business. I used to fish a good deal, and catch barbel or mudfish, but they are not good eating, as their flesh is muddy flavoured and they are rather full of bones. However, they formed a change in the perpetual course of fowl, or game meat, which becomes very monotonous after some time. After living about seven years in India and ten years in Central Africa, I became rather tired of fowls. They have very little resemblance to 
the fine, plump birds served up at home, and, instead of having a delicate flavour, some of them are very distasteful.

The things a man longs most for in tropical Africa are fresh home fish, good, tasty meat, vegetables, bread and butter, and milk. Sometimes the four latter can be got if one can keep cows and has a good garden and a capable cook. Some of the cooks make quite eatable bread, and such a man is a treasure, for good bread is a luxury when one can get it.

There are several native vegetables that are good eating, such as pumpkins, sweet potatoes, and ground nuts. Maize, or Indian corn, when it is fresh and soft, well boiled, and then eaten with a little butter and pepper, is quite excellent. Sweet potatoes are good, but one tires of them sooner than of European potatoes. The Angoni grow a vegetable they call itchaysani, which has a taste reminding one of fresh new potatoes and a slight flavour of artichokes.

There are a great many fungi in the country, some of which are good eating while others are poisonous. A small mushroom almost similar to those found at home, and a pink colour underneath, is called manyama; a bigger white mushroom is named chipendi, and the biggest is called boa. The latter is the first to appear when the rains break, and they are quite good when chopped up and boiled with chipped ground nuts as a seasoning. They have a taste something like codfish; and being rather tough and stodgy, a little goes a long way. The natives sometimes have a small variety of tomato growing in their gardens, and chillies can be got. A man who used to suffer a good deal from malarial fever told me that a native told him if he ate a lot of chillies he would not suffer, so he tried it, and found that he seldom got fever afterwards. This may be only a yarn, but he seemed to be in earnest when he told me of the fact, and I have seen him put as much as a teaspoonful into his soup and other courses, and seem to relish it; so he practised what he preached at any rate. 
The natives use many herbs as a relish to their daily food of ufa porridge, and they are extremely fond of salt.

In the dry season they collect great quantities of honey, and when they secure it free of extraneous matter it is very nice. It is hardly as strong as heather country, but darker than the ordinary white honey seen in Britain. Thay keep the wax after chewing all the sweetness out of it, and the Angoni used to use it for polishing the headrings that all the principal men wore. I believe they first made the rings of hair, and they coated them with beeswax and polished them round. The Zulus of the South wear these rings, and the fact that the Matabele do so, as well as the Angoni, shows their Zulu origin.

I remember while at Mzaza spending several days in trying to shoot a very nice impala ram that used to be with a herd. He was a particularly wary animal, considering that impala are not as a rule difficult to shoot. He usually kept on the safe side of the big herd; and as soon as danger was seen, for they seldom got my wind as I took care of that, he was off with a jump. At last I got him with a difficult shot I had to place between the forks of a large tree, and he ran off and fell in the grass some sixty yards away. He had not exceptionally long horns as they only measured I $8 \mathrm{in}$. on the curve, but they were pretty and wide set.

Several fine waterbuck heads have been shot in the vicinity of the Luangwa River, although the best out of a large number I have killed only measured $28 \frac{1}{2} \mathrm{in}$. on the curve. I have tried my best to get good heads; and, although I have managed to get a few better than the average, I have not had the luck to shoot anything near the record, except a small Sharpe's steinbuck which comes second, I think.

I would rather shoot the record buffalo than any other species, as the animal ranks as dangerous game, and a buffalo head, with its gnarled, rough appearance, is certainly one of the best trophies that can be got in Africa. 
With all its wealth of fauna and flora, the Luangwa Valley cannot be called a health resort, especially in the rains, when the country is flooded and damp, and I was often ill with malarial fever there, as well as undergoing a severe attack of blackwater fever.

In October and November, just before the rains, the heat was terrific at times, and hot winds used to sweep along, which seemed to frizzle one up. These siroccos used to burn my face, and I have often had to shield it with the brim of my old felt hat.

Then, just before the break of the rains the sky used to turn a molten bronze colour, and the air was sultry and oppressive. As the sun sank in the west it used to tip the peaks and ridges of the Machinga Mountains with the most beautiful colours, and I can never forget some of the sunsets I witnessed there, for they were lovely beyond the power of writing to describe or paint to portray. There is not much game high up on the Machinga range, with the exception of a good many rhinos and a few bushbuck and duiker. The higher peaks are the habitat of klipspringers; and elephants and buffalo have their chosen tracks from the Luangwa Valley to other haunts west of the range.

When thunder and lightning used to come, how the peals of thunder would echo among the clefts and ravines of the range, and the lightning appeared to run along the rockier parts. I expect the ground there is full of ironstone in places; in the Drakensberg Mountains in South Africa, the same thing occurs.

While shooting on the Luangwa River in I908, I found the spoor of a big herd of elephants on November I6. After my men and myself had followed the tracks for about four miles, we came on the herd, which consisted of quite thirty animals. Most of them were standing in some thick bush, although a few were moving about just outside it, in a patch of thick grass which had not been burned. Between myself and the elephants was a slight hollow, which at the bottom showed the sandy bed of a 
small stream. This was about sixty yards from the nearest of them. I could not see any very large bull and I fired at the best one I saw, which seemed to have $30 \mathrm{lb}$. tusks. He was standing fairly broadside on; so I took a line between the orifice of the ear and the eye, shooting a few inches forward of the earhole. At my shot he dropped and I thought I had brained him. Then the herd broke away in all directions, and two young bulls a little smaller in the ivories than the one I had dropped, came round at us.

We all made pretty good time to some trees in the rear. I stopped when I got to a tree about two feet in diameter. and so did the man who was carrying my cartridge bag, an Awemba named Kalenje, and he took up his position behind a tree a few paces behind me.

He then said to me that the elephant fired at was getting up, and on looking I saw it was making violent efforts to get on its legs. By this time the two young bulls had gone round towards the direction of the bolting herd, so I fired a shot at the wounded elephant which it did not seem to feel at all. As soon as it got on its legs it immediately started in our direction, for the last shot had evidently shown it where we were. Whether it was charging with intent it is difficult to say, but, judging from its demeanour and the shrill screams it gave, I think it was. Anyhow, it was coming straight for my tree, increasing its pace at every stride, and the "frou-frou" of its feet as they swept through the dry grass I still remember. After the first screams it was silent, and it held its trunk down covering its chest, making a heart shot useless.

I had in my hand a 303 sporting rifle holding ten shots in the magazine. As I had only put eight cartridges in to start with and had fired two shots, I had six shots left. As the elephant came along in a bee-line, I began firing at it, taking a steady rest against the trunk of the tree and shooting just above the eyes. He took the first two shots with a shake of his head, and the third shot, at a distance of about 20 yards, got his brain, and he lurched over on his 
side. With the momentum of his speed he slid for several paces along the ground, making large grooves with the bony parts of his body. I must say I was relieved to see him collapse, and so were the men, who gathered round smiling and making remarks about the way he fell.

When he came down the ground trembled with the shock, and I thought one of the tusks would be broken, but they were both sound, and eventually weighed close on $3 \mathrm{olb}$. apiece. This elephant belonged to a herd that made a practice of invading the native gardens, and they certainly are more dangerous than elephants that prefer to keep away from human habitations.

Most of the elephants in Central Africa will not miss an opportunity of a good feed of maize, but they are easily scared off. Others, like the herd this animal belonged to, are left alone, and lose their fear of man and resent being interfered with.

While shooting on the west bank of the Luangwa, not very far from Kacumbe's village, which is situated close to the river on the eastern bank, I one day was following a small lot of elephants that had been feeding in a big patch of pumpkins, which they had quite destroyed. There was a good bull in this small herd, and the tracks took me into the higher ground, covered with thick patches of dense thorn bush, through which there were many game paths of elephants and buffaloes. When rounding a bend on one of these paths along which the spoor was leading us we suddenly walked right on to the elephants, which I naturally thought was the herd we were following. It was fearfully hot, they were standing in a dense bunch, and one in the centre towered above the others; but I could not see his tusks, as two or three others were standing between. Their ears were flapping, and they swayed slightly backwards and forwards. As only fifteen paces separated us, I had to do something, and, as I could not get the heart shot, I fired behind the skull of the big bull, and then my men and I ran for all we were worth to an anthill on our left. It was just as well that we did, for the elephants 
ran at once, and one actually went between us and the anthill, but passed on.

Then several shrill screams vibrated through the air, and we saw a cow approaching us, accompanied by a small calf. I saw this cow was tuskless, and, as I did not wish to shoot her, as it is against the regulations to shoot cows (at least, it was at that time), I waited. After screaming, she rushed off, and I was very glad she did so. I now saw the bull getting up speed, for my first bullet had missed the brain and only dazed him. My men said: "Do not shoot him, Bwana, for he is a 'nungwa' "' (tuskless elephant), so I let him go. An elephant shot in the head, unless the brain is touched, never sustains much damage, especially from a small bore. Every elephant in this small herd of nine or ten was tuskless, as far as I could see, which was rather extraordinary, but which is a fact, nevertheless. On examining the ground further on, we found that this was not the herd we were following, but another herd, which had come from a different direction, and, on taking up the spoor, we found where the first lot had been standing before they bolted on hearing my shot. This shot also disturbed a few buffalo that had been resting among the thorn scrub, and I caught a glimpse of them running away after I fired as they went off with a crash. These thorn patches are nasty places to follow elephants in, for, except on their paths, it is difficult to move quickly in the thicker parts, and the elephants seem to look on such places as refuges or sanctuaries. The natives told me that elephants are very "okali" (fierce) when disturbed in these places, and, judging from my experience, this seems to be the case.

The natives living near the Luangwa here were much troubled by hippos, which invaded their crops and did almost as much damage as the elephants, so on November 9, I908, as I had failed to get a shot at some elephants I had spoored, I spent the rest of the day in shooting hippo. This is the account from my diary :-

Up before sunrise and got away just as the sun appeared in the East, and soon after leaving the village (Kanunta's) 
I saw a herd of twenty roan antelopes, which were as tame as cows, perhaps because I did not wish to shoot any, being after elephants. We soon found elephant spoor, but the guide took me further on, saying he knew where the elephants were going and we could cut the spoor again.

Saw a fine ram puku with a herd (I got this ram a few days afterwards) and a small herd of four bull waterbuck, one with a good pair of horns. Then we got on the elephant spoor which led us into the troublesome matete reeds, which are as sharp as needles and very difficult to walk in, as the elephants trample it down and it trips one up at every step.

After going some way in this dangerous country we heard the elephants just ahead. Coming to a slight ridge covered with grass, instead of matete, I got on it, and got the glimpse of the backs of three elephants, one male and two females, which had evidently heard us and were walking fast. Soon they were lost to sight, and we followed as far as the Luangwa, where the tracks showed that they had crossed to the west bank. As we were debating what we should do, we saw a second herd of elephants run towards the river and cross also, one cow helping a small calf which got into difficulties. I got one of the men to carry me across, and in the process I got wet to the middle as the water reached almost to his shoulders. We then took the track again, and several times got to within 400 yards or so of the elephants, but the wind kept shifting every few minutes, as it always does in the Luangwa Valley during the months of September, October, and November. These shifty winds are, I imagine, caused by the heat, which forms vacuums in the air.

When crossing the river we had seen a big herd of hippo playing themselves in a deep pool, and the villagers begged me to shoot some. At that time six hippos were allowed on the licence, and up to this time I had not shot any that year, although I had killed a number in previous years. When coming back towards the river after the abortive 



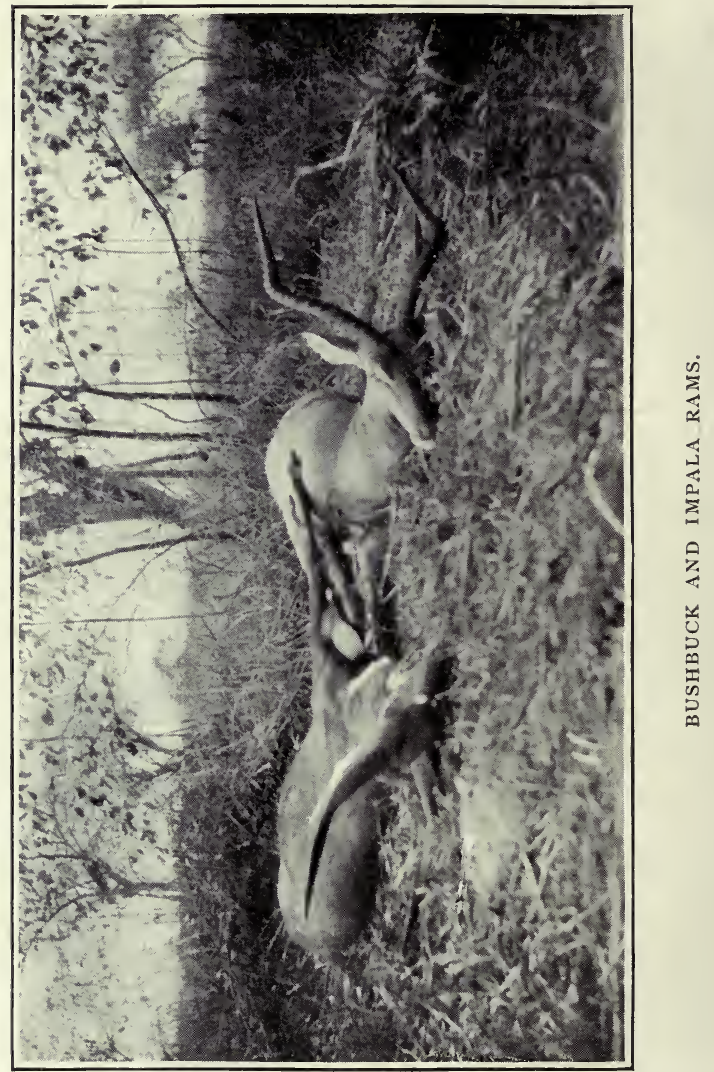


chase after the elephants, I shot an impala ram. On getting to the pool where we could hear the hippos grunting and splashing, I sat down and killed five with consecutive shots. The sixth cost me three cartridges, for after my first shot at him he was only dazed, as he left the water and stood on a sandbank, where I gave him two more bullets which killed him. This may seem dreadful slaughter, but I have mentioned that the hippos do great damage to the crops, and, moreover, the inhabitants of the villages round here were suffering from a famine, as they had finished most of their last season's crop of grain. This supply of meat, of which not a pound was wasted, would give them food for some time, and put strength into those who were ill from hunger. Instead of regretting such slaughter, I would do the same again for the same purpose.

Further, the natives are not allowed to kill large game like elephants and hippos themselves, so it is a good action on any white man's part to kill it for them, as long as he does not exceed his allowance.

However, as I do not believe, now-a-days, in giving the natives great quantities of meat for nothing, and as they had plenty of goats and I wanted the milk as much as they wanted the hippo meat, I told them that I would give one hippo for one milch goat, and they were quite agreeable, and the different headmen went off to bring the goats. A large hippo weighs quite $6500 l b$., and a big goat certainly not more than 8 olb., so they had certainly the best of the bargain.

Two of the headmen produced billy goats, saying they had no nannies, which I expect was a fib, so to square matters they had each to bring six fowls as well. This was only fair to the men who produced nannies, which are considered more valuable.

Another man who had no goats produced a pair of khaki trousers, which he said he had given fifteen shillings for in Salisbury, and on my refusing a hippo for them, as I told him I could not wear them, he almost exploded in tears, and begged me to take the pants and give him a hippo, for 
he and his people were very hungry. I relented, and he got his hippo, and I gave the trousers to my capitao (headboy).

Then the excitement began, as the men belonging to each hippo owner went in, and got the hippos out on a small sandbank, all in line. Unfortunately I had no films for my camera on this trip, so I lost some very interesting pictures. The natives had promised to keep the best of the hides, and all the teeth, for me, and they were soon busy hacking away at the meat, which they carried to the bank, where there was plenty of timber to make fires. Some of them busied themselves making stands to cook the meat on, and quite rooo natives must have collected for the feast; and the owners of the hippos, who, except to their own families, do not believe in giving something for nothing, were busy bargaining for prime lumps of sea cow.

Another memory that comes back is a day's sport near the Rukusi stream in North-Eastern Rhodesia, where I had gone after elephants. On September 29, I9o8, I had been out early looking for spoor fresh enough to follow, and I only found the tracks of a few cow elephants, which I did not want.

When travelling along the dried up bed of the Rukusi, we found the spoor of a big bull rhino which took us along the banks of the waterless bed for some distance. At last it lead us to the higher country, over undulating hills with many thorn trees here and there. At this time of year big game does not seem to care, if not harried much, to travel far, as the heat of the sun is tremendous and it makes the animals lazy. About ro a.m. I sat down to make a cup of tea and eat a little food; and as I always carry a big gourd of water, and often a lump of dried meat for my men, they also had some refreshment.

After smoking a pipe of tobacco we took up the spoor again. Machila, a fairly good tracker, was spooring, and I was walking to one side keeping my eyes ahead and to the flanks. Suddenly I saw a grey object just like a big rock, and snapped my fingers to draw the attention of the men. At first I was not sure whether it was not a big 



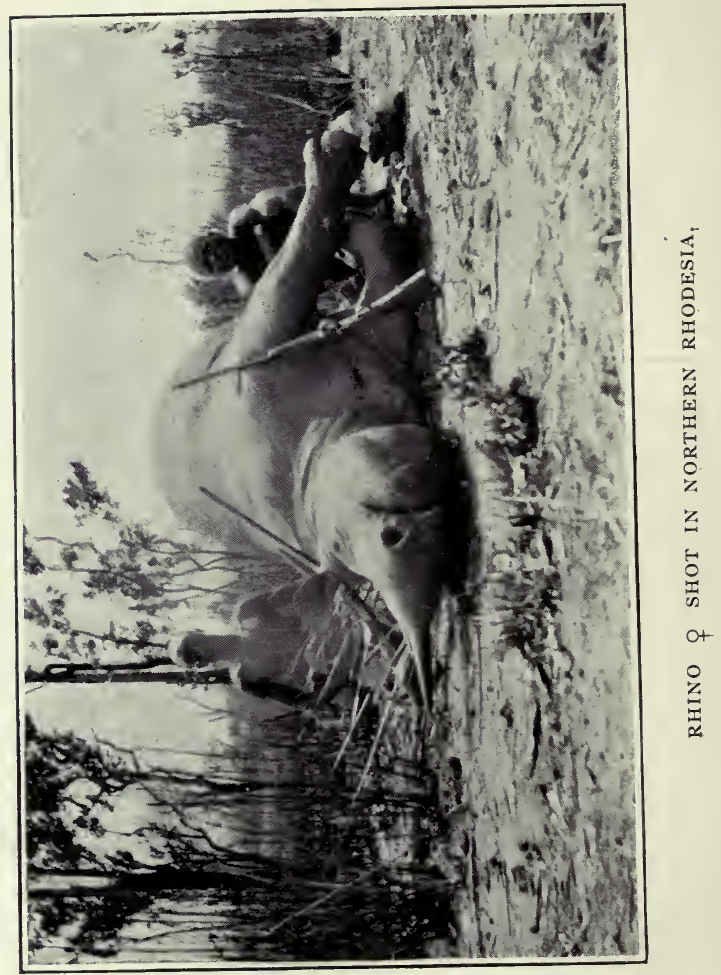


boulder, as there were many about there; but as we watched we caught the movement of a rhino's ears.

It would have been better had I whistled to make the rhino stand up and give me a chance of a good shot, for a sitting animal presents a poor target, if one wishes to get the bullet to a vital spot and kill quickly. However, I thought I could kill him quite well as he was, so sat down, and took a shot with a single 400 cordite Fraser rifle at his shoulder.

After the shot the cartridge jammed in the breech, which is not unusual with single falling-block rifles, and the rhino gave a startled grunt, and was on his legs and off before I could get the refractory case out and loaded again. We all ran after him and saw him disappear into a large patch of light coloured grass that threw off a very strong glare which nearly blinded me. Rushing along in this way I suddenly found myself within a few yards of the rhino, which had come to a stand half broadside on. There was not much time to waste, so I threw up the rifle, and got in a fine shot right on the point of his shoulder, and he dropped in his tracks. As he kept twitching his ears and eyelids, I gave him another bullet from my 303 , which settled matters.

$\mathrm{He}$ had very nice horns, the anterior one measuring slightly over 20 in. He was a very large bull in good condition, and his feet were big, so I took the front ones as trophies. The natives then cut off his tail, and we tramped back through the heat to the village, where a refreshing bath and good lunch awaited me.

It is very pleasant returning to camp after a successful day, and how different a man feels then compared to a long day's tramp when he has met with bad luck; or, worse still, wounded and lost a fine animal. In one case the exhilaration felt makes the miles slip past as nothing; in the other every step drags, and one's bad spirits are reflected on the faces of the natives.

I shall now change the scene to the Chiromo marsh, which is situated near the Shire river to the south of the Nyasaland Protectorate. On September 28, I9Io, I was 
camped at Muona's village and had spent several days looking for a good buffalo bull. There were plenty of buffaloes about, but up to this time I had not come on a very good bull, and often the tracks were hardly fresh enough to be worth following.

On the morning of that day I determined to get away very early, so got up before sunrise and dressed and breakfasted by candle light. As the darkness of night gave place to a soft grey light we left camp and went to some big maize fields to see whether game had been feeding on the dried stalks. All game is very fond of these stalks and come long distances to feed on them, and fresh spoor can usually be found in these places. In less than an hour we found the night tracks of three buffalo bulls, which, judging by their steaming dung, had just left the spot. We were soon going behind them, and had not got more than 300 yards into the thick bush and grass when a man who had climbed a large anthill said he saw them.

I was soon alongside him, and following his directions I looked ahead and saw the head and horns of a buffalo, which was evidently standing and listening, as he doubtless had heard us in the bush. I had a 404 magazine rifle which had a drag pull, and as I had not used this rifle much I made a mistake in not shooting with my $7^{\circ} 9 \mathrm{~mm}$. Mauser which I knew well. I forgot the drag pull of the 404 , as my $7^{\circ} 9 \mathrm{~mm}$. has an ordinary pull, so I made a bad shot and missed the bone of the neck. However, there was no doubt that I had struck the buffalo somewhere, for he grunted in an angry manner as he ran off with the other two. Then began one of the most exciting days that I have spent in Central Africa.

On reaching the tracks, there was a lot of blood scattered on the leaves and grass. About 8 a.m. we disturbed the buffaloes, which ran off again before I had time to get the rifle to my shoulder. After this we found the wounded bull had taken a line of his own, and on comparing the tracks I was glad to see that his were much larger than those of his companions. 



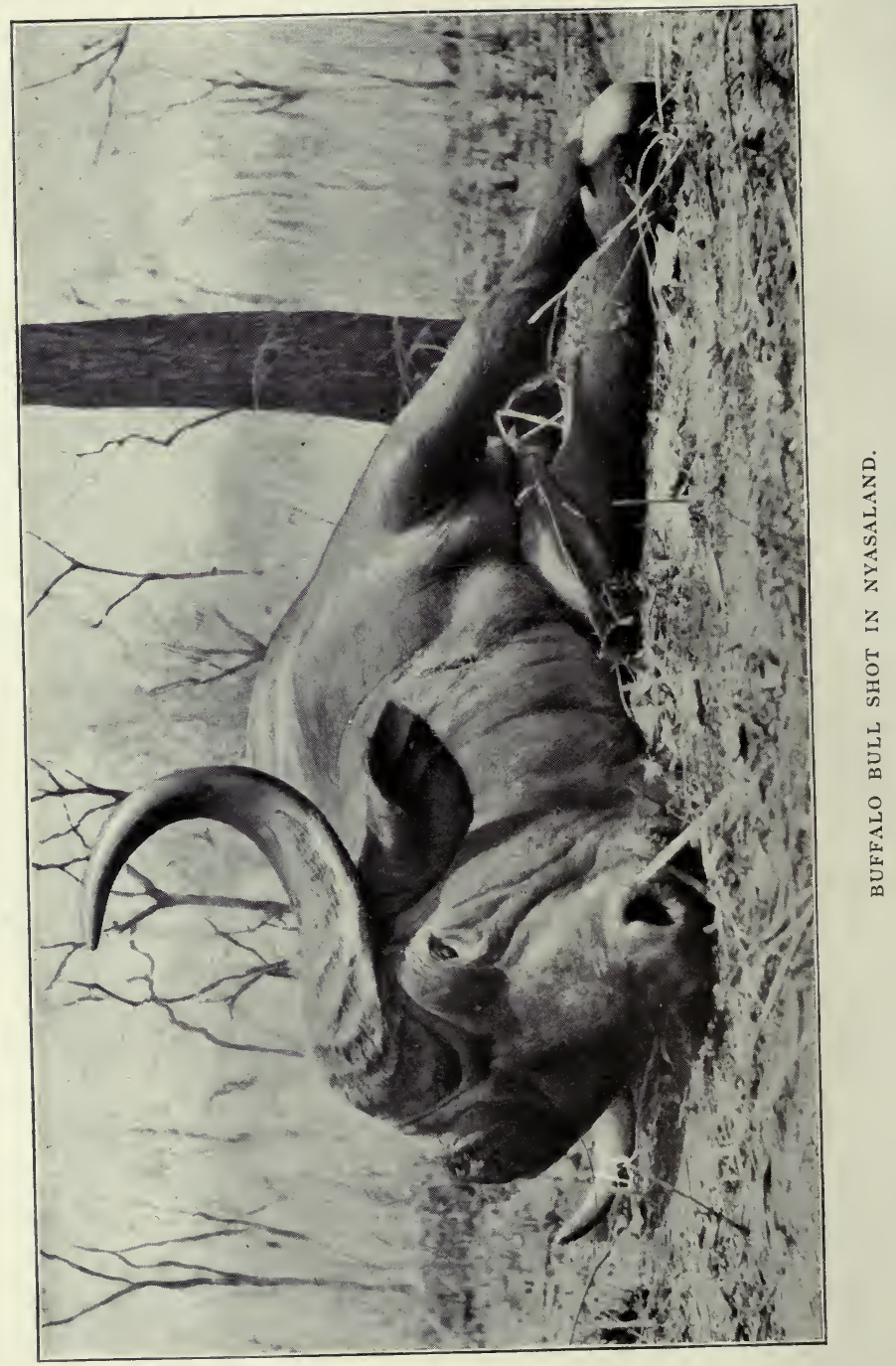


This was satisfactory in a way, as we now thought that he would not go very far before stopping. Besides it is: easier spooring one beast than three, and we knew we were behind the wounded animal.

The sun was terribly hot and the heat reminded me of the Zambesi and Luangwa valleys at the same time of year. Another three hours was spent in following slowly and carefully; for when I came to a particularly thick part of the grass I sent men up trees to look around, as I had no wish to stumble right on the horns of the beast in such cover.

Then, in some fairly open grass country, I saw him standing broadside on, except that his head was turned in our direction. I fired quickly with the 404 , and he fell on his back, and I thought I had broken his spine. However, I was mistaken, for he was on his legs again in three seconds, and off he went, with myself and the men running behind, as I wished to keep him in view as long as possible.

The gallant beast heard us following, and, like an old warrior, he turned to meet us, grunting loudly at times. $\mathrm{He}$ then began trotting in our direction, so most of my men began to climb trees, and I was amused at the calm way they did this, as none of them hurried. Molilo, a very plucky fellow, stayed behind me with the $7.9 \mathrm{~mm}$., and we stood and watched the buffalo, which seemed very sick. He looked up at the men in the trees, and could not see me well, as I had taken slight cover behind a big bush. Then he stopped and looked round with the sort of air that seemed to say "Come on; I am ready for you." When he stood I could not see his shoulder well, as a few saplings were in the way, so I fired at his hip-joint, and, on getting the bullet he swayed, and I thought he would fall. He did not, but, instead, turned round and walked slowly away. I now took the small rifle and ran alongside him, and he turned at once. The plucky old animal was now too sick to charge, I think, for he only stood glaring at me with his head up. At about twenty yards I fired for his heart, which 
lies very low in a buffalo's chest, and he fell for good, and began to moan and bellow.

Most buffaloes when dying bellow several times, and it is their last good-bye to life. I never hear the sound but I regret killing such splendid animals, for a buffalo is a much pluckier beast than most.

It was close on midday by this time, and, as I had hit the buffalo first before 6 a.m., it had been six hours of intense excitement and hard tracking work. A little water was left in the gourds, and there was enough to brew a cup of tea and give the men a few mouthfuls. I do not think I ever enjoyed a cup of tea more, or the pleasant smoke that followed it, as I sat and gazed at the fine beast I had had the good fortune to lay low. After that I took some photographs, which turned out very well, and, before covering him up with branches and grass, I measured his head, which was not exceptionally broad, but very deep over the frontlet, and old and gnarled. It was a fine trophy, but I had to work hard for it, which always makes it the more valued in the eyes of the hunter.

In the same month of the following year (I9II) I had another exciting day with buffaloes. This time I was camped at Machinjiri, a small stream, rising in the Cholo range and flowing towards the Shire through some of the best game country left in that part of Africa. The rains had been late, and therefore much of the grass was green, and there was a lot of water in the lower parts, which made tramping through the country hard work. On that day, September 25, I was off early, as it is necessary to make the most of the cool hours of the morning. The first animal I saw was a reedbuck, and then I saw a single bull waterbuck, neither of which I wished to fire at, as I hoped to see buffalo.

We had walked some five miles, when, suddenly, as we were skirting a large dambo full of grass, reeds, and water in its lower parts, four buffaloes ran out into the open. 



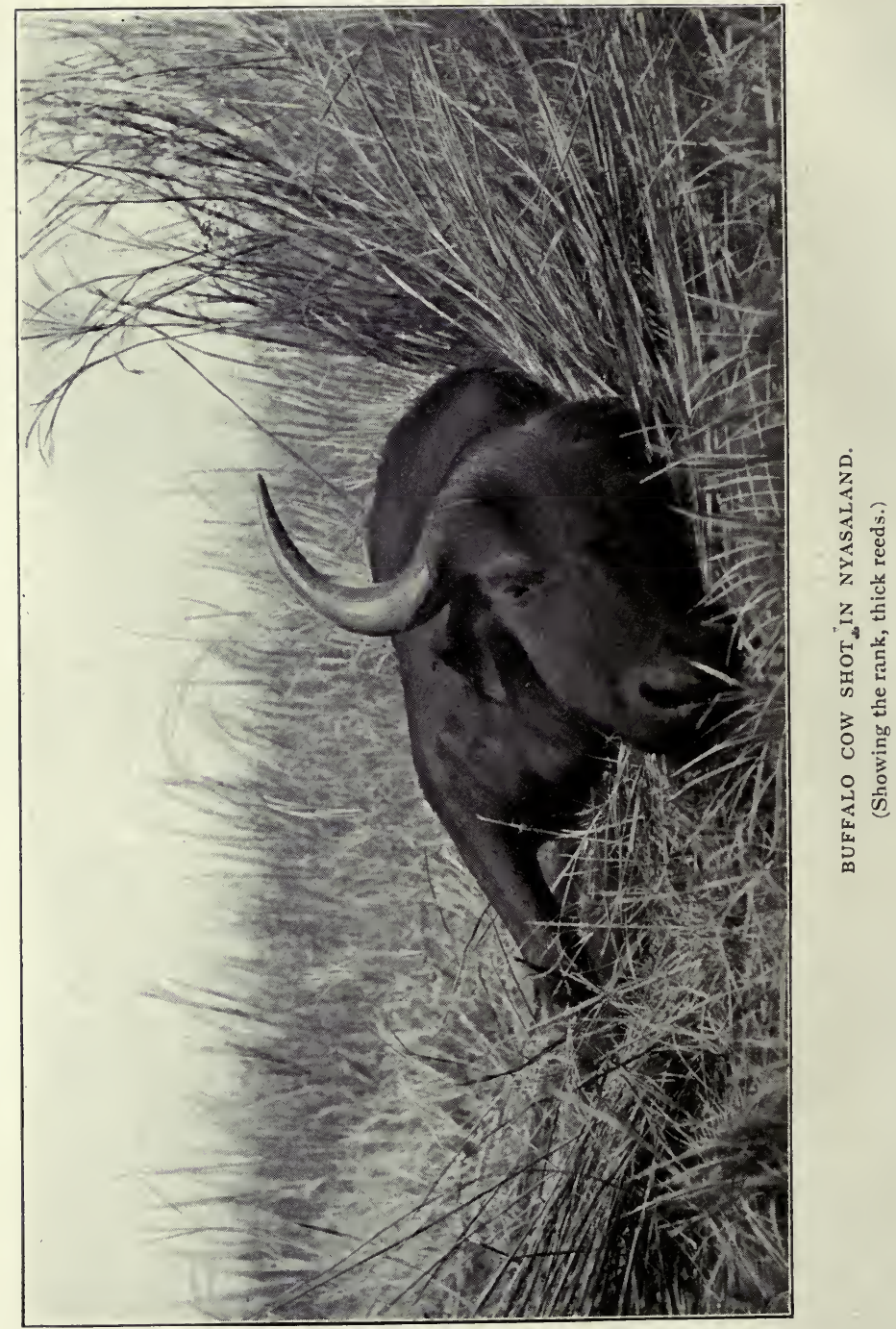


Two appeared to have fair heads, and there was little time to pick and choose so I fired at the nearest, and then fired again, and it ran a short distance and dropped. Then I hit two others, both of which ran back into the thick reeds, and one I heard bellow soon afterwards. The fourth, which I thought seemed the best, had run along the edge of the swampy ground where the vegetation was not so rank; I climbed an anthill and hit it twice, then went to find the two which had taken cover, and soon came on the carcase of the one I had heard bellow, which was lying in the mud and water. The other I heard near so I climbed another handy anthill and gave it a shot which seemed to drop it. I waited about a quarter of an hour and then went into the reeds, and on getting to within twenty yards the buffalo, which had been lying down, stood up, and I gave it a good shot between the neck and shoulder which killed it.

It was nasty work following buffalo in this kind of country as the odds were mostly in favour of the game, for it was quite impossible to see anything until one got to close quarters, and the soil was sticky and muddy, quite preventing quick movement.

I now went off to look for the animal that had gone along the edge of the dambo, and we soon found the footprints leading into the swamp. I took one man with me carrying a 400 cordite rifle, and carried my little $7.9 \mathrm{~mm}$., as I always feel safer with a rifle I know well, even although it is a small bore. We went slowly, and stopped every now and again to listen for the breathing of the wounded animal. Suddenly a black object caught my eye, and this was the buffalo's head, which was all that was visible. However, I knew he was standing almost head-on, so I fired at an imaginary mark about a foot below his nose. He got the bullet, as I heard the "phut," and he turned round and bolted. This was getting a bit too exciting, for I could not lift my feet out of the mud and water without some trouble, and every step made a noise in the rustling reeds and water. However, 
I decided that I must see the matter through as I had wounded a fine animal which it was my duty to try my best to finish, so I followed slowly. We had gone about a hundred yards at a slow pace, when I heard a loud grunt almost under my feet, and I saw the buffalo, which seemed very stiff, begin to rise like a cow by putting up its hindquarters first. Through weakness it could not rise quickly in the soft ground, so I took a most careful aim between neck and shoulder and fired with the small rifle, and I was both pleased and relieved to see it sink down and fall over on its side and begin the death bellow.

This buffalo was less than three paces from where I stood, which is a little too close, in my opinion; but " all's well that ends well." If it had not been severely wounded and weak, it is likely that it would have got me, as it would have been absolutely impossible to escape it in such ground. Therefore, for such work there can be no doubt that a man requires the heaviest rifle he can handle; and a 470 would be a much more reliable weapon than a $7^{\circ} 9 \mathrm{~mm}$., which is 3 I I bore. As all African sportsmen know, the buffalo is the hardest beast to stop once it has started a charge, so a weapon with great striking energy is the best tool for such work.

These buffaloes consisted of two bulls and two cows. The horns of the bulls were nothing to speak of, but one of the cows had the best head I have yet seen on a cow buffalo; and I took her complete skin off for mounting in a museum. She had an old bullet wound in one of her front legs, and she and the others were covered profusely with ticks. especially on the softer parts of the bellies, and the soft skin inside the thighs. Buffaloes are lumbering looking beasts, but they can go at a great pace, and being very heavy they break through thick cover, just like elephants and rhinos. Their colour when young is brownish; but when they get old their hides turn a greyish black, and in thick cover they are not easy to make out.

A few days after this I came on a small herd of elephants, but not having taken out an elephant licence, had to leave 



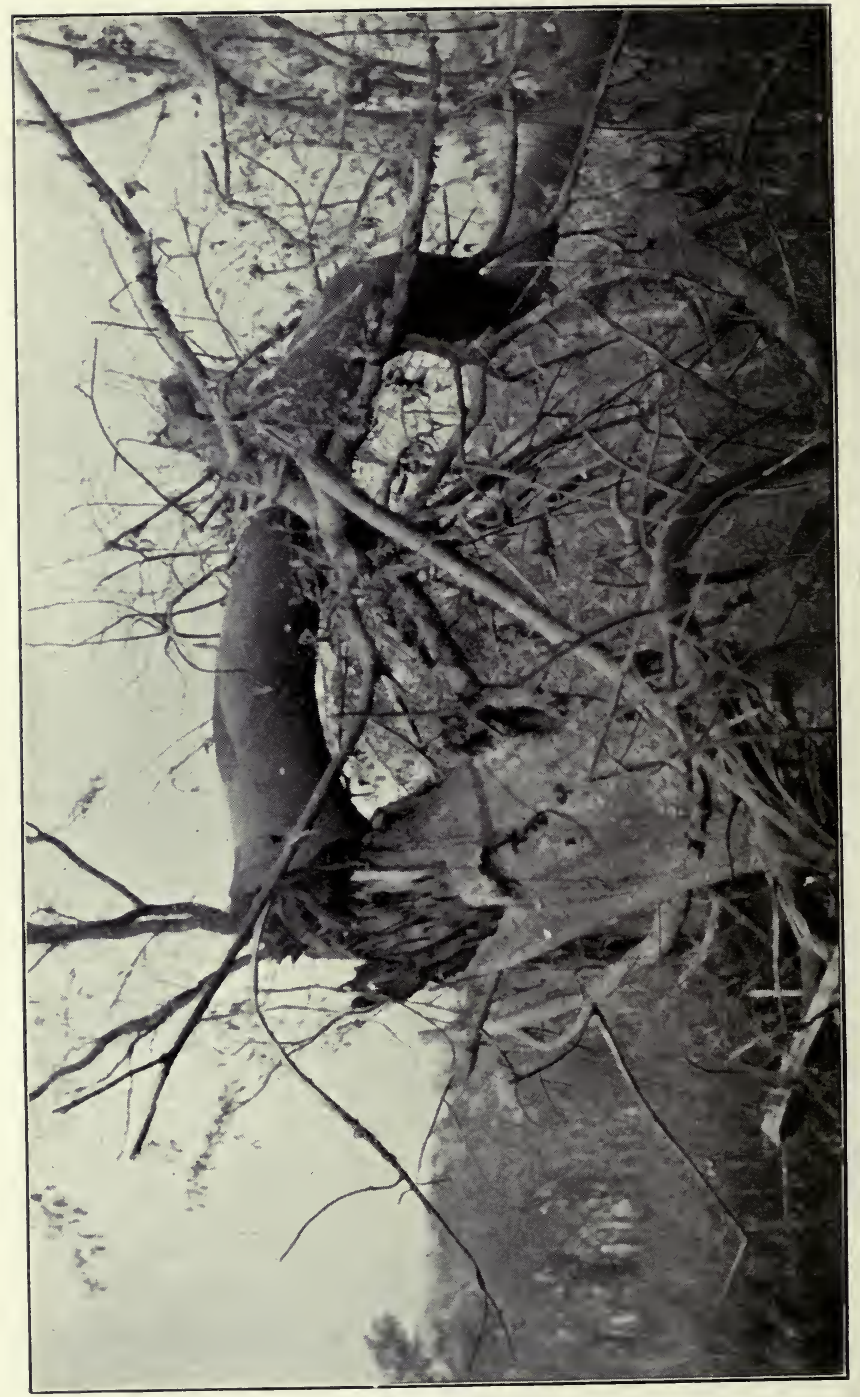

落 
them alone. Strange to say I saw this herd within 300 yards of the place where a white elephant hunter had been killed by a cow elephant the previous year. The natives told me that this cow was still with the herd, and when I saw the elephants and pointed to them, the villagers I had with me did not wait, but cleared off as if the devil was after them.

Not far from here I got a photograph of a very large tree broken by a bull elephant, and it measured just under the place it was broken $52 \frac{1}{2}$ in. in circumference. As far as I can remember it was an "nkuyu" tree, which is soft and stringy in the wood. Anyhow, it was an example of what a big bull elephant is capable of in the way of muscular strength.

The district under the Cholo range is flat, and game is most abundant, comprising many eland, buffalo, waterbuck, zebra, hartebeest, and reedbuck. Elephants are often found, and I saw the fresh spoor of a bull rhino one morning.

Close to the Shire River, that rare and lovely antelope, the inyala, exists, and in the Cholo hills sable antelopes are fairly plentiful. Bushbuck, too, are numerous all over the place, and some of them have good heads. I shot a reedbuck one day, the best I saw out of quite fifty of these animals, which are found in lots of from a couple to five or six animals, and it had a very pretty pair of wide-set horns measuring $17 \frac{3}{4} \mathrm{in}$. from tip to tip, and 14 in. along the curve.

It is possible to reach Chiromo in about four days from Chinde on the coast, and as there are plenty of boys looking for work during the dry season, which is the best shooting time, a sportsman who is in a hurry could not find anywhere in Africa a finer shooting ground. The heat is very great during the months before the rains, and if a man does not relish a tropical climate he had better not go there; but on the other hand if he wants good buffalo, eland, waterbuck, and bushbuck heads he is almost certain to get them there. Moreover, he has a very good chance, if he is a lucky man, of coming on lions, although during 
several trips there I have been unfortunate in not seeing any. It is probably the best district for lions in Nyasaland, and a good many have been killed there. In the rainy season, when the lions find the game difficult to catch, they often enter the township of Chiromo, and some grim tragedies have taken place there, many natives having been seized and killed, in some cases almost at the doors of the white inhabitants.

It was a great relief to get away from the plains by climbing the steep path at the top of the Cholo range, and I remember the lovely views of the game country stretching away in the blue distance, with many a grass fire sending up clouds of black smoke, which sometimes hung in the air, forming great long bars across the horizon.

The buffaloes leave the marsh in the rainy season and go to the top of the range, doubtless for coolness, and to get away from the flies, and perhaps, also, for a change of food. I noticed a good deal of old spoor on the plateau.

Again let me change the scene to the eastern border of Nyasaland, which is a very broken country, full of high hills and small ranges. I had gone to a place near Mausi Hill to get specimens of eland and sable antelopes to send to a South African museum, and I had passed along the valley of the Tuchila River to get there. The country was covered with big thorn trees, the stems of which often have a sickly appearance, as some are yellow, others an ochre, and many a nasty green colour.

Besides these large trees the vegetation is full of small thorns and sharp grass, which soon make a pair of bare legs very ugly, and some of these deep scratches are apt to fester, unless a man's blood is in good order.

The Tuchila Plains, as this place is often called, used to be a fine game country in the old days, and elephants were once abundant there; but constant persecution has made them trek to safer regions. When I got round the base of Machemba Hill, which has several other large single hills in close proximity, such as Nchesie, I came, after trudging for a few miles, to a small stream called Nandeu. Here the 



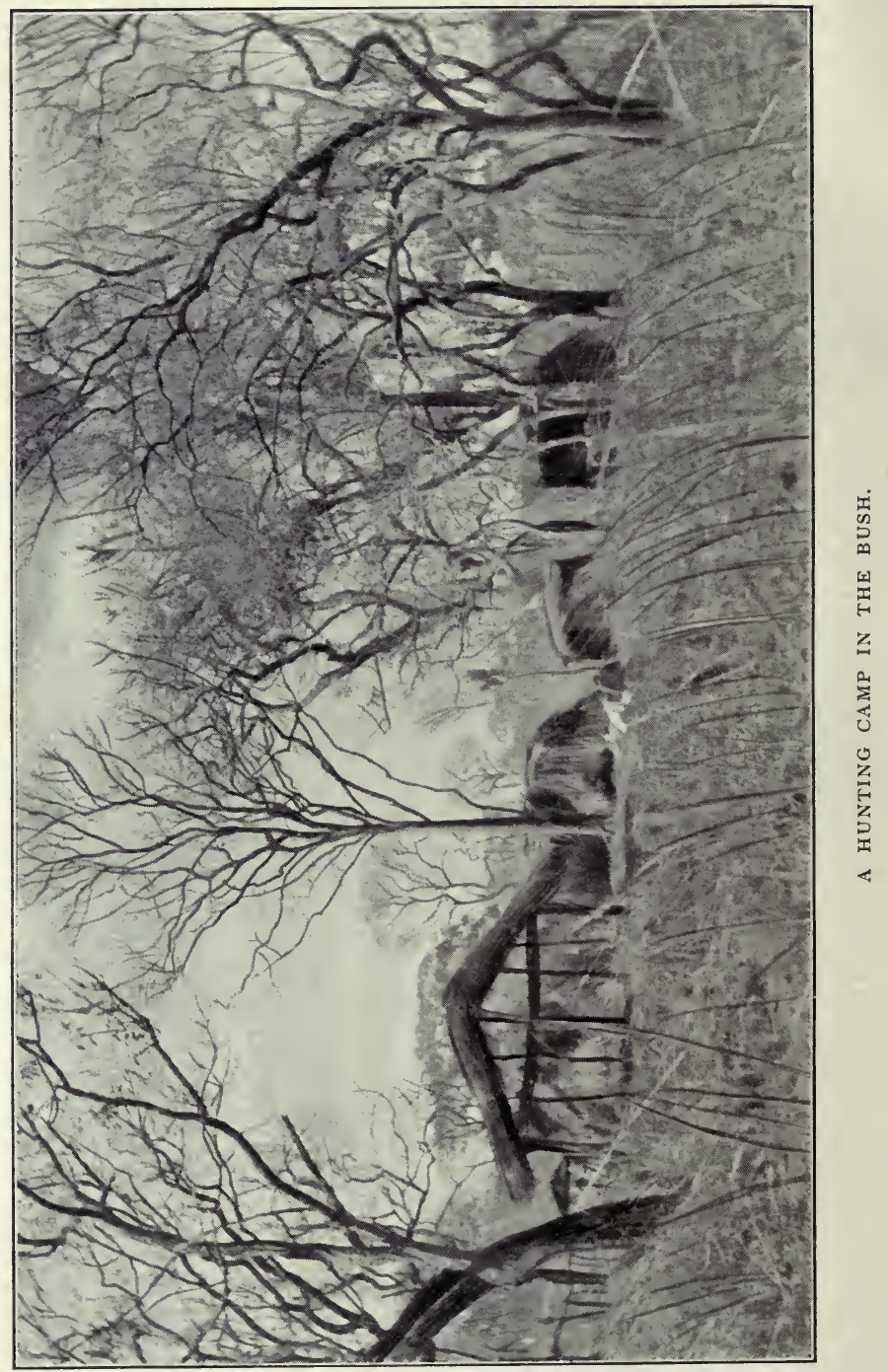


headman of the small village on its banks was named Beni; and he had served several years in the King's African Rifles, a fine corps of native soldiers. He showed me his medal for the Ashanti campaign, in which he took part, and he was a very civil sort of man, and offered to get another man and show me the best game country ahead. While he was away I had some lunch, and the carriers got a rest and some food. Then, Beni having returned with a friend, we started off through the bush for the country right under Mausi (pronounced "Ma-usi") Hill. Here we came to a dirty waterhole, so, as game spoor was thickly imprinted on the ground in every direction, I put my tent up under a big tree.

At three o'clock I went out with Beni and the other man, taking besides about six men to carry in any meat I got. The guide took me through some fairly open country, covered with short, stiff grass and full of thorn trees, and we had not gone far before I saw a herd of sable antelopes. Telling the men to sit down and keep quiet, I managed, with a good lot of trouble and a plentiful amount of scratches, to get within 150 yards of the game. One bull was very black, so I thought he would likely carry a good head, and I fired at him. At the shot he ran off with the herd, but stood after going a short distance, when I fired again and dropped him. I then killed another male before the herd had vanished.

The oldest animal measured 55in. at the shoulder, and he had rather an abnormal head, for the horns were extremely thick and cobby, though they only measured about 33in. in the curve. This was not a young sable, but a very old beast, with large bulges on the base of his horns. Only fully adult animals have these bulges. As his body measurements were very large, I came back next day and took his complete skin for setting up. Most of the meat of the other animal was carried to camp and eaten up that night by my hungry men.

On the $25^{\text {th }}$ I wounded a bull sable with a very pretty pair of horns, but lost him. After getting back to camp and having some food and a rest, I decided to go back 
in the afternoon and have another look for him. Going through some thick grass I found a good blood spoor, and followed it, when suddenly, within fifty yards, up jumped the bull, and I hit him hard somewhere in his stern. Going on, I put him up again, as I thought, and fired and dropped him with a shot in the spine. On going up to him I found that this was quite another animal, as he had no previous wound in his body, and I noticed the head was different, although it was quite a good one.

After searching around, one of the men found the blood of the first one, and I soon came on him lying down; but, when he saw us, he was quickly on his feet. However, he waited just a little too long, for I got the sights on his shoulder and killed him where he was standing. This was a most beautiful animal, being very slenderly formed in comparison to the one I had shot on the $23 \mathrm{rd}$. His horns also were much longer and thinner, as they measured nearly 40 inches on the curve, and had very even, sharp points. I took his complete skin, and it can, probably, now be seen in the Transvaal Government Museum in Pretoria, to which institution I sent it.

On the 27 th I went out to try to find eland, and came on the fresh spoor of a large herd which I spoored up. Eland are easy beasts to track, as being such heavy animals they leave a good print. When I first saw them they were all grouped together, and in the thick grass and bush in which they were standing I found it most difficult to see the best head.

I got on them with the glasses, and at last saw a fine big bull, so I took a steady shot and the bullet, a solid, went right through him, and raised the dust far on the other side. As he went off I fired two more shots, and hit with one at least.

I could see one of his hind legs dangling, so I knew I would get him, as a heavy beast can never go far with a broken back leg. Before I finished him I took two photographs of him moving in front of me, and then gave him a bullet in the heart, which quickly killed him. 



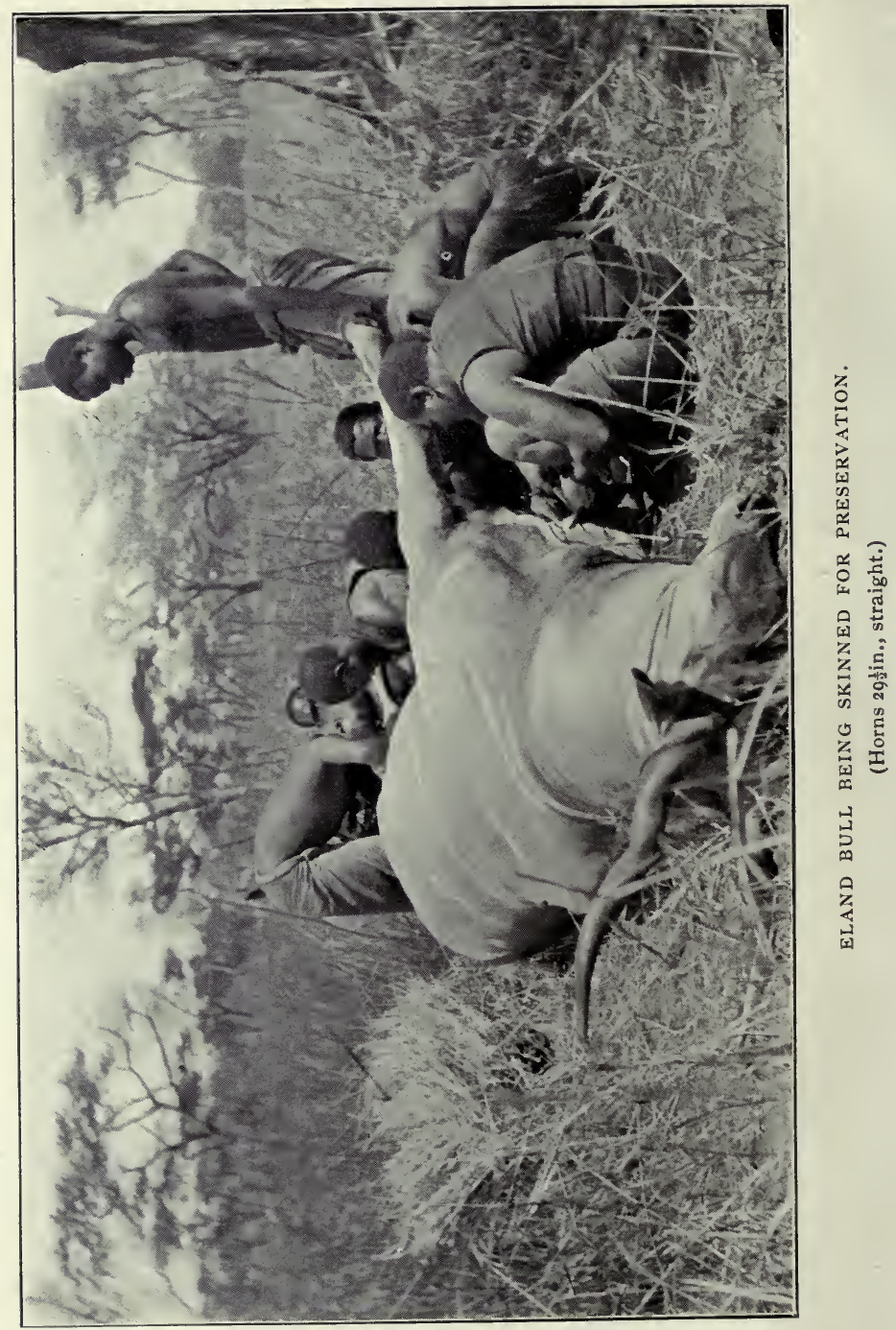


Some natives hearing the shots came running up, so I asked them to go and get some water for my men and myself from the stream near their village. One man also brought me back a few eggs in a small pot, which I boiled and enjoyed.

Wanting the complete skin of this animal for setting up, I took many measurements, but as I have given some of them in Chapter III., I will only say that he was $72 \frac{1}{2} \mathrm{in}$. in height, and his horns measured 29 $\frac{1}{2} \mathrm{in}$., and were nicely shaped. It took over three hours in the hot sun to get his hide off, and I was very tired and thirsty before I reached camp at sundown that evening; but a warm bath and a good dinner soon freshens a man up. I used to have a big camp fire every evening, and my happiness would have been complete if I had only had a congenial companion to talk to.

The next few days were cloudy, a few showers of drizzling rain came on at times, and I had the greatest difficulty in getting the eland skin dried. In such weather the thick neck skin will not dry, and in most cases it has to be thinned down with knives so as to hasten the drying. As I could not get my knives sharp enough I used a pair of good ivory-handled razors, which improved the skin, but not the razors.

Although I took a great deal of trouble over it, this skin eventually went bad on its way to the Transvaal, as, owing to the carelessness of a firm of Portuguese forwarding agents at Lourenço Marques, it was delayed in transit. Truly, collecting in a country like this is disappointing work, as after all one's trouble the results are liable to be spoilt by other people's negligence. Freight is very high there for all such heavy packages.

Chiromo district would be a very good one for any collector to work in, as there he would be near the river, where specimens could be placed on the steamers at once for transporting to Chinde. It is a difficult matter getting large skins carried safely through the bush, as they are very apt to be chafed by the thorns, rough trees, and 
bushes, but I managed this by covering up the ears and head with old sacking and newspapers.

I spent some days trying to get hold of a good bull kudu, as there were several herds in the vicinity of Mausi Hill. On one occasion I wounded a fine fellow with a quick snapshot, but he escaped me, although I spent a long time trying to find him. Another day I managed to stalk a very wary herd and I saw the horns of a bull, but owing to the position he held his head I could not tell whether they were big or not. The shot I fired killed him and I was disgusted to find that his head was a poor one, so I simply took the headskin, and sent it and the skull to the Transvaal Museum, as I thought it might prove interesting to students. of natural history to exemplify the formation of growth.

To show how a collector may be robbed of his spoils I shot a nice bull kudu when on a short trip to the Palombe stream, and he had a very pretty head. It was almost sundown when I got him and camp was a good three miles off, near the stream, which was clear running and pure. I managed by the help of two big fires to get his skin off up to the neck, so I cut it off there and rolled it up in a bundle and got home by 9 p.m., giving my legs some nasty bumps when getting through the thorny bush by dull moonlight. After cleaning my rifle and eating a good dinner, I went to bed, seeing that the skin was put up in the fork of a large tree beyond the reach of any prowling hyæna that might pay the camp a visit. Next morning I tackled the skin of the head, with the help of a Yao boy named Marki, whom I had taught to skin well. My cook then told me breakfast was ready, so I left Marki to go on with it for the part he was busy on was easy, as the ears had not yet been reached. When I was at breakfast Marki appeared and said in a plaintive voice that he had cut the skin of the neck, and on going over I found he had made a big gash right through it, which quite spoilt it for the purpose of setting up. His error cost me a very nice specimen and a considerable sum of money, so I told him he would be fined. 


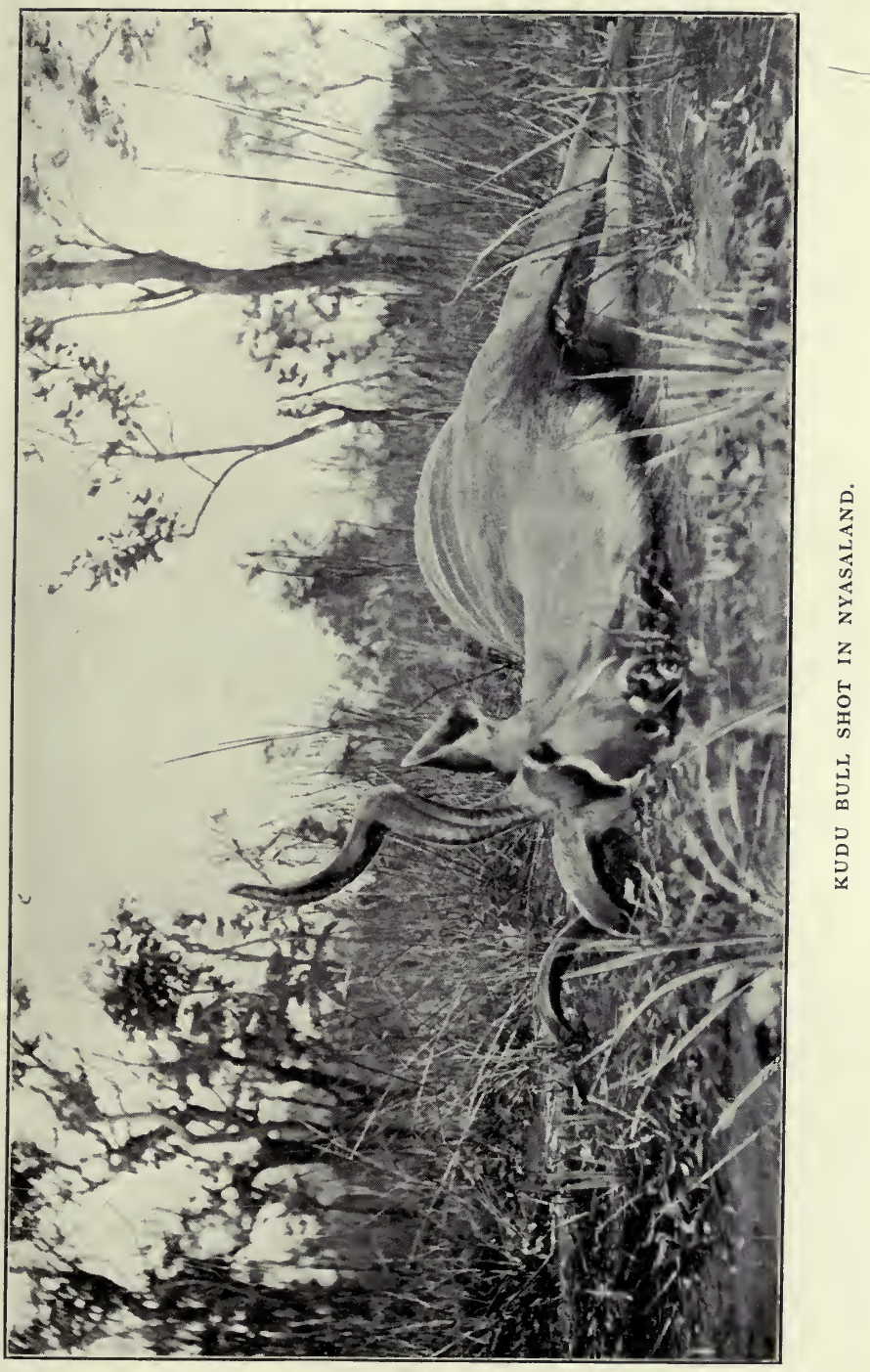



I then went out into the bush to look for another kudu, but without success; and on returning to the tent I found Marki had absconded, taking with him a small boy who carried his blanket when marching.

Another thing it is most difficult to make the natives understand is that they must keep skulls and bones seething with bacon beetles away from skins; and I constantly had to find fault with them for mixing them up. When I had taught them to be careful in camp by putting the skulls at one side and the skins at another, one would imagine that they understood, and yet when I started back for home they would place a skin on the ground, when resting, and then quietly deposit a bundle of skulls right on the top of it. This, to say the least, is aggravating, but only what can be expected from human beings who have not been blessed with moderate reasoning powers and the gift of perception. However, with all their faults, they are good, faithful servants, if kindly, but not familiarly treated. Their best points are most prominent when one is travelling in the wilds and shooting, for here they are in their element.

The grass was very sharp and hard near the Palombe stream, as it is round Mausi Hill, and one day I saw a man walking in front of me stop and look at his leg. I thought perhaps that a snake had bitten him, so I said "Chi-ani?" (What is it?); and he showed me a stem of thick grass sticking clean through the full thickness of his calf. I pulled it out, and he was all right; but I was surprised at a piece of grass being able to penetrate in this way, particularly in a native who has a pretty tough skin.

As I have mentioned, I always walk about and hunt in bare legs; and, although I got many cuts, scratches, and bumps I never ran a stem of grass through my leg. Once I got a long thorn right under my knee-cap, which caused great pain, and prevented me walking well for some time ; and, again, a thorn once penetrated a rope-soled shoe I was wearing and broke off in the instep, but otherwise my legs have not met with any serious accident 
although I have not been so fortunate with other parts of my body.

When in India long ago, tea planting, I dislocated a shoulder playing polo; and in the South African war two ribs were smashed by a fall off a "buckjumper," and I have met with a few minor accidents not worth mentioning, although I remember them, well; but up to the present no wild beast has managed to get hold of me, although they may have chances yet!

To conclude this chapter, I will give the account of an interesting day's tracking, or the best part of a day.

While marching along a narrow native path I saw a herd of hartebeest grazing near, but the rifle was in its cover, and just as I got it out and had loaded, the game began to move off. I fired a fairly long shot, and hit a large bull in the rump; but, instead of stopping him, the wound seemed to act as a tonic, and he went away fast. Before going further, I may say that hartebeests (Lichtenstein's) are usually the poorest sporting animals in Central Africa, as they often behave very foolishly, and watch their companions being shot down without making any attempt to run away, at least out of range.

However, when much shot at, a single bull hartebeest can become one of the wariest animals, and it will need careful stalking and much care to get within range of him. This fact I note, as many authors on sport seem to think the hartebeest is always an obliging animal in offering himself for the pot, and the very opposite can be stated at times.

After wounding the hartebeest, I waited until my cook and the carriers came up, and told them to go on to within an easy distance of the water, which was in front. I then took four men and began to spoor the hartebeest. We had gone quite three miles before we saw him, when I gave him two shots, which both hit, and he walked a short way and lay down. I then turned to get the "Kodak," and, as I was doing so, he jumped up quickly and absconded, and was into the thick bush before I could grab my rifle and fire again. Two hours after this I got a sight of him 
again, but he again bolted. This hartebeest had travelled a long way-a good six miles-from where I had first hit him, but I determined I would get him, not only because I had wounded him severely, but also because I wanted his skin as a specimen.

We then heard voices, and I found my men waiting under some big trees close to the path, and my little camptable: spread for lunch, so, as it was nearly midday and I was thirsty, I decided to have some tea-the best thirstquencher I know-and some food; and the waste of time, although hard on the hartebeest, would give him time to settle down.

In about an hour the men and I left again, and, to make rather an uninteresting incident short, I may say we found him dead close to where we had left the spoor.

He turned out to be a fine male; but, as one of my shots had broken the lower jaw and torn the skin badly, he was useless as a specimen, although his meat was much appreciated by my hungry men, who seldom complained of too much nyama. 


\section{CHAPTER VIII.}

\section{I.-Field Notes on the Game.}

The following animals described:

Elephant.

Rhinoceros.

Hippopotamus.

Buffalo.

Eland.

Roan antelope.

Sable antelope.

Kudu.
Common waterbuck.

Hartebeest

(Lichtenstein's).

\section{Sassaby.}

Situtunga.

Inyala.

Puku.

Lechwe (two varieties).

Bushbuck.
Reedbuck.

Impala.

Oribi.

Klipspringer.

Common duiker.

Sharpe's steinbuck.

Blue duiker.

Livingstone's antelope.

THE following notes are the results of ten years' experiences, almost wholly spent in the wild places of Central Africa, where game is very plentiful if one goes to look for it in its natural haunts. As I have written before, some people imagine, because game is less seen in this country than it is in more open spaces in other countries, that it is very scarce. This is quite a mistaken idea, and Central Africa - Nyasaland, Northern Rhodesia, and adjacent countriesholds a most plentiful and varied stock of game.

In previous volumes I have already written a good deal on this subject, but I think a book on shooting would be imperfect without giving an assorted list of the principal fauna, and this is my excuse for adding this chapter to the present volume. I give information here on other subjects, such as the approximate weight of the animals, good average trophies, and two native names in different languages, all of which I trust will prove useful.

The mark $\delta$ is for male, and $q$ for female. 
ELEPHANT (Elephas africanus).

NATIVE NAMES.

Chinyanja - - Njobvu. | Chingoni - Nkhlovu.

Approximate weight, $\delta \quad \ldots \quad \ldots \quad$ I 3 , ooolb.

Good average tusk, $\delta \ldots . \quad \ldots \quad \ldots \quad$ 4olb.

Good average length, $\delta \quad \ldots \quad \ldots \quad 66 i n$.

This grand animal is still very plentiful in the countries I write of, although many of the largest tuskers have been thinned out within the last ten years. It is certainly unfortunate for the elephant that ivory is such a valuable substance, as otherwise his body is of little use, except in supplying an abundance of meat, which the natives are very fond of, as they believe eating it gives them strength. The best ivory comes from this country, it is known in the market as Mozambique quality, and it is seldom that ivory of bad quality is shot here.

The best tusks are called "soft" ivory, and the inferior ones "hard" ivory. The former brings up to i5s. per pound in the European markets for bull tusks, and the ivory of the cows is much more valuable, as it sometimes fetches $£$ I per pound.

The most remarkable features about the elephant are his enormous strength and his powers in covering long distances. He is certainly "The King of Beasts," and one stamp of his mighty foot would flatten out a lion as a man can a beetle which he treads on.

Elephants in their natural haunts cover an immense extent of country in their daily wanderings, and they are always at it, except when they may find a good feeding ground, such as a large maize garden, when they will spend perhaps two weeks hanging around. In the rainy season they do not travel so much, as water and feed are plentiful, and this is a trait unlike most animals, which scatter and disperse in the rains.

The largest bulls often wander about singly or with a comrade or two, and such friends may be quite small 
elephants, or they may be almost as large as himselt. A fair tusker will have tusks about 4olb. each, though many grow bigger tusks.

A 70-pounder is an exceptionally good one, and I have not heard of any eleptant being shot in this country with tusks over r 2olb. each. In Nyasaland, where elephants are numerous in parts of Central and Northern Angoniland, the biggest I have heard of was a 95-pounder, but I have little doubt that a roo-pounder is wandering about somewhere in this country. The heaviest tusk known is one weighing $235 \mathrm{lb}$., length roft. $4 \mathrm{in}$., and $26 \mathrm{in}$. in circumference.

The longest measures I Ift. $5 \frac{1}{2}$ in., with a circumference of $\mathrm{I} 8 \frac{1}{2} \mathrm{in}$.

The largest tusker known to have been shot by a white man was one killed by Major Powell Cotton in the Congo Free State, and the two tusks weighed $372 \mathrm{lb}$, the larger tusk weighing I98lb., with a circumference of $25 \mathrm{in}$, , and gft. long.

That well-known elephant hunter, the late Arthur $\mathrm{H}$. Neumann, never killed an elephant with bigger tusks than I 2 olb., although he shot many over roolb. Selous hunted elephants in Southern Africa, where big tusks were scarce in his time, and his largest, I believe, was between $7 \mathrm{olb}$. and 8 olb.

Sir Alfred Sharpe, who has killed more elephants in Nyasaland than anyone else, never got an 8o-pounder, so such large tuskers may be considered very scarce in that country.

Certainly a pair of elephant tusks, if long and sharp pointed, are very nice trophies, and I may say the tail is a good trophy as well as the feet. The big front feet make nice receptacles for vases, etc., and the back feet, if cut long, make useful stick or umbrella stands.

The molars take a fine polish, and can be made into various articles such as paper weights. The best taxidermists make very pretty trophies out of feet and skin, though the latter is very apt to warp in changeable climates. 
The most dangerous elephants to shoot are herd bulls, as the cows with calves often charge at the shot, and these young bulls are not such staid, easy-going fellows as their larger brethren, which usualiy prefer their own company or the companionship of one or two chosen comrades. In their old age they get morose, and probably do not wish to be troubled with family affairs. It is impossible to say how long an elephant will live, but I believe some must attain an age of over I50 years. An elephant is probably not full grown until he is close on fifty years, and his tusks probably keep on growing for a much longer time.

When a man has shot a really big elephant he has probably shot an animal that was roaming the wilds before he saw the light of day; and to see such an animal fall always reminds me of seeing some monarch of the forest sink down before the implements of man. Elephants drink daily, and they travel long distances for water in the dry season, and often do not drink twice consecutively at the same water where they are much molested. If an elephant is killed, the others will leave the locality for a time, as they seem to dislike the smell.

Smell is the strongest sense in elephants, and I am sure they will scent human beings at about three-quarters of a mile if the wind is strong and steady. Such being the case, the direction of the wind has to be carefully studied before trying to approach elephants for a shot. Their sight is very bad indeed, and if a man moves slowly, and keeps still when the animal is looking in his direction, he can go up and smack an elephant's body on occasions. Some tribes-such as the Ndorobo of British East Africa -kill elephants with poisoned spears, and to do this they approach within a few feet.

When near elephants one will often hear the flapping of their ears; also strange rumblings made by their digestive organs, I think. At times they emit shrill cries, and I once heard a wounded bull crying like a child.

If an elephant had been wounded and closely approached, and becomes aware of the proximity of the hunter, he will 
often give vent to several piercing shrill cries, at the same time flapping his ears violently, and on occasion stamping his feet; then it is advisable to shoot very straight or get out of his way. An elephant can run very fast when he means mischief, and a man on foot would find it quite impossible to get away unless there was cover about. A good horse can outpace an elephant in open ground, as a rule; but if the horse was tired, or a sulky animal, it would go hard with the hunter. Long ago, when unlimited elephants could be shot, it was the custom of the best hunters to run them down on foot, and Mr. Selous told me that in hot weather he has sometimes run elephants almost to a standstill.

When carrying a heavy rifle in soft, sandy ground, this must have been the hardest physical exercise it is possible to imagine. Of course, old hunters did not dress, like some of the modern sportsmen do, in tight breeches, with leather gaiters, and their coats or shirts decorated with bright leather patches, and, in some cases, their belts covered with an assortment of knives and odds and ends, like a Christmas tree. No, they simply wore a hat, shirt, small pants (although these were often not worn), and a pair of shoes. It is a good thing for men to inure themselves to going about in bare legs, for they will move unhampered, and, if the occasion arises for a bolt, they will be able to run hard. A few scratches will not hurt anyone; in fact, after a time, one hardly feels them at all. Without doubt, elephant hunting is the finest sport in the world, and, when these fine beasts disappear-which I hope will not happen for a very long time-the finest beast on the earth to-day will have vanished.

The best shot at an elephant is, undoubtedly, the heart, as most accurate shooting and great experience is necessary to hit the brain. The heart, too, is very much larger than the brain and much more easily reached.

A $7 \cdot 9 \mathrm{~mm}$. bullet will sometimes go right through the heart of an elephant and be found near the skin on the opposite side, and, as penetration is the great desideratum, solid bullets should always be used. 


\section{RHINOCEROS (Rhinoceros bicornis)}

(The black rhinoceros).

NATIVE NAMES.

Chinyanja - - Chipembere. | Chingoni - - Chipimbere.

Approximate weight, $\delta^{*} \ldots \quad \ldots \quad \ldots \quad 7$ ooolb.

Good average front horn, $\delta$... $\quad \ldots \quad$ I 8 in.

The rhino, as he is generally called, is fairly abundant in some parts of the country where there is a good supply of thorn trees and bushes, as this variety does not eat much grass ; in fact, some naturalists say he never eats any grass, although, judging from the contents of the stomach of one I opened, I think that on occasions he feeds on it. His food is bark and twigs torn from thorn bushes, and he must have extremely powerful digestive organs to thrive on such food.

The natives seem to fear the rhino more than they do the elephant, buffalo, and lion; why, I fail to know, as he is not usually a dangerous animal to go near.

He has a fussy appearance, and, as he has the habit of knocking about his dung, the natives think this proves him to be bad-tempered. He has certainly a weird, antediluvian appearance, with his armed head and small, pig-like eyes, and his mouth has what one might term a dyspeptic look; and I can hardly blame him, for a breakfast, lunch, and dinner of thorn and bark must be a most unsatisfactory diet. Perhaps the rhino feels annoyed that Nature has not given him an appetite for more succulent vegetation, like the eland, sable, and kudu.

As thorn bushes are often found on rough, stony hills the rhino is frequently seen in such places, and they are interesting beasts to track, as on hard ground they sometimes leave a very faint spoor. The Machinga Mountains in North-Eastern Rhodesia are full of rhino, and they wander down to the valley of Luangwa River, where their footprints will often be seen. Here they are very easy to 
follow, as the soil is soft and sandy. Unlike elephants, they do not form herds, and it is usual to find them singly or in couples-a male and female-and sometimes such a pair will be accompanied by a calf.

Why Rhinoceros bicornis should be termed the black rhino I do not know, for I carefully examined a white and black specimen in the Cape Town museum, and I failed to notice that there was much difference in their colour; and, moreover, neither follow their names, as they both appeared to be a slaty grey colour.

The black rhino walks with his head held high, and I have read that the white variety holds his head low, and close to the ground.

The latter is a much larger and heavier beast, and measures much more at the shoulder, and he also grows much larger horns.

In the country I write of a $20 \mathrm{in}$. front horn is quite a good one, but in British East Africa the black rhino grows much larger horns than this.

They are very easily killed with modern rifles, and any small bore high-velocity rifle will account for a rhino quite easily. In fact, one only realises the power of such rifles when he sees how easy it is to kill elephants and rhinos with them, and it seems to me that it requires a really big and heavy-boned animal to fully bring out the power of such weapons.

Rhino flesh is often full of maggots, and the beasts themselves are usually covered with plastered mud, as, like pigs, they delight to wallow in muddy holes. Elephants have the same liking for mud holes in very hot weather, and I have seen a deep hole filled with mud and water which was just like a huge bath. I once followed a bull elephant that had just had such a bath, and he left mud on the trees as he passed, and it was possible to get a good idea of his height by these marks.

Rhino will often be found near elephants, so I suppose they leave each other alone; although they never intermix as antelopes of different species often do. The natives do 
not interfere much with rhino, and old iron bullets are not so often found in their bodies as they are in those of elephants and hippos.

Very few of the two latter animals will be shot without such projectiles being found, especially if they are old.

It is a good plan to get pretty close to rhino (as it is with elephants) so as to get in a good first shot, which is always the most important one.

Rhino and elephant when wounded badly do not stop quickly, as do antelopes, and they have the habit of walking on until they drop, so as long as the beast is in sight keep on shooting carefully, if it has already been hit.

Hippopotamus (Hippopotamus amphibius).

NATIVE NAMES.

Chinyanja - Mvuu. | Chingoni - - Mvu.

Approximate weight, $\delta^{*} \quad \ldots \quad \ldots \quad 600$ lb.

Good average tusk, $\delta \quad \ldots \quad \ldots \quad \ldots \quad$ 2oin.

This animal is often described in old sporting books as the "sea cow," but I never saw the least resemblance to a cow in a hippo. Some years ago his ivory was much used by dentists for making false teeth, but since other compositions have been introduced it is no longer used for this purpose. In South Africa hippo hide is in great demand for making whips, although it is not so strong as rhino hide. However, hippos are much more easily found than rhinos, and many of them have been slaughtered in the rivers and lakes near civilisation. While going from Tete to Chinde some years ago, in a houseboat, I saw about ${ }^{50}$ of these animals, and shot several for my men; and on other occasions I have seen plenty of them in the Zambesi, Luangwa, and Shire Rivers. In Central Angoniland there are plenty of hippos in the Bua River, and in other small rivers, and in Lake Nyasa they are abundant; so with all 
the persecution they have suffered they may still be considered plentiful. They are usually found in small herds of from three to a dozen individuals, although in the Zambesi River I have seen a herd consisting of over forty animals. The old bulls, like the males of other large animals, often wander off by themselves and lead a solitary existence, and sometimes such beasts, if wounded, will have no hesitation in attacking and upsetting a native canoe. I have shot a good many hippo from boats (not steamers) and from the banks of rivers, and I have only seen one that wished to resent its injury. However, a big European made boat is a different affair to a small, flimsy dug-out canoe, and if people made a practice of shooting out of these frail vessels they would doubtless meet with more accidents than they do. I think it is a great shame to shoot at hippos from a river steamer in motion, or, indeed, from any craft that is moving, as good shooting in such circumstances is quite impossible. A hippo's brain is very small, certainly not more than 6in. in diameter; so it can be imagined that it presents a small and difficult mark for the best of shots.

Yet some men who have hardly ever fired a rifle before think nothing of pumping bullets into hippos from the deck of a fast travelling steamer. The bullets may hit at times, so the hippo goes off with a painful wound, and retaliates on the first native canoe that appears, as mentioned before, possibly drowning the owner, or at any rate causing him the loss of his canoe and contents, which cannot often be recovered, as hippos nearly always frequent deep water in the daytime. The grunting of hippos is a common sound when camped near a lonely river or lake; they seem to do most of their wandering in the dark hours, and in the daytime lie asleep in thick patches of papyrus or reeds, and sometimes, where they have not been much shot at, will come into open deep pools during the day. The most deadly shot for a hippo is at the back of the head slightly below a line between the base of the ears, but when they are disturbed they will not often present this chance, and 
the usual shot will be a quarter one between the ear and eye or right up the nostrils. Once I killed four hippos in the Zambesi River with four shots, and every bullet hit the eye ranging back to the brain, and the hippos died and sank at once.

In very hot weather, and if the hippo is fat, the animal may rise to the surface within an hour; but if the water is cold and the hippo is a thin beast it may remain under water for quite six hours. It is simply a matter of buoyancy; caused by the formation of gas in the bowels and stomach; and a fat beast produces more than a thin beast, and consequently rises sooner.

The old bulls are darker coloured than the younger animals. It is a very difficult matter to get a glimpse of the teeth when the hippo is in the water, unless he is obliging enough to throw open his jaws. If very wary and shy, they will show little more than their nose above water, and sink quickly. A big bull is a very heavy animal and must weigh about three tons. The skin of their backs is a good inch and a half thick, and very heavy.

When the skin is cut for whips it should be divided into widths of about 2in., then slit at each end so that it may be hung to a tree or platform. Stones are then tied at the other end to stretch it well. If it gets hard before this can be done it can be softened by putting it in water for three or four days.

\section{Buffalo (Bos caffer).}

NATIVE NAMES.

Chinyanja - Njati. | Chingoni - Mbōō.

Approximate weight, $\delta$... I5oolb.

Good average horns ... $\quad \ldots \quad$ 39in. outside spread.

This is one of the finest game animals in the world, and a bull buffalo not only gives the best of sport, but he also grows one of the finest trophies a sportsman can procure in Africa. Buffalo are usually found in herds of from six to 
thirty animals, although at times many small herds collect, and form a large herd of two to three hundred. When shooting buffalo, great care should be taken over the first shot, for if he is only slightly wounded it is often dangerous work following him, as the buffalo, like all wounded animals, seeks the thickest cover he can find.

Although there is little difficulty in killing buffaloes with small or medium bore rifles, a heavy rifle-such as a 450 or 470 cordite-would be better to stop a charge. The buffalo is the most difficult beast to stop, once he means business, and, unlike an elephant or rhino, a badly placed shot will not often turn him. I have found that a buffalo's heart lies lower in the body than any other animal's, in fact it is right against the lower cavity of the chest; so a bullet placed half way up the shoulder would not strike the heart, although it would be likely to cut the big arteries leading into that organ. The lungs are high, but slightly farther back, and this shot is a most deadly one for all game. A large bull is much heavier than a cow, and although he does not stand as high on his legs as a bull eland, he is much broader in the chest and body, but less in the neck measurment. There are still plenty of buffallo left in this country, and they are very abundant in the Chiromo Marsh near Chiromo, and also in parts of Central Angoniland. In North-Eastern Rhodesia they are also common in the Luangwa Valley, and in the country between it and Lake Bangweolo.

Buffaloes usually like wild country with open dambos and plenty of thick bush to lie up in, and they are fond of eating the fresh leaves of bamboos, as, also, are elephants. As I have related, buffaloes give exciting sport when they have to be followed wounded into thick cover, and so I recommend a heavy bore for this work unless a man is a cool, good shot and is experienced. One should never go blundering into thick cover after a wounded buffalo, and the best thing to do is to wait for a short time, and then go very slowly as one has to trust to one's ears as much as to one's eyes. Also, it is a great mistake to be heavily 
clad, for the lighter one is, the quicker he can move, and heavy boots, leggings, and coats are not wanted at this work.

A buffalo's speed is astonishing considering his bulk, and it is quite impossible to judge pace by watching retreating animals at a distance. Once a buffalo gets hold of a man he is usually marked for life, if he has not the misfortune (or perhaps the fortune) to be killed at once. It is almost impossible to brain an oncoming buffalo, so his chest is the only mark to shoot at; and buffaloes have been known to be hit in the heart and yet have enough tenacity of life to travel a long way before dropping. Again, I may mention that a buffalo moves with his head up and nose straight out, and only dips his horns when within striking distance, and then the thing he strikes is usually deeply marked, for they are possessed of tremendous strength in their necks.

Buffaloes drink every day and they love to wallow in mud and water, so they often present a reddish colour. I once saw three buffaloes almost white, as they had been wallowing in some slaty white soil.

The cows have poor trophies compared to the bulls, and they are not nearly so difficult to kill, and the same applies to cow elephants. Buffaloes wander a good deal, and personally $\mathrm{I}$ have found that they take longer to get up to than is usually the case with elephants.

If much harried they become most wary, and travel a long distance before stopping to rest, and the old solitary bulls do this more than herds. However, a single bull is much easier to approach closely than a herd, as he is often dull of sight and hearing. In a herd comprising many younger animals there are always plenty of eyes and ears on the alert for danger. Herd animals never travel so far as single animals, for the cows and young animals make the herd lag and lie up quicker.

Young buffaloes are of a brownish colour, and when old become a slaty black, while some of the older animals may be almost hairless on their bodies. Their hoofs are nice 
trophies when mounted, and the tails of all game are interesting trophies; but, of course, the head is the chief prize, and, as I have said, it is, perhaps, the finest African trophy a man can shoot. An old bull's horns almost join on the frontlet, are usually worn down and much gnarled, and sometimes cracked in places; but all this enhances their value in the sportsman's eyes.

\section{ElAnd (Taurotragus oryx).}

NATIVE NAMES.

Chinyanja - - Nchefu. | Chingoni - - Mpofu.

Approximate weight, $\delta \quad \ldots \quad 1600 \mathrm{lb}$.

Good average horns, $\delta \quad \ldots \quad$ 28in. straight.

" " , ,

A big eland bull is a grand animal, and the humaneminded hunter will seldom kill one without regret, for he is a harmless, inoffensive animal, which never tries to resent an injury. Certainly there is very little satisfaction in shooting such animals, and, after doing so, a man never has that exhilarating feeling which comes over him after killing an elephant or buffalo. A few people are very fond of shooting antelopes, but leave the dangerous game alone; in my opinion, there is nothing great in killing non-dangerous game, as it simply needs a little exercise to find it and some skill with the rifle to kill it.

An old bull eland's most noticeable features are his great bulk and weight, the tuft of long hair on his forehead, and his blue appearance, for he is often nearly hairless, although he never becomes wholly so. He evidently rubs most of his hair off, and he certainly treats his horns roughly, as they get worn down to a remarkable degree. No old bull has ever very long horns, and, if they are much over 27 in., he cannot be very old.

When in their prime they may grow horns of from $28 \mathrm{in}$. to $33 \mathrm{in}$., and the former is an average head, the latter quite exceptional. 
The cows have usually longer and much thinner horns than the bulls, and two I have near me as I write measure as follows :

Horns of a large and old bull-

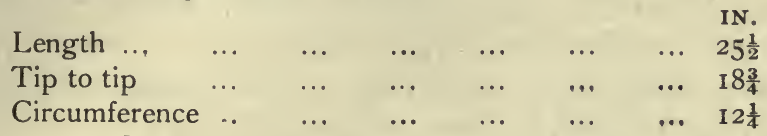

Horns of a large cow in her prime-

Length ...

$\begin{array}{llllllll}\text { Tip to tip } & \ldots & \ldots & \ldots & \ldots & \ldots & \ldots & 3 \mathrm{I} \frac{1}{2} \\ & \ldots & \ldots & \ldots & \ldots & \ldots & \ldots & 18 \frac{1}{2}\end{array}$

$\begin{array}{lllllll}\text { Circumference } \ldots & \ldots & \ldots & \ldots & \ldots & \ldots & 8 \frac{1}{2}\end{array}$

The above measurements show the great difference in the girth of the horns. The weight of the two heads, without lower jaws, were, the bull's 24lb., the cow's izlb. Thus the bull's skull and horns weighed almost twice as much as the cow's, but I must say this was an exceptionally heavy bull, in fact the most bulky eland I have ever killed, and his neck and body measurements were phenomenal, as I have mentioned in Chapter II.

His horns, when shot, measured 26in., and in the course of six months or so they had shrunk half-an-inch, which is usual with most horns; and ivory, also, dries up and gets lighter after being kept for some time.

Some elands have whitish tips to their horns, and this is sometimes seen in kudu and bushbuck horns. Situtunga and inyala also often grow white tips, I believe. Although I write "white," the colour is more of a light amber.

The cows and young animals have pretty reddish brown hides with stripes, and there is great difference between the weight of an old bull and a big cow.

At times elands can be found in enormous herds of from 100 to 300 animals. I recently saw a herd of about 200 of all sizes, but did not see any really old bull among them, and I think, like buffaloes and elephants, the very old stagers mostly lead a solitary existence, only consorting with big herds at intervals. 
Elands are easy beasts to track, as, being heavy, they leave a prominent spoor, especially if the earth is damp or wet. At certain times of the year they pack together, and they probably do this before leaving for some well-known haunt. Lions kill a good many of them, and they must find them much easier to kill than buffaloes. In South Africa it was considered an easy task to run down elands with horses, but in this country they are shot on foot.

In conclusion I may say that when elands are in good condition they yield a quantity of nice fat, which, when cut into small pieces and boiled, makes most excellent dripping for cooking purposes. It should not be cleaned in water, which is inclined to make it rancid. It is better not to keep it in tins for the same reason, and native pots made of earthenware are the best receptacles.

\section{RoAn Antelope (Hippotragus equinus).}

NATIVE NAMES.

Chinyanja - - Chilembe. | Chingoni - - Twacambwa.

Approximate weight, $\delta$ Good average horns, $\delta$
7 oolb. 26 in. curve. 25in. ",

This animal evidently got its name from its colour, which is usually strawberry roan, although some animals are a blue roan, and I think the old animals are usually the latter. Roan are fine beasts, but their horns are insignificant compared to the fine trophies that sable antelopes grow. A roan has very large ears, and his hair is longer than most other antelopes, except waterbuck, or the water-loving situtunga and the inyala. They seem to fight more with one another than do most antelopes, and I never saw roan consort much with other species as do zebra, sable, and hartebeest.

The roan is a good deal locaiised, but where they exist they are numerous, and they are particularly so in Central Angoniland and North-Eastern Rhodesia: they are also 
found away to the north in British East Africa and the Sudan.

They seem to dig with their horns, as I have often seen places where the ground had been routed up by them, and the horns of the oldest animals are often chipped and broken. Their flesh is pretty good eating, if the animal is not too old, but not so good as eland flesh, or even hartebeest. - The roan, sable, and gemsbuck have the reputation of being the fiercest antelopes; and I have often seen the eyes of wounded roan and sable gleam with rage when approached closely, so it is better to finish a wounded beast of either of these species with a bullet. If an animal is sitting up it will often have the strength to rise again, and a stab from roan or sable horns would be equivalent to a dig with a blunt spear, and forced by the power of their necks it would go right through a man's body. When a beast is stretched on its side it seldom gets up again, so if a roan or sable is in this position one can approach carefully and seize the uppermost horn, and put one's foot on the lower one and press it down strongly against the ground. Then the operation of cutting the animal's throat can be performed, but a very strong grip should be kept while this is being done. Roan are found in herds, and the old bulls are not so inclined to lead a solitary existence as are old sable bulls and other animals. An ordinary herd will consist of from ten to fifteen animals, although I have at times seen larger herds.

\section{Sable Antelope (Hippotragus niger).}

\section{NATIVE NAMES.}

Chinyanja - - Mpala-pala. | Chingoni - - Nyambuzi.

Approximate weight, $\delta$. $\ldots \quad \ldots \quad$ 55 olb.

Good average horns, $\delta$... $\ldots$ 4oin. curve.

$$
\text { " " " क ... } \ldots . \text { 28in. " }
$$

Most sporting writers give the sable antelope a high place in the list of African antelopes, and he is certainly a splendid looking animal with his long curving horns and 
black coat with snow white belly. He is a much bolder animal than the kudu, which prefers to keep to fairly thick cover, but the sable is very fond of wide, open spaces, although he retires to the bush when the sun gets hot. I have mentioned that in Nyasaland few sable grow horns longer than 43in., but in North-Western Rhodesia this is a common length, and heads have been procured there close on 5 oin.

This species was first brought to the notice of naturalists, about the year 1838 , by the late Sir Cornwallis Harris, and it was long known as the "Harrisbuck." The Boers of South Africa have a very descriptive name for the sable, as they call it "Zwartwitpens," which, in Dutch, means "black, with white belly."

Sable antelopes used to inhabit a great range of country in Africa, they are still numerous in the country lying north of the Zambesi River, and they are particularly abundant in parts of Nyasaland, Portuguese East Africa, and North-Eastern and Western Rhodesia. Anyone who wishes to get a really big pair of sable horns should go to the latter country, and I am sure he will get what he wants.

Sable are usually found in herds of from ten to twenty-five animals, and sometimes much larger herds will be seen.

The old bulls seem to love to lead a solitary existence at times, and they are then much easier to shoot than the herd bulls, as their hearing and sight fails, and they have not the safeguard of the younger and more alert animals as a protection.

The largest pair of sable horns I have shot only measure 43in. I found the animal sleeping at a distance of sixty yards or so, and killed him as he lay, so there was little true sport in the affair.

I got this bull in North-Eastern Rhodesia, and near where I shot him I wounded, on another day, a biggerhorned bull, which I lost after spending the best part of two days spooring him. He was only slightly hit, or I 


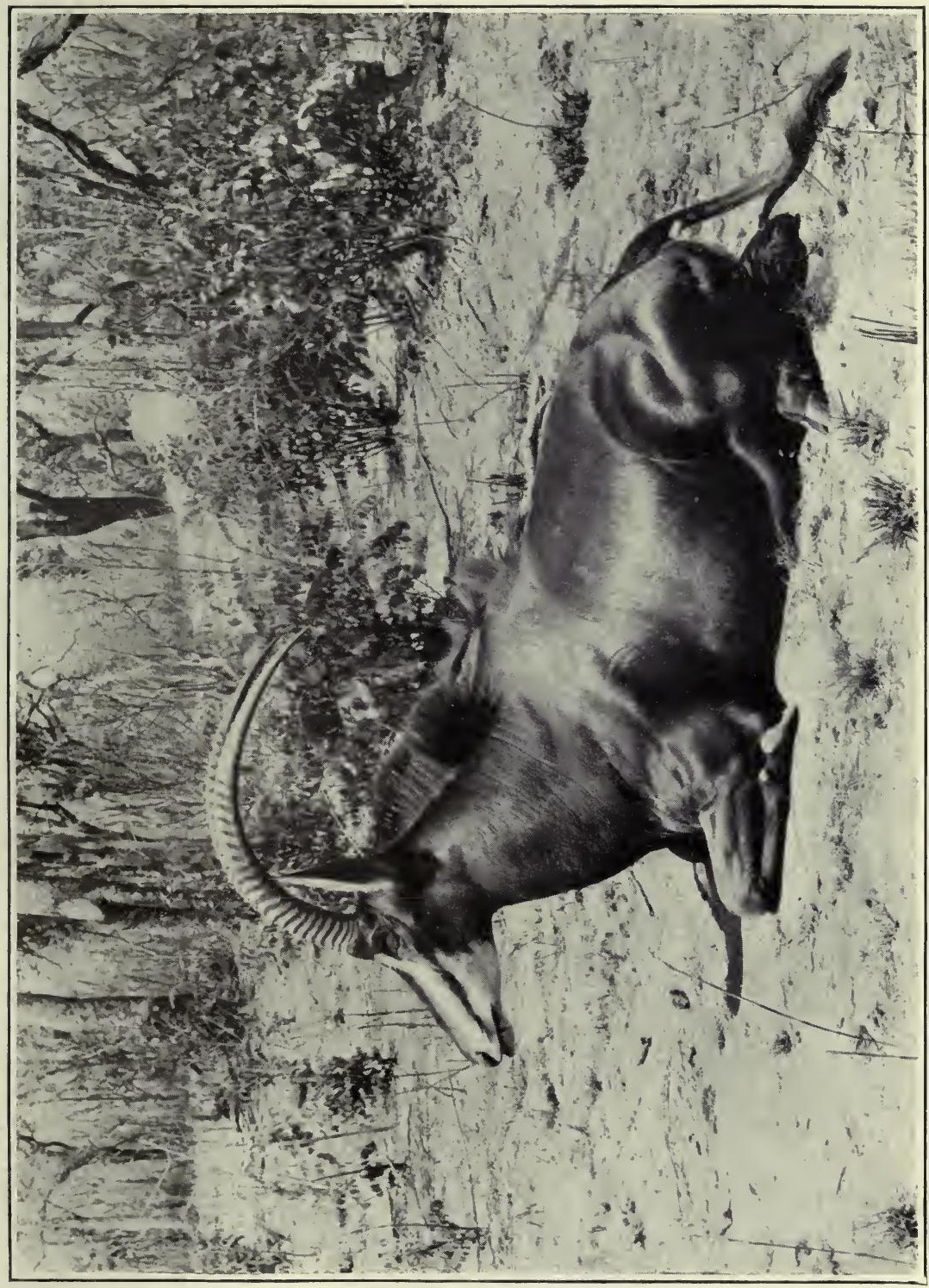



would likely have been successful in finding him. Again, when travelling to Broken Hill, in North-Western Rhodesia, I wounded a very large-horned bull, which I also lost, as a rainstorm came on and washed out his tracks. I had a good look at this animal's horns before firing at him, and they were certainly not less than 45 in. Such is hunter's luck, or, perhaps, I should term it indifferent shooting. To a man keen on good game-heads the sight of an exceptional pair of trophies is very apt to cause bad shooting, especially before he has learned by experience to keep cool and shoot steadily.

When disturbed I have noticed that sable often run into the open, whereas more bush-loving animals, such as kudu and bushbuck, inmediately run for the thickest cover they can find. I think sable depend more to their eyesight than the two latter species, who trust in their hearing more as a protection against danger. Young sable are a rufousred colour, and about the third year they begin to turn darker; but it takes some years for them to assume the jet black coat of the old beasts. Even the oldest sable will show reddish hairs on the ears, and old bulls fight a good deal and get their ears torn and split, as I have shot several with half their ears gone. Sable meat is fairly good eating, and the marrow from their bones, as well as that of other large antelopes, is very tasty. The bones are easily cracked with a stone, hammer, or axe; and the marrow can be cooked by putting the bone on a camp-fire; but, before doing this it is better to crack one end, or the accumulation of steam inside will likely split the bone and scatter the contents.

All old sable, bulls and cows, have a prominent bulge on the base of the horns which gets smoothed up, although the rings are easily visible.

If a good pair of sable horns are shot which do not show this bulge, it is likely that they have not reached their full growth. The horns of the females are much thinner than those of the bulls, and they never form a great curve. 
Kudu (Strepsiceros kudu).

NATIVE NAMES.

Chinyanja - - Ngoma. | Chingoni - Kugea.

Approximate weight, $\delta^{\circ} \ldots \quad \ldots \quad 55 \mathrm{olb}$.

Good average horns, $\delta$... $\ldots$ 53in. curve.

A big bull kudu is a picture of beauty when seen standing on some scrubby hillside with his long spiral horns laid back, and his ears raised to catch the slightest sound. However, he is not often viewed like this, as he is generally a most wary animal, who knows how to take care of these long curving trophies of his, and the usual view is that of a herd, with one or two bulls, doing very good time through the thick bush.

The bulls are much heavier and taller than the cows, and I do not think many of the females would weigh more than $35 \mathrm{olb}$. Kudus have extraordinary large ears, and it is evident that their ears were made for the purpose of selfprotection, as, their lives being spent in fairly thick country, they depend for safety mostly on their powers of hearing.

Kudu browse more than most animals, except perhaps bushbuck and eland. Besides their splendid heads (the males only bear horns although exceptional cases of cows growing horns are on record), their most noticeable features are, besides abnormal size of ears, their pretty blue-grey hides profusely striped with white, and their graceful small hoofs. The males also grow long hair under their throats, which enhances their beauty. I have never seen very large herds of kudu, and a collection of thirty animals may be considered a very large one. Like sable and eland, the old bulls often wander by themselves, although not to such an extent as the former animals, and it is a fairly common sight to see several good bulls consorting together. I recently saw five fine bulls running with a herd of elands.

An old bull kudu (often spelt koodoo) may become almost hairless, when the prominent stripes will become very faint. 
There is a very fine specimen of a bull kudu mounted in the Natural History Museum at South Kensington, and a glance will show what a perfect animal he is, but he looks finer still if one has the luck to see him standing on some bare ground with the rocks and scrub all round and a blue sky overhead.

I should imagine that leopards kill a large number of kudu fawns, as they inhabit the same type of country, and there is no doubt that the larger animals are often killed by lions. On several occasions I have seen kudu make long jumps, something like impala, when much startled, and 1 once saw two medium-sized bulls fighting, but this was more of a pushing match than a battle with their horns.

I heard of a pair of kudu horns being found interlocked, and it was evident that the poor animals had met with a painful death, by degrees, of starvation. A large kudu must have a good eye for measurement, as he will often dash between two close-growing trees, just sufficiently wide to pass his horns, although he can twist his neck considerably to decrease their space if he wishes to do so.

\section{Common Waterbuck (Cobus ellipsiprymnus).}

NATIVE NAMES.

Chinyanja - Nakodzwe. | Chingoni - - Chuzu.

Approximate weight, $\delta \quad \ldots \quad \ldots r \quad \ldots \quad 500 l b$.

Good average horns, $\delta$. $\ldots$. $\ldots . \quad \ldots \quad 28$ in.

There are several varieties of waterbuck in Africa, and two of them are present in this part of it, the common waterbuck and Crawshay's ; the latter is found in the most northerly parts of North-Eastern Rhodesia.

The difference is slight, as the former shows a white ring on his rump, whereas the latter has a white patch.

A waterbuck has a better carriage than most antelopes, as he does not have a droop in the hindquarters, and when 
disturbed he holds himself well. Their colour varies considerably, like roan antelopes, but the prevailing colour is an iron-grey brown, and variations of colour will sometimes be seen in the same herd. The hair is often fairly long and shaggy, and generally the bulls have long hair under their throats. My friend George Garden, of Mlanje, in Nyasaland, once showed me a photograph of a bull waterbuck he had shot which had extremely short hair on the body and neck, and without a vestige of the long neck and throat hair common to most bulls of this species. Waterbuck are found in herds, though at certain seasons the bulls will consort together and keep apart from the cows and younger animals.

Waterbuck swarm in the Luangwa Valley in NorthEastern Rhodesia, and they are usually common near all large rivers and lakes. Their name would seem to imply that they live in water, which is far from being the case, although they are never seen far from it. They are fond of living in stony hills bordering rivers, but they drink daily and often lie up close to water. If a hunter is thirsty and sees waterbuck or impala, he may be sure there is water somewhere near. I once saw a wounded one run into the Luangwa River, but, his heart or strength failing him, he stood up to the belly in water, and I put him out of his misery with another bullet, and I have often regretted not having had a camera with me at the time, as he was a splendid picture of an antelope.

The waterbuck, or Steedman's antelope, was discovered by Andrew Steedman, who travelled in South Africa early in the nineteenth century. He published "Wanderings and Adventures in the Wilds of South Africa," 2 vols., 8 vo, London, 1835 , and exhibited at the Colosseum, Regent's Park, in that year, a panorama called the African Glen, with a large collection of African trophies, birds, animals, native arms, etc., the catalogue of which extends to 346 items, according to a copy in my possession. Steedman named the waterbuck Ellipsiprymnus, from the wel -known circular white mark on its hind quarters. 


\section{HARTEBEEST (Bubalis lichtensteinı).}

NATIVE NAMES.

Chinyanja - Ngondo. | Chingoni - Nkonze.

Approximate weight, o $\ldots$... $\quad$ 40olb.

Good average horns, $\delta$... $\ldots \quad$ rgin. curve.

" , "

All over Africa various varieties of hartebeest exist, although only one variety is present here-Lichtenstein's.

These antelopes used to be much more plentiful than they now are. They are unusually foolish animals, unless when much hunted, and then they become very wary and difficult to get shots at, especially in thick bush.

Hartebeests are of a companionable nature, and I have often seen them consorting with sable, zebra, and gnu. They are sometimes found in herds up to thirty or forty, but the usual number is from ten to fifteen in places where they have been much molested. Both sexes bear horns, and these are peculiarly shaped, being well curved inwards, and then taking an abrupt bend backwards. The hartebeest has a long skull, and he is not a prettily shaped antelope, like a waterbuck. In moving, they have a stiff action, rather mechanical, and not graceful. They inhabit much the same type of country as sable antelopes, are often found in the the open in the cooler hours, and when the sun gets hot they retire to the shelter of the bush.

I think their meat is very good eating and prefer it to most of the other species except eland, bushbuck, impala, and klipspringer. There is not a very noticeable difference between the weight of fully grown adults of the two sexes, although the bull is slightly heavier. 


\section{SASSABy (Damaliscus lunatus).}

\section{NATIVE NAMES.}

Chibisa - - - Mtengo. | Chiwemba - Mtengo-Maroli.

Approximate weight, $\delta$ Good average horns, $\delta$
$400 \mathrm{lb}$. I $6 \frac{1}{2}$ in. curve.

This animal's name is often written Tsessebe in old books on sport. They are extremely localised in this country and only found in the districts bordering Lake Bangweolo, in North-Eastern Rhodesia. It is strange that they do not occur to the south of this, as they are not present again until the country known as Southern Rhodesia is reached. The heads in North-Eastern Rhodesia are better than those usually shot in the south. Sassaby are fond of the open and seldom go into thick cover, but find shade below small clumps of bush or trees, where these can be found.

Enormous herds exist, and up to a thousand can be seen together at times. Their skins are a beautiful giossy colour. The females vear horns which are thinner than those of the males, as the horns of females always are in those species in which the females grow them.

\section{Situtunga (Tragelaphus spekei).}

NATIVE NAMES.

Chibisa - - Nzowe. | Chiwemba - - Nsowe.

Approximate weight, $\delta \quad \ldots \quad \ldots l \ldots \quad$ 20olb. Good average horns, $\delta^{*} \quad \ldots \quad \ldots \quad \ldots 28$ in. curve.

This is the most water-loving antelope in Africa, and they spend most of their time in swampy country, although I do not believe that they often stand in the water up to the tops of their backs ; for if they did so the crocodiles would quickly decimate, them. 


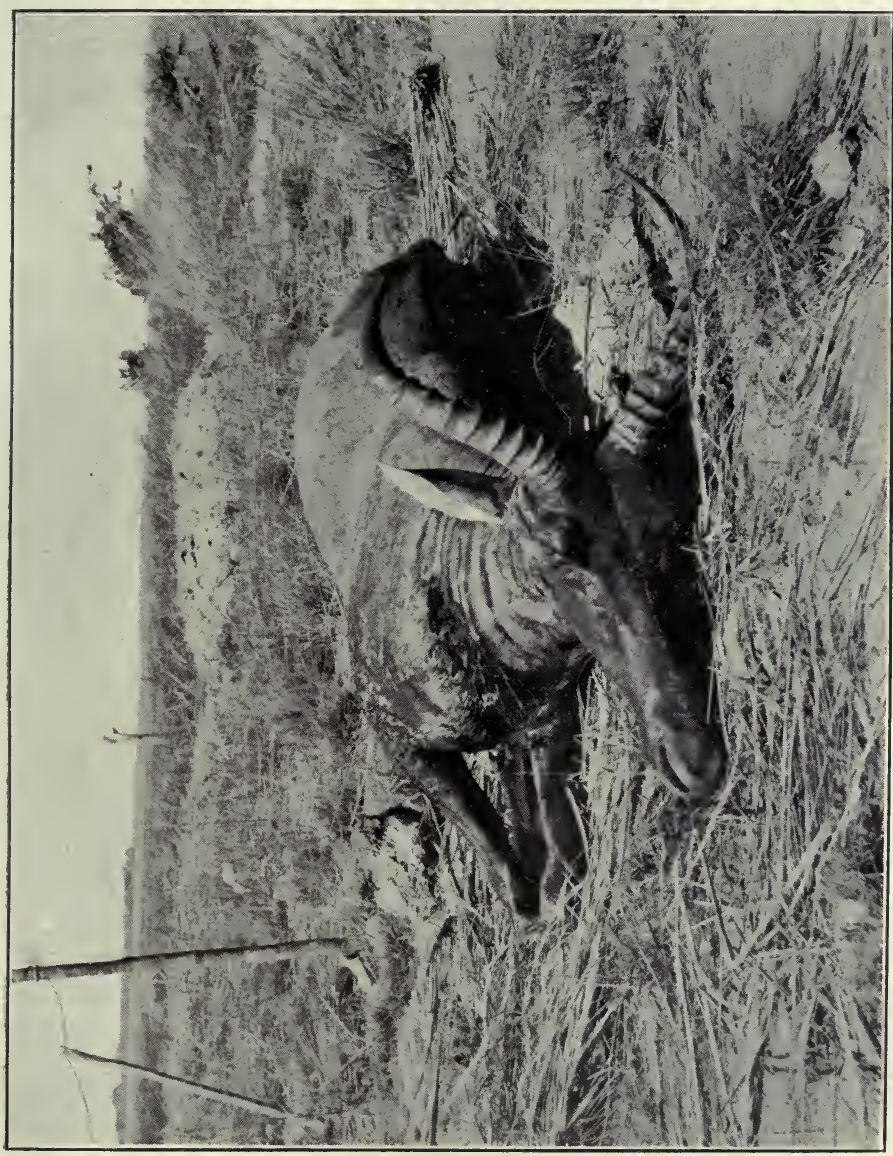

돌

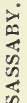



They are plentiful near Lake Bangweolo and the rivers flowing into that lake, and they are also found in Lakes Moir and Young, two small lakes widely separated in North-Eastern Rhodesia. They occur, too, near Lake Victoria Nyanza in British East Africa.

Their most noticeable features are their elongated hoofs and their long silky hair. The hoofs spread out in walking and help them to walk in soft ground without sinking.

Several men have shot situtunga, and Mr. T. A. Barns shot a number in the swamps of Lake Bangweolo. Mr. C. H. Timmler got several on the borders of Lake Young, and I have heard of several being shot near Lake Moir. Most of the horns seen have been traded from the natives, who kill great numbers in the rainy season by spearing them from canoes, after they have been driven into the water.

The females are hornless and much smaller than the males. I think there is always a greater difference between the weights of males and females when the latter are hornless than there is when the females grow horns.

\title{
INYALA (Tragelaphus angasi).
}

\author{
NATIVE NAME.
}

Chiyao - - - - - Bōō (pronounced "bow," long).

Approximate weight, $\delta$... $\ldots \quad 225 \mathrm{lb}$.

Good average horns, $\delta$... $\quad \ldots \quad$ 26in. curve.

Often written "Nyala," as the " $\mathrm{N}$ " is pronounced " in." This animal is, without exception, the most beautiful medium-sized antelope in Africa, as he is most gracefully formed and prettily marked; but it will take much trouble to shoot a male, as they are most difficult to find, even in country where they exist in moderate numbers. The inyala used to be plentiful in parts of South-East Africa, and that well-known hunter and field naturalist, Mr. F. C. Selous, shot several fine specimens near the Usutu River, within a reasonable distance of Delagoa Bay. 
In Nyasaland they are known to occur sparingly on the Shire River, and are slightly more numerous near the Muanza River, flowing into the former.

Twice I have tried to find them, but on both occasions something came in the way, and I never saw a wild inyala, although I have still hopes of doing so.

My friend, Mr. C. H. Timmler, told me that he once shot two buck considerably larger than bushbuck, when they had come to drink on the Luangwa River, in North-Eastern Rhodesia. He fired across the river, and they both fell; but, as darkness was near, he had to leave them, and next morning he found that they had been removed by crocodiles. He firmly believes that they were inyala, and I see no reason to doubt that they do exist in parts of the Luangwa River, as I have heard of two other cases of antelopes being shot there like inyalas; but the successful sportsmen were not experienced hunters or field-naturalists, or they would certainly have kept the heads and skins for identification.

Parts of the Luangwa valley certainly look typical inyala country, as there are large tracts of thick papyrus and reeds bordering the river. On the Muanza River, however, the inyala, I believe, inhabit thick scrub near it, and do not live solely in the dense reeds.

I examined carefully a very fine specimen of a full-grown, though not aged, male which is in the Durban Museum. The hair is long under the neck and belly, and reaches some way down the legs, the prevailing colour of the animal is a silver grey, and the sides of the body are striped with white, with a few white spots on the haunches. The legs of this specimen were a rich rufous colour below the knees; but I believe the oldest males lose this colour in time.

The females are hornless and differ in colour from the males. In a book written by the late Captain Faulkner, about I868, entitled "Elephant Haunts," he mentions shooting an antelope, near Cape Maclear, on Lake Nyasa, which from his description was probably an inyala. 


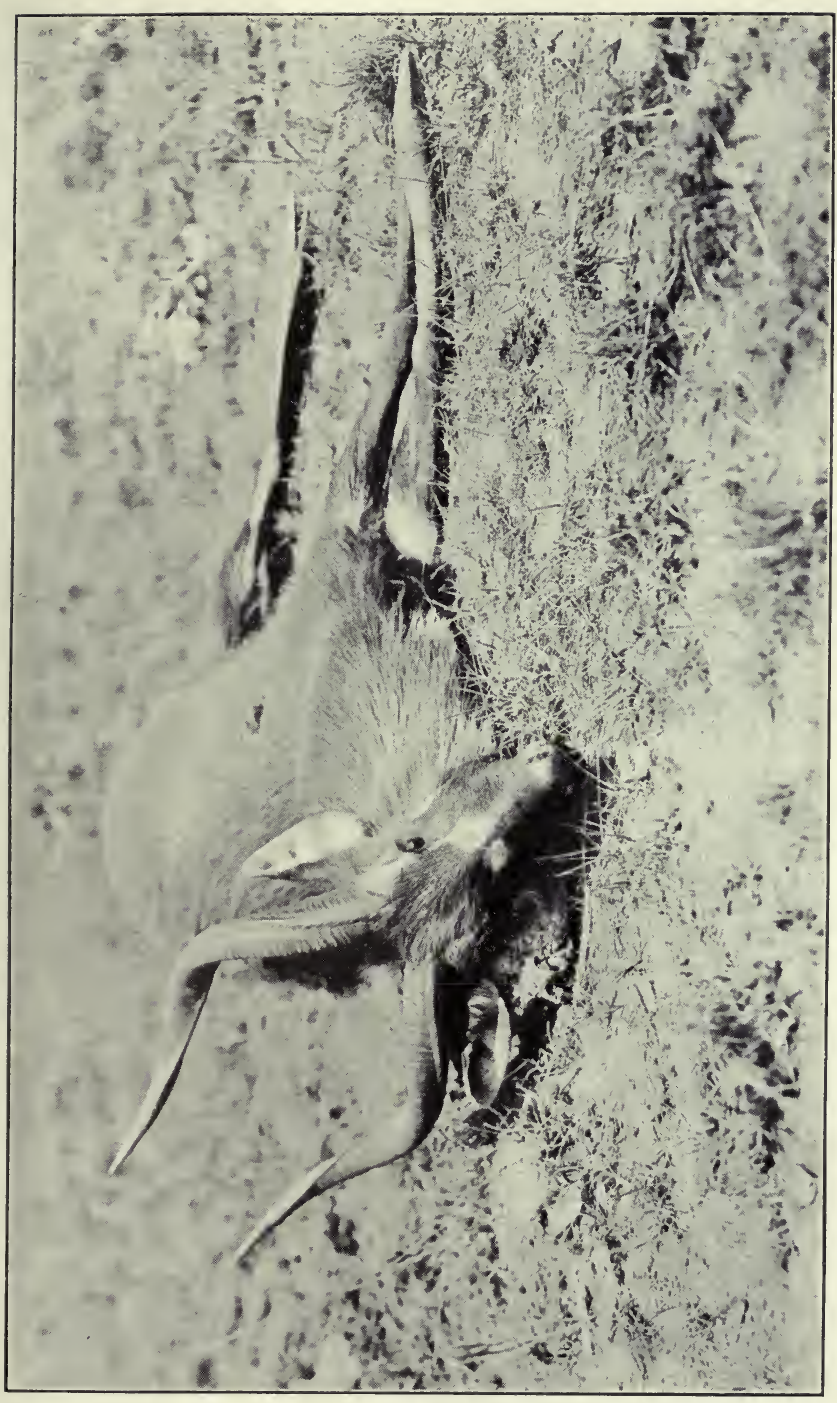

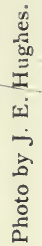

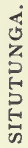



I have never heard that inyala exist there, but it is possible that they do, or they may have existed and been exterminated; although this is doubtful, as the natives are not possessed of guns, and they would be unlikely to exterminate any species by hunting with dogs and spears, or even with nets, in the type of country these antelopes inhabit.

I believe that when the valley of the Luangwa River becomes better known, that the existence there of the inyala will be proved as a fact; and it is possible that it also inhabits other little-known country in Central Africa.

\section{PUkU (Cobus vardoni).}

NATIVE NAMES.

Chinyanja - - Seuli. | Chingoni - Seuli.

Approximate weight, $\delta$. $\ldots$... $\quad$ I 7 olb.

Good average horns, $\delta \ldots \ldots \quad \ldots \quad 16 \frac{1}{2}$ in. front curve.

Scarce in Nyasaland, and very localised, although they exist in great numbers in the Luangwa valley, and on the banks of most of its tributaries. In Nyasaland it is only found on the Bua River, and the heads there are not nearly so good as those of North-Eastern Rhodesia, where they sometimes grow to over 20 in.

The puku also exists south of the Zambesi in suitable localities. It is never found far from water, and I have often seen them lying on the sandbanks of the Luangwa River in the dry season. It is of a yellowish colour, with white belly, and in shape well formed. The meat is tough eating, and the animal is very tenacious of life, like the waterbuck, unless well hit, when it is as easily killed as any antelope.

The males fight a good deal. I have noticed them doing so on several occasions, and I once picked the point of another ram's horn out of the neck of one I shot. Sometimes when a ram is shot it will attack another, thinking it was the cause of the injury. Puku rams often 
collect in herds comprising males only, and in a herd of females there will generally be only one old ram.

The females are hornless and their flesh is better eating than that of the males. The Chibisa name for the puku is seula.

LECHWE (two varieties).

The Red (Cobus lichi).

The Black (Cobus smithemani).

NATIVE NAMES.

Chibisa - - Nja. | Chiwemba - - Nja.

Approximate weight, $\delta \quad \ldots \quad \ldots \quad$ I 8 olb.

Good average horns, $\delta \quad \ldots \quad \ldots \quad 27$ in. front curve.

The common or red lechwe is found south of the Zambesi in much the same type of country as is inhabited by the puku. The species is not found in Nyasaland, but in North-Eastern Rhodesia it is very abundant in the country bordering Lake Bangweolo where both varieties are present. The black variety is a most handsome antelope with rich rufous black colouring on the sides, the top of the back being a rich black and the belly white. Considering their size, lechwe grow fine trophies of a lyre shape, and well ringed.

Like other members of its genus they are fond of water, and in the rainy season the natives of Lake Bangweolo kill great numbers by driving them into deep water and then spearing them from canoes. The hoofs are long and well spread, and the females are hornless.

\section{BushBuCK (Tragelaphus scriptus).}

\section{NATIVE NAMES.}

Chinyanja - - Balala. | Chingoni - Mbawala.

Approximate weight, $\delta \quad \ldots \quad \ldots \quad$ I 5 olb.

Good average horns, $\delta$... $\ldots 15$ in. curve.

One of the prettiest of the medium-sized antelopes, and very plentiful in most parts of Central Africa, particularly 


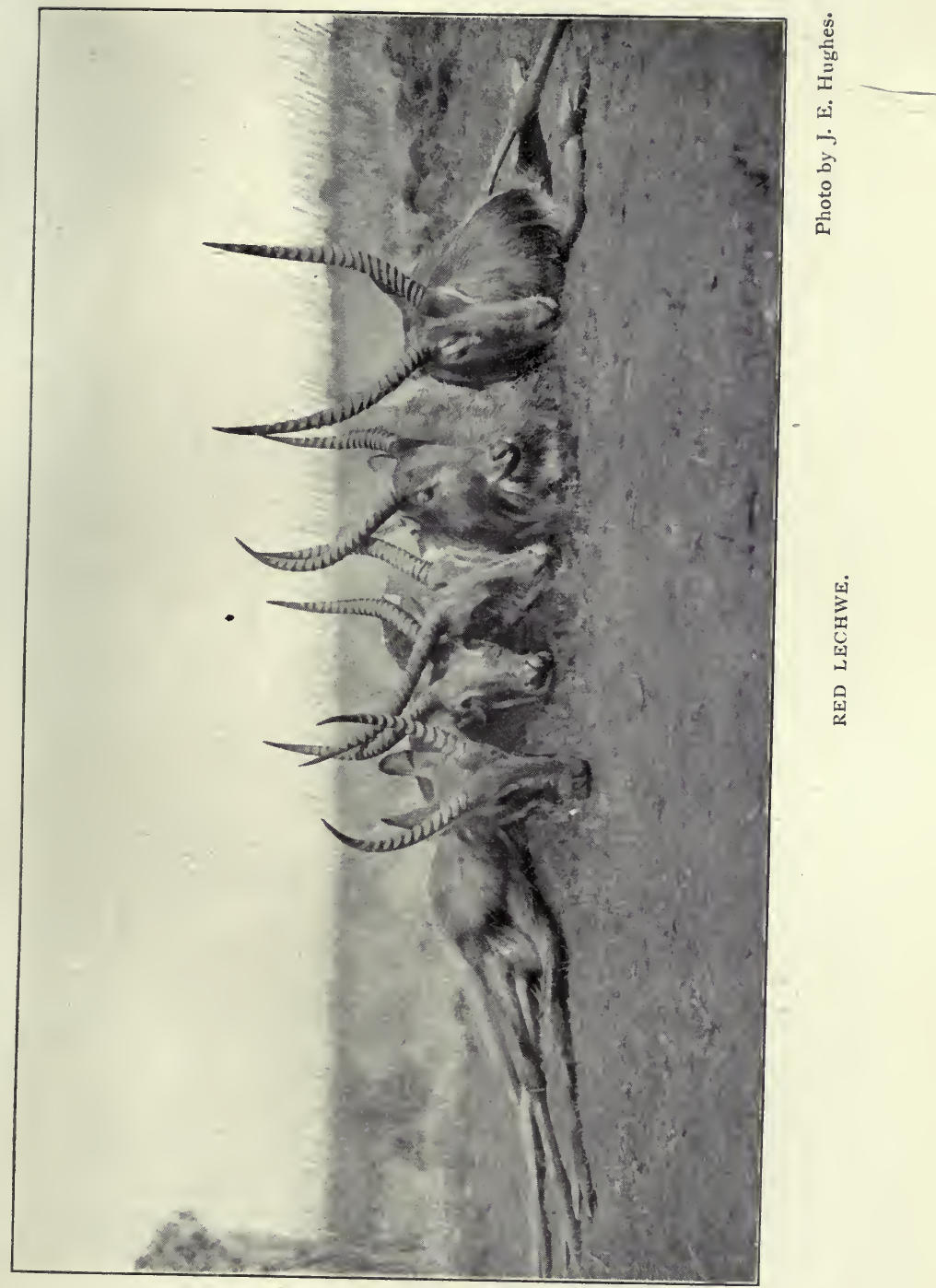






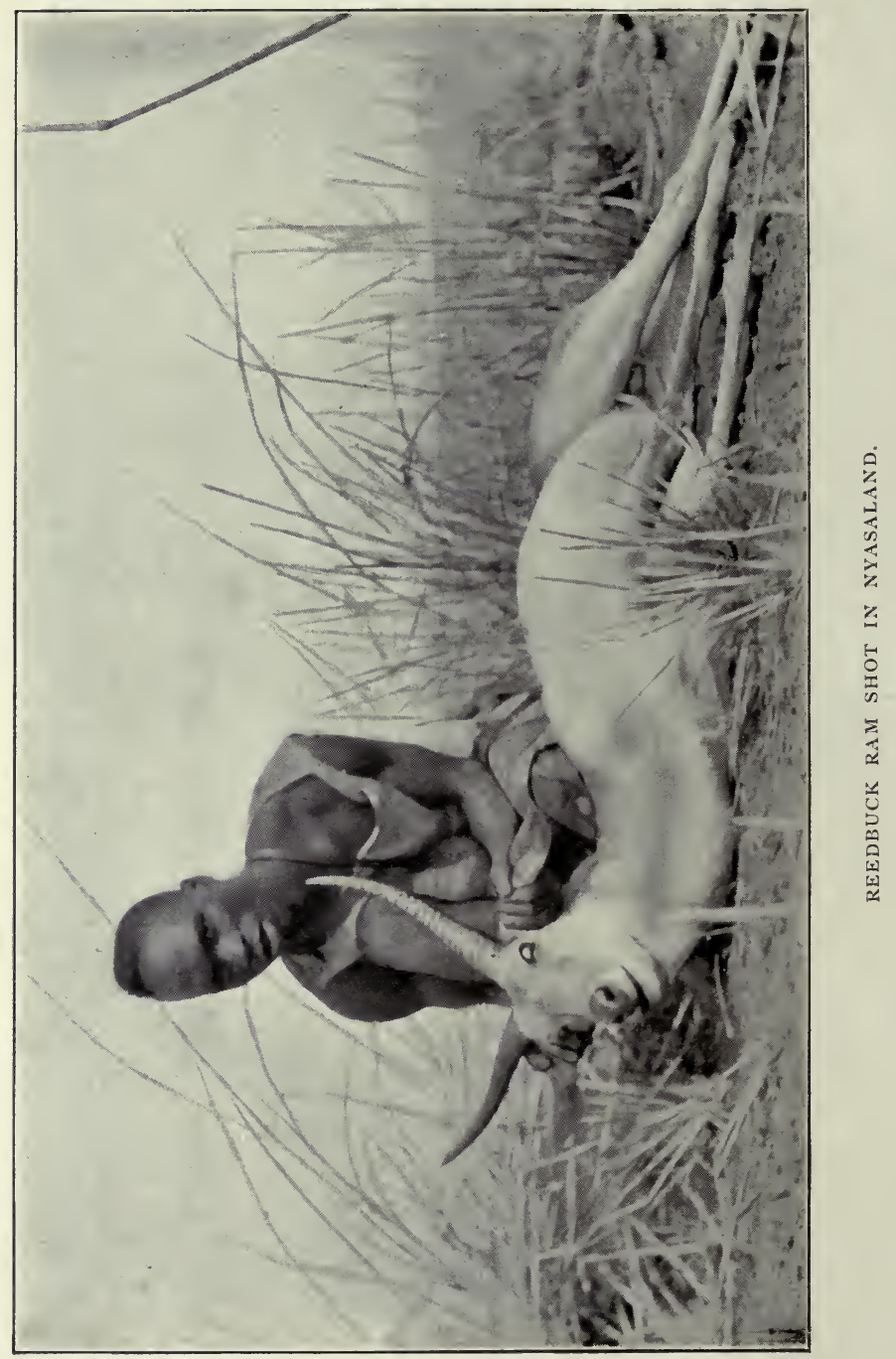


so near the larger rivers. Along the Shire River they are abundant, and in the Luangwa Valley they are very plentiful indeed.

The skins are prettily marked with spots, and the old males get darker with age. Some of the younger animals are bluish, although the usual colour is a light brown.

The horns have often white or amber-coloured tips, and are prettily curved. Bushbuck have a bare patch on the throat which looks hairless, though if it is closely examined it will be seen to be covered with very fine short hairs. They abound in hilly country, and prefer fairly thick bush. The best head I had seen was one killed by a leopard near Gwazas, on the Shire River, in Nyasaland, and it measured I $9 \frac{3}{4}$ in. on the curve, and was for long the record; but lately, my friend, Mr. C. H. Timmler, showed me a head of a bushbuck he had bought at Chinde, and, on measuring it, I found that it gave $19 \frac{7}{8}$ in. on the curve, so it is evidently the record.

Bushbuck are sporting animals, which usually give the sportsman some trouble to find. At times they bark just like a dog, and they often make this noise when disturbed at close quarters by human beings or carnivorous animals. Their flesh is very good eating.

\section{REEDBUCK (Cervicapra arundinum).}

NATIVE NAMES.

Chinyanja - - - - Mpoyo.

Chingoni - - - - Shangu (sometimes Mpoyo).

Approximate weight, $\delta \ldots \quad \ldots \quad$ I 5 olb.

Good average horns, $\delta$... $\quad \ldots \quad$ I zin. front curve.

As its name implies, prefers reeds and grass country near water. Fairly common and well distributed, and often seen in small lots up to six or eight, although the usual number is from two to five animals.

When disturbed, gives a shrill call, which carries for some way and puts other game on the alert; so it is 
better, if stalking an animal, to give reedbuck a wide berth.

The skin is very thin, just like strong parchment, and the hair soft and fine. As reedbuck run they hold their tails up, and, as the tails are large and are white underneath, they will often be the first thing to catch the eye. The meat is soft and tender, but rather insipid, and I have noticed that it goes bad sooner than other meat.

The females are hornless, and weigh much less than the males.

$$
\text { Impala (Apyceros melampus). }
$$

NATIVE NAMES.

Chinyanja - - Nswala. | Chingoni - - Nswala.

Approximate weight, $\delta \ldots \quad \ldots \quad$ I I olb.

Good average horns, $\delta$... ... I $\quad$ in. front curve.

One of the most gracefully formed of the medium-sized antelopes, and very numerous and well distributed wherever there are large rivers. The presence of impala always denotes that water is near, and waterbuck, puku, and reedbuck are an index to the same conditions.

Impala are often found in large herds of from fifty to a hundred animals. They are particularly common in the Luangwa valley, and their numbers there are probably greater than any other species. They are of a pretty light brown or fallow colour, with white belly, and the heads of the rams, for the does are hornless, are a beautiful shape and nicely ringed. Their flesh is particularly good, being tasty and tender.

The males, at certain seasons, consort together, and sometimes a herd of over twenty will be seen. In a large herd there is not often more than one full-grown ram. When startled, impala often jump high into the air and give a kind of bark, as do bushbuck when frightened.

The variety found here is smaller in the body and horns than those found in British East Africa, and is known as Johnston's impala. 


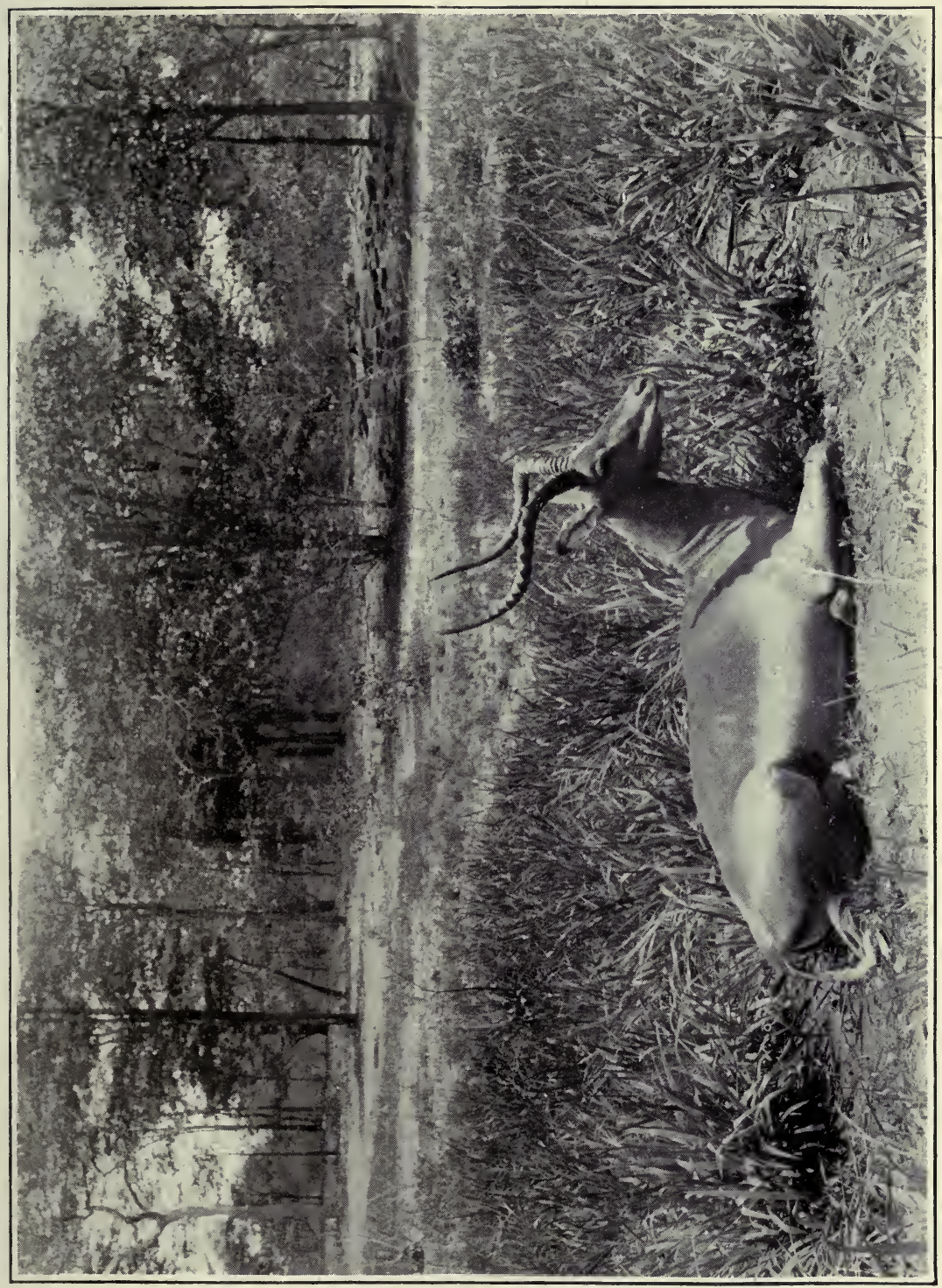



They inhabit pretty "park-like" country where they form lovely pictures of wild life.

I weighed a full-grown ram, and he scaled irolb. (uncleaned).

\section{ORIBI (Oribia scoparia).}

NATIVE NAMES.

Chinyanja - Choe, often Gwapi. | Chingoni - - Chozimbi.

Approximate weight, $\delta$..... 4 olb.

Good average horns, $\delta$. $\ldots . \ldots 4 \frac{1}{2}$ in. straight

These pretty little antelopes are usually found in couples. and they are fond of open dambos, where they often remain during the day unless the sun is very hot, when they will retire into the thin bush, but they are very seldom found in very thick cover. As they are small bodied animals they are difficult to shoot unless fairly close; and anyone who can get most of the oribi he fires at ought to do well on larger game.

Their skins are a reddish yellow with white belly, and a noticeable feature is their small neatly formed feet, which leave a track not unlike a miniature hartebeest's.

It is wonderful how seldom one sees a young one with any of the smaller antelopes, and I think they leave them behind in cover until they are almost the same size as the parents.

Oribi meat is tender but rather insipid; their kidneys and liver are very good when fried fresh.

\section{KLIPSPRINGER (Oreotragus saltator).}

\section{NATIVE NAMES.} \begin{tabular}{c|c} 
Chinyanja - - Chinkoma & Chingoni - - Chinkoma. \\
(sometimes Gwapi). &
\end{tabular}

Approximate weight, $\delta \quad \ldots \ldots \quad$ 35 lb.

Good average horns, $\delta \quad \ldots \quad \ldots 3 \frac{3}{4}$ in. straight

The Boers call this little animal the "klipbok," which means stone buck, and rockjumper is the English meaning 
of the word klipspringer. The most noticeable features of these animals are the long wiry hair, which will come out with a hard stroke of the hand, and I have seen a bullet send a shower of hair away after its exit from the opposite side; also the small feet, which are only worn down in front, as the klipspringer lives mostly among rocks and hard ground, although they will often wander down to the lower ground in the evening, and I have sometimes seen their spoor in a native garden, near hilly ground. The Boers use the hair to fill saddles with, as it is said not to pack with use, and it is springy and light, in fact, just like small quills.

Only the males bear horns, and they are usually seen in pairs, although a number of pairs may feed and intermingle when feeding. I once counted eight couples of these animals in an undulating valley on the plateau of a long range of hills overlooking Fort Manning, in Central Angoniland.

Klipspringer meat I consider more tasty than that of any other antelope, as it resembles tender mutton, and has not the soft, insipid taste of some of the other species.

They are most sporting little animals, and to get a shot at one it is often necessary to climb high, when lovely views of the surrounding country will be seen. I have climbed many a lonely hill to look for them, many probably never trodden by the feet of civilised man, and when doing so I have kept my eyes open for minerals; but I never found any, probably because I know little about geology or prospecting work. It is often the way that the first men in a new country gain little, and those who follow are the lucky ones.

In running off, klipspringer often stop and look back from the top of a big boulder, and thus offer a fine chance for a quick shot. If they are startled and bolt, it pays to wait, and not risk a doubtful running chance, as they will likely have one look back before disappearing for good.

Klipspringers are found throughout Africa, where the country suits them, but it is hard work following them, 
although the beautiful scenery, and the trophy and meat, are a recompense for such hard exercise under a hot sun. They seldom drink, and doubtless get all the moisture they need by eating juicy and wet vegetation.

\section{Duiker (Common) (Cephalophus grimmi).}

NATIVE NAMES.

Chinyanja - Gwapi. | Chingoni - Phunzi.

Approximate weight, $\delta$ Good average horns, $\delta$

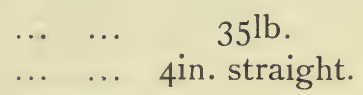

The duiker is one of the commonest small antelopes in Central Africa, as they are found all over the country.

They usually run in couples, inhabit fairly open bush, and go into the open in the cooler hours to feed. The females are, as a rule, hornless, although I have heard of several cases of their bearing horns, which, however, are smaller than those of the males.

As they are small-bodied animals, it needs fairly accurate shooting to kill them. They are very tenacious of life, considering their small size, and I have seen them go off with most severe wounds, although it is easy to recover them by spooring them up.

They have a habit of returning to the same place to deposit their droppings, but they are not singuiar in this respect, as many other animals do the same thing.

I do not think they drink often, as they are sometimes found far from water. They probably get all the moisture they require by eating wet grass and leaves, and also plants that are full of moisture.

Their colour is a brownish grey and they are well formed, and like other small buck can be easily tamed when taken young. The males have a long tuft of hair between the horns which, when they are close, look like a third horn. Their meat is fairly good eating, and their kidneys and liver are particularly good. 


\section{Sharpe's Steinbuck (Raphiceros sharper).}

\section{NATIVE NAMES.}

\section{Chinyanja - Kasenye. | Chingoni - - Nsumpe.}

Approximate weight, $\delta$... $\ldots \quad$ 2olb.

Good average horns, $\delta \ldots \quad \ldots \quad$ I $\frac{1}{2}$ in. straight.

A very localised species, but where found may exist in fair numbers. Inhabits fairly thick bush, and is seldom seen in open country. The colour of the skin is a reddish brown with white hairs interspersed. When they run off they do not often stand and look back like oribi, klipspringer, and duiker. They could easily be killed with a shot gun and heavy shot, such as a charge of No. 4, but I think it is more sporting to shoot them with a rifle.

I have seen them near Gwazas, on the Shire River, in Central Angoniland, and different parts of North-Eastern Rhodesia. They seem to have acute senses of smell and hearing, and are seldom seen standing. Only the males grow horns.

Blue Duiker (Cephalophus nyasa).

NATIVE NAME.

Chinyanja - - Kadumba.

Approximate weight, o $\ldots \quad \ldots \quad$ I 4 lb.

Good average horns, $\delta$... ... $\quad I_{2} \frac{1}{2}$ in. straight.

The females grow horns as well as the males, and both sexes show an inward curve on the horns. The colour varies from a blue brown to a chocolate brown. I have seen these tiny antelopes in the Mlanje district of Nyasaland, and also at Mpezo about fifteen miles from Blantyre, where there are a few of them, although their numbers are kept low by the natives, who set snares across their runs. They are very wary, and it is most difficult to get a shot at them with a rifle. I believe they are plentiful in parts of Portuguese East Africa, and I saw the skins of 
two of the chocolate-coloured variety, which were got in the stony hills bordering the Lupata Gorge, on the Zambesi River. In Mlanje, where they used to be very plentiful, they inhabit the thickest of cover, and the natives there also kill great numbers with their snares.

In running they assume a crouching attitude, and so creep through small spaces among the thick vegetation, and, once they are startled, they do not stop to look back, but go right away. The female does not, probably, weigh much more than $\mathrm{a} 2 \mathrm{lb}$. Their feet are very small and gracefully formed, and they are the smallest antelopes in this part of Africa.

\section{LiVINGSTONE'S ANTELOPE.}

When living, about a couple of years ago, for a few months near Mikolongwe, in Blantyre district, a friend (Mr. J. Maiden, of Midima Estate) gave me a pair of horns, on frontlet of skull, of a small antelope killed by one of his natives with a shotgun on the slopes of Midima Hill. At the first glance I thought it belonged to a male Livingstone's antelope, so I wrote Mr. R. Lydekker, F.R.S., of the Natural History Museum, London, and sent him, with a full description, a pencil sketch of the horns, and he replied that I was correct in thinking it belonged to this species. I have never seen another specimen, and it is a pity Mr. Maiden was not able to keep the full skull and skin; but he happened to be away from home when his boy shot it, and the horns were all he could recover.

I think it is worth putting on record that this species exists here. I know it is plentiful near Shupanga Mission Station, on the south bank of the Zambesi River; but it is a long way from that place to Midima Hill, in the Blantyre district of Nyasaland, and I never heard of it as existing on the north bank of the Zambesi.

I have heard of the common steinbuck being shot in Central Africa, but not having met with it, or seen the horns or skin of a specimen shot there, I prefer not to include it in this list, as its existence is doubtful. It 
is possible that in the northern parts of Nyasaland and Northern Rhodesia that one or two small species of antelopes may exist that have not yet been brought to the notice of naturalists, as some of that country has been but little shot in, especially by men with any knowledge of field natural history.

It needs a man with a certain amount of experience to notice a difference in the markings or features of animals, and some discoveries must have been lost to science owing to this want of observance in hunters. 


\section{CHAPTER IX.}

\section{II.-Field Notes on the Game.}

\section{The following animals described:}

Lion.

Leopard.

Cheetah.

Serval.

Zebra.

Warthog.
Bushpig.

Hyæna (two

Wild Dog. varieties).

Jackal (two varieties).
Otter (two

varieties).

Civet Cat.

Antbear, or

Aard-Vark.

Native names given for many other animals not strictly speaking classed as game. Also names for some of the birds, snakes, \&c., are also given.

\section{LION (Felis leo).}

NATIVE NAMES.

Chinyanja - - Mkango. | Chingoni - - Ngwenyama.

Approximate weight, $\hat{\sigma} \quad \ldots \quad 400 \mathrm{lb}$.

Good average skin, ơ ... ... gft. 3 in., unstretched.

THERE is no African animal that has inspired writers on sport in that continent, or the interest of those who have never seen Africa, to the same extent as the lion; but in his natural state he does not present the hairy and dignified appearance that he does when looking through the bars of a cage with sleepy-looking brown eyes.

Wild lions, especially in very hot regions, do not often have good manes, and Mr. F. C. Selous has quite conclusively proved that the profuse growth of hair seen in lions in the zoological gardens and menageries in Europe is the result of the cold climate; and possibly regular feeding may have something to do with it.

Long ago, in the higher parts of Southern Africa, lions grew large manes with long hair under the forelegs and along the belly, and to-day lions exist on the higher plateaux 
of British East Africa with much better manes than those inhabiting the warmer lower country. Some people with good experience aver that lions lose their manes through inhabiting thick thorn bush, as they get the hair matted and tangled with blood when feeding, and it is then caught by thorns and pulled out. I have seen lion hair hanging to a thorn bush when a maneater that had killed a woman had gone off with some of the flesh, and lain under this bush eating it. He left a little hair behind, but this is no proof that thorns would make a lion lose all its mane, as it would keep growing.

Lions originally came from cold and temperate zones, and all animals inhabiting cold countries are hairier than those which live in the more tropical parts of the earth, so there is little doubt that a cold climate is responsible for the profusion of a lion's mane.

Large lions have been killed weighing over 50olb. but few will be shot weighing more than 40olb. It depends greatly whether a lion is weighed before or after a good meal, as I think he can easily stow away quite $7 \mathrm{olb}$. weight of meat when famished with hunger, and lions are usually rather hungry, often going without food for several days. Then they will eat anything that is eatable, and they are not averse to having a dessert of masuko plums, when these are ripe and fallen on the ground.

Lions are most dangerous on dark, rainy nights, for in the rains most of the antelopes scatter all over the country, as water is plentiful everywhere. They do most of their killing in the hot and dry season by lying in wait at the isolated water holes, and at favourite drinking places on rivers. They do most of their hunting by scent and hearing; and, regarding this fact, the colouration of animals is no help to them in escaping, and they have to depend on their own hearing, scent, and speed for safety. This is where the closet naturalist falls into the trap with regard to so-called protective colouration of animals preyed on by others; and, although many more able men than myself have written on this subject, I intend to give a few lines on 
it before completing this volume. Further, I do not wish to write much on lions as compared to Mr. F. C. Selous and Mr. F. Vaughan-Kirby, my experience of them having been very small indeed, as I have had very bad luck in finding them. Considering the immense amount of wild country I have walked over, I have come to the conclusion that lions are rather scarce in Nyasaland and North-Eastern Rhodesia, except in certain parts, and as a rule it is pure chance coming on them.

The proper way to measure a lion or leopard skin is to stretch the animal out as straight as possible and put a peg in at the nose and another at the end of the tail, and measure the space between them. This should be done when the animal is freshly killed, as it will stiffen up soon. To measure a skin that has been flayed from the animal is no true index, as it is an easy matter to stretch it about a foot, particularly if it has been soaked in water for twelve hours.

Lions kill by biting, and use their claws for gripping their prey, and a charging lion comes along low, like a big dog; so it offers a better target than a leopard, which bounds. They often break into cattle, sheep, and goat kraals, and do this by forcing a space between the poles near the ground, for they will seldom jump into such an enclosure. If they are disturbed, however, they have no hesitation in jumping through the interstices of the poles where they are usually wider apart, about Ioft. or $12 \mathrm{ft}$. from the ground, and in doing this they will go right through big thorn branches. Lions realise that their existence largely depends on the soundness of their pads, so they are usually careful about interfering with thorns, except when they are famished with hunger, when they become heedless of anything.

They kill numbers of native pigs, and have little difficulty in breaking into the flimsy enclosures that natives often keep them in.

In a wild state they kill many buffaloes, elands, and zebras, and they like donkeys; so if such animals are taken 
on a journey through a lion country, they should be well guarded at night.

The lion's great feature, excluding his name, is his roar, and it is certainly a wild sound when heard on a dark rainy night. I have only heard lions roar close once, and and by close I mean within Ioo yards; and that was during a night in the rains on the Luangwa River in North-Eastern Rhodesia, and it was raining hard at the time.

The air seemed to vibrate with the sound, and the rats, crickets, and other tropical insects were evidently frightened, as they kept quiet. A dog I had in the hut with me was fairly well scared out of his wits, for he shivered and trembled, although he was a very plucky terrier, and eventually met his death by running out at night to tackle a leopard singly. The lions-I think there were five-took up the chorus, and I could hear the long sigh after each roar. In wild places one will sometimes hear lions roaring at a distance, and I have often listened to the sobbing grunts of lions as they were prowling round; but, though I sometimes went to try to find them next day, they were somewhere else. As Mr. F. C. Selous and other authors have written so much on the lion, it is needless for me to write more about this fine animal.

\section{LEOPARD (Felis pardus).}

NATIVE NAMES.

Chinyanja $-\left\{\begin{array}{l}\text { Nyalugwe. } \\ \text { Natave. }\end{array} \mid\right.$ Chingoni $-\left\{\begin{array}{l}\text { Kyingo. } \\ \text { Ngombwa. }\end{array}\right.$

Approximate weight, $\delta$... ... I I olb.

Good average skin, $\delta \quad \ldots \quad \ldots \quad 7 \mathrm{ft}$. 3 in. straight.

The leopard is one of the wariest animals in the world, and he seems to know how to look after his skin, which is a very handsome trophy, and really much prettier than a lion's, unless he has a fine mane. Leopards are fond of hilly country and thick bush wherever it is found, so as the country I write of is covered in parts with trees and bush, 
there are plenty of leopards, but they are most difficult to get a shot at, as they seem to have most acute hearing. Usually, when disturbed, all one will see is a flash of yellow, and they disappear into the bush or grass. They are very plentiful in the Mlanje range of mountains in the south of the Nyasaland Protectorate, and they find plenty of food there in the shape of bushbuck, pig, and klipspringers on the higher parts.

They are easily obtained by putting out a set-gun baited with part of their kill, or, better still, with a dead dog. Dog-flesh seems to be most attractive to them, and many a fine terrier has been taken in Africa and India by a leopard. In their habits they must resemble cats, and, like them, they eat great quantities of field rats and mice, and are not above filling up corners with lizards and anything they can catch. In the breeding season they are said to become bad-tempered and liable to attack man, and I have heard of several man-eating leopards which haunted districts near villages and killed the natives at night, usually a young boy or girl, which the leopards probably know are easier to kill than fully grown adults. I lately treated a man who was mauled by a leopard, which jumped on his back and gave him a few scratches. This man was so grateful that he brought me a fowl, which is rather unusual, as natives do not, as a rule, show much gratitude; although the Angoni and Yaos do occasionally. Natives are averse to offering thanks, but I think that in their hearts they are often grateful.

If a sportsman wishes to shoot leopards, the best plan is to sit up over a kill, or try to find out where the leopard goes to rest during the hours of day, and take up a position to intercept it as it comes out for its nightly prowl. Leopards cannot be systematically hunted by walking about, even in rubber shoes, as being so close to the ground they seem to be able to catch the slightest sound, not only of the legs and boots rubbing against branches, grass, and stones, but the vibration in the ground, which must carry for some considerable distance. 
Leopards and hyænas must kill a great number of fawns which are unable to run, as these are left by the mother in some cover when she is feeding.

Hill leopards, at least those found in Mlanje, seem to be smaller bodied and more profusely spotted than those inhabiting lower levels, and the natives say that the smaller kind are fiercer when wounded than the larger variety.

Leopards will often be heard grunting at night, as they move about, and their grunts are sharper and quicker than a lion's, and at times sound just like a saw being worked in hard timber.

They often break into goat kraals, and, like lions, they will then kill much more than they can possibly eat, and it is apparent that the lust for killing comes over them. Lions kill their prey by biting the upper part of the neck behind the ears, and leopards nearly always grip the windpipe under the throat. When in India I saw the carcases of several bullocks and cows killed by leopards, and this was how they acted. Tigers kill like lions by gripping with their claws, and biting the neck behind the head. I heard of a case in Mlanje district of a small lot of bushpig chasing a leopard into a tree, and my friend George Garden saw the place and told me that the pigs must have remained for some time round the base of the tree, as the earth was much trampled by their feet. On another occasion I heard some bushpigs grunting, and also the grunts of a leopard, and I found the spoor and noticed that, instead of the leopard hunting the pigs, he was being hunted, as in places the pigs' tracks covered those of the leopard.

\section{Cheetah.}

I have only seen one skin of this animal in Nyasaland, and it was obtained from natives near Dedza, in the southern part of Central Angoniland. As far as I remember, it was about $6 \mathrm{ft}$. in length, and much whiter coloured and less profusely spotted than a leopard's skin. 
These animals are plentiful in the more open parts of British East Africa, and they doubtless exist in the big plains near Lake Bangweolo. The spoor of the cheetah is slightly longer than that of the leopard, and the back part of the pads is convex in the centre instead of concave as in the leopard. Cheetahs are very fleet for a short distance but they soon get winded, and cases have been known of a horse overtaking them. In India, as most sportsmen are doubtless aware, they are used for hunting the blackbuck, although they are not always successful in killing, unless they manage to stalk near enough to get close with the first rush.

\section{Serval (Felis serval).}

\section{NATIVE NAMES}

\section{Chinyanja - - Ndudzi. | Chingoni - - Njosi.}

Approximate weight, $\delta$. $\ldots$... 3 olb.

Good average length, $\delta^{*} \quad \ldots \quad \ldots \quad 3 \mathrm{ft}$. 6 in.

Very numerous all over this country, inhabits bush country and goes into the open to hunt at night. It is very fond, as most carnivorous animals are, of walking along native paths, where it can go quietly.

Kills small antelopes, and likely catches many fawns and hares. The skins are prettily spotted, with fairly long light hair under the belly. The natives kill numbers when hunting with dogs, so it would seem that, like the cheetah, the serval is short-winded when followed far. Although the claws are retractile they are not so to the same extent as lions and leopards, as in muddy ground I have often seen them in the spoor. When startled, all retractile clawed animals shoot out their claws, probably to take a better grip of the ground in dashing off. In a sandy nullah in India I once saw the pugs (tracks) of a tiger that had chased a bullock at close quarters, and each pug showed the front cut of the long claws. In moments of excitement the claws are shot out, and cats do it when watching a bird near at hand. 


\section{ZeBRA (Common) (Equus burchelli).}

NATIVE NAMES.

Chinyanja - - - - Mbizi.

Chingoni - - - - Lidua, sometimes Chimbeti.

Approximate weight, $\delta$. $\ldots$... $\quad \ldots \quad 6$ 6oolb.

Very common in most parts of Central Africa and only one variety is found here, although there may be slight differences seen, such as some of the animals being brown coloured on the nose, instead of black; and the striping of some beasts is more distinct just above the hoofs, round the fetlocks, than it is in others.

These very slight variations mean little, I think, and certainly do not contribute a difference great enough for the classification of a variety. One might as well group Englishmen, for instance, into groups, because some happen to have black hair, others brown, and others flaxen hair. A light skinned lion may give birth to two cubs, one black maned and another light maned; and such differences mean little or nothing.

Zebras are found in herds up to thirty or more animals, and they are a charming ornament to a wild country, but a great nuisance when hunting other game, for they make a tremendous rattle and clatter in running away if disturbed on hard, stony ground. This puts more valuable game on the qui vive, so, like reedbuck, which whistle loudly, they should not be frightened, and it is better to make a detour to get round them.

Quite recently I weighed a large old zebra mare I shot, and, without the contents of the stomach and entrails, it gave a weight of $525 \mathrm{lb}$., so a large stallion alive would certainly weigh quite 6 oolb.

A zebra skin, being very thick, is useless as a trophy for placing on the floor, although a good taxidermist could likely thin it down and tan it soft, when it would be pretty and useful. The young have very pretty skins, and, being thin, they make pretty rugs. 
A zebra I shot in British East Africa-Chapman's variety, I think-seemed very similar to those I have seen in Central Africa. The only difference I noticed was that the skin seemed paler and more bleached, and it lacked the rich, whitish-yellow and black velvet colours of the Central African type.

Zebras are not more different to see than any other game, although closet-naturalists aver that they are protectively coloured; but as their natural enemy, lions, do not hunt them by sight but by smell, this can be no protection at all. In some lights they look dark, in others almost white, and it all depends on what side the sun is. When standing in timber and bush, they betray their presence by the constant flapping of their tails or by the movement of their ears. Zebra are not difficult to kill with small-bore rifles when hit well forward, and, being thickset, cobby animals, they offer an easy mark for a shot. Their hoofs are often cracked all round the edges, doubtless caused by sharp stones, as they often live on rough hills, where they probably go for coolness and to get away from the flies. Many animals which are usually found on fairly flat ground have this habit of ascending hills.

When zebras are seen, it will be noticed that they generally all face in one direction, and prefer to feed up-wind. In running away from danger, game will often run down-wind for some way, and then they will gradually work round, so as to get the wind in their faces.

\section{WARTHOG (Phacochoerus zthhiopicus).}

NATIVE NAMES.

Chinyanja - $\left\{\begin{array}{l}\text { Njiri, often. } \\ \text { Mbango. }\end{array} \mid\right.$ Chingoni - $-\left\{\begin{array}{l}\text { Kaprika. } \\ \text { Nagu. }\end{array}\right.$

Approximate weight, $\delta$. .. $\quad \ldots \quad \ldots \quad$ igolb.

Good average upper tush, $\delta^{*} \ldots \quad \ldots \quad$ Ioin. curve.

This ugly, though inoffensive, animal used to be much more plentiful than it is, as the natives kill great numbers by hunting them with dogs and spears, and they seem to 
have little difficulty in getting up to them. I have shot a large number of warthogs, and never found them dangerous, and have only seen three, one boar and two sows, that seemed to wish to resent their injuries, and as. they are very easily killed, there is no risk in shooting them. They are certainly not so plucky as bushpigs or the Indian variety, which is usually willing to stand and put up a fight for its life. A common sight is to see a family of warthogs with the two parents and a litter of from six to ten youngsters, and one of the latter is quite good eating when cooked like a sucking pig at home.

The older beasts are tough, the flesh tastes rather strong, and it is darker than pork, and of course not so fat.

A big boar, with his yellowish-white ivory and warty lumps on his face, is a weird-looking animal, and he has no pretentions to good looks, for in washing himself he likes his water dirty, delighting to wallow in mud holes during the heat of the day.

Here is the weight of one I weighed in sections, and he was a big, heavy boar :-

\begin{tabular}{|c|c|c|c|}
\hline Head (with skin on) $\ldots$ & & & \\
\hline Four legs (cut off at the joi & & & \\
\hline Body (clean) $\quad \ldots \quad \ldots$ & & & \\
\hline Skin with entrails enclosed & ... & . & \\
\hline
\end{tabular}

Another 6lb. to Iolb. should be added for loss of blood and matter in cutting up, and as this pig was shot in the lungs he dropped a lot of blood before he fell, so it may be assumed that an exceptionally large boar would reach 2oolb. in weight.

Warthog keep their lower tushes very sharp, as they are constantly rubbing on the flat of the upper teeth; and although the big tushes are often broken, the lower ones are generally in good order.

The skin on their knees is very hard, as in rooting in the ground they go down on their knees, so callosities are formed in the course of time. 


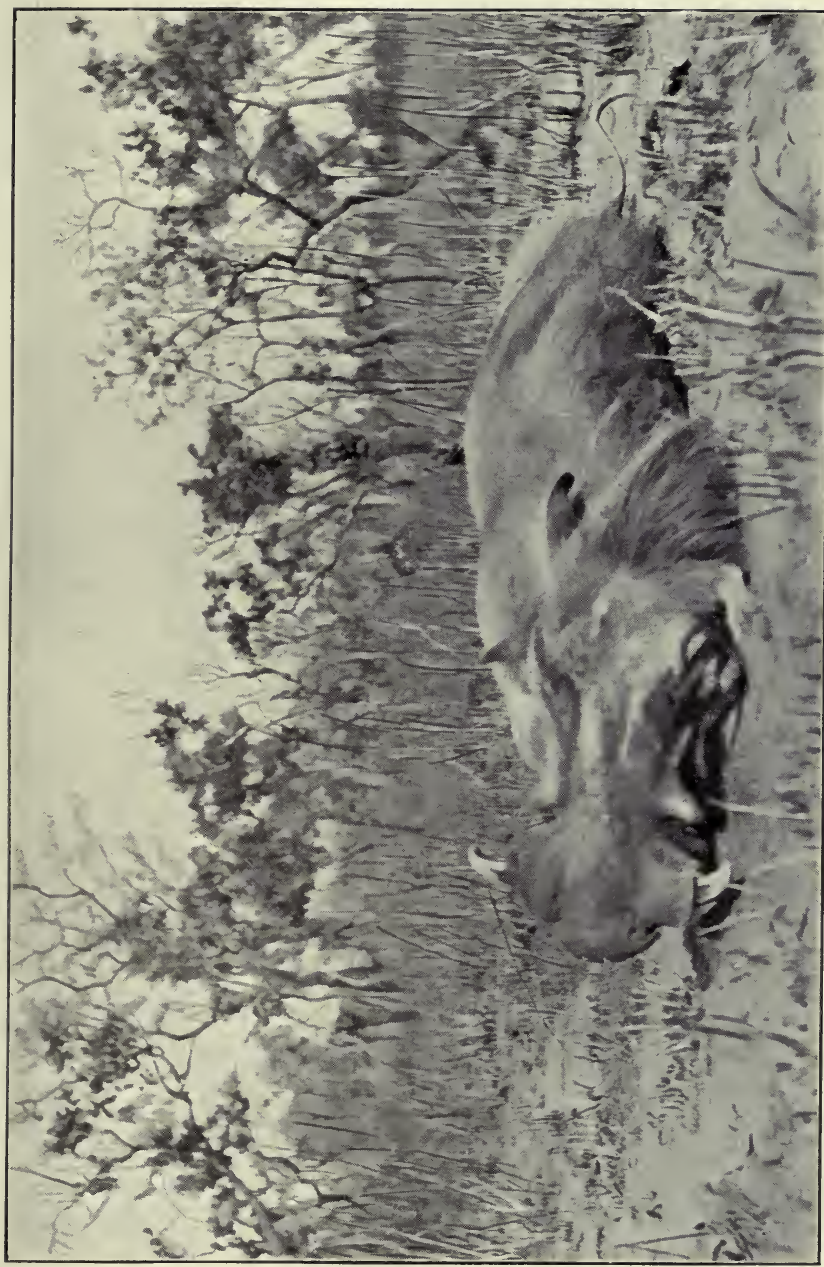

0
0
0
0
0
3
3
3 
A noticeable feature of warthogs is that when running they hold their tails straight up, which gives them a rather ludicrous appearance. I have only heard of one instance of a warthog injuring a human being, and that was a native who met one on a narrow path near his garden one morning. I think it had probably been frightened, and on seeing him in the way it gashed his leg severely.

Many years ago I visited Sadiya in the northern parts of Assam, and the police officer told me that he had a Gurkha soldier in hospital who had wounded an Indian boar with a Martini rifle, and that it knocked him down and gashed and cut the softer parts of his body into ribbons; but that he was recovering, as they were only severe flesh wounds. This shows the ferocity of the Indian pig, and it is certainly a much pluckier beast than the African warthog.

Warthogs are a greyish colour, and have long hair along the neck and back.

\section{BUSHPIG (Potamochorus choropotamus).}

NATIVE NAMES.

Chinyanja - - Nguruwe.| Chingoni - - Nguruwe.

Approximate weight, $\delta$. $\ldots . \quad \ldots \quad 2$ 2olb.

Good average upper tush, $\delta^{*} \quad \ldots \quad 5$ in. curve.

Bushpigs are pluckier beasts than warthogs, although their teeth are smaller. The cutting teeth are thicker and kept very sharp. Bushpigs are heavier than warthogs and are of a reddish colour with long hair along the top of the neck and ridge of the back, and also hairy on the body.

I have mentioned cases of them attacking leopards, and I have no doubt that several of them could kill one of these animals if they managed to get him cornered.

There seems to be a variation in the size and colouring of bushpigs in different districts of this country, and those found on Mlanje Range in Nyasaland seem to me to be larger and much hairier than those found in other places. It is very cold on the plateau of Mlange Mountain during 
most of the year, especially at night, and I have little doubt that the pigs there have grown hairier skins as a protection against the lower temperature.

Bushpigs do great damage to native crops, and the natives usually make fences to keep them out of the gardens. On the other hand warthogs do not often invade the grain fields, as they prefer to keep to the bush and plains. I have heard of a small pig in this country which must resemble the peccary; but I never saw one. The natives mention the existence of this animal near the Luchenza River flowing past Mikolongwe, in Blantyre district, and a friend, Mr. W. P. Ronaldson, told me that he had seen their spoor, which was very small; so I think it is probable that these little pigs exist there. They are said to keep to the thick bush during the daytime and only to go into the more open country in the hours of darkness.

Lions kill a great number of bushpigs and I should think they are better eating than the skinny, long-snouted native pigs they also feed on when they can break into a kraal.

I should say that a big male bushpig is slightly heavier than a warthog boar, as he is thicker made and larger in the limbs.

HYÆNA (Two varieties).

(I) Spotted hyæna (Hyæna crocuta).

(2) Brown hyæna (Hyæna brunnea).

NATIVE NAMES (Spotted variety).

Chinyanja - - Fisi. | Chingoni - - Pisi.

Approximate weight, $\delta$ c.. $\quad \ldots \quad \ldots \quad$ I $25 \mathrm{lb}$.

There are two varieties of hyænas in Central Africa, but the spotted hyæna is the only one that is likely to be met with, and I never saw a specimen of a brown hyæna although I heard of one being shot in Mlanje District many years ago. I have also heard that they are slightly more 
numerous in Portuguese East Africa, which adjoins Nyasaland.

The cry of the spotted hyæna will often be heard at night, and the repertoire of the hyæna in the making of weird sounds is unique.

Hyænas howl, shriek, cackle, clack, and laugh according to the state of their stomachs, and if a dead elephant or other large animal has been left out for a night, all in the district seem to collect for the dinner party.

Lately I left a bull elephant, and on coming back next morning, I found that the hyænas had eaten half the trunk. I made a fence round this elephant, which took more than half the day, so by nightfall I had only got out the tusks and cut up part of the animal. The hyænas that had visited the carcass on the previous night came back at dark with many more, and I will never forget the sounds they made that night. One could hear their cries of disappointment in finding the natives and myself camped near, for the natives slept inside the enclosure, and I in my tent, pitched about fifty yards to windward so as to escape the strong stench.

As the natives had fires and I had not, the hyænas kept roaming round the tent in a most fearless way, and, as they sang their various songs quite close to my ears, I could not sleep much.

If hyænas cared to, they might be dangerous, as they are possessed of tremendous power in their jaws, and, considering the amount of walking they do in search of food, they must be wiry and hard. Occasionally they will take half the face off a native or give a human being a tearing bite in the leg, but, considering their numbers, they do little harm.

I have seen the thigh-bone of a big elephant broken in half by them, and this, of course, was not the result of one bite, but continual gnawing and crunching.

Any ordinary bone they will snap with a single bite, and, as they feed mainly on bones left by lions and leopards, their droppings are usually of a bluish-white colour. It is 
often easy to see what a carnivorous animal has been feeding on from the nature of its dung. There is a difficulty in telling the sexes of hyænas, as the organs are similar. I once weighed a large male hyæna, and it scaled I $25 \mathrm{lb}$., and I do not suppose they ever exceed I $50 l b$.

Considering their moderate weight, their strength is marvellous, and twice I have known them remove a slab of hippo hide which was a good load for two strong men to carry on a pole, and which presumably weighed quite I6olb., and on both occasions they dragged the skin for some distance and then gnawed it. It must have been a tough and stodgy meal, although not so sharp or hard as a load of chipped bones. The hyæna enters largely into native superstitions, doubtless through their quiet, sneaking habits and strange cries.

\section{WILD DOG (Lycæon pictus).}

NATIVE NAMES.

Chinyanja - - Mbulu.

Chingoni - - - Mesengyanga, sometimes Mbulu.

Approximate weight, $\hat{\delta} \quad \ldots \quad \ldots \quad 8$ olb.

It is possible that there may be more than one variety of the wild or hunting dog in Central Africa, as a certain amount of difference can be noticed in their markings in different districts. I have only shot about ten wild dogs, but I have seen them on several nccasions when after game, without firing at them.

Those I shot in Central Angoniland seemed to have more white on their bodies than two I shot near the Luangwa River in North-Eastern Rhodesia, and were also slightly larger.

Their colour is a mixture of blotched markings of black, yellow, and white, and they are often mangy and dirty. The bitches bring forth their young in deserted antbear holes, and they must leave them behind when hunting, as I never saw young animals running with a pack. They are 
sporting animals, but they do great damage to the game, as they are always at it, for it must take a lot of meat to feed a pack of fifty or sixty of them.

They range the country until they disturb an antelope and then hunt by scent, following quickly and steadily until they wind their prey, when it is easy to kill it, except in the case of sable or roan antelopes, when I fancy the dogs get killed at times, as both these antelopes are plucky and well armed with their long, curved horns. I once saw a large pack hunting a bull waterbuck, and the chase cannot have lasted long, as the waterbuck was showing signs of being done and was not far in front. He was likely doomed unless he crossed water, which would be the only thing to stop the dogs, as they would lose the scent of the spoor. An old native once pointed out a small detached hill to me, where he said a pack of wild dogs had killed a lion, long ago; and after killing him they ate him. I expect this is true, but that the lion was an old animal pretty near a natural end with old age and hunger, and that it had neither the strength to run far or put up a good fight for its life.

I asked the native if it was a lion or lioness, and whether it was old, and he said that when the people saw the animals fighting they were afraid to go near, and that the dogs soon ate up the meat and skin.

Some authors give wild dogs a bad character, and say they are dangerous, although I never saw them make an attempt to attack human beings, even when wounded. The natives, however, say they are dangerous, and I believe they imagine so for the reason that when wild dogs are seen they never seem in a great hurry to bolt, and will often trot a few yards and look at the disturber, and give vent to a clacking sound.

One I wounded badly near the Luangwa River allowed me to go up and push it with my foot, and it only cringed and turned over, so I put it out of pain quickly with another bullet. The habits of the African wild dog must be very like the wolves of Eastern Europe and America, and 
as they get most of their food by running it down, I think they are worthy of being classed above vermin, for at least their methods are "sporting."

JACKAL (Two varieties).

(I) Side-striped (Canis adustus).

(2) Black-backed (Canis mesomelas).

NATIVE NAMES.

Chinyanja - - Nkandwe.|Chingoni - - Kandwe. Approximate weight, $\sigma^{\star} \quad \ldots \quad \ldots \quad \ldots \quad 33$ lb.

Although these animals are fairly plentiful, they are not very often seen unless one is out very early in the morning, or late in the evening when darkness is near. Then a jackal may now and then be disturbed in a patch of grass, or seen leaving such a place where he has spent the day resting and sleeping. They are fond of walking on native paths, and I have shot a few I have met in this way. Their sharp cries will be heard at night, although not so often as in India, where the jackal (of a different variety) is much more plentiful than I have ever seen it in Central Africa. In the cold season their skins are very pretty, as they are more thickly haired at that time than in the rainy months. In South Africa various tribes make nice karosses (fur rugs) with jackal and other skins; but I have never seen the natives of Central Africa make rugs of any skins, although they make bags and ornaments of wild cat and other small skins.

Jackals eat locusts when they are about and they doubtless eat lizards, snails, mice, rats, etc.; in fact anything they can catch and kill that is eatable. They eat berries and fruits, also, and when big game is killed they visit the remains after the lions and hyænas have left, and they probably follow both these animals to pick up the leavings. I think the black-backed variety is commoner than the side-striped; the latter being slightly the larger of the two. 


\section{OTTER (Two varieties).}

(I) The large, clawless (Lutra capensis).

(2) The small, with claws (Lutra maculicollis).

Chinyanja - - Katumba.| Chingoni - - Ntimi.

The former ( $\mathrm{I}$ ) is clawless and both varieties feed on fish, crabs, and insects. The latter (2) can be distinguished by spots on the neck skin and from its smaller size.

Their skins are pretty and soft, and great numbers have been exported by traders who used to buy a good skin from the natives near Lake Bangweolo for a yard of calico, value 3 d., though I fancy the natives know their value better now and ask and receive more.

Otters give a grunting cry, which can occasionally be heard when camped near rivers and lakes. They are found on all the large bodies of water, and a favourite haunt is the muddy swamps surrounding Lake Bangwelo.

\section{Civet Cat (Viverra civetta).}

NATIVE NAMES.

Chinyanja - - Chombwe. $\mid$ Chingoni - $\left\{\begin{array}{l}\text { Fututu. } \\ \text { Chimbwe. } \\ \text { Chiwanda. }\end{array}\right.$

Good average skin ... $\quad \ldots \quad 3 \mathrm{ft}$. gin. straight.

Fairly numerous, but seldom seen except by the natives, who kill a few when their dogs disturb and tree them.

The Angoni have three different names for the civet cat, which I give above. The skin is black, with greyish spots and stripes, and from the back of the ears to the tail the hair is long, especially about the rump.

They feed mainly on fruits and berries, although they probably eat meat when they can get it.

It is almost wholly a nocturnal animal, and, during all the years I have lived here, I only remember seeing one in the day time, which I saw on the side of a rocky hill when after klipspringers. They live in holes, and possibly in hollow trees at times. 
ANTBEAR (OR AARD VARK) (Orycteropus afer).

NATIVE NAMES.

Chinyanja - - Zimba. | Chingoni - Pendwa.

Approximate weight... $\quad \ldots \quad \ldots \quad$ I 30 lb.

This is one of the strangest denizens of Africa, and it is purely nocturnal in its habits. Its abandoned holes will be seen all over this country, as it spends its time digging for termites. It is not difficult to notice when it is "at home," as the earth will be seen to be newly dug, and the fresh spoor of the animal's entrance will be seen. Then it has to be dug out, which will take some time, as the earth is often caked and hard. Its claws and paws must be very powerful, considering the work it does, and, if any animal works hard for its living, surely the antbear does.

Its tongue is long and pendulous and covered with sticky moisture, and it licks up the ants when it finds them in quantities. The Boer name "aard vark" means "earthpig," and in some ways it is not unlike a pig, as it has a long snout. The colour is bluish grey, and it is almost hairless, and the skin is thickly covered with a fatty substance which makes it most difficult to cure, and the only way to preserve it is to thin it down. I never saw one of these animals alive, but I have seen three dead ones killed by the natives.

I will now give a list of other animals and birds to be found here.

\begin{tabular}{|c|c|c|c|c|}
\hline Crocodile & & $\ldots$ & $\begin{array}{l}\text { CHINYANJA. } \\
\text { Nigona. }\end{array}$ & $\begin{array}{l}\text { CHINGON } \\
\text { Mwena. }\end{array}$ \\
\hline Baboon ... & $\ldots$ & $\ldots$ & Nyani. & Korwe. \\
\hline Monkey, comn & non (I)... & $\ldots$ & Pusi. & Nchasi. \\
\hline Monkey, dark & coloured (2) & $\ldots$ & Mchima. & Seymango. \\
\hline Honey Badger & $r \quad \ldots$ & $\ldots$ & Chuuli. & Nsairi. \\
\hline Wild Cat & $\ldots \quad \ldots$ & $\ldots$ & Vumbwe. & Ligora. \\
\hline Rusty Spotted & Genet ... & $\ldots$ & Mwiri. & Simba. \\
\hline Reed Rat & $\ldots \quad \ldots$ & $\ldots$ & Mawpini. & Mafondo. \\
\hline Large Shrew & $\ldots$ & $\ldots$ & Sakwe. & Tondo. \\
\hline Small Shrew & $\ldots$ & $\ldots$ & Yidenga. & Tondo. \\
\hline Stoat ... & $\ldots$ & $\ldots$ & Lakongwe. & Kakeedi. \\
\hline Porcupine & $\ldots$. & $\ldots$ & Nungu. & Nungo. \\
\hline Galago ... & $\ldots$ & $\ldots$ & Changa. & Chingwe. \\
\hline
\end{tabular}


Bush Baby

Scaly Manis

Hare

Hyrax (I)

Hyrax (2)

Zorille

Slender Mongoose

Marsh Mongoose

Red Mongoose

Banded Mongoose

Mellor's Mongoose (?)

Squirrel...

Mole

House Rat

Field Mouse
CHINYANJA.

Kamunde.

... Nkaka.

.. Kalulu.

... Kafwaombwe.

... Mbira.

... Kanyimbi.

... Nyenga.

... Kakaka.

... Kakaka.

... Msulu

... Msukunya.

... Pati.

... Mfuko.

... Koswe.

... Mbeywa.
CHINGONI.

Kanganjea.

Nshoni.

Mvunja.

Nteraicha.

Mbira.

Kanyimbi.

Nshangana.

Chikanda-

Matika.

Gerenenzi.

Luwara.

Gorogoro.

Mfukosani.

Gundani.

Mbeywa.

\section{Flies and Insects, etc.}

\begin{tabular}{|c|c|c|c|c|c|c|}
\hline Butterfly ... & $\ldots$ & $\cdots$ & .. & $\ldots$ & & $\begin{array}{l}\text { CHINGONI. } \\
\text { Bobo. }\end{array}$ \\
\hline Tsetse $\quad \ldots$ & ... & .. & .. & $\ldots$ & ... & Kamsembe. \\
\hline Bat $\quad \ldots$ & ... & ... & .. & $\ldots$ & $\ldots$ & Chimkopeete. \\
\hline White ant & $\ldots$ & & .. & ... & $\ldots$ & Ninswa. \\
\hline Hornet $\ldots$ & $\ldots$ & ... & .. & $\ldots$ & $\ldots$ & Magu. \\
\hline Bee $\quad \ldots$ & $\ldots$ & $\ldots$ & & $\ldots$ & $\ldots$ & Njuchi. \\
\hline Small black ant & $\ldots$ & $\ldots$ & .. & $\ldots$ & $\ldots$ & Nyerrairi. \\
\hline & & & BIRI & & & \\
\hline Vulture... & ... & $\ldots$ & & $\begin{array}{l}\text { CHINYAN } \\
\text { Mwimba. }\end{array}$ & & $\begin{array}{l}\text { CHINGONI. } \\
\text { Linki. }\end{array}$ \\
\hline Crested Crane. & $\ldots$ & $\ldots$ & $\cdots$ & Mangalu. & & Lehaemu. \\
\hline Plover ... . & $\ldots$ & $\ldots$ & $\ldots$ & Kwiri-Kwi & & - \\
\hline Wagtail & $\ldots$ & $\ldots$ & $\ldots$ & Tye-Tye. & & Luvaivi. \\
\hline Guinea Fowl & $\ldots$ & $\ldots$ & $\ldots$ & Mkanga. & & Pangaira. \\
\hline Partridge & $\ldots$ & $\ldots$ & $\ldots$ & Nkwali & & Nkwali. \\
\hline Duck $\quad \ldots$ & $\ldots$ & $\ldots$ & $\ldots$ & Bata. & & Sasamanzi. \\
\hline Crow & $\ldots$ & $\ldots$ & $\ldots$ & - & & Mowboru. \\
\hline Goose $\ldots$ & $\ldots$ & $\ldots$ & $\ldots$ & 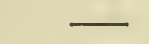 & & Lachekwe. \\
\hline Kingfisher & $\ldots$ & $\ldots$ & $\ldots$ & $\longrightarrow$ & & Periweri. \\
\hline Dove $\quad \ldots$ & $\ldots$ & $\ldots$ & $\ldots$ & - & & Lidjua. \\
\hline Pigeon ... & $\ldots$ & $\ldots$ & $\ldots$ & 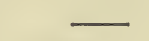 & & Kombocombo. \\
\hline Owl $\quad \ldots$ & $\ldots$ & $\ldots$ & $\ldots$ & 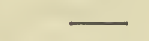 & & Chikova. \\
\hline Osprey ... & ... & ... & $\ldots$ & - & & Nquasi. \\
\hline Parrots ... ... & $\ldots$ & $\ldots$ & $\ldots$ & $\longrightarrow$ & & Ngur-guru. \\
\hline Secretary Bird. & & $\ldots$ & $\ldots$ & $\longrightarrow$ & & Makonongo. \\
\hline Bustard... & $\ldots$ & $\ldots$ & $\cdots$ & - & & Chikwaysha. \\
\hline
\end{tabular}


SNAKES.

CHINYANJA. CHINGONI. CHARACTER. Python ... ... ... Nsatu. Satu. HarmIess.

Red combed snake (?) ... ㄴ M Mbobo. Dangerous.

Mamba ... ... ... - - Mamba. Dangerous.

Green long snake... ... _ _ N Nwaima. Dangerous.

(?) $\quad$.. $\quad$. $\quad-\quad$ Kalukaquiti. Dangerous.

Water snake $\quad . . \quad \ldots \quad \quad \ldots \quad$ Mbevu. Dangerous.

Puff adder... $\quad . . \quad \ldots \quad$ Piri. $\quad$ Piri.

(?) $\quad$.. $\quad$.. $\quad-\quad$ Mshawa. Harmless.

Small snake like porcupine quill... ... .. $\quad \ldots$

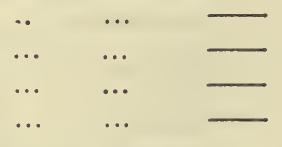

Mapingo. Harmless.

Kapapasha. Dangerous. Chipiri. Dangerous. Nalongo. Harmless.

The ordinary word for a snake is njoka, and natives do not differentiate unless asked to do so.

I do not know the Chinyanja names for many of the above snakes, and I have got several Chingoni names from an old chief named Shauri, which I could not identify with many I know, as his description was too vague. I have written against each whether it is dangerous, and he seems to think that most of them are, and even states that the python will kill men, and in doing so thrusts its tail in the victim's nose! The mbevu, mamba, piri, and mbobo, he considers very "bad" snakes, and the latter he affirms. kills by hanging from a tree and biting at anything that passes beneath, with fatal results to the passer-by. Few natives can distinguish between poisonous and nonpoisonous snakes, although they naturally know which are the most dangerous. 


\section{CHAPTER X.}

\section{Native Characteristics, Customs, ani) Beliefs (MAINLY ANGONI).}

Most noticeable characteristics of the natives-Internecine war in olden days -Witchcraft and the things it can do-A strange custom with children - Boiling water ordeal-Charms against death-Dead returning in the shape of animals-Digging up corpses-Cooking children of enemiesNames given to commemorate events-Old name for the Angoni raceDistribution of the Angoni tribe-Marriage customs-Women workers Polygamy defended for natives-The "White Father's" MissionStrange legend about the Angoni trek-Putting not-wanted people out of the way-Strange custom to get a case heard-Kindness of natives to others of same tribe-Superstitions about planting crops-Hardihood under painful wounds-Bible not suitable for natives-Untruthfulness of natives-Civilisation not beneficial to natives-Fondness of hunting and meat - Natives good servants - Patience with natives best Atrocities practised by natives-Mild justice inadequate at times-Love of children-Natives as soldiers-Adaptability in learning quicklyLiking for music-Cruelty to animals-Splendid porters-Staunchness at times-Mission boys-Missions discussed-A strange custom with pigeons-A funny native woman-Old Mpseni-Peculiar ideas with regard to births-Child murder-Impossibility of natives reasoning as do Europeans.

IF a newcomer was asked what were the most noticeable characteristics of the natives, he would probably say their love of making a noise, their strong smell, and their liking for meat and native beer. He would be right, but there are also hundreds of other interesting traits which it takes a long time to discover, as to do so one has to live near them and understand their customs and manner of thought and action. In the old days before the whites went there, it was purely a "survival of the fittest," as they were constantly making war on other tribes; and many people died by drinking the ordeal poison, and other poisons introduced into their food by enemies. 
The natives firmly believe that a person can cast a spell on, and kill, another person, and they believe absolutely in various compounds, which if enclosed in a small horn, can cause death or sickness. One case that was mentioned to me was that of a child who was found one morning with all the teeth of its upper jaw missing, and they assert that there are medicines which cause persons the loss of various organs of the body; so that some fine morning a man or a woman can wake up without a nose, or with only one eye or one ear, and perhaps a toe may have departed in the night.

The Angoni had a strange custom with regard to children who had the misfortune to cut the teeth of the upper, before the lower, jaw. If this happened, the mother would call a lot of old women to witness the occurrence, and then they would march down to the river with the child, when the mother would tie it tightly in a skin or piece of calico, and fling it into deep water, just like a puppy or kitten. This custom was called "kunameera."

Their idea was that should the child grow up it would be able to cast a spell on anyone it was unfriendly with, so it was put beyond doing harm in a watery grave; and the mother and her friends returned quite relieved that they had done the best to save future trouble.

Infant mortality used to be very great, as the natives had a custom of throwing away babies that showed, in their estimation, the least blemish. For instance, if a child was born with dark skin round the nipples, or if the lips were very red, it was thrown into the bush.

Even to-day the natives kill many infants for the same paltry reasons.

A mother who gave birth to a child suffered from severe internal pains, doubtless caused by inflammation due to straining in deliverance. She affirmed that as soon as the cut navel of the child had healed that the pain would leave her.

Another strange idea is that they will not break sticks of firewood in a hut near a newly born child, as if this is done they believe the child will get ill. 
Should a person be accused of a bad action and he or she feels guiltless of it, an instant offer is made to undergo the boiling water ordeal, which consists in heating a bowl or pot of water over a hot fire until it boils. Then a stone is thrown into the bowl and the accused picks it out and puts it in, several times, in the view of witnesses.

If nothing happens the person is held to be guiltless, but if the flesh is burnt or scalded, this is considered a sign of guilt. My informant averred that no innocent person can possibly be burnt by the hot water; and he asked me to accuse him of something he could not have done, and he would prove it. However, I did not feel quite heartless enough at the moment to experiment in this way. The effect of the ordeal is heightened if the accused undergoes the trial in a hot sunlight, it is usually performed after the sun has set. I said that the accused person put something on the hand which prevented scalding, but this my informant strenuously denied.

Some natives accuse others of carrying poison under the finger nails which they use at times against their enemies, and they find this a convenient way of transporting it and keeping it secretly. Many natives put charms round their necks or wrists as a guard against Mfiti (witchcraft), or as a charm against danger in different shapes and forms. One will have a charm against illness, another against an enemy, another against lions, another against snakes, and so on.

This reminds me of the witch doctor's charm against the white man's bullets in the Matabele Rebellion. His charm did not work, for he died; but had he had time for an explanation he would doubtless have stated that he had brought the wrong charm out that day, and that he had another at home which was infallible.

The Angoni believe that the spirits of wild animals can enter into human beings, and when a man-eatıng lion is killing the natives they will say that is So-and-so who died, and is now tormenting the people who are left by killing and eating them. An elephant I shot which fell in a 
kneeling position, like an Indian elephant kneeling for people to mount into the howdahs, was said to be an old chief who had turned into an elephant, and that he was kneeling to ask forgiveness or pity for past misdeeds to his fellow men. This was rather a quaint and interesting idea I thought.

Hyænas which came to feed on the elephant were the dead followers of the chief who had collected to bewail his loss; so the natives imbue the most ordinary happenings with superstitious ideas.

After an Angoni raid against an enemy, such as the Achewa tribe, the captured slaves, cattle, and other livestock, would be sent ahead, followed by the warriors chanting songs of victory. Many dances would take place, much native beer be consumed, and cattle, sheep, and goats be slaughtered for a big feast.

But if a chief had been killed, a herald was sent in front to the village, where he placed the shield of the dead warrior near the door of his hut. He walked slowly and with his head bent on his chest, and the people knew their chief was dead, and the maliro, or wake, for the departed began, and lasted for many days, according to the importance of the chief. The widows would not marry again for, perhaps, five years, and all this time they would not wash their bodies, as by doing so it was believed that they were trying to make themselves clean and beautiful, and were anxious to marry again. Cattle and goats were killed, and the widows wore strips of skin or mat round their heads and waists ; and often bark string is used as a mourning band. I have not heard that within the last hundred years any chief has been accompanied to "The Happy Hunting Grounds" by an escort of slaughtered wives and slaves, as used to be customary in parts of West Africa.

A chief's grave was often zealously watched for some months, so that body snatchers did not dig him up.

Some madmen are said to dig up bodies to get certain organs with which to manufacture witchcraft medicines, 
and some races in Central Africa, mainly the Anyanja and Anguru, dig up bodies to use as food, which is a loathsome and disgusting habit, and very much worse than ordinary cannibalism, when the freshly killed victims are eaten. When the Angoni raided an Achewa village, all the full-grown men and women were speared; but the young boys and girls who could walk were spared and taken back as slaves. The poor infants would have their brains dashed out with knobkerries, then goats and other livestock would be slaughtered and eaten, and often the victors would leave a big pot simmering on a fire in a hut, filled on the top with goat's flesh and underneath it a small baby.

The people who had escaped into the bush would watch the raiders depart, then return tired and famished to their huts, and seeing the pot of good meat, would often eat most of it until they came to the bottom, where they saw the slaughtered infant-probably their own-and this was the so-called practical joke. I have spoken to natives who have done this, and they were often quiet, good-mannered men; but when war was on they turned into bloodthirsty savages.

Many of the older men's names were given to commemorate past events, such as M'meza (or Memeza). He happened to be born when the Angoni were collecting for a big raid, and the word M'meza means sending round. This man is one of the nicest and most gentlemanly natives I ever met, there is nothing savage or coarse in his features, and he has the reputation of being a kind-hearted man who disliked shedding blood. At present he is the headman of the Angoni villages round Fort Manning, although his nephew, named $\mathrm{Zulu}$, is the Boma (Government) capitao.

Zulu's father (of the same name) was a son of old Mpseni (pronounced Impseni), the paramount Angoni chief, and Memeza is another son of the same old chief.

An Angoni chief I know well, named Shauri, is also a son of old Mpseni, and a brother to Zulu, Memeza, and 
Mkumbi, all mentioned here. He got his name at the time the Angoni were preparing for a raid, and the word Shauri means sending out a party to see if the enemy is about.

Mkumbi, yet another son of Mpseni, means clouds, and he was brought into the world on a cloudy day.

The old Angoni name among themselves, and other tribes, was Mazite, and it was a dreaded word long ago. in this part of Africa, for the Angoni are descended from the Zulus of Natal, probably the finest race of savages in the world, as they are splendidly built men with plenty of pluck and fighting qualities.

A part of the Zulu race split up and trekked north. Some stopped in Matabeleland and formed that nation, which lost its paramount chief Lobengula when the whites. occupied that country. Then others went farther on and crossed the Zambesi and settled in different parts of Central Africa under different chiefs.

One lot is found round Dedza, in the southern part of Central Angoniland, and they are called Ngabi's section. Another big detachment settled in the country round Fort Manning, in Nyasaland, and Fort Jameson in NorthEastern Rhodesia. This is known as Mpseni's section. Then another went farther north still, and formed Mombera's section; and, strange to say, internecine war often was carried on between all these people who belonged to the same tribe. It is said that the Awemba in the northern parts of North-Eastern Rhodesia and the Masai, of British East Africa, are of Zulu blood, but I have not sufficient knowledge of ethnology to state whether this is so or not.

The tribal customs of the Angoni are most interesting, and these have often a great amount of common-sense intermingled with superstitions and old myths.

When the young boys and girls reach a marriageable age they marry, as do most savage races. A young girl is called a bhuto, and at the age of puberty she is known as a namwali. Long ago the men did not marry at such an early age as they do now, as their thoughts were more bent 


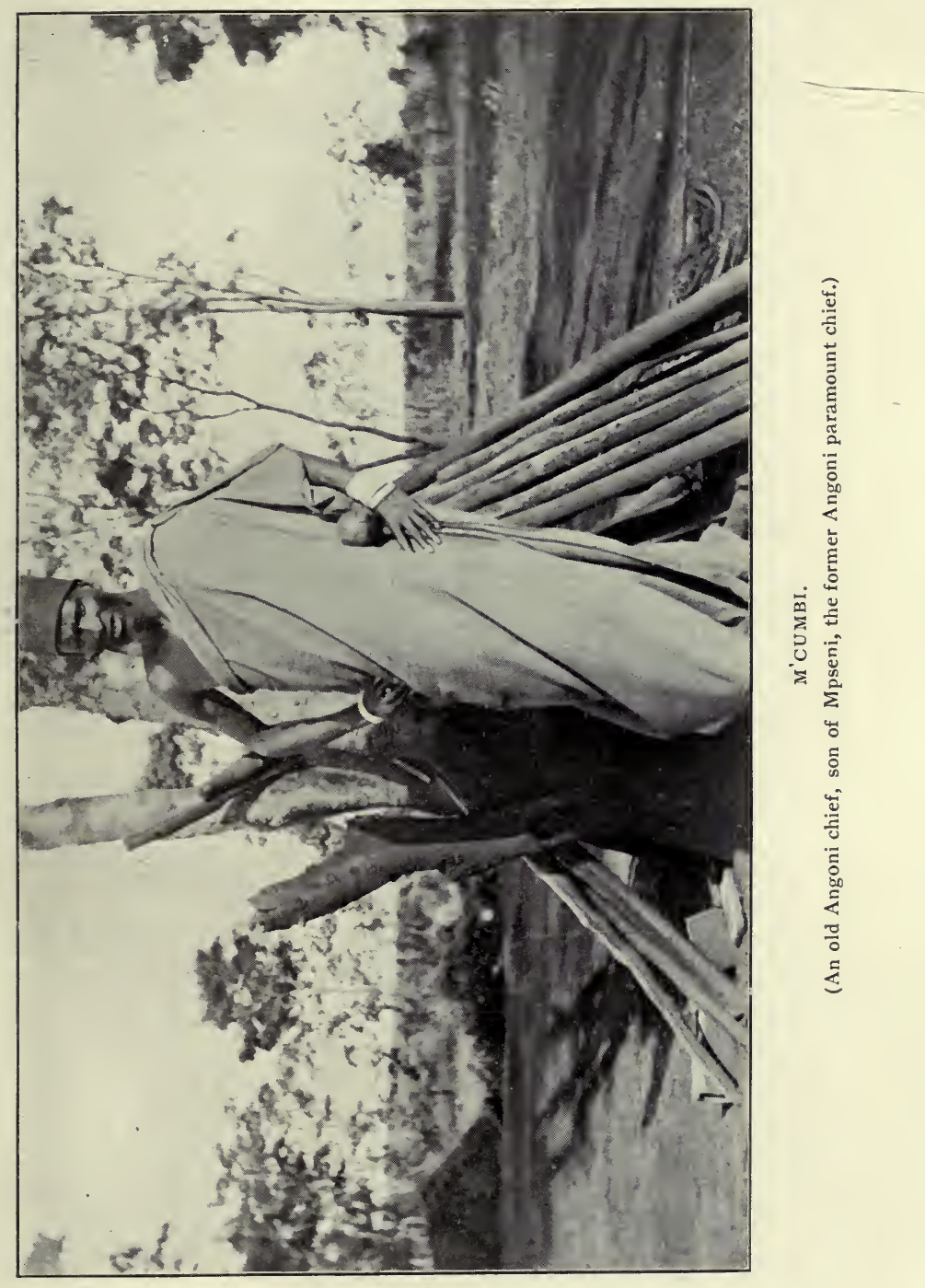



on war and a "free lance" existence. Now, as wives are sometimes scarce, they take them young.

When the Angoni had plenty of cattle, as many as twenty cows would be paid to a father for his daughter, although the usual number was from five to ten beasts.

Now all the youth does is to arrange with the parents and the girl, and then hand over a few shillings, or some cloth or beads, and the girl is his. Then a beer drink usually takes place, and the youth, who has probably got a hut ready for his bride, takes her off and they cohabit.

The missionaries are trying to instil into the minds of the natives that a single wife is much preferable to a number, and they are teaching the natives to read and write and relinquish their polygamistic habits, and many of the younger men have done so.

This is a big question, but, so far as I can see, this system does not work well with natives, particularly with the older men who have from three to ten or more wives; if these are cast off they either lead immoral lives or they hold an inferior position for being unattached. A man's wealth and food supply depends largely on the extent of his household, or households I should write it, as each wife has her own hut.

The women do the greater part of the hard work, as they perform most of the hoeing in the gardens, and they cook their husband's and children's food, get water and firewood, and do a lot more; so if a man has only one wife he will find that his garden will be small, and often, if she is ill, there will be no food to eat, as it is hard work for her to pound grain, and do the other necessary daily tasks. Therefore many of the old men have refused to give up any of their wives, and as they are too old to bother about learning to read and write they lead their old lives, except that fighting and raiding play no exciting part.

The man usually does the heavy work of timber felling and making a garden, and he hunts pig and small buck with his dogs and a spear. The old men always have a great craving to imbibe native beer; and they often travel 
long distances in search of it. I know several old native chiefs like this, and they are happy souls with little to worry them, except the difficulty of finding enough silver to pay the annual hut tax for all their huts. The younger generation are also pretty fond of beer, and they often waste a great amount of maize in making it, and consequently suffer from hunger at the end of the hot season, before the new crops, which are planted as soon as the rains break, have had time to bear.

The "White Fathers" Mission do a considerable amount of good work among the Angoni, and they have mission schools in most of the more important villages, in charge of educated native teachers, who get a small wage. If a youth or maiden wishes to attend such a school they are welcome, and after being able to repeat "the Lord's Prayer," they are presented with a chain and crucifix, and they are very proud of this symbol; but I question if they fully understand its meaning, and I think it is rather absurd to give it to them. They simply look at it as a pretty ornament, and I have had boys who wore them who were just as liable to lie and steal as others who lacked this symbol of Christianity.

Most of the "White Fathers" are Frenchmen, and they are broad-minded and intelligent men; but I consider that they are going a "bit too fast," and no native should be given a crucifix until it is proved that he is wholly converted. The missionaries live in good brick houses, and usually have livestock, such as cattle, pigs, and sheep, and a fine vegetable garden. I think they are very wise in making themselves comfortable, as. without good health they would be unable to perform their duties of attending to the sick and holding services throughout their district.

All of them, both the priests and the laymen, come out for the term of their natural lives, and they do not go home unless they are seized with severe illness which needs medical attention that cannot be got in this country. This Catholic mission is much more broad-minded than the Scotch and English missions in the country, and, personally, 
I have found them most friendly and hospitable. Any fault that may be found does not apply to any of them individually, and it is the result of a system which they have to follow. Although I have stated that certain of the natives who have been given a crucifix may be dishonest or untruthful, I think that many are influenced for good by the teaching they receive. If a native has more than one wife he cannot get a "mtanda" (crucifix), but it is only the younger natives who seem to care to possess one. To teach natives to read and write, and also to work at various trades, is most admirable, but to teach them merely to sing and chant hymns, and repeat the Lord's Prayer, is rather futile, as they have not the slightest idea of the true meaning, and simply do so because it is an excuse for making a noise, and a native is very fond of hearing his own voice. Natives, in their habits, are most gregarious, they like to collect together, and the way they have formed themselves into communities shows that they believe there is safety in numbers. This habit was doubtless caused in the old days, when they found it advisable to build their huts close together and live near one another. A negro is always inclined to show more bravery in front of his fellows than he is when by himself, as he does not possess that strength of mind and self-reliant spirit which enables him to depend on himself.

A strange story was told me with regard to the invasion of this country by the Angoni (Zulus).

They firmly believe that Zonandowa, the father of old Mpseni, when he came to the Zambesi River, made the waters go apart and leave a path for the army to cross safely to the other side. They say the place is not far from Nungwi (Tete), and some of the older men can point it out at the present day. Considering the old Scriptural story of the same kind, I think it most interesting that they should have such a belief.

When a man is fierce or bad-tempered, the Angoni say that the spirits of wild animals have entered into him; and this is particularly the case when the "peppery" individual 
has killed a lot of big game, as they assert that he cannot help it, as the elephants', buffalos', and lions' spirits have found a place in his heart, and that they are responsible for his irascibility.

Old Mpseni seems to have been a rather fiery personage, for he ruled his people with an "iron" hand. An Angoni tells me he remembers often seeing adulterers killed, and this was done by either dashing out their brains with knobkerries or, more usually, taking them to a big tree and binding them to it with bark-string, placed round the neck and round the trunk. This quickly killed by strangulation, and then the bodies were thrown to the hyænas. At that time the indunas had great power, as "they had the ear," so to speak, of Mpseni, as the ordinary people were afraid to go near him. Some of these indunas are still alive, and they always struck me as cunning old men, and they were, probably, the most expert liars in existence in getting up false cases against people who were in their way.

In a thunderstorm, when the lightning is bad, the Angoni object to having black dogs, sheep, goats, or pigs in their huts, as they believe their presence will cause the lightning to strike the huts. Further, they keep the fire low, and they believe that should a black sheep look up to the roof the lightning will immediately strike the hut and kill the occupants.

The eldest son of old Mpseni (I write "old" Mpseni because the present chief of the Angoni here is young Mpseni, son of Singo, who was the eldest son of Mpseni), by name Singo, was killed when the whites occupied this country. He was sentenced to death, and a native tells me the soldiers fired twice at him, and hit him, but he did not die, so a white man took a big knife and cut his throat. This I do not believe, but it is what the natives believe, and, once they get anything into their heads, it is difficult to get it out, as they have that dull, stubborn nature which it is difficult to enlighten.

The death of Chibisa, son of Patamoyo, a son of Mpseni, seems to have been simply a murder. One day some 
Achewa police were out raiding, when they heard the cries of a child in some reeds, and they called out, when Chibisa who was herding some goats, and had taken his young brother with him, came out of the reeds holding the child. The murderous Achewa then told Chibisi, who was only a youth about fifteen years of age, that they intended to kill him, so he asked permission to place the child to one side in a safe place. He then walked back, and the scoundrels shot and killed him. This murder greatly impressed the Angoni and they still talk of Chibisa, who was said to be a good-looking, kind-hearted youth. Singo they considered a grand fellow and he seems to have been the beau-ideal of a Zulu warrior, for he was tall and good-looking and in their various fighting and raids he was always the "bravest of the brave."

Some tribes, including the Angoni, have a peculiar idea with regard to having a case heard by their chief. If the chief refuses to listen, considering that the case is small and petty, the man will go out and kill an innocent person, whereby attention is drawn to the previous case. An occurrence lately took place in this country when a man, who was refused a hearing in the first instance by his native headman, took a spear and went out and killed a young woman he met in her maize garden. The European magistrate heard of it and he was caught, tried, and hanged. So much for native reasoning!

Natives often make friends with another person, forming a kind of blood brothership, or blood sistership, and then they are always presenting each other with presents, which it is considered courtesy to return.

Natives can be very kind-hearted and generous at times, especially to those of the same tribe and family, and if a person is sick, a man will take quite a lot of trouble in getting the sufferer medicine from the bush; or if he expresses a wish for meat it will be got.

There are many quaint ideas with reference to planting the crops; for instance, they do not plant ground-nuts without scattering some reddish looking powder made from 
the roots of a plant, named "kula," over them. If this is not done and a woman who is unwell with her usual sexual complaint visits the patch of ground-nuts, they affirm that they will not be fruitful. If, after visiting such a patch, the woman then goes to a plot of pumpkins, they will also be rendered unfertile.

Again, among the Achewa tribe, if a woman in pregnancy should go into the growing maize fields, this will cause the maize to wither, and they often do not wash until the crops are gathered. The Achewa when the crops are growing lead celibate lives; but when they are safely gathered and stored in the big bins, they resume their married state.

Black races of mankind are wonderfully tenacious of all wounds, and little children will often get severe cuts and burns, which through bad and dirty treatment may gradually develop into large ulcers, which may trouble them for the remainder of their lives. The usual treatment for a bad cut or burn is to plaster it with cow dung, or put certain leaves and herbs on it, which instead of curing makes the wound worse.

Their commonest cure for sickness is to bleed a person, using a piece of cow, or antelope horn, as a cup. The small hole is sucked after placing the larger aperture on a small incision made.

They do not care to ask medicine or treatment from a white man unless they know him well, and then only if they know he has cured someone else of some injury or malady. Being suspicious, and full of superstitions, they are always ready to put down any natural event to some occult influence.

It is, therefore, a mistake for a white man to give medicine to a man he has had a disagreement with in the past. He may be close to death's door with some malignant complaint, and the best Harley-street doctor would be unable to save his life; so if, out of the kindness of his heart, a white man gave the sufferer a grain of opium to soothe his pain, and he died, as die he must, the relatives would all say that the white man had killed him. For this. 
reason one has often to see men in agony and, because of the senseless beliefs of the people, be unable to alleviate pain.

A person never dies from a purely natural cause in the opinion of the natives. Some enemy has cast a spell on the deceased and caused his or her death. Even if an ablebodied, sound man be killed by an elephant or buffalo, some person has caused the accident.

It will take a very long time for the missionary teachers to eradicate these superstitions and beliefs, so it can easily be seen that as long as the minds of the natives are full of such fantastical ideas, their intellects are quite unable to assimilate the truths of the Christian religion. What we look on as fancy and superstition, they consider wellgrounded facts, and it will take many years of sound education to cause their enlightenment. Without any desire to be considered sacrilegious, I consider the Bible an unsuitable book for them, as many of its stories are too much akin to their own beliefs. The miracles described in that book are only extra nourishment for their minds in the shape of the supernatural.

A native is quite unable to "read between the lines," and he always looks at bare lacts, and anything that happens to be on paper can seem nothing but the truth to him.

As many natives are notorious liars, and some are dishonest, it would be better to teach them to try and be truthful and honest, and also to stop practising senseless cruelty on human beings and animals.

Before they ever saw a white man they had a belief in a supreme being who was able to influence men for good or bad, and they call this being "Mlungo" (God).

If it rains too hard or too little, this is the work of Mlungo. If a man dies, the Mlungo has made another man kill him, and so on. Therefore, they are not altogether Pagans.

Contact with the more highly developed kind of civilisation cannot be said to benefit the natives; indeed, it does 
them harm, for they do not copy the best of the Europeans they come across, as they have less to do with them than the lower class whites, who assume friendliness so as to get their money.

The natives who go to the South African mines are highly paid in comparison to the moderate wages they earn in this country for their labour. Thus, they learn extravagance and wants that are useless to them in their natural lives. They learn to imitate the whites in dress, and thus appear most grotesque, although they do not know it. This sale of inferior European clothing is said to be good for trade; but, if fine races of savages are to be ruined because this trade benefits a few low-class white traders, it is time it was stopped. Again, natives love strong drink, and we know how this has ruined and practically exterminated fine races of savages throughout the world. White men, with all their higher qualities of self-denial and selfrestraint, have often a great struggle to resist the drink demon, so what can be expected of weak-minded natives?

The native is quite happy in his own country, and he can, if he wishes, make more than enough to be comfortable. The Government hut tax is moderate, a single month's work will pay it, and a remission is allowed if a native works for a white man for a month. In fact, I think it would be a good thing if the tax were raised, as this would prove an incentive to the natives to do more work.

For three months they are pretty busy in their gardens, but for the rest of the year they can idle and loaf about, and they spend their time chiefly in drinking beer and holding dances.

A native is an expert in killing time, yet on occasions he can work. hard, and his good qualities in this respect are never more apparent than when he accompanies a white man on a shooting trip. Then he gets heaps of meat, and he enjoys the hunting and cutting up of the game, and there is nothing he enjoys better than plenty of fat.

The Angoni have that arrogance of race seen in all fighting tribes which at one time were rulers of a great 
extent of country. All dominant races show this in their bearing and the way they walk, and it is noticeable in animals also. A lion by day, when he is disturbed, has a furtive, slouching look; but when he has fed and drunk, I expect he looks round with an air of command and contentment, as he feels dominant.

The elephant, with his easy, dignified manner, when he has not been frightened or hurt, seems quite oblivious of anything else on earth, and, among animals, he is king, for nothing can harm him except puny man; and it is only by man's ingenuity in making weapons of destruction that he is able to assert his superiority.

The Angoni make good personal servants, and the younger lads are intelligent when they are taught. It cannot be expected that they can accustom themselves to the white man's ways all at once, so, although they may at first be aggravating and stupid, it is best to be patient with them.

Some years ago I was rather inclined to be hasty with them, for during a residence of some seven years in India I had become accustomed to the intelligent Indian servants, and I found it very difficult to put up with the stupid, procrastinating ways of the Africans.

Central Africa is a land where patience and forbearance has to be exercised if one is to be tolerably happy. It is one of the most isolated countries in the world, for mails take six weeks to come from home, and nothing is done in a hurry.

The white man who possesses a slow, phlegmatic nature is likely to be more popular with the natives than an energetic man who likes things done quickly; and who also likes to live like a civilised being, and not among dirty surroundings.

Above all things natives like honesty of purpose in the white man, although they do not always practise this themselves, so one should never break a promise given or attempt to cheat the natives, as I am afraid many low-class Europeans do. 
Natives are very sensitive to ridicule or sarcasm, and a little of this will often act better than a good beating. I do not believe in the use of the hippo whip called "chikoti," for it is a most cruel implement when used severely, and it should only be used in extreme cases. There is no comparison between a few punches with the fists and a dose of the "chikoti," which will cut a man fearfully, and in some cases kill him if he happens to be unwell. The use of a light boot occasionally or a smack on the head is usually quite sufficient; and if a boy deserves beating often for lying or theft, he can be dismissed, as there are generally plenty of others to take his place. Of course, as in Europe, there are scoundrels that deserve the whip, and there is no doubt that the natives have been accustomed in the past to much more severe treatment than they ever get from white men.

There are two men living near me at present who lost their ears in the old days, for theft; and it was a common thing to treat "kapolo" (slaves) in this way if they stole from their masters. Other atrocities were common, and the Awemba, in the northern parts of North-Eastern Rhodesia, suffered much cruelty from their chiefs, but it must be remembered that such treatment was the only - one the chiefs could exercise to keep their unruly followers in hand.

The milder and more civilised justice of the whites is often laughed at by the natives, as what were considered serious crimes long ago, such as theft, are hardly punished at all. A man may steal pounds of sugar in a month for which he may get a month's imprisonment, where he enjoys better and more plentiful food than he usually gets in his. own home. Imprisonment is little punishment to a native, as he does not feel it any disgrace; in fact, he has a good rest and plenty of food. Incarceration for a long period, however, must be very irksome to a native, for being a savage he likes freedom, and the separation from his wives and children he must feel dreadfully, as all natives are domestic creatures. 


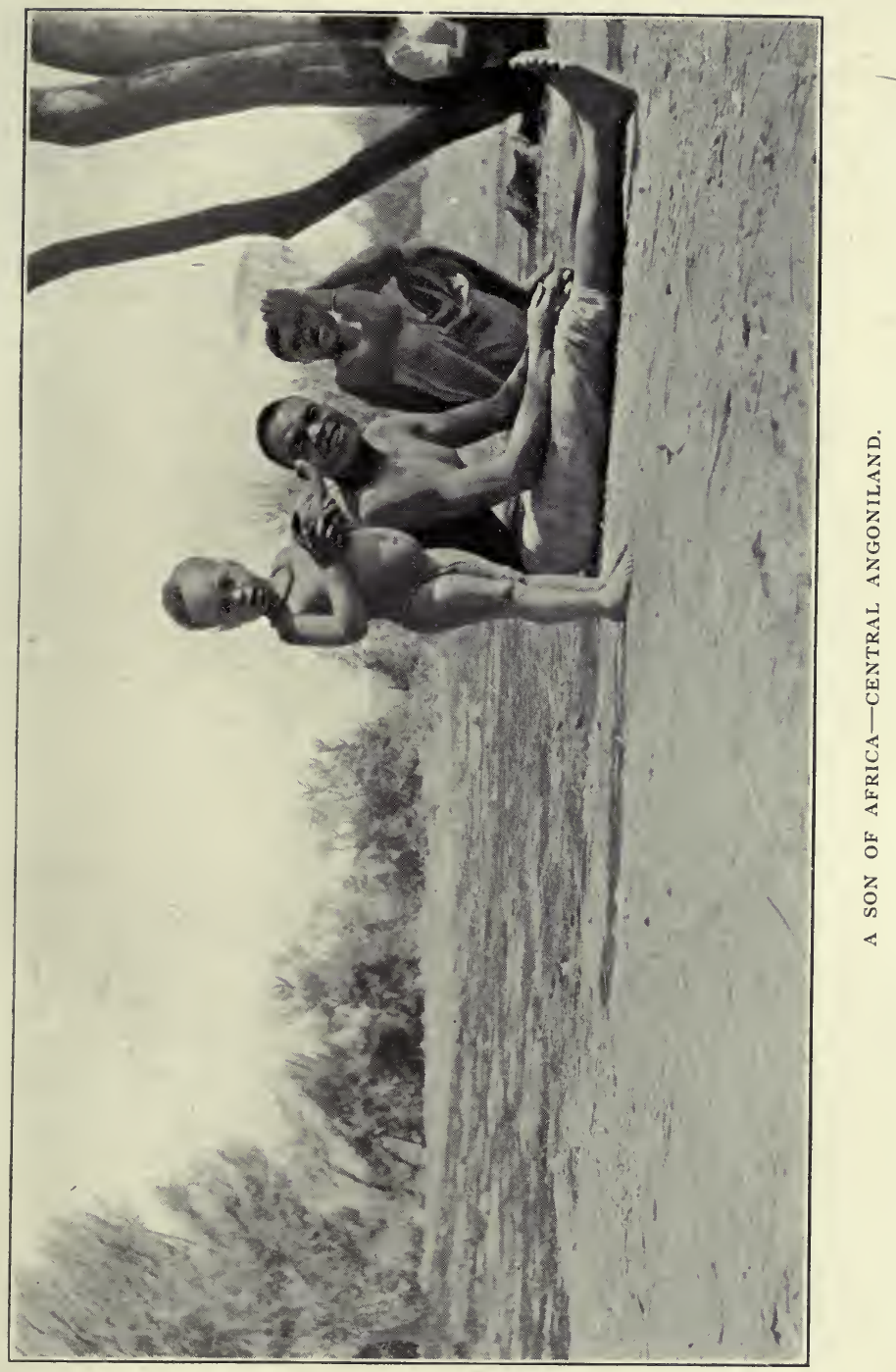



I think one of the best points about the natives is their love for their children, and nothing interests them more than handling and fondling them. They do not kiss them, but they play with them and amuse them. On the other hand the wives are simply domestic drudges, and certain bad-tempered men are constantly thrashing them. When a man possesses a plurality of wives, there are naturally many squabbles caused by jealousy, and the women of Africa are just as prone to suffer from this complaint as are those of more civilised races of mankind.

The Central African natives make good soldiers and police, as they seem to like military drills and duties. That fine body of men, the King's African Rifles, has battalions raised in different protectorates, and I think those recruited in Nyasaland take a leading place for intelligence and smartness. In various African campaigns these men have proved staunch and reliable, and they are wonderfully quick in learning their duties. While residing in Zomba, in 1903, an officer taught several men signalling, and before they were able to take down messages they had to be taught the alphabet. A number of them were proficient in three months, and I think this is a wonderful example of intelligence, as these were grown men of from eighteen to twenty-five years of age, and not youths, who are usually more easily taught.

Again, the King's African Rifles' band in Zomba was taught by an Indian bandmaster to play all kinds of tunes, and certain of the officers, who took an interest in the matter, introduced new tunes, which the natives would master in less than a week, and play almost as well as some regimental bands at home.

Natives naturally have a liking for music, and when their interest is aroused they take great pains over learning anything; and this shows that they have intellect, if it is only awakened and led into interesting channels.

One of the worst features of the natives is that they are brutally cruel, as they have little sympathy for others or for animal life. A boy will take a blunt knife to cut an 
antelope's throat, and saw away for some minutes without getting through the skin, and they will treat domestic creatures in the same way. I got so disgusted with the time they usually took to kill the fowls used for daily food that I made them use a small American axe with which to decapitate them.

I showed them how to do it with one chop on a block of wood, and I remarked to my cook, who is a mission boy with a crucifix round his neck, that the fowl died quickly, and did not suffer pain. He replied "Yes master, but it is only a fowl," evidently meaning that it did not much matter whether it suffered pain or not.

I think that instead of teaching natives to recite the Lord's Prayer and sing hymns, it would be much better to try and instil into their minds the crime of senseless and thoughtless cruelty to man and beast.

That they feel sorry for persons suffering I do not doubt, more especially close relatives; but I have seen them mimic the contortions of a dying man, which so disgusted me that I seized a stick and went for them. Afterwards, I heard them laughing at the white man's strange ways, and I have no doubt they mimicked me as I went for them with that stick.

Should a white man be ill, they often seem quite distressed and sympathetic; but this is not usually true sympathy, for they are simply afraid that, if their master dies, they will be blamed, and their sympathy is for themselves, and not for their master.

They are most patient when suffering from hunger, over-exertion, or sickness; in fact, they are more like animals in this respect than human beings.

In carrying heavy loads for long distances day after day they are unsurpassed by any savages I have ever seen. A white man could not do it, as he would chafe and fret under the constant fatigue and monotony; and I think their brains get so dulled at times that they walk mechanically.

Previously I have mentioned how staunch they can be in times of danger, and many Africans have saved their 
masters' lives from wild animals, and in other ways. Certain races, such as the Yaos, Awemba, and Angoni, are ahead of others in showing personal bravery; and, with regard to them accompanying their master on dangerous enterprises, a good deal depends on their trust. in their master. If they know a man is a good game shot, they will probably be willing to take risks that they would not do with a white man whom they had seen betray fear, or one who was a poor hand at killing game. Natives are not prone to trust much to first impressions, and it takes them some time to get to know a man. Therefore, it is important that the magistrates, residents, or native commissioners in charge of districts should be kept there, and not often changed to other districts where the conditions are new to them, and where it will take them a long time to obtain the full trust and confidence of the inhabitants.

As a whole, the officials of all the British protectorates and colonies of Africa are a good lot of men, although some of the younger of them are inclined to impress on the natives that they are the "big" masters, and that the non-officials are nobodies.

To properly understand this, it is necessary that a European should have been an official, and then, when he becomes a non-official, he is able to see the difference with which many natives treat him. This shows clearly that in many instances the natives only respect power, and, when official power is wanting, they at once take advantage. It depends greatly on the temperament of the non-official whether he is treated badly by the natives or not, and he has to assert himself with certain natives and prove that he is quite able to safeguard his own interests. They soon get to know whether a man can be browbeaten or otherwise, and they are just like children in taking advantage of patience and kindness.

The natives living near civilisation are much worse in this respect than the raw savages. Personally I much prefer the latter, and I cannot bear the swaggering Blantyre mission boy in European clothing, hat, and boots; who 
in many cases is most insolent to white men. These mission boys are frequently scroundrels and past masters in lying and thieving; but they are cunning to such a degree that the missionaries are often quite hoodwinked by them, and think them paragons of virtue and integrity. This is not a singular opinion; but is that of most men who have had a good experience of this country. I do not wish for a moment to insinuate that all mission boys are of the type I have portrayed, but that the majority are is a fact that cannot be gainsaid by all honest men.

On the other hand, the mission teachers (natives) of the White Fathers' missions throughout this country are a much better type of native, as they are taught to be respectful and honest; and my former remarks apply to the native so-called converts of the Scotch mission in Blantyre. The whole matter is one of education, and the White Fathers are a much better type of men in their own country than are most of the missionaries of the Scotch mission. There is a very strong feeling in the country about the missions, and they have only themselves to blame for this feeling, as they go about their work in the wrong way, for they try to go too fast, with the result, to use a slang term, that they "botch" it, and instead of improving the natives, as is probably their earnest desire, they unfortunately end by spoiling most of them. The medical part of the Scotch mission is a most worthy one, and so are all industrial missions.

To get back to the Angoni, I saw a strange custom the other day. A man had bought some pigeons, and in putting them into the cote the man put in the hen birds and his wife the cocks. I asked the reason and was told that if this was not done the birds would prove unfertile.

Not very long ago I shot a hippo in the Bua River. The men had disrobed to get it out of the deep pool, and were in a state of nature-in other words stark naked. An old woman who had smelt the meat appeared and was a keen witness of the proceedings. Some of the men shouted to her to go away, and I was greatly amused at her reply, for 
she said that she was too old to be interested at the sight of naked men. As her presence interfered with the operations, I told her to leave for the present and come back later, when she would get plenty of meat, and she departed smiling.

Some of the natives are quite as sensitive as white people in exposing their persons, especially to members of the opposite sex, and it is a mistake to think that all tribes are lax in this respect. Even the Angoni youngsters wear a certain amount of clothing round the waist, it is only the babies that are unclothed, and even they are covered at times.

In moments of distress both adults and children use the word mai (mother), and they will cry "A-Mai", "A-Mai" when they are hurt, meaning "oh, mother," "oh, mother." I have mentioned that the Angoni believe in a "Mlungo" (God, or supreme being) and they have a very good idea of the meaning of right and wrong, and long ago they had a stern code of laws. Most native tribes live in communities under different headmen, who are sometimes the sons of old chiefs, or men who by their own intelligence and strength of body and will have been elected chiefs. In old Mpseni's time he acted as an autocrat, and the power of life and death rested in his hands, although he granted great powers to his sons and indunas. Like Lobengula, the former chief of the Matebele nation, he soon squashed any chief who was getting too strong, and these old savage potentates doubtless thought the proverb "A stitch in time saves nine," a good one. It was the survival of the fittest, and the word "fittest" not only meant a strong following of warriors, but also quickness of perception. Mpseni's big hut has been described to me by some of his sons. It was a large round affair, full of lion and leopard skins; on the floor was laid a great pile of elephant ivory, which was covered with skins and mats, on which Mpseni spent most of his time, swilling large quantities of native beer and hearing reports brought to him by his principal indunas. 
When the natives wished to have a "Mlandu" (or case) they first approached the induna, who then carried the story on to the head induna, who likewise informed Mpseni. Naturally a good deal depended on the integrity of the indunas, and I have no doubt that many cases were distorted considerably before they reached the "fountain of justice."

A son of Mpseni told me he had often a vile temper, so at such times his wives, children, and indunas gave him as wide a berth as possible until he cooled down a bit. At certain times the practice of witch smelling took place, and many innocent persons were murdered. The young unmarried people live free lives, and Mpseni did not let his warriors marry until they were well on in life, so great licentiousness was common; but when once married, if a man or woman committed adultery, they were knocked on the head or strangled to death.

A strange belief is still prevalent among most of the tribes in this country. Should a woman in a weak moment have mistaken another man for her husband, she will betray nervousness in putting salt in his food, and on seeing her fear, he at once accuses her of wrong. Nowadays, people are not killed for crimes such as this, although the injured husband will doubtless thrash the woman unmercifully. Child murder, under exceptional circumstances, still takes place, notwithstanding their love for children, and an Angani told me that a year or two ago a woman gave birth to three crows and a large stone, the crows appearing first. I expect this was the woman's statement for disposing of a malformed child. The same person told me that another woman had a child with a human body, but its head and hair was just like a warthog's.

I have not much more to write about the Angoni, except that they are a fine race of savages, and it will be a lasting pity if the tide of civilisation brings harm to them. The white man's civilisation and religion is not suited for savage peoples, and they should be left alone to work out their own ends. 
It would be a wise provision to prevent them leaving the country for the South African mines, where they can only learn evil, and the only exception to this should be when they are serving as disciplined soldiers under good officers.

More attention should also be paid by the Government to the methods of the missions, which in many cases do them harm instead of good.

They cannot look at matters from our standpoint, and a native told me that in a native church in Fort Jameson the missionary handed round a small basket for the collection, and that he (the native) thought it strange that the white man should take the money of the natives for himself. I, of course, explained that it was for the upkeep of the church and the payment of the native teachers; but the native would not see this, and went away unconvinced.

As a whole, the natives live far happier lives than do the poorer classes at home. They have only to scratch the soil to reap abundance, and at present their wants are few and easily supplied; so why try to bring them up to our level, which for them can only result in unhappiness and discontent?

Since writing the foregoing, I met with a very interesting case of perception on the part of a native, which shows thought and reasoning much above the ordinary. A native said to me in the native language: "God must be very clever, for if I plant three grains of maize, the stalks bear many cobs, which have very many grains; and if I plant one ground nut, many grow from this. God sends the rain, too, to make things grow, and what would be the end of people without rain, for we would all starve to death?"

This shows a power of thought and an admiration for natural laws very much above the average intelligence of the natives, who generally take things as they are, and do no inquire into causes. 


\section{CHAPTER XI.}

\section{VARIOUS SUbJEcts FOR THE SPORTSMaN AND NATURALIST.}

I.-Protective colouration of animals.

II.-Preservation of trophies.

III.-Buying secondhand guns and rifles.

IV.-Native implements, foods, price of labour, etc.

V.-Health in the tropics, and climatic influences.

VI.-Different routes to Central Africa.

VII.-Information for the settler regarding the leasing and purchase of land.

VIII.-The literature of big game shooting.

IX.-A few remarks on rifles and equipment.

\section{Protective Colouration in Animals.}

A GOOD deal has been written of late on this subject in the columns of the Field newspaper, and it would seem that the hunters of big game, such as Mr. F. C. Selous and C. H. S., who lately wrote a very interesting article on the subject in the paper mentioned, disagree almost wholly with the ideas of the closet naturalists and entomologists who have also been writing on the same subject.

The theory when applied to insects may hold good to a certain extent, as birds which feed on insects doubtless seek their food by sight.

It is the opposite with animals, as they hunt by night and by scent; and it makes no difference to them whether their prey has a black, red, or white coat, or whether it is marked with all the colours of the rainbow, if such an animal were possible.

Animals were doubtless antecedent to man on the face of the globe, so why should man suppose that his existence 
is of any account. Instead of hunting by scent he hunts by sight-long ago with spears and bows and arrows, and now with deadly small bores-but it makes no difference to him what the colour of the game is, because it never keeps still for long, as Nature has decreed that all animals must constantly move their bodies, tails, and ears. Certainly an elephant standing motionless in high dark bush, or a zebra in open bush with rays of light pouring through, are both difficult to see at times, but how often does this happen in a hunter's experiences?

It is impossible to know why a sable antelope should be coloured black and white, and a kudu a slaty blue; and I suppose all species have some colouring matter in their skins which cause these noticeable differences. Animals that live mostly in the open, in a country where the rays of the sun are very powerful, get scorched and bleached.

This is very noticeable in the zebras of British East Africa which inhabit vast open plains. The zebras of Central Africa, Nyasaland, and Northern Rhodesia, which live in a heavily bushed country, have brighter shades of black and whitish-yellow in their striped hides. A photograph of any example of protective colouration is no proof at all, as the eye of man does not view objects as the lens of a camera does. Possibly in past ages animals lived in surroundings more like their colouration, but destructive man has changed the face of nature, or driven game out of its natural surroundings, and it has failed to keep pace with the change.

However, this is almost as fantastical an idea as protective colouration itself, and it will hardly hold good, I am afraid. It is generally assumed that Nature can make no mistakes, so if animals are not coloured to imitate their surroundings, I suppose that Nature did not think it necessary to do so.

Therefore it is a subject not worth worrying about, as the whole matter rests on no basis, except that animals in their own bodies possess natural proclivities of transmitting their own colours to their descendants. 
The idea that colour helps any animal to escape an enemy that is seeking to kill it is absurd, as all carnivorous beasts hunt by scent, hearing, and speed, so the hunted animal has to depend on its own scent, hearing, and speed if it is to escape.

A lion probably hardly raises his head many inches from the ground when he is on the tracks of a zebra or an antelope; and as he doubtless sees better in the dark than can human beings, he probably makes his last rush by eyesight. In the dark it would be impossible to see more than an animal's faint outline, so it matters not what its colour is. After insects, reptiles are more protectively coloured than any creatures, and it certainly requires very quick and acute eyesight to see a slumbering puff adder, but this is more a matter of habit than keen sight. The puff adder's skin is a wonderful imitation of dead leaves and vegetation; but the leaves and vegetation are not coloured the same in all the seasons of the year.

If animals are supposed to be protectively coloured, why do not they all change with the seasons? I know that certain animals and birds in the colder regions of the world do change their covering in winter, but this can be of little avail, as their enemies hunt by scent; although in the case of birds of prey their hunting is done by sight, It would seem that climate has more to do with the colouration than anything else, except that animals living in the same climate exhibit many contrasts of colour.

Naturalists may be convinced that certain reptiles and insects are protectively coloured; but they will never convince big game hunters that colouration is of any use to any animal, as it is fully proved that such is not the case.

There is too strong a tendency to try reasoning the subject from the human standpoint, whereas man, not being implicated in the scheme of Nature, as it applies to wild creatures, is out in the cold, so to speak. The intelligence of man is capable of many wonderful things; but I do not think he will ever know much more about Nature's colour scheme than he does at present. 


\section{II.-The Preservation of Trophies.}

Before a trophy is taken, careful measurements should be made, so that the taxidermist will be able to mount it exactly as it was on the dead animal.

Sportsmen usually either take the bare horns and skull

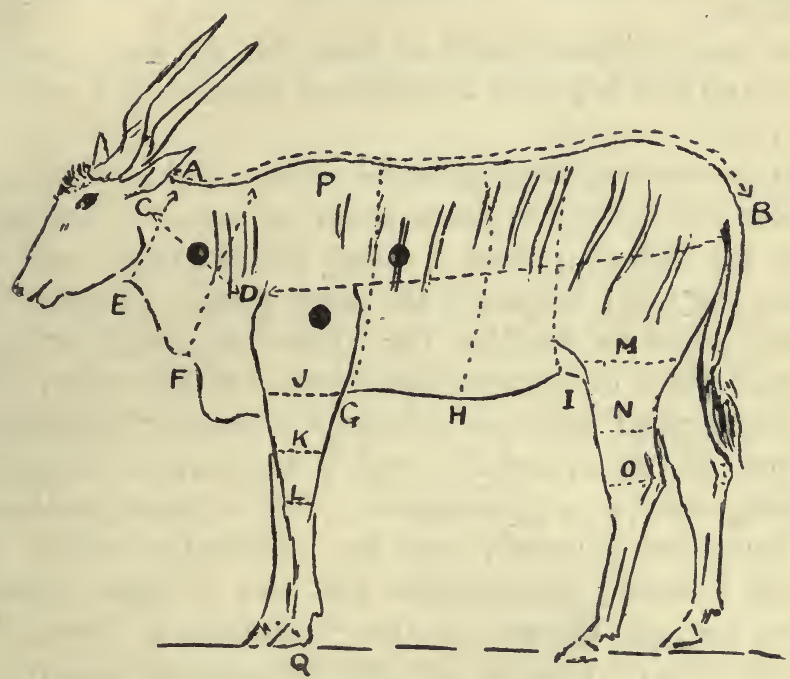

FIG̊. I.

Eland Bull, Showing the Way to Take Measurements for Specimens Intended for Mounțing in Museums.

A to B-From back of skull to root of tail.

$\mathrm{C}$ to $\mathrm{D}-$ From base of ear to shoulder.

$\mathrm{D}$ to $\mathrm{B}-\mathrm{From}$ shoulder to root of tail.

E, F, G, H, I, I, K, L, M, N, and O-Circumferences.

$\mathrm{P}$ to $\mathrm{Q}-$ Standing height. Taken by putting peg in the ground at top of shoulder and bottom of a forefoot.

The four leg bones ought to be kept for the use of the taxidermist.

- Denotes heart, lungs, and neck for vital shots. The brain shot should not he used, as it destroys the skull.

or they also take the headskin. In the latter case, the lower jaw of the animal should be kept, as the taxidermist will have great difficulty in making a jaw to suit. - To take measurements, a steel tape is best; and the only measurements necessary for a headskin trophy are those of the 
base of the neck and the neck just behind the ears. The cut should be made right over the shoulders, for, if the skin is short, the trophy will be an ugly one when mounted. Cut up the edge of the mane hair to behind the horns, and then make two cross cuts to the base of the horns, and go round them as close as possible without injuring the horn substance.

The most difficult parts to skin are the ears, eyes, and nose; and this is purely a matter of practice if a good job is to result.

Natives cannot skin properly without being taught, and it takes some time to make them proficient. Nothing is better for skinning than a sharp pocket-knife with two blades, one fairly large and the other small. A small hone is most useful for keeping the knife sharp, and, for larger knives, a piece of emery-stone is better than a hone. I do not recommend expensive cutler's "hunting" knives, for they are too thick, and the steel is too hard to sharpen on anything except a grindstone. The various implements sold for skinning usually turn out practically useless. For animals a strong pocket-knife and two or three soft-steel bladed knives, known as the "Bushman's Friend" or "Green River" pattern, are all that are necessary. For birds, a small pocket knife, a pair of scissors, and a brainscoop will do the best of work.

Many good taxidermists sell preservatives of their own mixing, but, for the sportsman, the principal chemicals required will be alum, saltpetre, salt, and turpentine. For birds, arsenical soap is probably best, as it does not harden the thin skins and make them crack as alum will do; but it should be kept under lock and key, as it is dangerous stuff to leave lying about for native boys to tamper with.

The best way to clean skulls is by boiling them in a big pot, although some antelope horns will not come off the cores readily-such as hartebeest and eland-so care has to be taken, when boiling, to keep the horn substance above the water-line. 



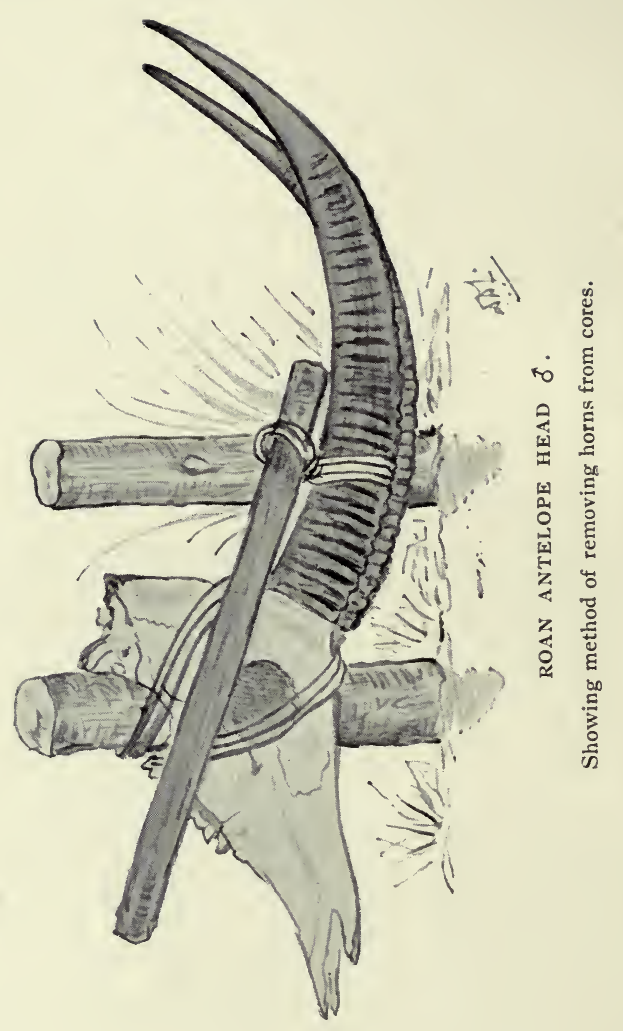


Kudu and sable horns can be forced off the cores, after a week or two, by putting two short poles deeply in the ground, and tying the skull to one pole and a loop on the horns, so as to pass a strong stick through. This is then levered against the second pole, when the horn will usually leave the core and come away.

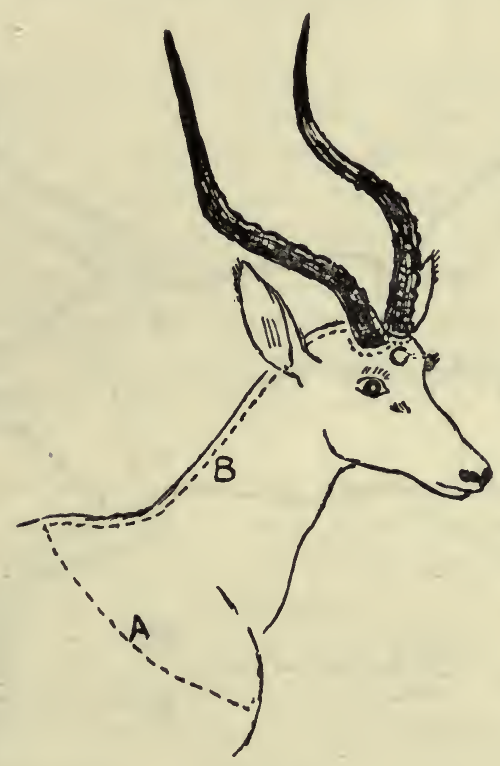

FIG. 2.

Impala Head and Neck, Showing the Way to TAKE Headskin.

A-Cut round neck close to shoulder.

B-Cut up neck to within an inch of horns.

$\mathrm{C}-$ Cut round horns close as possible without injuring the horns.

Note that when the entire skin is taken that the cut to get out head and jaw only begins at B. See Fig. 3 for cuts to take off whole skin.

When skins are taken entire, for setting up, careful measurements are made, and I give a diagram of this which appeared in my "Nyasaland for the Hunter and Settler." Other diagrams are also shown from the same 
volume as to how to make the necessary cuts for the removal of skins. The main point in preserving skins is to get them thoroughly dry, and to do this a strong sun is required. Then every few days they should be inspected and lightly beaten with a stick or whip, to dislodge the

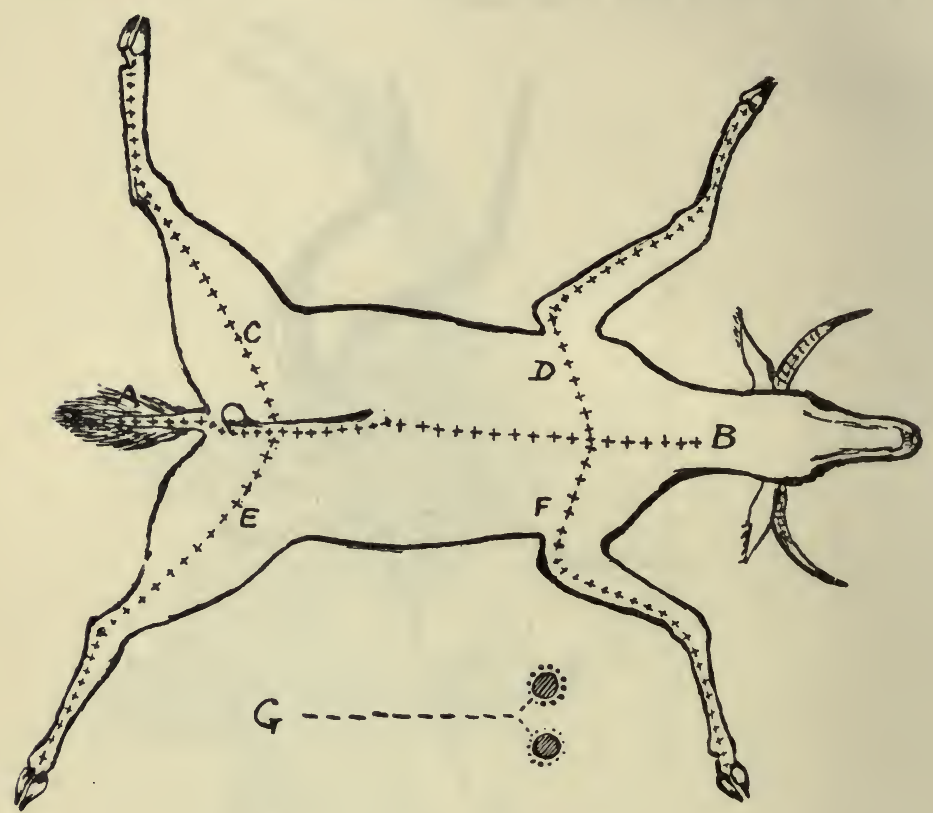

FIG. 3.

Reedbuck, Showing the Way to Take Whole Skin.

$\mathrm{B}$ to $\mathrm{A}-\mathrm{Cut}$ from base of neck to end of tail.

C, D, E, and F-Cuts along inside of fore and back legs.

G-Cuts up back of neck and around horns so as to get head and jaw out. (See Fig. 2.)

ubiquitous bacon beetle which is the bane of all trophy collectors. Particular care should be taken that the fine hair and skin of the ears and nose should not be handled roughly. Moreover, never put uncleaned heads near skins or the beetles will at once get at them, and in a short time ruin them. 
The best way to send skins home would certainly be in big boxes with a tin or zinc lining, which could be soldered down after drenching the contents with turpentine, and putting some naphthalene marbles inside.

As the transport on these would be very expensive, the next best thing is to send in canvas tightly sewn, with instructions that care and despatch should be used in their transportation.

In packing horns, some coarse canvas packed with paper should be wrapped round the points to prevent chipping or breakage, and the same applies to the points and bases of elephant ivory. There is a rather heavy duty on the export of ivory from the different territories in Central Africa, and in North-Eastern Rhodesia. The duty on elephant ivory is $2 s .6 d$. per pound, and on hippo ivory and rhino horns $2 d$. per pound. There is no duty on the export of horns and skins, but a small stamp charge is levied for the permit.

Natives, as I have mentioned, can be taught to skin well, although it will take them some time to master the more difficult parts, such as the skin of the ears, eyes, and nose, so these should be done personally.

In taking a skin, the natives invariably cut it on the outside of the legs, instead of the inside. Skins taken off like this would be useless for natural history purposes.

Finally, the main desideratum is to keep all skins dry, and to inspect them often, to see that destructive insects are not present.

\section{III.-Buying Second-hand Rifles and Guns.}

Often a good weapon can be picked up second-hand and several first class London gunmakers sell very reliable firearms of this description, but several points have to be considered when buying such a weapon.

In both rifles and guns, the barrels are obviously the main feature, as naturally the wear and tear in a weapon affects the barrels more than any part. 
I am a believer in best quality hammer weapons as their construction is simpler than hammerless actions, and the pull-off of the locks is much sweeter and sharper than in any hammerless type of action I have seen or tried.

Further on I shall give my ideas as to the best type of shotgun for abroad, and it is wise to choose a hammer weapon, for if anything goes wrong it is much more easily remedied with the simple tools that one has. It would be useful to carry spare strikers and a spare top lever spring in case of breakage.

Not having done much shotgun shooting for some years I do not know what is the best powder for shotguns at the present day, but a very experienced gunmaker tells me that nothing can beat "Smokeless Diamond" for good killing and for its non-corrosive qualities to the barrels.

In Central Africa common black powder I2-bore cartridges cost over $£ \mathrm{I}$ per $\mathrm{IOO}$, so if the sportsman intends using a shotgun much, he had better bring out plenty of ammunition.

As I shall mention further on in a chapter on rifles and equipment, I consider that nothing is better than the Mauser action for a sporting rifle; but this is purely a matter of personal choice. If a hammerless weapon is chosen, get the weapon fitted with a non-automatic safety bolt. Probably beginners would be safer with a good quality hammerless gun or rifle, but my objection to them is that when loaded the mainsprings of the locks always stand at full-cock, and with a hammer weapon the weapon is only cocked when ready to be used.

When inspecting a weapon, especially a rifle, carefully examine the rifling for wear and the breech for corrosion and pit marks, and see that the striker, or strikers, if double, is in good order and strikes the cap a good blow.

In a double gun or rifle see that the breech locks close, and hold it up sideways to the light to see if light can be seen between the barrels and breech block.

Do not buy a shotgun that has had the barrels shortened, or one in which the barrels have been rebored. If fitted 
with a top lever see that the gun closes with a sharp metallic ring, without any hard grating or dull sound.

On no account buy a new cheap hammerless gun. A man would be far better with a good second-hand hammer-gun, which probably cost $£ 40$ to $£ 50$ new, and which can now be bought in London for a sum of from $£$ I 2 to $£$ I 6 .

If one goes to a maker with a good name he can usually be trusted to sell a sound weapon. The Field newspaper always has advertisements from several good gunmakers who sell second-hand guns and rifles, but it would be invidious to mention names. Buyers should remember that no really first-class London shotgun can be turned out at less than $£ 40$ new.

\section{IV.-Native Implements, Foods, Price of LABOUR, ETC.}

It is impossible to help noticing how expert the natives are with their inferior implements, and, although their work is, naturally, coarse and roughly finished, it serves their purpose. Their soft iron axes are wonderful cutting tools, and most of the natives are expert axemen. Some of the African woods are so hard they would often splinter European or American axes, which are usually made with too high a temper, except for soft woods.

The natives' adzes, too, are very useful articles, and a great amount of work is executed with them. Their small axe-heads are often used as an adze by being put in another handle with a differently angled slot.

Their knives, except those they buy at European stores, are simply soft iron; and often they use the soft hoopiron binding that is sent to this country round crates, boxes, or bundles. It is roughly shaped, and one end is bound with some bark string. With such a tool, used something like a saw with both hands, they get through a hippo hide like a grocer cutting cheese. 
If the knife bends, which it often does, it is quickly straightened with a stone or lump of wood, or with the fingers.

I once saw a native arrive at the cutting up of an elephant with an old bayonet, but he did not do as good work as others with their scraps of hoop-iron.

Natives are very handy at making baskets, and their small, flat ones, called "luchairo," are used for cleaning the chaff from the flour after it has been pounded in their wooden mortars, the pestles of which are simply 5 - ft. poles of some hard wood, roughly smoothed up to begin with, which take a fine polish with the constant rubbing of the hands.

The young girls are fond of pounding the grain and if a woman has a daughter old enough, it is usually her duty to do most of the flour-making for the family.

Maize, of course, is the staple grain, but there are others grown, such as mapiri, rapoko, and koche. Sugar-cane ("imphfe," native name) is also grown.

Then there are native potatoes; yams, in certain districts; and a very nice vegetable, named itchasani, which tastes something like a young English potato, with a flavour not unlike an artichoke.

In some places bananas or plantains will be seen, and I have even seen the natives growing pineapples and the paw-paw, or papaya, fruit; but I expect these men had worked for Europeans, and got a liking for such fruits.

Considering that many settlers and most of the missions grow fruits, it is strange that the natives do not care to plant them, as they could easily get the seeds by asking for them; but the fact is that they are too lazy.

That fine fruit, the mango, is now found throughout Central Africa in certain localities, and there is a particularly fine lot of huge mango trees about thirty-five miles north of Tete, on the old Fort Jameson road from that place.

These trees were planted by the old Jesuit missionaries over three hundred years ago, and, if they could arise and 
tell what they had seen in the old slave-trading days, "they could many a tale unfold." Many is the poor miserable wretch, tired to death with marching with the "kori stick" bound to his neck, who must have died within sight of this fine plantation. A cool stream meanders through the valley, and it is a welcome spot to reach after passing through the stony and scorched country which lies between here and Tete.

From August to December this is one of the hottest places I have seen in Africa; the heat is often so great that the natives in the stonier parts find it difficult to walk, as the rocks and stones will burn one's hand if they are touched, and hard though the natives' feet are they get blistered and burnt. If there happens to be a good moon, the best thing is to march by night, although night marching is most tiring, as it is impossible in the more shaded parts of the path to see holes, stumps, and rocks, and many a grunt will be heard from the carriers, who give their bare feet nasty jars and cuts. But, as I have said, the natives are most patient and long-suffering when engaged on rough travel, and one cannot help admiring their fine qualities in that way.

Besides the grains and sweet potatoes which they grow, the natives have a certain amount of livestock, such as sheep, goats, pigs, pigeons, ducks, and fowls, and a few of the chiefs keep cattle.

A bird like a fowl is no meal for a native, as he could easily eat five or six at a sitting without feeling uncomfortable, but it affords a relish, what they term "ndeo," pronounced indeo, to their usual dish of ufa porridge. They gather various wild plants and eat wild mushrooms of different kinds, and sometimes they grow chillies for a seasoning. One of their favourite seasonings is the ground-nut, and they grow large quantities of them, and, of course, the pumpkin is commonly grown all over the country.

Cucumbers of a coarse variety, are also grown and eaten uncooked, as we eat them with our salmon and salads at 
home. Tomatoes are found everywhere of a small variety, and they grow in the native gardens.

A vegetable which has a hard, shell-like skin is grown, and these are made into gourds for carrying water and for drinking it. They call the large gourds "chipanda," and the small ones for drinking out of "tumo."

In some districts with large lakes and rivers in the vicinity they catch and eat a quantity of fish, and the ordinary barbel or mud-fish is the commonest.

It has a very muddy taste and is rather full of bones, and the European will think them but poor eating compared to the delicious fish he gets at home. There are many other kinds of fish, but as I have never lived on Lake Nyasa, which I believe is full of fish, I do not know the names of the commonly used kinds.

In the large rivers, such as the Zambesi and Luangwa, there are several sporting fish, including the tiger fish, which needs the strongest piano wire traces to hold him, as he has jaws like a pair of nippers, and will go through an ordinary gimp trace without the least effort. I have never had the necessary equipment there to go in for fishing, and, except for a year spent on the Luangwa River in 1905 , I have not lived near any very large river which could afford good fishing. Doubtless there are a number of fish in this country that would give good sport, and I believe spoons are the best lure, although minnows might be useful also. For bait, the entrails of fowls are good.

The hooks should be pretty large, and, for ordinary mudfish, twisted wire is better than gut. The latter deteriorates here very quickly when exposed to heat, and is not strong enough for African fish.

The following are the usual prices away from a township for the livestock and foodstuffs sold by the natives:

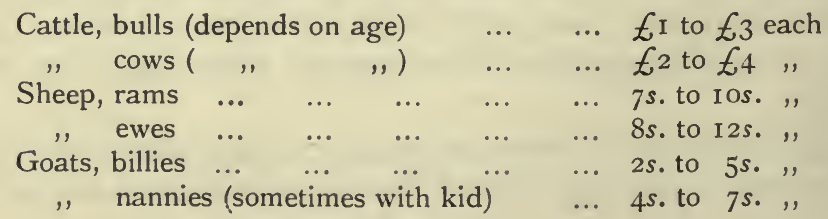


Ducks

Fowls (sometimes $4 d$. or 6, . each) $\ldots$

Pigeons ...

... Is. to $2 s$, each

Maize (depends on district and season)

... 3 d.

... $2 d$.

Sweet potatoes (dependson districtand season) $\frac{1}{2} d$. to $2 d$. per $\mathrm{lb}$.

Eggs (often bought for a dessert-spoonful of salt)

Pumpkins

Bananas or plantains ...

Ground nuts

Mushrooms (four varieties)

Three a penny.

Id to $2 d$. each.

... $6 d$. per bunch.

.. $\mathrm{I} d$. to $2 d$. per lb.

$\begin{array}{lll}\ldots & \ldots & \ldots\end{array}$

Many of the above commodities can be bartered for meat or salt, which are always in great demand.

\section{Prices of Implements, etc.}

Native axes or adzes

EACH.

Baskets (according to $\begin{array}{lllll}\ldots & \ldots & \ldots & \ldots & \text { Is }\end{array}$

$\begin{array}{llllll} & \text { short (6ft. or so), } \quad, \quad, \quad \ldots & \ldots & 6 d .\end{array}$

$\begin{array}{lllllll}\text { Goatskins ... } & \ldots & \ldots & \ldots & \ldots & \ldots & 3^{d} \text {. }\end{array}$

$\begin{array}{lllllll}\text { Wildcat skins } & \ldots & \ldots & \ldots & \ldots & \ldots & 6 d \text {. }\end{array}$

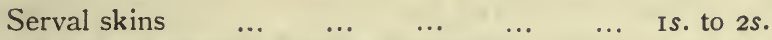

Otter skins (in some places cheaper) $\ldots \quad \ldots \quad \ldots 2 s$. to $4 s$.

$\begin{array}{lllllll}\text { Leupard skins } & \ldots & \ldots & \ldots & \ldots & \ldots & 5 \text { s. to Ios. }\end{array}$

$\begin{array}{llllllll}\text { Spears } & \ldots & \ldots & \ldots & \ldots & \ldots & \ldots & \text { Is. to } 3 s \text {. }\end{array}$

Native drums (the real thing) $\ldots \quad \ldots \quad \ldots \quad \ldots \quad$ Ios. to $£$ I

$\begin{array}{cccccc}\prime \prime \quad & \Rightarrow \quad \text { (made to sell) } & \ldots & \ldots & \ldots & 2 s .6 d \text {. to } 5 s . \\ \text { Dugouts (canoes)... } & \ldots & \ldots & \ldots & \ldots & £ \text { I to } £^{2}\end{array}$

Ordinary sleeping mats used by natives $\begin{array}{lllllll}\text { (mpassa) } & \ldots & \ldots & \ldots & \ldots & \ldots & 3^{d} \text {. }\end{array}$

Usual Prices of Labour (Native).

Hunters (gunbearers and spoorers)

Per Mensem.

Carriers (usual price $4 s$. and food extra)

... 4s. to Ios.

Cooks (according to experience) ...

... $4 s$. to $6 s$.

Table boys (according to experience) $\quad \ldots \quad \ldots \quad \ldots s$. to $8 s$.

Platewashers and pot cleaners (according to experience)

Head boys (capitao)

Common plantation labour

Children (the women do not often work on plantations) 
Per Mensem

Brickmakers (I000 to I 200 bricks per day) ... IOs, to I $2 s$.

Bricklayers (according to experience)

Carpenters (", ", )

Native clerks ( ", , )

Machilleros (men to carry a machilla) ...

Interpreters (cooks and head boys often speak

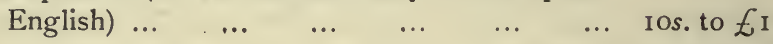

The price of labour in Nyasaland and North-Eastern Rhodesia, especially away from the Zambesi river, the railway, and townships, is much more moderate than it is in North-Western Rhodesia, where the prices of labour seem to have followed those usual in Southern Rhodesia. In the latter place a boy will often get $\ell_{1}$ to $£_{2}$ per mensem but he will cook and work hard. In Nyasaland and adjoining territories the personal servants necessary follow the custom of India, but not to such a degree, and one usually keeps too many boys whose time is not fully employed.

Unless European ladies are present it is not usual to engage female labour, although round Blantyre the cook's wife will often be able to wash and iron clothes, as she may have been taught the work at the mission.

Ladies often keep a female dhobie or washerman, and a nurse, when they get one; but more often the latter is a young boy who attends to the white children, and takes them out for their daily. coach ride and breath of fresh air.

This youngster also bathes and amuses the male children, and he will often take great interest in their welfare, and be most reliable and trustworthy.

The youngsters are more intelligent than the adults, as they more readily adapt themselves to their altered conditions of life-in fact, some of them get too smart at times and require censure.

All labour is so cheap here that people who at home have not been in a position to keep many servants will find that their lives are much easier in Central Africa than they could ever be in Britain. 


\section{V.-Health in the Tropics and Climatic}

\section{INFLUENCES.}

If a man cannot keep well in tropical Africa, he had better leave it for another climate, as he will have no happiness there if his health is bad, for the discomforts and hardships he will often need to undergo, if he lives a wild life, will be more than he can bear.

There, is no doubt Central Africa induces an irritability in white men, and often well educated and sensible men behave here in a way they would never think of doing at home. I have not noticed that liver complaint attacks white men here to the extent it does in India, but the climate has often a very deleterious effect on European brains, and this often turns an intelligent, humane-minded man into little better than a wild beast, causing him to treat natives brutally and unjustly.

The natives are often to blame, for they seem to have wonderful powers of aggravation and annoyance, not always from intent, but through pure stupidity and cussedness. Europeans who possess a highly sensitive nature, or who are naturally short or hot-tempered, suffer in this way more than those of an easy-going, patient nature, whose equanimity it is difficult to upset.

If a man suffers a great deal from malarial fever, or has suffered from it in another country before he came here, as I did, he should never bathe in the evening, particularly in cold water, as this is sure to induce a chill and bring out the fever. The best time to bathe is about midday, before having lunch. I suffered greatly from malarial fever before I had a bad attack of blackwater fever, but since then I have suffered little, and I think the blackwater fever carries most of the germs out of the system. I only give this opinion for what it is worth, as I am not a medical man, but such has been the case with myself, and I have also heard others mention it. When a man gets wet from being soaked by rain, or from perspiration after a hot walk 
in the sun, it is a foolish proceeding to sit in his wet clothes, particularly when the sun has gone down and the temperature is falling. I suppose nothing has caused more fever in the tropics than this, and it is a wise plan at all times to have a warm tweed jacket or a woollen sweater handy, to put on when the air gets chilly. In the tropics changes of the temperature take place very rapidly, and, as one is usually very lightly clothed in the heat of the day, there is all the more reason to be prepared for the cool of evening and night. Another frequent cause of a chill is lying on a bed half naked, and going to sleep like this. An hour or two before dawn the temperature falls several degrees, and the sleeper becomes chilled, and then pays for it with a sharp attack of fever.

The best thing is to be covered by wearing pyjamas, and have the blankets folded and ready to draw up, and this is done unconsciously, as it becomes a habit.

Fever is the most common complaint, and I do not intend to mention others, as I have little medical knowledge; but it will be a good thing for the newcomer if he notes what I have said. It is, of course, almost impossible to escape getting fever, especially in a country where mosquitoes are plentiful; but although a man has got the parasites in his blood, he can guard against bad fever. It is a good thing to make a practice of taking five grains of quinine two or three times a week, particularly in the rainy season, when the mosquitoes are most abundant.

Some people say that quinine does them harm, though the majority of Europeans will find that they do not have fever so often if they take it frequently. Warburg's Tincture suits some people better than quinine, though personally I think the latter is much the best drug for this complaint.

Europeans should live fairly well in the tropics and not stint themselves of a few luxuries at times, as nothing causes sickness more than unpalatable food. 



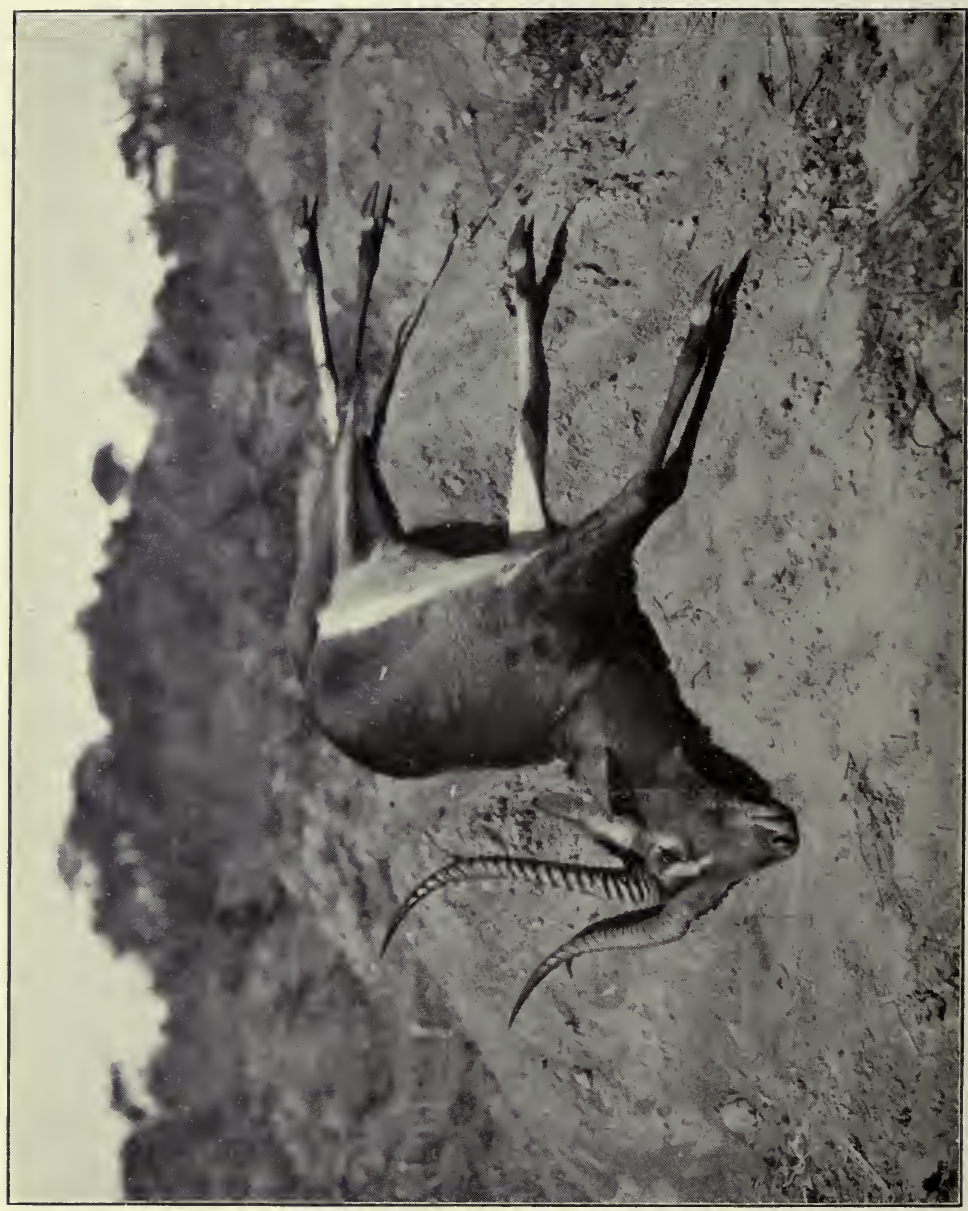

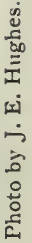

选 


\section{VI.-Different Routes to Central Africa.}

Should a sportsman be coming to Nyasaland then he ought to book a passage to Chinde on the east coast, and as the large steamers cannot cross the Chinde bar on which there is not much water, all passengers and baggage have to be transferred to a tug which comes alongside the ocean steamer. There are two tugs kept at Chinde for this purpose, and they are named the Kadett and Adjutant, and they both belong to the German East African Line. The Union-Castle Line run big steamers which touch at the Chinde buoy, and take passengers. Most Britishers will prefer to travel by a British line, although the steamers of the German line are usually quite comfortable.

When the passengers and their baggage have been put abcard the tug, she casts off and makes for Chinde, which is about ten miles from the buoy. The tug often bumps as she crosses the bar, but very seldom runs aground.

British Chinde consists of a fenced in concession, and all cargo for British possessions is landed free here, and pays duty for Nyasaland at Port Herald, the customs station. Many passengers and goods for North-Eastern Rhodesia come viâ Chinde, and I think it is the most interesting route into North-Eastern Rhodesia. As a river steamer is usually ready to proceed up the river for Port Herald, there is little delay, and passengers are often able to leave for up-country the day they arrive. Various companies have river steamers, such as the British Central Africa Company and the African Lakes Corporation Ltd.; and the river voyage is interesting to the lover of nature, although little large game will be seen.

Perhaps a few hippo may be noticed occasionally, although they are pretty wary. They dive before the steamer gets close, and appear again when it has passed. I think it is a great shame for passengers to fire at these animals, as they are seldom killed, though sometimes 
wounded. Besides, as a hippo sinks when shot dead, and takes a considerable time to rise, there is no chance of recovering the body, so it is senseless cruelty firing at them.

A few days from Chinde, the river steamer gets into the Shire River, where the scenery is more broken and prettier, and a fine view of the Morambala range is obtained. On reaching Port Herald, the traveller passes his belongings through the customs, and next day, as the steamers usually run in connection with the trains, he leaves for Blantyre, a distance by rail of I 3 miles. Then, if he intends going for a shooting trip, there are several firms that will help him to get boys and carriers, and he can buy all kinds of foodstuffs there, though I advise him to bring his rifles, ammunition, tents, and camp outfit from home, as they will be cheaper. A comfortable deck chair and a mosquito net should never be forgotten.

If the sportsman is bound for North-Eastern Rhodesia, he can get there via Chinde and Blantyre; and, if he does not intend to shoot in Nyasaland on the way, his dutiable articles could be sealed and passed through "in transit"; but the shooting in the central and northern parts of Nyasaland is as good as it is North-Eastern Rhodesia, and all game found in the latter place exists in Nyasaland, except a few species, such as situtunga, lechwe, and sassaby ; and these need a long journey in North-Eastern Rhodesia to reach their haunts.

Another way into North-Eastern Rhodesia is via Tete, on the Zambesi; but although this is an interesting journey, it is slower and more expensive.

For North-Western Rhodesia the sportsman's best route is via Cape Town, and on by rail to Livingstone or Broken Hill, at either of which places he could find boys and carriers. Shooting in North-Western Rhodesia is much more expensive than it is in the other two territories mentioned, and, as I have not spent much time there, I will say little about it. I have entered or left Nyasaland and North-Eastern Rhodesia by all the routes I have mentioned, some on several occasions, and I once went 
all the way from Tete to Chinde in a large houseboat, and though it was not as comfortable travelling as by river steamer, it was more interesting, as I could stop for shooting when I felt inclined. In the dry season, especially towards the end of it, and during September, October, and November, the rivers get very low, and the steamers find it impossible to get far up them, and so the traveller is obliged to travel by houseboat. These have a small cabin or house, fitted aft, and some of these shelters are large enough to hold a box or two, and a deck chair, but a considerable amount of manœuvring has to be exercised if one's head is to. escape many a hard bump. I always think the river travelling delightful, either by river-steamer or houseboat; many small villages will be passed, and a good deal of bird life will be seen. There is plenty of game within a short distance of the river, but it must be remembered that most of the journey is through Portuguese territory, so it is best to ask permission to shoot there from some commandant.

On the Zambesi river there are several official stations, and although the officials seldom care anything about the game, it is a matter of courtesy not to break the game laws.

Twice I was asked by a Portuguese official to shoot as many hippo as I could, as they had been upsetting native canoes, and on one occasion had attacked and sunk a houseboat. The Portuguese soldiers often amuse themselves by shooting at them with old Sniders, and, the bullets of these rifles being made of very soft lead, and having a low velocity, they wound many more than they kill; and the poor hippos try to get some of their own back on the first craft they see, which is usually an old man and a boy in a leaky dugout. The dugout goes to the bottom in deep water, and the old native and his son are left lamenting. The canoe may not be worth more than a few shillings, but its loss is a great disaster to a poor native, who probably does not possess much more than the yard of calico round his loins and a few pots at home. 
Considering the fine quality of the sport obtainable in Nyasaland and North-Eastern Rhodesia, and the great expense of shooting in British East Africa, it will not be many years until sportsmen pay more attention to these fine countries, which in some places are hardly known to Europeans,

\section{ViI.-Information for the Settler Regarding the LEASING AND PURCHASE OF LAND.}

No Crown land is now sold in Nyasaland, and it can only be had on lease of seven, fourteen, and twenty-one years. When I last lived in North-Eastern Rhodesia, land could be purchased from $6 d$. per acre; but I do not know the price at present, although I have not heard that any change has taken place. There are many points to be considered when leasing or buying land for planting or farming projects, and, as regards Nyasaland, the following sentences, which appeared in my "Nyasaland for the Hunter and Settler," are well worth consideration by the intending settler. They are these:

I. Cost of transport to nearest railway or steamer landing.

2. Quality of soil for the purpose it is required for.

3. Cost of land, or lease of same.

4. Water supply (running water essential).

5. Elevation above sea level.

6. Prospects of labour supply.

7. Whether there is plenty of food for the labourers.

8. Grazing facilities for stock.

9. Rainfall in district.

I0. Extent of cleared land (native gardens).

II. Quantity of bamboos (for building purposes).

12. Amount of good timber (for sawing and big posts).

13. Firewood (for personal and natives' use and for tobaccocuring, etc.).

14. Freedom from insect pests (especially tsetse fly).

I5. For cotton (distance from a public ginnery).

I6. Distance from a township. 
ViII.-The Literature of Big-Game Shooting.

Perhaps the greatest incentive to young men is the reading of accounts of travel and adventure in far-off lands, and there is no doubt that if we Britons did not possess a very large and interesting collection of such literature, not nearly so many young fellows would leave comfortable homes and go to wild countries, where they often have to suffer hardship and discomfort.

Mr. F. C. Selous has mentioned how the reading of Gordon Cumming's and Baldwin's books fired his imagination long ago, and the reading of the same books and those written by Mr. Selous himself, did the same to me.

How well I remember the long winter evenings on the East Coast of Scotland, when it used to get dark about four o'clock in the afternoon, and how I used to sit near a roaring fir-log fire, with a red-shaded lamp near me, and pore over such books.

One of the earliest books I remember was a volume entitled "Ungava," all about the fur traders on Hudson Bay, in Canada. This story appealed to me so much that, with the help of my brothers and sisters, I built a little log cabin in a plantation of fir trees not far from the house. An old iron pipe served for a chimney, and my bed was made of fir needles covered with two blankets. Then I used to sally out, first with an air gun, and then with a rook rifle, shoot blackbirds and thrushes, and roast them on a spit. In the way of big game, many is the fine tom cat that fell to my $\cdot 220$, and I have often wondered if the owners had any suspicion as to where their pets got to. Later on, I shot much wildfowl on the estuary of the River Tay, and sometimes I would cross over to the Fife coast and shoot there.

I managed to shoot some very rare birds on the coast, and among them I can mention the following: Little stint (rare so far north), red-breasted snipe (an American species, then having been shot only once or twice before in Britain), 
Ross's gull (very rare), shoveller duck (not often got in Forfarshire), etc.

Then I went to Ceylon, and soon after to India, where I spent some years tea-planting; but the jungles are too thick in Eastern India to expect much shooting unless one can command the use of elephants. I went to Central Africa in 1903 and have been there ever since; but I will go on to mention some of the most fascinating books on sport I have read.

A very fine book is Mr. J. G. Millais' "A Breath from the Veldt," and this accomplished author has the great gift of being able to illustrate his works with beautiful drawings.

I advise all sportsmen to read the "Life of William Cotton Oswell," written by his son. Oswell was the beau ideal of a fine hunter, and he was modest and reserved about his doings. He only wrote a few chapters to the Badminton Big Game series.

Gordon Cumming was a daredevil, and his book was considered by many people to be fictitious when it appeared; but the experiences of later sportsmen show that he wrote the truth. About the middle of the nineteenth century many authors were inclined to exaggerate and embellish their writings, as there were then few people experienced enough to gainsay what they wrote, and the sportsmen of that time were more out for killing than nature study.

A very interesting writer was the late William Charles Baldwin, and most of his shooting was done in SouthEastern Africa, in the country now known as Portuguese East Africa, and Natal.

Perhaps one of the soundest writers we have had was the late Sir Samuel Baker, and his books are standard works. There is no doubt that he was not only a mighty hunter, but he was a good observer and field naturalist.

Everyone knows Mr. F. C. Selous' writings, and I think there is no author who can put his facts so clearly. I consider his books "A Hunter's Wandering in Africa" 
and "Travel and Adventure in South-Eastern Africa" two of the finest volumes on African sport and travel that have ever been written.

I have often wished I could write like Mr. Selous, or be able to draw like Mr. Millais; but we cannot all be gifted in this way so we have to do the best we can.

Some splendid works have been written on Indian sport, and I remember how interesting I found E. Baker's "Sport in Eastern Bengal." This is a little known work, but one much above the average.

A splendidly illustrated volume is Williamson's "Indian Field Sports," and Simson's book about pig-sticking and tiger shooting is also very interesting.

General A. A. Kinloch's book about sport in the Himalayas is well written and illustrated, and another volume on the same region I remember enjoying greatly is Major C. S. Cumberland's.

With regard to the shooting and habits of the Indian elephant, the best work in existence is the late Mr. J. G. Sanderson's "Thirteen Years Among the Wild Beasts of India," as he had great experience of elephants and other game during the time he was in charge of the Government Keddahs in Southern and Eastern India.

There are several other most interesting books about Indian shooting and natural history, such as the works of Forsyth, Markham, Rice, Macintyre, Sir Victor Brook (written by a friend), General Douglas Hamilton, Newall, Jordon, Inglis ("Tent Life in Tigerland"), Hornaday, Durand, Gerard, and many others.

Some other authors on African sport I have not mentioned are Drummond, Cotton, Kirby, Teleki, Wallace, Sykes, Stigand (a fine sportsman and an able field naturalist), Foa, Dugmore, Willougby, Bryden, Dickinson, Leatham, Drake-Brockman, Peel, Stevenson, Faulkner, Neumann (one of the finest hunters who ever shot in Africa), Patterson, Buxton (a most interesting writer), Sir Cornwallis Harris, Gibbons, Methuen, Alexander, Chapman, Andersson, and very many more I have forgotten. 
A great number of books have been written on American shooting, and one of the very best is Van Dyke's "StillHunter," and I remember how I enjoyed reading BaillieGrohman's book on British Columbia.

Mr. F. C. Selous' "Hunting Trips in British North America" is very interesting, and so is Mr. J. G. Millais' "Newfoundland and its Untrodden Ways." Mr. H. Hesketh Prichard's volume, "Hunting Camps in Wood and Wilderness," is also a work much above the average.

The literature about European sport (especially the northern parts of that continent) is a very varied collection, and there are few authors who can compare with Mr. Abel Chapman, whose books "Wild Norway" and "Wild Spain" are full of good matter. Then an old work is Lloyd's "Field Sports of the North of Europe." A more recent account of sport is Sir Henry Pottinger's "Flood, Fell, and Forest," in two volumes, and other authors whose writings are well worth reading are Sir Henry Seton Karr, who also wrote on American sport, Mr. E. B. Kennedy ("Thirty Seasons in Scandinavia"), and numerous others.

Since giving this list of writers on British sport, I remember other interesting authors, such as Sir R. Payne Gallwey, Speedy, Moray Brown, Scott, Shand, "Nimrod's" "Life of John Mytton," Jeffries, Jones, Hartley, GathorneHardy, "The Badminton Small and Large Game Shooting," and the "Encyclopædia of Sport."

Most of us have read the best known books on shooting and natural history in Britain, and they can be numbered by the dozen, but the best include the works of St. John ("Wild Sports in the Highlands," etc.), Sir John Colquhoun ("Moor and Loch," etc.), Lieut.-Col. Peter Hawker (on wildfowling), Mr. J. G. Millais ("The Natural History of British Game Birds," "British Deer and their Horns, etc.), Morris, Dixon, Corballis, Daniel (an old author I8oI-I3), Mr. Abel Chapman ("Bird Life of the Borders"), Scrope (on deerstalking), Grimble (on shooting and fishing), Lamond (on fishing), Calderwood (on salmon), Malloch, Hodson, Stewart, Tod, Leitch (these five write on wet-fly 
fishing). Then about dry-fly angling we have Halford's books, as well as some others I have forgotten.

Young sportsmen have much to be thankful for at the present day, for not only have they an abundant literature on sports of all kinds, but the way has been made comparatively easy for them by the spread of civilisation, and communications are so rapid that they can soon reach any ordinary shooting and fishing ground they wish to visit.

How different was it in Mr. Selous' early days, when he hunted in the country which is now known as Southern Rhodesia. Then travel meant a slow progress with ox waggons or on horses, and when he was shooting round Bulawayo and Salisbury he was more cut off from civilisation and the comforts civilisation brings than are most men in the depths of Central Africa to-day.

As I have mentioned in this volume, it is still possible to get quite in the wilds and view Africa as it was; and it is a great mistake to suppose that Africa as a whole is getting shot out, for such a statement is incorrect. Certain parts, such as Southern Africa and other places close to European settlements, have certainly lost most of their game, and will never regain it unless the country were to be totally abandoned; but even in such a small territory as Nyasaland there are many hundreds of square miles that have hardly been trodden by the feet of civilised man, and here the game is likely to survive for many generations to come.

When reading some of the old books I have mentioned, over twenty-five years ago, I thought that I was too late to experience any really wild free sport; but, as I mention in the preface, this country is still in much the same condition as I first knew it ten years ago, and the only parts that have slightly changed are those round the small townships, where the land has been taken up by settlers for the planting of tobacco, cotton, and tea.

Therefore, the young sportsmen who are still acquiring knowledge at public and private schools need have no fear that all the game in Africa will have disappeared before 
they are old enough to go on their first trek to the wilderness. They are not likely to be able to drop sixteen elephants in one day, as the late Mr. Arthur H. Neumann once did in British East Africa, as, very wisely, the Governments of all our African possessions have now limited the number of the game allowed to be shot annually; but they will be able to shoot all they want for trophies, and what more could any sportsman desire than that.

The best guide for the trophy-hunter is, of course, that well-known work, "Records of Big Game," by the late Mr. Rowland Ward, and in it will be found much information regarding the haunts of game all over the world.

The tyro will pick up many useful hints from books which are bound to be useful to him at some time or other, and so much information is now published about the best game countries in different parts of the world that he will have little difficulty in finding his way to a good game country.

It should be remembered that the best sport is usually got by those who leave the beaten track, and who have the energy and self-reliance to break into new lands where the game has not been molested or disturbed.

A last word of advice to the beginner is to shoot in a thoroughly sporting manner, and to remember that other generations of sportsmen will arise who, in their time, will long for the same wild freedom and sport that we to-day are able to enjoy.

In the playing fields he will learn to behave in a manly and sporting manner, and, when he is old enough to engage in field sports, this will not be forgotten.

The charm of all shooting, be it large or small game, is that here we get to the heart of Nature, for the charm is not in the killing, but rather in the wild, natural surroundings, which always give an indescribable fascination to the sport. 


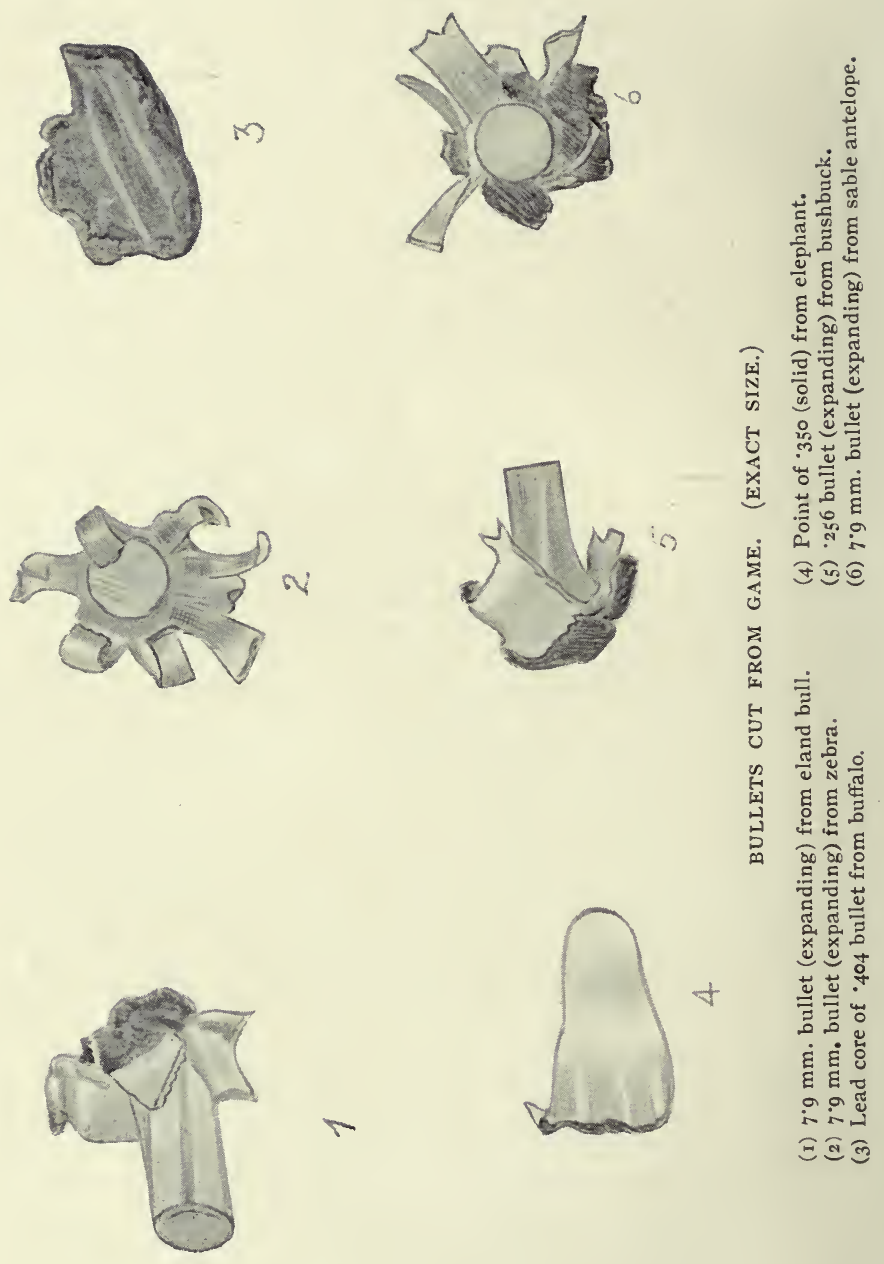


\section{IX.-A Few Remarks on Rifles and Equipment.}

Most of the books on sport published at the present day have a chapter on the subject of battery and outfit, and there is no doubt that it is a most vital matter that the sportsman should have at least one reliable rifle with him.

I may say that my remarks here are intended as a help to the tyro who has not had any practical experience in the field, and who has to take a gunmaker's advice on the selection of a suitable weapon, or weapons, for a hunting trip. This advice is not always disinterested, unless, perhaps, the budding big-game shooter goes to one of the leading rifle makers. I would never pretend to give advice to a good rifle maker on technical matters as to rifle building, but the practical hunter is more likely to know what is the best killing weapon for big game than the rifle maker, who probably never saw a wild animal outside the bars of a cage in his life.

In choosing a weapon, there are several points which have to be kept in view, and these might be summed up as follows :

I. Lightness and handiness.

2. Efficient killing power.

3. Soundness and reliability of mechanism.

4. Possibility of getting ammunition in the country shot in.

I here refer to what is called an all-round weapon, and I may say that I am a believer in such a rifle for the simple reason that if a large bore is taken it is seldom at hand when most needed. Therefore, let the small bore be sufficiently powerful to deal with any game from elephant down to duiker.

Having tried the following high-velocity rifles on game, . $450, \cdot 400, \cdot 375, \cdot 360, \cdot 350, \cdot 318,7 \cdot 9 \mathrm{~mm}$. (·3 I I) , $303, \cdot 275$, and 256 , I think nothing heavier than the 318 is needed, and I have done my best work with a $7.9 \mathrm{~mm}$. Mauser made by a well known London firm. This rifle is stronger than the 303 , and although its velocity and striking energy are not so great as the 318 , I found that the latter did not 
kill game a bit better. The $35^{\circ}$ old pattern, not "Magnum," is a very fine weapon with its 3 ro grains oldtype bullet, but I found it slightly heavier to carry than the $7.9 \mathrm{~mm}$., so prefer the latter, which will kill any game in Africa.

It is often in error called $8 \mathrm{~mm}$. , and this bore is usually found in the Mannlicher form of magazine.

Let me describe my $7 \cdot 9 \mathrm{~mm}$. It has the well known Mauser bolt magazine, with non-automatic safety catch, the barrel is 24in. long, and I got it made detachable. It has three sights for 100,200 , and 300 yards, and a very small ivory bead front sight. Both back and front sights are screwed down. It weighs, with four cartridges in the magazine and one in the breech, $7 \frac{1}{4} \mathrm{lb}$. With it I have killed elephant, rhino, hippo, buffalo, eland, most of the Central African antelopes, and other game, such as zebra, warthog, pig, etc.

It is so light and handy that I can carry it during a whole day's shooting in rough country, so I am always ready for what turns up.

Some sportsmen prefer double rifles, but no practical hunter uses them, and I think a second barrel a needless encumbrance to carry; and, considering that magazine rifles are so quick, there is no necessity to waste money in buying an expensive double, as a really reliable weapon of this kind cannot be purchased for much less than $£ 5^{\circ}$, and many makers charge a good deal more for their best double hammerless ejectors. Single falling block rifles are beautifully balanced weapons, but I never saw a falling block that ejected the fired case well, so I think the magazine action by far the best.

In magazine bolt rifles there are several varieties, such as the Mauser, ordinary Mannlicher for clips, MannlicherSchönauer for chargers or hand loading, and the LeeMetford or Lee-Enfield.

Having tried all these, I prefer the Mauser, although the Mannlicher-Schönauer has a beautiful, nice-working action.

Before I got the $7.9 \mathrm{~mm}$. Mauser mentioned, I did good 
work with a 303 Lee-Enfield; but this is not nearly such a good action as the Mauser, and the powder in the 303 cartridges, I found, damaged the chamber and barrel of the rifle much more than does the powder in $7.9 \mathrm{~mm}$. cartridges.

Personally I do not believe in bores less than the 303 , and I found with the ordinary ${ }^{2} 56$ Mannlicher and the $.275(7 \mathrm{~mm}$.) Mauser that one had to shoot most carefully if wounded game was not to be lost.

The new "Magnums" 256 and $\cdot 275$, with light sharppointed bullets, I put on a par with the much advertised 28 o Ross rifle. These may be very satisfactory on small or medium sized animals, such as red-deer and some of the lesser antelopes; but they are not safe to use on heavy or dangerous game, especially with solid projectiles, as these do not maintain their true direction after hitting hard round bones, and they zigzag all over the place. A man naturally wishes his bullet to carry true and penetrate efficiently. The great maxim of a good killing rifle is that the bullet should be arranged to penetrate almost through the body of the animal struck, and come to rest on the opposite side. Then the beast sustains the full energy and killing power of the bullet.

It is natural that with a rifle giving a velocity of 3oooft. sec. efficient penetration is more difficult to arrange, as the great velocity is very apt to shatter the bullet and make it lose itself in small splinters. This doubtless produces great shock in the bodies of small or medium sized animals, but it is not good enough for the larger species, which have more tenacity of life, with their larger bones, flesh, and muscle.

Many men with large experience of ordinary game recommend the $\cdot 280$ and similar rifles, but I never heard a man with practical experience of the largest of African game praise these rifles. By largest game I mean elephant, rhino, buffalo, and eland.

A friend of mine who purchased a 280 a few years ago told me he would much prefer a 303 with its heavier bullet. 
If the young sportsman chooses a $\cdot 280, \cdot 275$, or $\cdot 256$ Magnum, he had better get a second rifle shooting heavy blunt bullets as a standby, but then it will often not be handy; whereas if he had a 350,318 , or $7.9 \mathrm{~mm}$. in his hand all he has to do is to change the cartridge if a solid is necessary for use on an elephant or rhino.

Buffalo are easily killed with a hollow point or slit bullet, but let the slits be short. A "Dum-dum " form of bullet, that is one which has a very small amount of lead showing at the point, is a most excellent projectile for buffaloes or elands, and it will easily kill an elephant or rhino with the body shot.

Never have an automatic safety catch on a rifle. These are not fitted to magazines, but on falling blocks and hammerless doubles they are usually fitted, so it is best to get them altered to non-automatic, which, I believe, it is easy to do.

An automatic catch flies back to safety when the breech is opened, and a non-automatic stays as it is until altered by the thumb.

In hilly ground a sling is useful, so the rifle ought to. have an eye fixed to the barrel and stock for fixing the sling to.

As to sights, I think the open broad $v$ best, made very broad with a silver line, or ivory or platinum pryamid, leading to the centre of the notch. These are much quicker in use than any form of peep sight, and I consider telescopic sights only necessary for old men whose sight has failed. They are heavy and very easily damaged by a. fall or knock, and in cases where they are fitted an opening should be left for using the ordinary $\mathrm{V}$ sights when necessary. They are sometimes fixed to the side of the barrel, which is a good plan.

After firing at an animal with a magazine rifle, load up. at once, as the noise of the discharge drowns the noise of the magazine working. With practice one can be very quick with a Mauser or Mannlicher-Schönauer; in fact so quick that a charging animal will not have come far before one is ready. 
A single magazine or a falling block is generally more accurate than a double, as with the latter it is difficult for the rifle maker to adjust both barrels to shoot the same.

People who have done a lot of shooting with a shotgun often prefer a double rifle, as they say they can shoot quicker, especially for running shots. This may be so, but rifle shooting and shotgun shooting are two absolutely different accomplishments.

With a rifle, if the sights are not properly aligned on the object, the bullet will not hit it except by the greatest fluke, and with a shotgun hand and eye act together, and there is not the need of great accuracy with a charge of small shot.

No doubt if some of our best shots with a shotgun had bullets in their guns instead of shot, they would often hit at short ranges, but they would not hit much at the ordinary range for big game shooting, which is usually between 100 and 200 yards, even if the ball carried as far.

For a sum of from $£$, 12 I $2 s$. to $£ 20$ one can get the best magazine rifle made, and nowadays fairly large bores can be got in magazine form, such as $375, \cdot 404, \cdot 416$, and 425 .

The 416 , which has lately been introduced by a first class London firm, shoots a very strong charge, and the solid bullets have particularly well covered nickel jackets, so as to improve penetration. Such a rifle I would infinitely prefer to a double $45^{\circ}$ or ${ }^{\circ} 470$; and with a $7{ }^{\circ} 9 \mathrm{~mm}$. as the small bore for all-round work one could not do better than get one of these new 416 Mausers for use on very heavy and dangerous animals. Being special rifles, they cost 30 guineas, but this figure includes a rubber heel pad and a spare front sight.

Such a rifle would be the best for elephant and rhino obtainable, used with solid bullets, and, with hollow point or soft nose bullets, buffaloes would seldom need more than one shot with such a rifle. The bullets weigh 410 grains, the velocity is about $2400 \mathrm{ft}$. sec., and the striking energy at muzzle is over $5000 \mathrm{ft} \mathrm{lb}$., which is equivalent to the $45^{\circ}$ type of nitro rifles. 
In making particular mention of the $7.9 \mathrm{~mm}$. and $4{ }^{1} 6$ rifles I have, I believe, mentioned two of the best weapons in existence for the big-game hunter.

For Asiatic or American shooting these would be just as serviceable as for African game, although for the latter country the $7 \cdot 9 \mathrm{~mm}$. is enough.

The $45^{\circ}$ and 303 bores are barred for importation into India, and also into Uganda, I think, except to Government officers.

Having given my ideas as to the best rifles, whatever these opinions may be worth, I shall now mention something about tents and camp equipment.

As with firearms, the great desideratum should be lightness combined with strength, so I think the best tent is a single fly covering. A good pattern is the "Whymper," as it only weighs about $35 \mathrm{lb}$. complete with poles, pegs, ropes, and hammer, and it has a ground sheet sewn in which is useful as an aid to comfort.

Instead, however, of having the back sewn as a fixture, I think it should be made to open like the front, and, if a small window with mesh is made, it makes the tent cooler.

If a window is made, there should be an outside flap, with tapes (or hooks and eyes), to draw over the opening in case of rain or wind.

Another good tent is one known as the "Patrol," 7ft. high and $8 \mathrm{ft}$. by $8 \mathrm{ft}$. It has walls of about $2 \mathrm{ft}$., and is roomier, but slightly heavier, than the "Whymper."

Needless to say, all the tents and everything made of canvas should be the canvas known as "Green Willesden."

There are several good patterns of beds, and I have found none to beat the " $\mathrm{X}$ " pattern; tables and chairs can be bought of this pattern also, though the strongest chair is an ordinary deck-chair with seat made of green canvas to lace on.

A folding canvas bath and a bucket and basin of the same material will be most necessary, and, of all the kit, perhaps one of the most important items is a small-mesh mosquito net. I say "small mesh," as sandflies will go 
through an ordinary-sized mesh, and they are quite as troublesome in some places as mosquitoes.

Candle lamps are the best for travelling, as paraffin oil is difficult to carry without leakage, and if it gets on things, especially foodstuffs, it is most objectionable.

Cooking pots are best made of aluminium, as it is very light and strong. Its wearing qualities are most excellent.

A china or crockery cup or two is a comfort, and the best I know are a German pattern, made very thick and solid. These are 'seen on the German East African line of steamers. It is wonderful how a china cup will last through much rough travel, and I have had cups remain unbroken for a year or two. Of course, a few enamelled iron cups and plates should be taken, and these latter are more easily cleaned than aluminium.

The sportsman will likely take a camera, and a Kodak of $3 \mathrm{~A}$ size (post card size) is one of the best.

A pair of binoculars and perhaps a good telescope will prove most useful, in fact necessary at times, and the kind chosen is a matter of personal choice.

Cartridge bags as well as gun covers are best made out of green or brown canvas.

As to a shotgun, I think nothing is better than a good quality I 2-bore hammer gun, bored right cylinder left choke, and weighing $6 \frac{1}{2} \mathrm{lb}$. Such a gun will shoot a round ball true up to 50 yards if care is taken to get a mould that is an exact fit. The best locks that can be purchased are Brazier's and the best barrels are made of Whitworth fluid compressed steel. Such a gun will last a lifetime, and will outlast a dozen cheap hammer or hammerless guns.

Revolvers and pistols are not much use, except for shooting oneself with by mistake; but a most useful weapon is a small 220 rifle for use with the "long rifle" or "short" ammunition. It will kill small antelopes if held straight at short range, and is most useful for killing guineafowl, pigeon, or duck for the pot. The cartridges are very light and are little trouble to carry. 
Hunting knives, as usually sold by cutlers, are useless; when they get blunt they cannot be sharpened without the use of a grindstone, and a file will not usually cut them.

The best knife to carry is a strong two-bladed pocket knife, and some spare ones might be taken. Get shackles fitted to these to fix to a chain, or to the catch on the body belt.

Then half-a-dozen soft steel butcher's knives, known as "The Bushman's Friend" or "Green River Knife," should be included for cutting up game, and a strip of emery stone is a most handy adjunct, as well as a small hone. An American axe, a soft steel one, is a tool that should always be taken; and a pair of pincers or pliers, a few files, some emery cloth, some screws and nails, a small hammer, and a small hand vice will all, at times, be needed for doing some small job.

I have found a narrow keyhole saw handy, and, of course, several screwdrivers will be included, with spare parts for the rifles.

For cleaning weapons, vaseline and Rangoon oil are as good as anything, and I rub plenty of the former on the stocks of rifles to make them waterproof.

A big waterproof sheet, several green canvas bags with staples and padlocks; and one, or two, watertight tin cases should be bought for putting the various kit into.

A most important item is good footgear, and nothing can beat boots fitted with rubber pads known as Scarfe's patent. In the dry season boots with chrome soles last well ; but it is better to get bars or nails fitted, or they will become slippery on dry grass and leaves. These chrome soles are no good for the rainy season, as they get soft and sodden with wet.

One cannot go silently when wearing heavy shooting boots. Kubber soled boots or shoes are splendid for the grip and silent going; but then they are unbearably hot in the tropics and soon get cut to bits.

Shorts, the same as runners or rowers use at home, made of a greenish brown khaki, gabardine, or garbette, 
are better than tight breeches, and I like to shoot in bare legs.

A light suitably coloured coat, a kind of semi-Norfolk jacket, is handier for carrying things than a shirt. If a coat is worn there is no necessity to wear a shirt underneath, and a thin singlet or undervest is quite sufficient.

Use natural colour socks, as blisters will be a common occurrence, and dyed socks may cause blood poisoning.

The amount of blisters one can get depends largely on the ease with which the boots fit, so great care should be expended in finding comfortable footgear, as nothing else will conduce to the comfort (or otherwise) of a hard walking shooting trip.

As to head covering, get a drab or brown double "Terai" hat, and for walking in open country, or along broad roads, a pith helmet will often be a comfort, though the latter is most uncomfortable to shoot in, especially when lying or doing the crawl often necessary in a stalk to close quarters.

A very useful article is a strip of waterproof material made to button, or tie, round the action of the rifle. This keeps water from the action and saves much trouble in cleaning when one returns to the camp or headquarters.

Anklets, made of leather or canvas, might be taken to fix over the tops of the boots, though personally I cannot be bothered with anything tight round any part of my legs, as it hinders free walking.

For the rains a good waterproof coat is needed, and I like one made of cloth, such as an "Aquascutum," for any rubber or rubber-lined coat is too hot, and causes violent perspiration.

Again, I would remark that in most cases I would prefer to get wet and change on my return to camp rather than be hampered with having to carry such a garment when shooting.

However, for marching, and for times when it is inconvenient to get soaked, a coat is necessary. When the cool of evening comes on, a warm tweed jacket should be at 
hand to put on, and I warn sportsmen or travellers not to sit in the chill of evening in damp clothes, as nothing is more likely to cause fever.

If one is cold in a tent, wear plenty of clothes, and a warm pair of socks helps to keep the body warm. I have sometimes had hot ashes spread under the camp bed, and when undergoing an attack of the "shakes" (ague), a glass bottle filled with hot water will do as a bed warming pan and be a comfort.

Never go out in a hot sun without head covering, as one will often see men do. A touch of the sun is not an affair of minutes, but simply a matter of a second or two. If the hat has to be removed, it is, therefore, best to get under the shade of a tree, or anything else that will give shade, and not stand uncovered under a blazing tropical sun.

I am afraid I do not always practise what I preach, but all the same the above hints are good advice, as I know from experience of my own and of others.

As to medicines, there are certain well-known drugs that should be taken, though I do not advise a sportsman to buy a ready-made medicine chest, which usually contains many medicines which will seldom be needed. A fair quantity of the following are necessary :-

Quinine, vegetable laxative, calomel, Livingstone's rousers (good for natives), boracic acid powder (most useful), phenacetin, permanganate of potash, carbolic oil, toothache cure, lint, surgical needles and thread, scissors, forceps, tourniquet, sticking plaster, adhesive tape, vaseline, safety pins, bandages, lancet, etc.

Most of these things will be used for treating natives, who often get bad cuts and scratches. The most common complaint among them is constipation, which causes fever and headaches; and their cuts are treated so badly that they often develop into large ulcers.

For the sportsman the best drink is hot tea, as the water for it has to be boiled, which kills dangerous germs. When one is hot and tired, nothing is more refreshing than tea, and if I go off for a day in the bush, I usually carry a 
small kettle and some tea and sugar, as well as a little food, such as bread, biscuits, a tin of sardines, and some jam or honey.

It is wise to carry plenty of tinned milk, and also a good supply of hops and baking powder, to make good bread or scones. Some cooks can make excellent bread with native beer, and, when this is well fermented, it makes the flour rise as well as the best prepared hops.

Tobacco can be bought in Nyasaland, as it is grown locally, and the price is about $2 s .6 d$. per pound. It is rather rank, but one can get accustomed to it.

While mentioning rifles, I omitted to note the amount of ammunition necessary for a six months' trip. For the small-bore, I oo rounds per month, which totals 600 rounds, would be more than ample; and out of this 200 might be loaded with solid bullets and 400 expanding, either Dum-dum, hollow, slit, or soft nose.

For the large bore, if one is taken, 200 solids and fifty expanding would be quite sufficient for the same time.

A bag, known as a rucksac, is very handy at times, and it is large enough to take a blanket, a waterproof sheet, and a change of clothing, should one intend sleeping out for a night.

I repeat that it is unwise to make a habit of sleeping on the ground, though a night spent so on occasions will harm no one if it is the dry season, when there is no damp about.

If one takes care not to catch sudden chills and get bitten by mosquitos, rather impossible in some places, the health will not suffer; and if the sportsman is troubled with fever, it is good advice for him to take quinine regularly, as it is the only drug yet discovered that is a preventive of that complaint.

Finally, when shooting at game, get close, and make sure of the shot. Of course, one can get too close at times, and lose a good chance by trying to get too near; but the majority of game that is sent away wounded has been hit by long, uncertain shots when standing in a bad 
position. Do not aim at the whole animal, but carefully pick the spot that you wish to hit, and this depends on the angle at which the animal is standing.

Needless to say, this advice is for beginners, and not for experienced hunters.

\section{APPENDIX.}

Ballistics of the Best-KNOWN High-Velocity RIFLES.

\begin{tabular}{|c|c|c|c|c|c|c|c|}
\hline Bore. & & $\begin{array}{l}\text { Weight of } \\
\text { bullet in } \\
\text { grains. }\end{array}$ & $\begin{array}{l}\text { Velocity } \\
\text { at muzzle, } \\
\text { ft. per sec. }\end{array}$ & $\begin{array}{l}\text { Striking } \\
\text { energy at } \\
\text { muzzle in } \\
\text { foot lb. }\end{array}$ & $\begin{array}{l}\text { Usual } \\
\text { weight of } \\
\text { single rifle } \\
\text { in lb. }\end{array}$ & $\begin{array}{c}\text { Usual } \\
\text { weight of } \\
\text { double rifle } \\
\text { in lb. }\end{array}$ & $\begin{array}{c}\text { Type of } \\
\text { cartridge } \\
\text { case. }\end{array}$ \\
\hline${ }^{2} 256 \quad \ldots$ & $\ldots$ & 156 & 2400 & 1990 & $7^{\frac{1}{2}}$ & $8 \frac{3}{4}$ & Rim. \\
\hline •256 Magm. & ... & 136 & 3000 & 2730 & $7^{\frac{3}{4}}$ & - & Rimless. \\
\hline $275 \ldots$ & $\cdots$ & I 73 & 2300 & 2000 & 7 & - & Rimless. \\
\hline$\cdot 280 \quad \ldots$ & ... & $140-160$ & 3000 & 3050 & 8 & $9 \frac{1}{4}$ & $\left\{\begin{array}{l}\text { Rim and } \\
\text { Rimless }\end{array}\right.$ \\
\hline $303 \ldots$ & $\ldots$ & 215 & 2050 & 2070 & $7 \frac{1}{2}$ & $8 \frac{3}{4}$ & Rim. \\
\hline $375^{-} 303$ & $\ldots$ & 215 & 2500 & 3000 & $7 \frac{3}{4}$ & $9^{\frac{1}{4}}$ & Rim. \\
\hline *. 3 I I $(7.9 \mathrm{~mm}$. & & 225 & 2030 & 2060 & $7 \frac{1}{4}$ & - & Rimless. \\
\hline *.3 318 & ... & 250 & 2500 & 3460 & $7^{\frac{1}{2}}$ & - & Rimless. \\
\hline **350 Rigby & ... & 310 & 2150 & 3200 & $7 \frac{3}{4}$ & $9^{\frac{1}{4}}$ & Rim. \\
\hline 35o Magm. & $\ldots$ & 225 & 2600 & 3400 & 8 & - & Rimless. \\
\hline $400-360$ & $\ldots$ & 300 & I950 & 2530 & $7^{\frac{3}{4}}$ & $8 \frac{3}{4}$ & Rim. \\
\hline 36o No. 2 & ... & 320 & 2200 & 3400 & $8 \frac{1}{2}$ & 9 & Rim. \\
\hline $375 \quad \ldots$ & ... & $270-320$ & 1970 & 2400 & $7 \frac{3}{4}$ & $8 \frac{3}{4}$ & Rim. \\
\hline$-450-400$ & ... & 400 & 2150 & 4100 & $8 \frac{1}{2}$ & $10 \frac{1}{2}$ & Rim. \\
\hline $404 \ldots$ & ... & 400 & 2125 & 4000 & $8 \frac{1}{4}$ & - & Rimless. \\
\hline 416 Rigby & ... & 410 & 2370 & 5000 & 10 & - & Rimless. \\
\hline $500-450$ & ... & 480 & 2170 & 5035 & $9 \frac{1}{4}$ & I $1 \frac{1}{2}$ & Rim. \\
\hline $500-470$ & ... & 500 & 2120 & 5010 & $9^{\frac{1}{2}}$ & I I $\frac{3}{4}$ & Rim. \\
\hline 450 No. 2 & ... & 480 & 2170 & 5035 & $9^{\frac{1}{2}}$ & I I $\frac{1}{2}$ & Rim. \\
\hline 475 No. 2 & $\cdots$ & 480 & 2200 & 5150 & $9^{\frac{1}{2}}$ & I I $\frac{3}{4}$ & Rim. \\
\hline $500 \quad \ldots$ & ... & 570 & 2150 & 5840 & 10 & $12 \frac{1}{2}$ & Rim. \\
\hline $577 \quad \ldots$ & $\cdots$ & 750 & 2050 & 6990 & $10 \frac{1}{2}$ & I $3 \frac{3}{4}$ & Rim. \\
\hline
\end{tabular}

Above statistics are only approximate, but they will be found to be nearly exact, and they give a good enough idea to the sportsman.

The three weapons marked with an asterisk are the best "all-round" weapons I know, and either of them will kill anything in Africa, and this being the case, they are good for game in any other part of the world.-THE Author. 


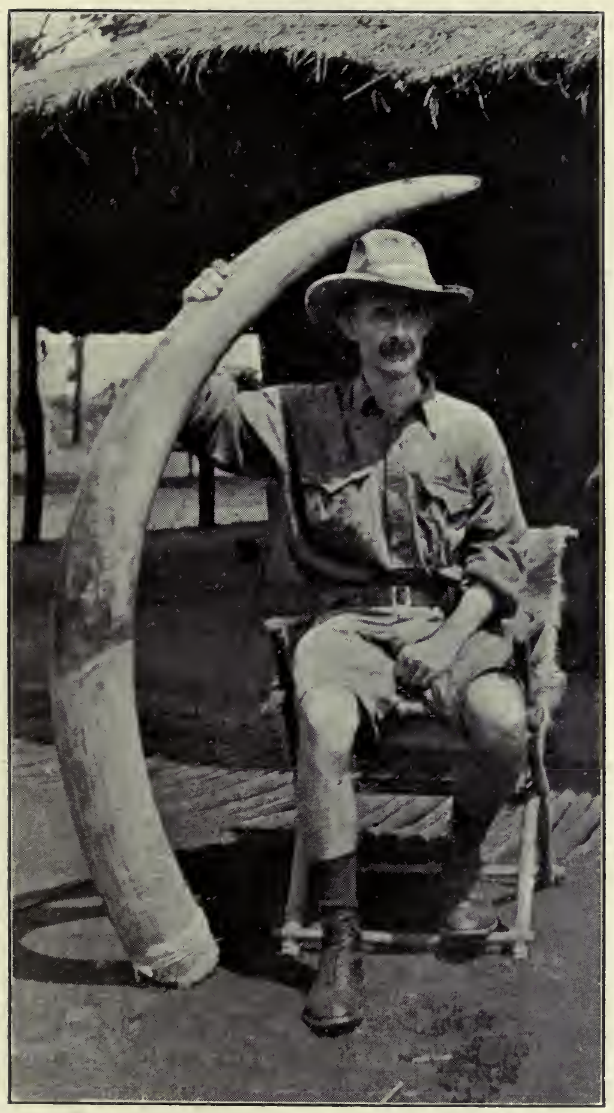

THE AUTHOR. 



\section{INDEX.}

Accidents, Big game, 88, 89.

", Causes of big game, 80 .

Achewa, Beliefs of, 224 .

Africa, Different routes to Central, 253, 254, 255, 256.

African Lakes Corporation, 63 .

Angoni, Ancient name of, 2 I 8.

," Customs, etc., of the, 2 I 3.

", Old raids of the, 2 I 6 .

", Strange story related by the, $22 \mathrm{I}$.

Animals, The mode of attack of, 96, 97 .

Ant (white and small black), 2 I I.

Ants, Ducks and fowls killed by, 6 .

Axe (American), Usefulness of, 10.

Baboon, I I 2.

Native names of, 2 IO.

Badger (Honey), Native names of, 2 IO.

Baldwin, The late Mr., 8 I.

Bangweolo (Lake), Lechwe abundant near, i 84 .

" , Otters plentiful near, 209.

" , " Sassaby numerous near, I 80.

Bat, Angoni name of, 2 I I.

Situtunga found near, I $8 \mathrm{I}$.

Barns, Mr. T. A., 53, 70, 7 I, I 8 I.

Bee, Angoni name of, 2 I I.

Bees, Fowls killed by, 6 .

Big game hunting, Good training of, 24 .

Big game shooting, The risks of, 80.

Bird life (Luangwa river), I3 $\mathbf{I}$.

Birds, Native names of, 2 I I .

Blood smears, The way to take, 40.

Boers, Game slaughter by, 77, 78 .

Borer insect, 9 .

Boxes (Watertight), 5 . 
British East Africa, A visit to, I.

Bua river (Nyasaland), 8, I 5, 99, I I 5, I 27, I 83 .

Buffalo, Disturb some, 139 .

" Escapes from, 84, 89, 93 .

" Fine horns of, 135 .

, Kill large bull, 144, I 45, I 46 .

" Native names and description of, I67, г68, г69, I 70.

" Shoot four, 147,148 .

, The dying bellow of, I 46,147 .

Bullets (Native), 60.

Bush, Erecting huts in the, 9 .

Bushbaby, Native names of, 2 I I.

Bushbuck, Abundance of, I 49.

" Good horns of, 185 .

, Native names and description of, 184,185 .

Bushpig, Native names and description of, 203, 204.

Bustard, Angoni name of, 2 I I.

Butterfly, Angoni name of, 2 I I.

Camp, Building the permanent, II.

" Change my, 71.

, Description of my, 37 .

, Making a, 6.

Camping ground, How to choose a good, I 25.

Canvas, A good kind of, 6.

Cat (Civet), Native names and description of, 209.

Cat (Wild), Native names. of, 2 Io.

Cedar wood forests (Mlanje), I 7 .

Central Angoniland, Description of, 15.

Cheetah, I98, I 99.

Chibisa, Death of, $222,223$.

Chiperoni (Mountain), I 10.

Chiromo Marsh, Buffalo plentiful in the, r 68.

Cholo range (Nyasaland), I 46, 150.

Cobras, 7, 99.

Codrington, The late Mr. Robert, I 28.

Cotton, Elephant killed by Major Powell, i6o.

Crane (Crested), Native names of, 2 II.

Crocodile, 132, 2 Io.

" Boy taken by, 132, r33.

,$\quad$ Native names of, 2 Io.

Crocodiles, Length of, 49, 50, 51 . 
Crops (Native), Damage done by animals to, 76, 77 .

Crosby, The late Mr. (killed by a buffalo), 89 .

Crow, Angoni name of, 2 I I.

Crown lands, Rules about occupation of, I4.

Cumming, The late R. Gordon, 8 r.

Dambo, Meaning of the word, 15.

Dangerous game, Comparison between, 95.

Dedza (Nyasaland), 2 I 8.

Deerstalking, Remarks on 25.

Dog (Wild), Native names and description of, 206, 207, 208.

Dogs (Wild), Lion killed by, 207.

Dove, Angoni name of, 2 I I.

Duck, Angoni name of, 2 I I.

Duiker (Blue), Native names and description of, I90, I9I.

Duiker, Native names and description of, 189.

Eland, Easy spooring of, 33 .

,$\quad$ Fat of, $\mathbf{1} 72$.

, Good horns of cow, 24.

Horn measurements of, $17 \mathrm{I}$.

,$\quad$ Invasion of native gardens by, 18,76 .

, Lion kills young, 72 .

" Measurement of large bull, 35 .

"Native names and description of, I70, I7 I, 172.

"Shoot, 19, 24, 34, 1 52 .

, Wound an, 20.

Elephant, Amount of food eaten by, 76 .

Broken tusker, 59.

Close quarters to, 55 , I 38, I 39 .

Cutting up an, 63 .

Distributing meat of an, 67 .

Fatal accidents caused by, 88, 89, 94, 95, 96.

Hard work of tracking, I $24,125$.

Hunting, 52 .

Kill a charging bull, $137,1_{3} 8$.

Mr. Melland kills a large bull, 42 .

Native names and description of, r59, 160, 16 1, 162.

Search for an, 27 .

See and lose a fine bull, 56 .

Shoot a good bull, 57, 58, 59 .

Size of feet of, 28 .

Stones in stomach of an, 108. 
Elephant, Strength of, 97, I 49.

Tall bull, 53 .

Tuskless, I39.

Tusks of, 160 .

Wound and lose an, 55 .

Europeans, Climatic influence on, I 2.

Evidence, A case of false, 39.

Fat, Method of preparing, 35, 36 .

Faulkner, The late Captain, Animal like inyala shot by, I 82 .

Fiere, The late Octave (killed by a buffalo); 94 .

Firearms, Buying secondhand, 243, 244, 245.

Old, 80.

Fleas, Ducks killed by, 6 .

Footgear, The best form of, 25 .

Footpaths, Native, 64, 65 .

Fort Manning (Nyasaland), Good elephants killed near, 28, 60.

Fries (Mr. de), Adventure with a buffalo bull, 93.

Galago, Native names of, 2 Io.

Game, Field notes of the, 158.

Game regulations, 78 .

Game, The best shots for, I I3, I I 4 .

Garden, Elephant wounds Mr. George, 93.

Genet (Rusty-spotted), Native names of, 2 Io.

German East Africa, Slaughter of game in, I 20, I 21 , I 22.

Gibbs (gunmaker), Mr. George, 82 .

Goats, Barter hippo for, I 4 I.

Goddard, The late Mr. (killed by an elephant), 88 .

Goose, Angoni name of, 2 I I.

Graetz, Buffalo mauls Lieut. O., 94.

Grass, Burning of the, 16,65 .

" fires, Animals destroyed in, 65 .

" Following buffalo into thick, $147,1_{4} 8$.

Graves, Old native, 8 .

Grey, The late Mr. George (killed by a lion), 9 I.

Grey's Scouts, $9 \mathrm{I}$.

Ground, Sun heats the, 66 .

Guineafowl, Native name of, 2 I I.

Gwazas (Shire river, Nyasaland), I 90.

IHare, Native names of, 2 I I.

Hartebeest (Lichtenstein's), Native names and description of, 179. 
Hartebeest, Companionable habits of, 40.

Heat, Oppressive, 16, 57.

Hides, The Stretching of, 53 .

Hippo, Extraordinary behaviour of, 73 .

Kill six, I4O, I 4 r.

Native names and description of, 165 .

Shoot a, 73 .

Shoot three, 62,63 .

Recovering a, 75 .

Holland and Holland (gunmakers), 92.

Honey, Abundance of, 26.

Hornet, Angoni name of, 2 I I.

Hornets, Snakes and, 7 .

Stings of, 7 .

Horns, Luck in getting fine, $4 \mathrm{I}$.

Shrinkage in length of, 22.

Hut, Life in a native, 4.

Huts, Engage natives to build, 8 .

Hyænas, Dead elephant eaten by, 62 .

" Strange sounds made by, 205.

" (Two varieties), Native names and description of, 204, $205,206$.

Impala, Abundance of, I 28.

" Kill a ram, I4 $\mathrm{I}$.

" Native names and description of, I 86, I 87.

See a fine, 45 .

India, Snakes numerous in, 7 .

Insects, Native names of, 2 I I.

Inyala, Native names and description of, $181,182,183$.

Ivory, Grades of, $6 \mathbf{r}$.

Age reduces weight of, 22.

Jackal (Two varieties), Native name and description of, 208.

Jameson, Fort (Northern Rhodesia), 72, 2 1 8.

Johnstone, The late Mr. (killed by an elephant), 88 .

Kalenje, Staunchness of gunbearer, 137 .

Kamwendo, Tracking powers of, 27, 28, 54 .

Kingfisher, Angoni name of, 2 I I.

Kirby, Mr. F. Vaughan, 83, I95.

Klipspringer, Native names and description of, 187, I 88.

Kudu, Abundance of, 32,

,$\quad$ Difficulty in finding, 32 . 
Kudu, Measurements of horns of, $3 \mathrm{I}$.

„ Native names and description of, I76, I77.

., Shoot bull, 31, 66 .

, Wide-spread horns of, 31 .

Labour, Cost of native, $249,250$.

Lechwe (Two varieties), Native names and description of, $S_{4}$. Leeches, I I I, I I 2.

Leopards, Agility of, 98, I 29.

, Native names and description of, 196, I $97,198$.

, Natives killed by, i 97.

Lion, A bad tempered, I 30.

"A young eland killed by a, 72 .

, How game is killed by, 96, 195 .

,. Measuring skins of, 195.

, Native names and description of, 1 93, 1 94, 1 95, 196.

,, Natives killed by, I00, IOI, 102.

, Using dogs for hunting, 96.

Literature (Big game shooting), 257.

Livingstone's antelope, Nyasaland specimen of, I91, 192.

Loneliness, Bush life and its, 43.

Long range shooting, 2 .

Long shots at big game (Field article quoted), 46.

Luangwa river (Northern Rhodesia), 72, 1 27, I 29, I $31,133,136$,

I 38, I 39, I 40, I 45, I 65, I 82, I 83, 206, 207.

Lupata Gorge (Zambesi river), 62.

Machinga mountains (Northern Rhodesia), I36, I63.

Maiden, Mr. J., IgI.

Maitland, The late R. P. Fuller, 94.

Manis (Scaly), Native names of, 211.

Manning, Fort, 10, 28, 60, 2 I 7, 2 I8.

Maponda's village (Nyasaland), 69.

Marki (Gunbearer and skinner), I 54.

Mausi hill (Nyasaland), Sable antelope plentiful near, I50, I5I,

I 54 .

Meat, Cooking and preserving, 8.

Melland, Fine elephant shot by Mr., 42 .

Memeza, Angoni chief named, 2 I 7.

Memories of big game hunting, I 27.

Mines, Natives going to work at, $3 \mathrm{~S}$.

Missions, Central African, 220, $221,225,232$.

Mitala's village (Nyasaland), 69 . 
Mkumbi, Anzoni chief named, 2 I 8.

Mlanje mountains (Nyasaland), I6, I7, I97, 203, 204.

Moir Lake, I 8 I.

Mole, Native names of, 2 I I.

Mongoose (five varieties), Native names of, 2 I I.

Monkey, Native names of, 2 I 0.

Mosquitoes, I I 2.

Mouse (Field), Native names of, 2 I I.

Mpezo (Nyasaland), Blue duiker seen near, i 90.

Mpseni, Old Angoni chief named, 2 I 7, 22 2, 233.

Mzazas (Luangwa river), 43, I28, I29, I3 1 .

Native, An insolent, $37,3^{8}$.

Natives, Adaptability of the, 229.

.. Characteristics of the, 2 I 3.

,. Courage of, 103.

.. Happiness of, 235.

.. Implements and foods of the, 245 .

.. $\quad$ Liking for music of, 229.

,. Meat-eating powers of, 23, I 32 .

.. Treatment of, 227.

Nawalia (Northern Rhodesia), 88.

Ndorobo, Elephant-killing by, i6 I .

Neumann, Elephant injures, 85 .

The late Mr. A. H., 55, 6i , $\varepsilon_{4}, 85$, I 60.

Nyasa, Hippo in Lake, I 65.

Nyasaland, Abundance of game in, I.

Game in, 77, 78, 79, I I 5, г 6 .

Hills in, 16.

Wealth of timber in, 16 .

Ordeal, Hot water, 2 I 5.

Oribi, 39, I Io.

.. Native names and description of, $\mathbf{I} 87$.

Osprey, Angoni name of, 2 I I.

Ospreys, I 3 I.

Oswell, The late Mr. William Cotton, 8I, 95.

Otter (two varieties), Native names of, 209.

Owl, Angoni name of, 2 I I.

Parrots, Angoni name of, $21 \mathrm{I}$.

Partridge, Native name of, 2 I I.

Paths, Native, 64, 65.

Pests, Tropical, 5. 
Photographing big game (Field articles quoted), 47, 48 .

Pigeon, Angoni name of, 2 I I.

Pinda's village (Nyasaland), 73 .

Plants, Troublesome, I I I.

Plover, Native names of, 2 I I.

Porcupine, Native names of, 2 IO.

Protective colouration, $236,237,238$.

Puff-adders, 98, 99.

Puku, I 40.

, Native names and and description of, I 83, I 84 .

Python, Native names of, 2 I 2.

Rains, Duration of the, 16.

Rainstorm, A tropical, 75.

Rash, Meat causing skin, 26.

Rat (House), Native names of, 2 I I.

Rats, Damage done by, 5 .

Reedbuck, Native names and description of i $\delta_{5}$, I $S 6$.

, Shoot, 39, 69.

Reed-rat, Native names of, 2 Io.

Remarks on sport, etc., I.

Rhino, Native names and description of, $163,164,165$.

, Shoot a bull, I 43 .

Rigby and Co. (Gunmakers), Messrs. John, 92.

Rifles and Equipment, $26_{3}$.

" Power of modern, 54, 81, 92, 107.

Rites, Mohammedan, 26.

Roan antelope, Abundance of, I 29.

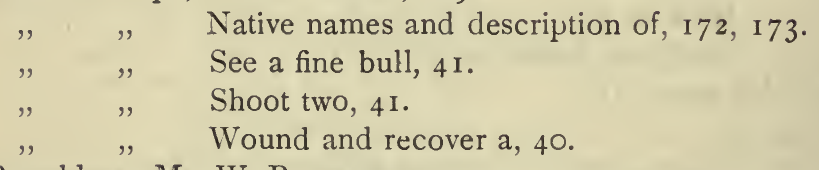

Ronaldson, Mr. W. P., 42, 204.

Rukusi stream (Northern Rhodesia), I 42.

Rules, Shooting, 18.

Ruspoli, The late Prince (killed by an elephant), 96 .

Ryan, Mr. Martin, 60.

Sable antelope, Native names and description of, I73, I74, I75.

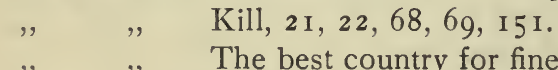

" $\quad, \quad$ The best country for fine, 23, I74.

, $\quad$ Wound and lose a fine bull, 45 .

Sanderson, The late G. P., 76 . 
Sassaby, Native names and description of, 180.

Secretary bird, Angoni name of, 2 I I .

Selous, Mr. F. C., 2 I, 81, 82, 83, 84, 94, 181, 193, 195, 196, 236. $, \quad, \quad$ Inyala shot by, I8I.

Serval, Native names and description of, 199.

Settlers, Information for, 256 .

Shauri, Angoni chief named, 2 I 7.

Shaw, The late Mr. (killed by an elephant), 88.

Shire river (Nyasaland), Good shooting near, 146, 149, 165, 182, $18_{5}, 190$.

Shooting (Central Angoniland), 15, I 7, 33.

Shrew (Two varieties), Native names of, 2 Io.

Situtunga, Native names and description of, I 80.

Sleeping sickness, Game and, 40, 79, I I 5 .

Snake-bite, Treatment of, 99.

Snakes, Angoni names of different, 2 I 2.

Somalis, 2 .

Poisonous, 7,98 .

Spoorers, Best native, 27 .

Spooring, 3 .

Squirrel, Native names of, 2 I I .

Stalking, 25.

Steinbuck (Sharpe's), Native names and description of, I 90.

Stigand, Capt. C. H., 86, 87, 88.

Stoat, Native names of, 2 ro.

Streatfield, Mr. Frank, A puff-adder bites, 99.

Sugar, Use of, 26.

Tarlton, Mr. Leslie, Large bag of lions made by, 92 .

Tea, The use of, 9 .

Tete (Zambesi river), 72.

Thunderstorm, A terrific, 44.

Ticks, I I I.

Tilden, The late Mr. (killed by an elephant), 89 .

Timmler, Mr. C. H., 181, 182, 185.

Trackers, 3 .

Tracking, 105, 106, 107, 108.

Traits, Various native, 230, $23 \mathrm{I}$.

Trees, Elephants break large, I 49.

, Most useful, 9.

Trophies, Preservation of, 239.

, Treatment of, 155 . 
Tropics, Health in the, $251,252$.

Tsetse, Angoni name of, 2 I I.

Tuchila plains, 150.

" river, I 50.

Vegetables, Native, I 34 .

Vegetation, Obnoxious, 29.

Vulture, Native names of, 2 I I.

Vultures, Sight of, I3I.

Wagtail, Native name of, 211 .

Walks, Long, I 7 .

Warthog, 36, I Iо.

, Native names and description of, 201, 202, 203.

," Weight of boar, 202.

Waterbuck, 2 I, 75, I 35, I 40.

,, Native names and description of, I77, I 78 .

, Steedman first discovers, 178 .

Whirlwinds, 72 .

Wild animals, Confinement of, I 23, I 24.

Wild cat, Native names of, 2 ro.

Wild dog, Native names and description of, 206, 207, 208.

Wilds, Hints to one lost in the, I $25,126$.

Yakobo, My cook, 67, 74 .

Young, Lake, I 8 I.

Zambesi river, Hippo in, 62, 63, 74, 166, I67.

valley, Great heat in $16,72,145$.

Zebra, Native names and description of, 200, $20 \mathrm{I}$.

Shoot three, 26.

Zoological gardens, $123,124$.

Zorille, Native names of ,2 I I

Zulus, 135 .

\section{Appendix.}

Ballistics of the best known high volocity rifles, 274 . 


\section{GABARD I NE}

WEATHERPROOF T ROPICAL KI T

"Insures comfort and security in every kind of weather \& climate."

GABARDINE, woven by G BURBERRYS from fine and light yarns, completely satisfies the varied requirements of sport and every-day life in tropical climates.

\section{WEATHERPROOFED by exhaustive systems,} Gabardine prevents ill-effects arising from exposure to heavy rain, mist, or dew.

NATURALLY VENTILATING and airylight, Gabardine is not fatiguing or overheating on the hottest day. $\mathbf{R}^{\text {EMARKABLY DURABLE }}$ owing to its close weave, Gabardine is invaluable for bush or jungle sport, as even exotic thorns are powerless to penetrate its flexible yet leather-like texture.

"GABARDINE IN PEACE \& WAR"
A handbook of equipment for every
part of the world. Fully illustrated.
A copy, together with patterns of
Gabardine, post free on request.

B UR B E R R Y S Haymarket LONDON Bd. Malesherbes PARIS and Agents throughout the World.

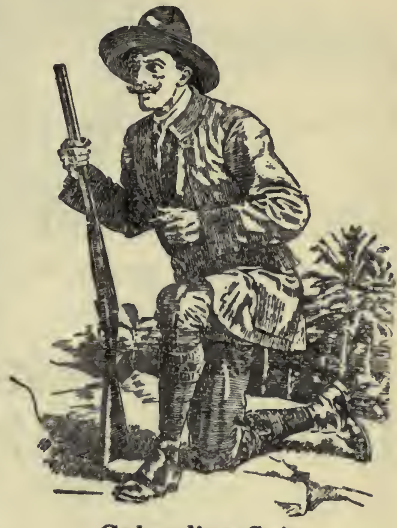

Gabardine Suit.

The finest outfit available for rough work and hard wear.

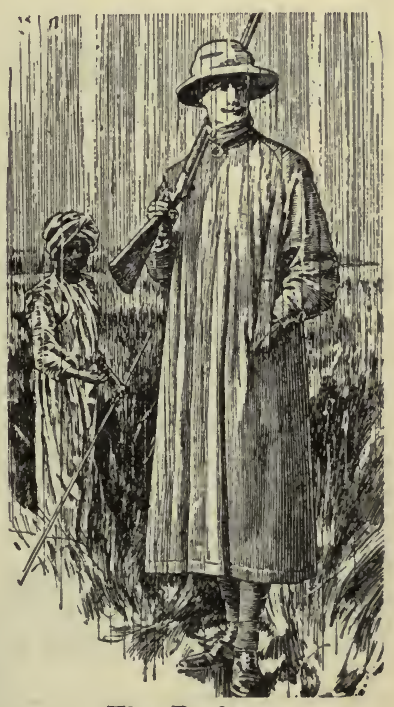

The Burberry.

Weatherproof, healthfully ventilating and lightweight. 
Second Edition. Demy 4to. Price 25s. net.

\section{Central African Game and Its Spoor.}

By CAPT. C. H. STIGAND, F.R.G S., F.Z.S., and D. D. LYELL, F.Z.S. With Introduction by F. C. SELOUS.

Second Edition. Demy 4to. Profusely and Beautifully Illustrated. Price 21s. net.

The Game of British East Africa. By CAPT. C. H. STIGAND, F.R.G.S., F.Z.S.

Demy 4to. Beautifully Illustrated. Price 21 s. net.

Hunting Trips in Northern Rhodesia. By DENIS D. LYELL, F.Z.S.

Demy 8vo, Cloth Boards. With Map and 23 Illustrations.

Price 5s. net.

NYASALAND FOR THE HUNTER AND SETTLER. By DENIS D. LYELL, F.Z.S.

Super Royal 8vo, Cloth Boards (Bevelled). Price One Guinea net.

BIG GAME SHOOTING IN INDIA, BURMA, AND SOMĀLILAND.

(ILI.USTRATED.)

By COL. V. M. STOCKLEY (late I8th Cavalry, Indian Army).

Demy 8vo, Cloth Boards. Profusely Illustrated. Price 6s. net. INDIAN SMALL-GAME SHOOTING FOR NOVICES. By C. A. G. RIVAZ. 


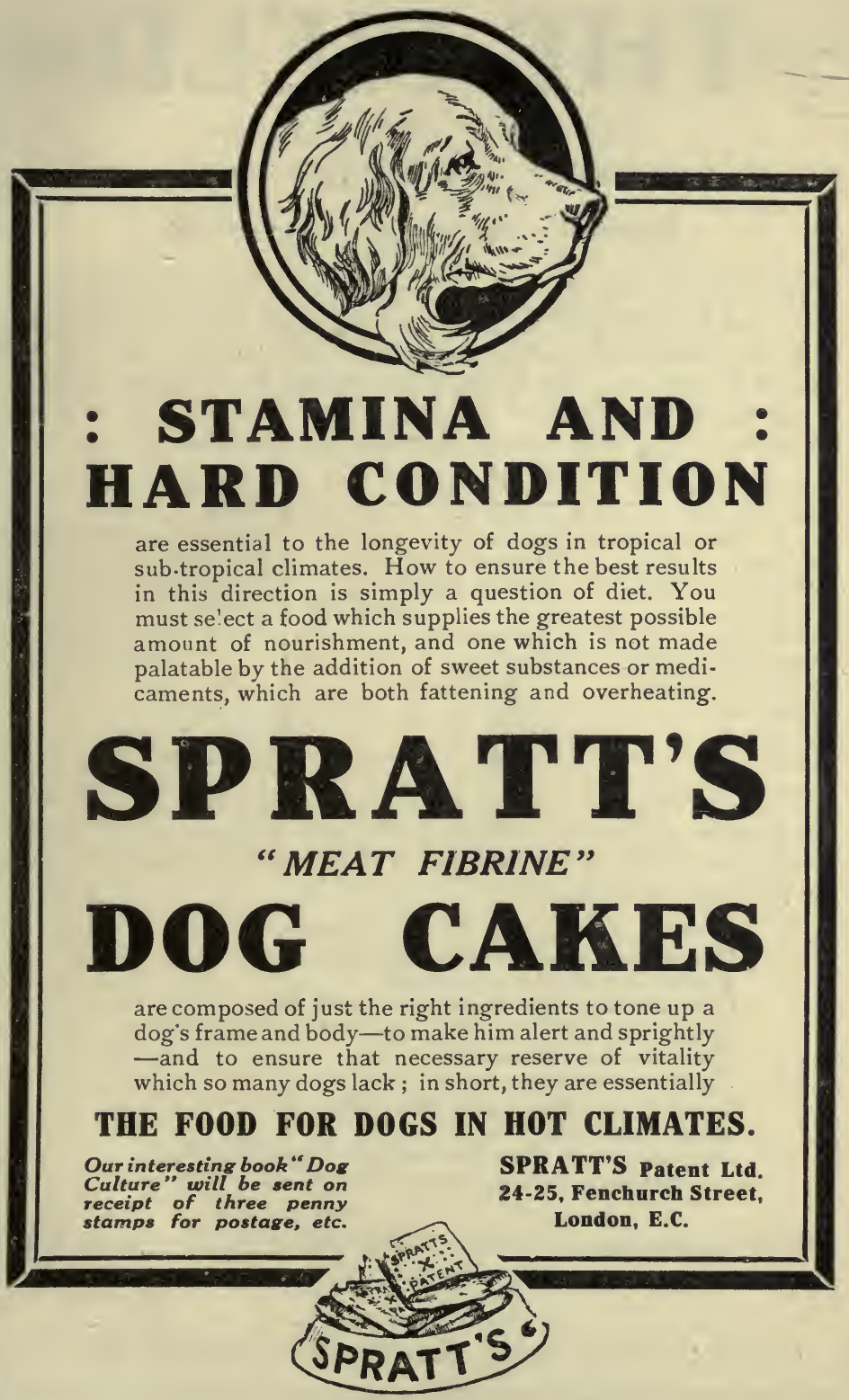




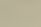

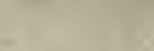

1

(

\section{7}

1 


\section{RETURN CIRCULATION DEPARTMENT}

TO $\rightarrow 202$ Main Library

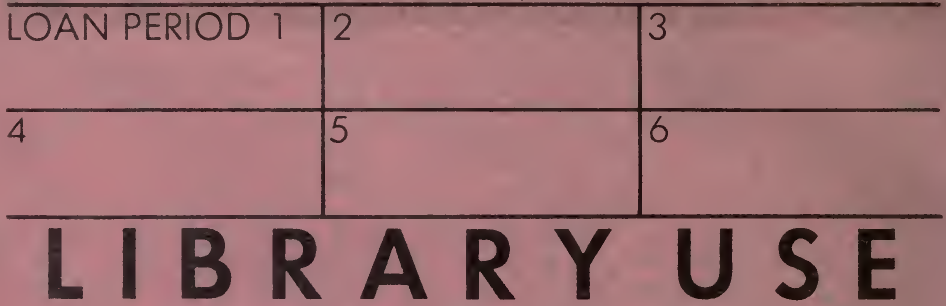

This book is due before closing time on the last date stamped below

\section{DUE AS STAMPED BELOW}

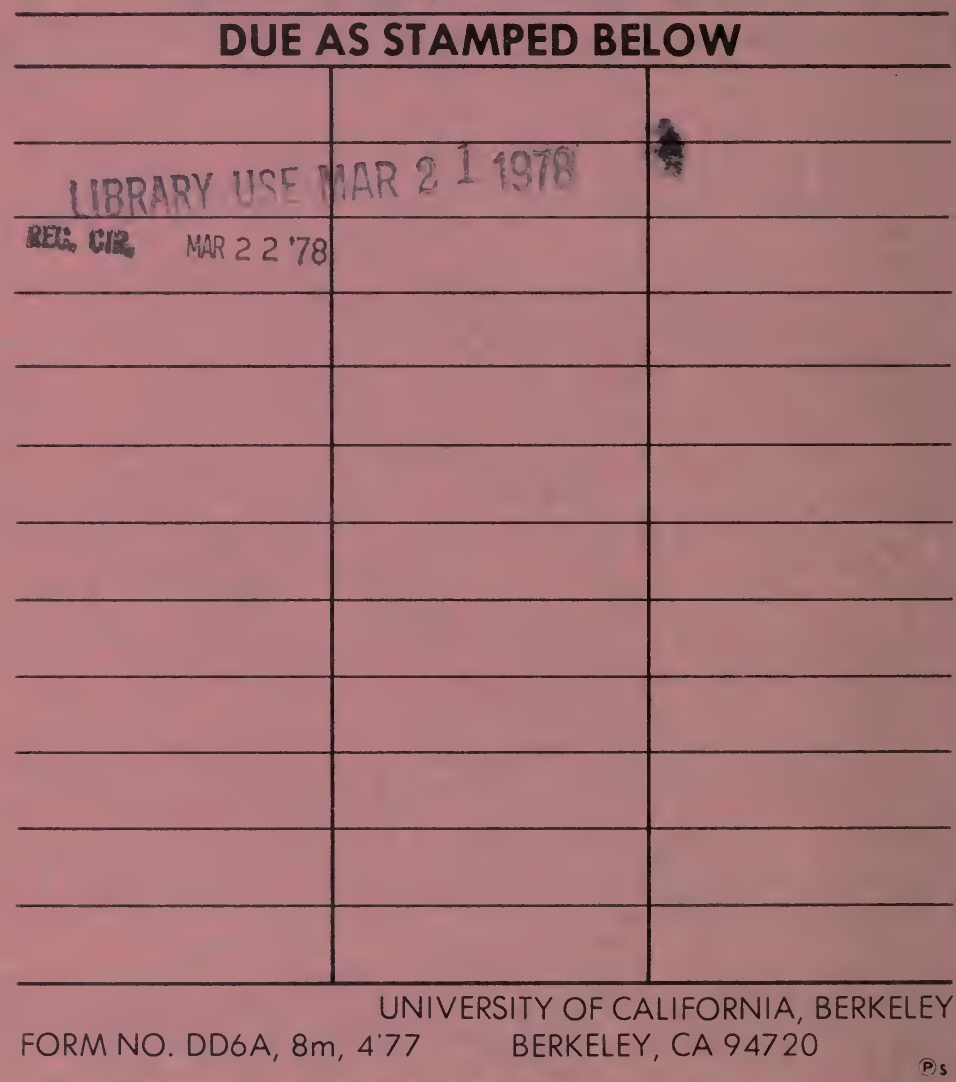



